Guy Cliquet do Amaral Filho

\title{
REQUISITOS PARA SISTEMAS DE CONTROLE DE SISTEMAS PRODUTIVOS INTEGRADOS À GESTÃO
}

\author{
Dissertação apresentada à Escola \\ Politécnica da Universidade de São \\ Paulo para obtenção do título de \\ Mestre em Engenharia \\ Programa: Engenharia Mecânica \\ Área de concentração: Engenharia de \\ Controle e Automação Mecânica - \\ Engenharia Mecatrônica \\ Orientador: Prof. Dr. Diolino J. dos \\ Santos Filho
}

São Paulo 


\author{
AUTORIZO A REPRODUÇÃO E DIVULGAÇÃO TOTAL OU PARCIAL DESTE \\ TRABALHO, POR QUALQUER MEIO CONVENCIONAL OU ELETRÔNICO, PARA
}

FINS DE ESTUDO E PESQUISA, DESDE QUE CITADA A FONTE.

\title{
FICHA CATALOGRÁFICA
}

\section{Amaral Filho, Guy Cliquet do}

Requisitos para sistemas de controle de sistemas produtivos integrados à gestão / G.C. do Amaral Filho. - São Paulo, 2005. $194 \mathrm{p}$.

Dissertação (Mestrado) - Escola Politécnica da Universidade de São Paulo. Departamento de Engenharia Mecatrônica e de Sistemas Mecânicos.

1.Sistemas de controle 2.Sistemas produtivos 3.Redes de Petri I.Universidade de São Paulo. Escola Politécnica. Departamento de Engenharia Mecatrônica e de Sistemas Mecânicos II.t. 
A Solange como declaração do meu amor e carinho, ao presente e futuro de meus filhos, aos meus pais como eterna gratidão, a toda minha Família e meus queridos Amigos. 


\section{AGRADECIMENTOS}

Sou grato a Deus pela vivência e oportunidade concedidas durante esta tarefa.

Ao meu orientador Prof. Dr. Diolino José dos Santos Filho, agradeço pela janela aberta em minha carreira, pela motivação agraciada através da valorização da pessoa e pela sabedoria durante a orientação.

Grato a minha companheira Solange e meus filhos Beatriz e Pedro pela paciência em suportar a ausência, assim como a presença carinhosa nos instantes de angústia durante a finalização da tarefa.

Agradeço aos Prof. Dr. Newton Maruayama e Profa. Dra. Emilia Villani pelo estímulo, orientação e apoio.

Grato também a meus pais, que souberam apoiar ao longo da tarefa seu progresso, e que também partilharam da minha ausência.

Sou grato a todos os professores e colegas da Escola Politécnica pelo interesse, sugestões e apoio fundamentais para o sucesso desta tarefa.

Quanto aos meus amigos, agradeço a todos pela compreensão da minha ausência em todas as ocasiões em que este trabalho teve prioridade e ao apoio e incentivo motivadores que auxiliaram no término desta tarefa.

Finalizando, agradeço aos amigos do grupo de estudo da Mecatrônica, André Cavalheiro, Antonio Guardado, Cristina Matsusaki, Francisco Nakamoto, Gustavo Alves, Lindolpho Araújo e Osvaldo Asato, que contribuíram decisivamente de forma direta ou indireta, colaborativa ou crítica, para a realização deste trabalho. 


\section{RESUMO}

As importantes transformações das organizações nos últimos anos mostram que diferentes princípios de qualidade, competitividade e inovação devem ser conjugados para o projeto de sistemas de controle de sistemas produtivos. Esta abordagem, que traz benefícios às organizações, é viável em virtude da evolução das estratégias de integração e da tecnologia da informação.

A partir da norma em elaboração ANSI/ISA S95, esta dissertação desenvolve procedimentos para definição do escopo funcional, requisitos e modelagem para o projeto de sistemas de controle de sistemas produtivos integrados à organização, atuando de forma estruturada, em conformidade com padrões técnicos de automação e engenharia de requisitos.

Como resultados, estabelece procedimentos para o início do projeto que definem o escopo funcional do sistema de controle de sistemas produtivos integrado à gestão da organização. A seguir, estes procedimentos estabelecem os domínios semânticos dos subsistemas necessários para o desempenho de suas funções, acompanhados das respectivas linguagens de modelagem. A dissertação completa-se com a modelagem dos subsistemas através do E-MFG com comunicadores, modelagem esta que suporta os padrões existentes de programação da automação. Neste contexto, parte-se dos requisitos de cada subsistema coletados por uma versão modificada do caso de uso da UML, convertidos finalmente para o E-MFG com comunicadores. 


\begin{abstract}
The important changes that are happening inside organizations show that different principles of quality, innovation and competition should be combined during the design of control system of production systems. This approach is possible thanks to the evolution of integration strategy and information technology, generating benefits to organizations.

Procedures are established to define system's functional scope, requirements and models, based on the integrated approach of ANSI/ISA S95 standard. The procedures are developed by a structured process and according to automation standards and requirements engineering.

The work's first result is a procedure that defines a functional scope for control system design of production systems integrated with organization. As a second result, procedures help to define semantic domains of all subsystems needed to develop control system functions, as well as the modeling techniques for each domain. The result is complemented by modeling subsystems using an extended version of Mark Flow Graph (E-MFG with communicators). This task has the assistance of a modified use case version from "Unified Modeling Language" to collect requirements before modeling.
\end{abstract}




\section{LISTA DE FIGURAS}

Figura 1.1. Ciclo de desenvolvimento do projeto de pesquisa.

.19

Figura 2.1. Diagrama conceitual básico do sistema de controle de sistemas de eventos

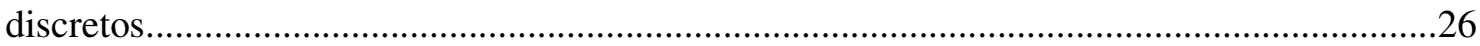

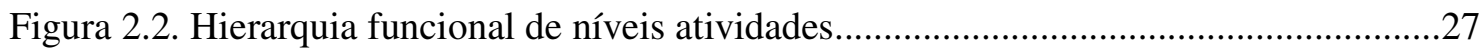

Figura 2.3. Exemplo da interconexão de equipamentos de um sistema de controle distribuído

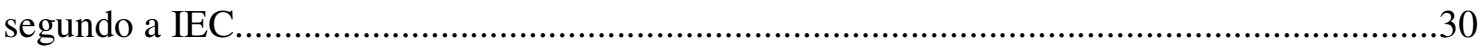

Figura 3.1. Exemplo da evolução de estado de um SED.......................................................35

Figura 3.2. Exemplo de representação gráfica de modelo MFG............................................41

Figura 3.3. Exemplo da dinâmica de disparo de uma transição.............................................42

Figura 3.4. Exemplos de marcas individuais e composta, e boxes funcionais básicos.............43

Figura 3.5 - Representação de box controlador alterando o estado de uma marca individual..45

Figura 3.6. Alteração e atributos das marcas decorrentes do disparo.....................................47

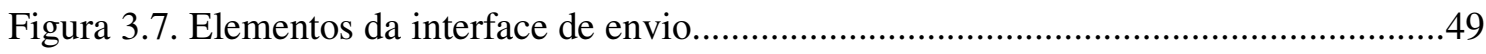

Figura 3.8. Exemplo de atuação da interface de envio........................................................50

Figura 3.9. Exemplo de atuação da interface de recepção......................................................51

Figura 3.10. Sintaxe original da interface de recepção para habilitação condicionada a

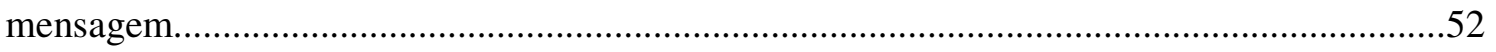

Figura 3.11. Exemplo de atuação da interface de recepção para habilitação condicionada a

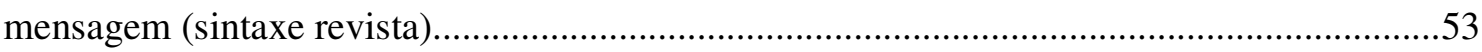

Figura 4.1. Representação do relacionamento de um modelo formal com domínio semântico.. 
Figura 5.1. Modelo da gestão operacional da manufatura.................................................73

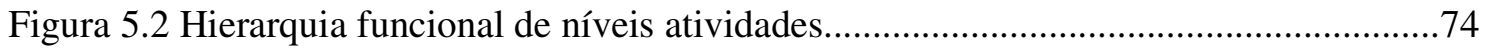

Figura 5.3. Modelo de atividades genérico da gestão operacional da manufatura...................75

Figura 5.4. Exemplo de seleção dos modelos operacionais de gestão.....................................86

Figura 5.5. Exemplo de seleção de atividades para o escopo funcional do SCSP...................90

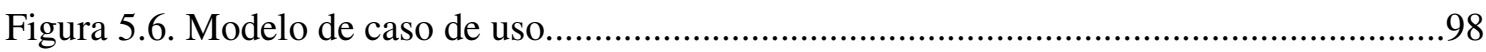

Figura 6.1. Exemplo da conversão do fluxo de eventos de Caso de uso em modelo MFG....103

Figura 6.2. Exemplo de escopo funcional de SCSP.............................................................109

Figura 6.3. Exemplo da conversão do fluxo de eventos de caso de uso em modelo E-MFG

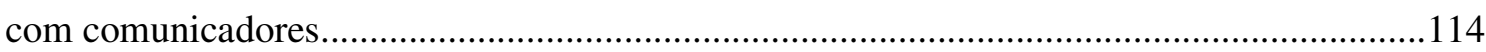

Figura 6.4. Dois novos tipos de interface de recepção......................................................123

Figura 6.5. Interface de recepção de habilitação associada à informação..............................124

Figura 6.6. Interface de recepção para parametrização de regra adicional............................125

Figura 6.7. Disparo da transição condicionada à regra adicional parametrizada por interface de recepção para parametrização de regra adicional..................................................................126

Figura 6.8. Algoritmo completo de conversão do caso de uso em E-MFG com

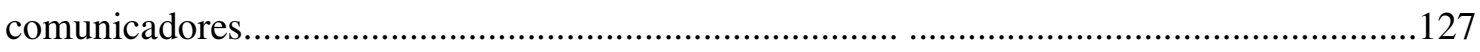

Figura 6.9. Algoritmo de definição do escopo de modelagem...........................................128

Figura 6.10. Algoritmo de conversão para sequiência de ações do fluxo de eventos básico...129

Figura 6.11. Algoritmo de conversão de interface de recepção............................................131

Figura 6.12. Elementos sintáticos comuns a todos tipos de interface de recepção..................132

Figura 6.13. Algoritmo de conversão para detalhamento da interface de recepção................135

Figura 6.14. Conversão da ação exemplificada em interface de recepção..............................136

Figura 6.15. Conexão de uma interface de recepção à pré e à pós-condição..........................137

Figura 6.16. Complementação da conexão da interface de recepção com box controlador...137 
Figura 6.17. Algoritmo de conversão para conexão da interface de recepção a boxes 138

Figura 6.18. Algoritmo de conversão para interface de envio

Figura 6.19. Exemplo de conversão para interface de envio 140

Figura 6.20. Algoritmo de conversão aplicado aos fluxos de eventos alternativos 141

Figura 6.21. Algoritmo de conversão de interface de recepção para fluxos de eventos alternativos. 141

Figura 6.22. Representação do algoritmo de conversão aplicado ao início de fluxo de eventos alternativos 143

Figura 6.23. Conversão para conexão da interface de recepção a boxes em fluxos alternativos.

Figura 6.24. Algoritmo de definição dos atributos de marca 145

Figura 7.1. Algoritmo de conversão do caso de uso restrito em E-MFG com comunicadores.. 156

Figura 7.2. Algoritmo de conversão do caso de uso restrito em E-MFG com comunicadores (continuação: conversão do fluxo básico de eventos) 157

Figura 7.3. Algoritmo de conversão do caso de uso restrito em E-MFG com comunicadores (continuação: conversão dos fluxos de eventos alternativos) 158

Figura 7.4. Algoritmo de conversão do caso de uso restrito em E-MFG com comunicadores (continuação: detalhe da conversão para interface de recepção)

Figura 7.5. Estrutura de dados do caso de uso restrito 160

Figura 7.6. Estrutura de dados do modelo convertido E-MFG com comunicadores (continua). 161

Figura 7.7. Estrutura de dados do modelo convertido E-MFG com comunicadores (contin.) 162 
Figura 7.8. Estrutura de dados do modelo convertido E-MFG com comunicadores (contin.) 163

Figura 7.9. Estrutura de dados do modelo convertido E-MFG com comunicadores (contin.) 164

Figura 7.10. Estrutura de dados do modelo convertido E-MFG com comunicadores (contin.) .165

Figura 8.1. Esquema do SP com seus elementos. 167

Figura 8.2. Escopo de atividades do Modelo operacional de gestão da produção do SCSP..172 Figura 8.3. Escopo de atividades do Modelo operacional de gestão do inventário do SCSP.173 Figura 8.4. Modelo de Caso de Uso da partição 'Controle de Processo Local' 176

Figura 8.5. Modelo de Caso de Uso da partição ‘Controle de Recursos de Transformação’.177 Figura 8.6. Modelo de Caso de Uso da partição 'Controle de Transporte'. 177

Figura 8.7. E-MFG com comunicadores relativo ao caso de uso de 'Controle do recurso'...180 Figura 8.8. E-MFG com comunicadores resultante da conversão do caso de uso 'Controle de processamento do produto ELE_B'.... 182

Figura 8.9. E-MFG com comunicadores resultante da conversão do caso de uso 'Controle da escala produtiva do recurso EST_4', 183

Figura 8.10. Exemplo de fusão de lugares para o E-MFG com comunicadores resultante da conversão do caso de uso 'Controle de recursos de transformação' aplicado sobre recurso EST_4 184

Figura 8.11. Exemplo de fusão de lugares para o E-MFG com comunicadores resultante da conversão do caso de uso 'Controle de recursos de transformação' aplicado sobre recurso EST_4 185

Figura 8.12. E-MFG com comunicadores resultante da conversão do caso de uso controle de transporte de produção. 187 


\section{LISTA DE TABELAS}

Tabela 6.1. Tabela de classes do ambiente. 109

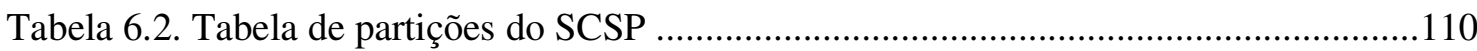

Tabela 6.3. Posições das classes dentro das ações do caso de uso..........................................113

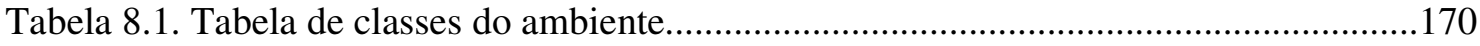

Tabela 8.2. Tabela de partições do SCSP (relação de classes das partições homomórficas do

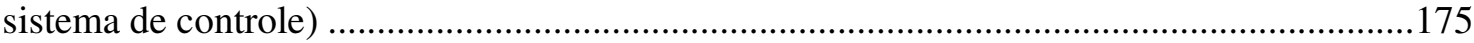

Tabela 8.3. Classes das partições do SCSP envolvidas...........................................................178

Tabela 8.4. Fluxo básico de eventos para o caso de uso 'Controle do recurso' ......................179

Tabela 8.5. Classes das partições do SCSP envolvidas......................................................180

Tabela 8.6. Fluxo básico de eventos para o caso de uso 'Controle de processamento do produto ELE_B'

Tabela 8.7. Fluxo básico de eventos para o caso de uso 'Controle da escala produtiva do

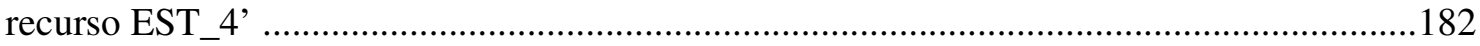

Tabela 8.8. Classes das partições do SCSP envolvidas........................................................185

Tabela 8.9. Fluxo de eventos básico do caso de uso 'Controle de transporte de produção'...186 


\section{SUMÁRIO}

CAPÍTULO 1: INTRODUÇÃO ............................................................................15

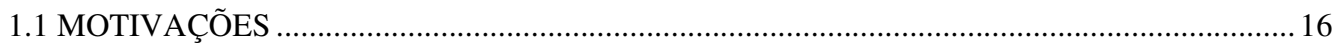

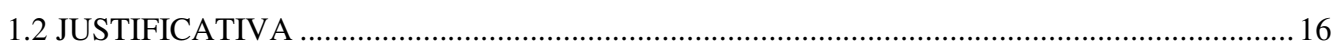

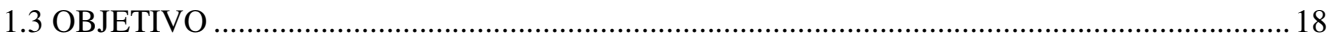

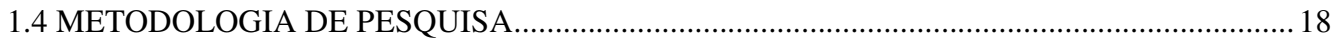

1.5 ESTRUTURAÇÃO DO TEXTO ..................................................................................... 19

CAPÍTULO 2: AUTOMAÇÃO DO CONTROLE DE SISTEMAS PRODUTIVOS .. 22

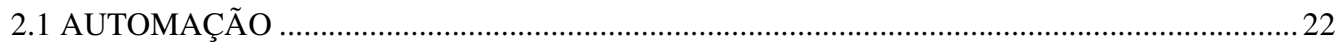

2.2 HISTÓRICO DA AUTOMAÇÃO E SEU CICLO DE VIDA ……………………...................2

2.3 TECNOLOGIA DA AUTOMAÇÃO APLICADA AO CONTROLE DE SISTEMAS

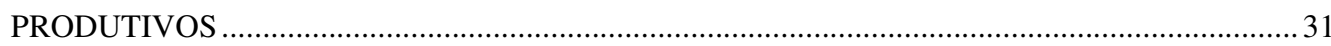

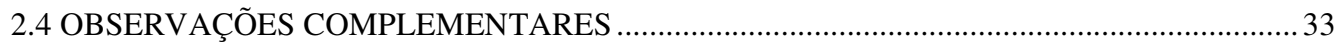

CAPÍTULO 3: APLICAÇÃo DE MODELOS À AUTOMAÇÃO DE SISTEMAS

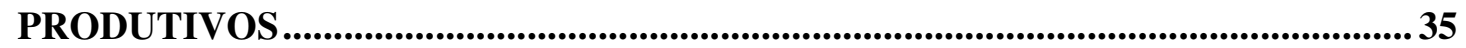

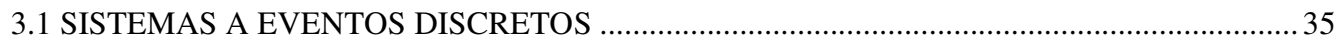

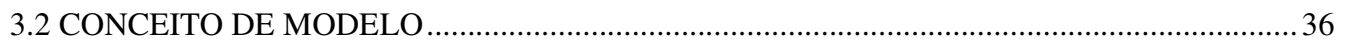

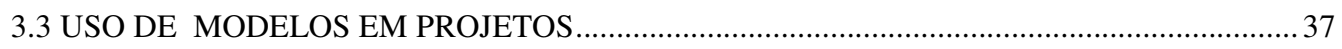

3.4 MODELAGEM DE SED APLICADA AOS SISTEMAS PRODUTIVOS ………….................... 38 
4.1 REQUISITOS E ESPECIFICAÇÕES

4.2 LINGUAGENS DE ESPECIFICAÇÃO 56

4.3 REQUISITOS PARA LINGUAGENS DE ESPECIFICAÇÃO. 61

CAPÍTULO 5: ESCOPO FUNCIONAL DE UM SCSP 69

5.1 NORMA ANSI/ISA S95 E A GESTÃO OPERACIONAL DE SISTEMAS PRODUTIVOS

5.2 LIMITES GERAIS DO ESCOPO FUNCIONAL DE UM SCSP

5.3 DEFINIÇÃO DO ESCOPO FUNCIONAL DE UM SCSP

80

CAPÍTULO 6: ESPECIFICAÇÃO DAS PARTIÇÕES DO SCSP ................................. 100

6.1 E-MFG COM COMUNICADORES E CASOS DE USO DA UML 101

6.2 RESTRIÇÕES AO CASO DE USO PARA CONVERSÃO EM E-MFG COM

COMUNICADORES 104

6.3 CONVERSÃO DE CASO DE USO RESTRITO EM E-MFG COM COMUNICADORES ...

6.4 FUSÃO DE LUGARES NO E-MFG COM COMUNICADORES 144

CAPÍTULO 7: SISTEMAS DE MODELAGEM DO SCSP 148

7.1 DEFINIÇÃO DO ESCOPO DO SCSP 148

7.2 ESPECIFICAÇÕES DAS PARTIÇÕES EXPRESSAS POR E-MFG COM COMUNICADORES 
CAPÍTULO 9: CONCLUSÕES FINAIS.................................................................. 188

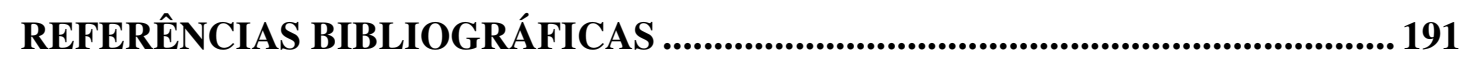




\section{CAPÍTULO 1}

\section{INTRODUÇÃO}

$\mathrm{O}$ ambiente das organizações passou e ainda passa por transformações importantes, atendendo novos valores fundamentados nos princípios da qualidade (DEMING, 1990), da competitividade (PORTER, 1985) e da inovação (NOORI, 1997), entre outros.

Diversas estratégias sustentam tais transformações; a evolução tecnológica tem constituído um dos principais sustentadores (PORTER, 1985); (DRUCKER, 1997), com a oportunidade atual intensificada através de novos paradigmas proporcionados pelo emprego da tecnologia da informação ${ }^{1}$ (DRUCKER, 1997); (LACERDA et ALLI, 2001) ; (SANTOS FILHO, 2000).

Em particular, a evolução da tecnologia da informação ocorre em todas suas vertentes, tanto nos aspectos de "hardware" quanto de "software". A engenharia de "software", refletindo tais mudanças, realizou progressos notáveis em diversas áreas. Na área da qualidade, a evolução do ciclo de desenvolvimento de "software" (PRESSMAN, 1995); (JACOBSON; BOOCH; RUMBAUGH, 1998) e a engenharia de requisitos (ZAVE; JACKSON, 1997) contribuíram na melhoria do atendimento de requisitos, implícitos ou explícitos (ISO 9000), demandados pelos usuários para os quais os projetos são dedicados. Na área da competitividade, a engenharia de "software", atendendo a estratégias de integração (PORTER, 1985), proporcionou soluções (aplicativos integrados de gestão empresarial, tais como o "Enterprise Resource Planning") e recursos tecnológicos, tais como os padrões "Extended Markup Language" (XML) elaborados

\footnotetext{
${ }^{1}$ A utilização estratégica da tecnologia da informação abrange todos os aspectos dos processos de negócio da corporação, passando na cadeia de valores do negócio por todas as partes da estrutura organizacional (PORTER, 1985).
} 
pelo "World Wide Web Consortium" em 1998 (MUENCH, 2000) e ferramentas de desenvolvimento orientadas a objeto (JACOBSON; BOOCH; RUMBAUGH, 1998), que abriram novos campos a serem explorados em todas as áreas das organizações visando integração.

Os sistemas produtivos, como parte da estrutura de uma organização (PORTER, 1985), também são atingidos por todo este processo de transformação. Esta dissertação pretende auxiliar junto a metodologias de projeto de sistemas de controle de sistemas produtivos na direção desta transformação, adicionando elementos provenientes da engenharia de requisitos e de padrões de integração.

\subsection{MotivaÇõeS}

A motivação para esta dissertação é a ausência de uma abordagem que conduza projetos de sistemas de controle de sistemas produtivos (SCSP) integrados à organização da qual fazem parte. É reforçada pela constatação de que atuais abordagens dos projetos de SCSP possuem visão focada no próprio sistema produtivo (SANTOS FILHO, 2000); (MATSUSAKI, 2004); NAKAMOTO, (2002).

Esta motivação é oportunidade para desenvolver métodos que procurem assegurar a integração eficaz de um SCSP ao sistema produtivo e a todos outros sistemas existentes na organização.

\subsection{JUSTIFICATIVA}

A migração do ponto focal do projeto de um SCSP da visão centrada no objeto de controle do SCSP para uma visão integrada ao ambiente organizacional permite representação mais adequada do papel dos sistemas produtivos dentro das organizações. Justificamos tal mudança pela obtenção de benefícios advindos das estratégias de 
competitividade através da integração (PORTER,1985), qualidade através do cumprimento de requisitos funcionais (DEMING,1990); (TAGUCHI;ELSAYED;HSIANG,1989) e inovação por liderança (NOORI, 1997) às organizações.

A estratégia de integração pode ser concretizada graças ao recente padrão em desenvolvimento pela ISA (ANSI/ISA S95 - "Enterprise/Execution System Integration”), já adotado por fornecedores representativos no mercado (em sistemas de gestão, também em sistemas de manufatura). A norma em questão padroniza terminologia e práticas envolvidas com a integração de sistemas de gestão operacional e sistemas de informação gerenciais, que servem de referência para a elaboração de requisitos do ambiente do sistema produtivo e é usada nesta dissertação. Proporciona meios para a definição do escopo funcional de um SCSP, assim como de sua adequação a este escopo e ambiente com o propósito de integração.

Por outro lado, a estratégia da qualidade procura preservar a realização do objetivo de integração do SCSP à organização. Para que se possa assegurar que requisitos sejam transferidos de forma adequada à modelagem de um SCSP e, portanto, atendidos pelo seu projeto, outra oportunidade surge pela incorporação de elementos da engenharia de requisitos (WING, 1990); (PARNAS; MADEY, 1995) (ZAVE; JACKSON,1997); (MITCHELL; MCKIM, 2001) às técnicas de modelagem existentes.

Desta forma, ao inovar o projeto de um SCSP através do emprego da estratégia de integração, com o suporte da estratégia da qualidade para garantir propósitos, mudamos o focal do projeto de um SCSP da visão centrada no objeto de controle do SCSP para uma visão integrada ao ambiente organizacional, o que trará benefícios às organizações que adotarem. 


\subsection{OBJETIVO}

Este trabalho visa desenvolver uma sistemática que auxilie na definição do escopo, requisitos e na geração da modelagem do SCSP, atuando de forma estruturada e padronizada em conformidade com normas técnicas que tratam da regulamentação desse assunto.

São metas necessárias para este objetivo o estabelecimento de procedimentos que:

- auxiliem na definição do escopo de requisitos funcionais do SCSP, a partir de uma visão integrada do ambiente existente,

- auxiliem na identificação dos domínios semânticos adequados para cada projeto específico, levando em consideração o ambiente existente e as funções desempenhadas pelo SCSP e

- auxiliem na especificação das partes do sistema referentes aos domínios semânticos identificados, permitindo a inclusão sistemática dos requisitos estabelecidos na modelagem do SCSP dos respectivos domínios semânticos.

\subsection{Metodologia de Pesquisa}

O projeto de pesquisa foi iniciado com uma revisão bibliográfica, de cunho qualitativo, visando métodos e técnicas que abordam projeto de SCSP, do evento de sua partida até sua modelagem e engenharia de requisitos, utilizada para o desenvolvimento de sistemas computacionais.

Devido à dificuldade imposta pela diversidade de métodos e técnicas empregados, consideramos necessário o uso de prototipagem para realizar a validação das soluções elaboradas ao longo da pesquisa. Sucessivos protótipos foram validados, permitindo analisar aspectos tais como 
viabilidade da solução e integração dos métodos. A análise de cada validação permitiu a realização de revisões nas soluções elaboradas, indicando necessidade de novas pesquisas e abordagens. Como resultado da validação positiva do último protótipo realizado, a abordagem terminou obtendo o estudo de caso apresentado.

A figura 1.1 apresenta os principais aspectos abordados nesse trabalho, identificando os domínios de conhecimento que suportaram a elaboração da dissertação.

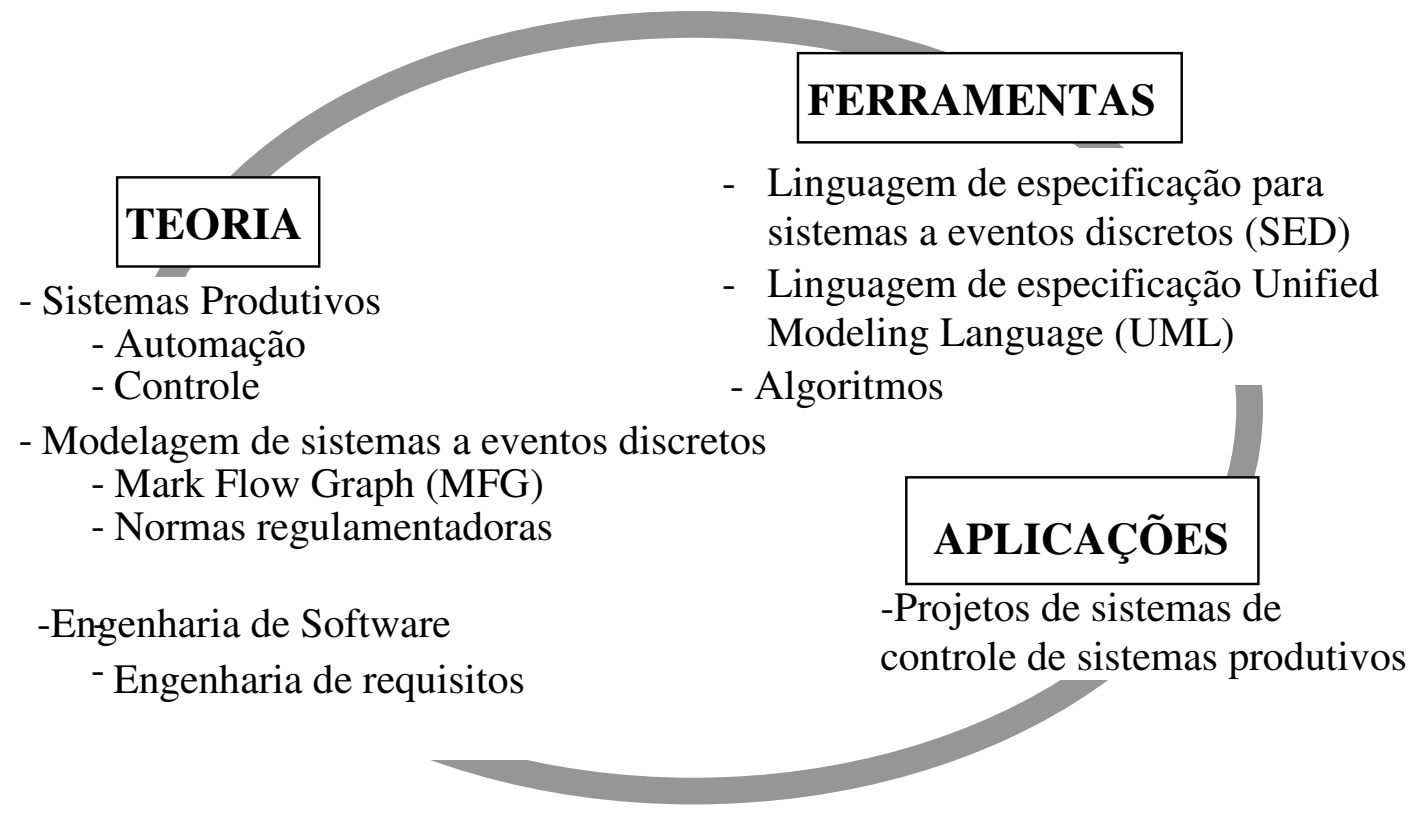

Figura 1.1. Ciclo de desenvolvimento do projeto de pesquisa

\subsection{ESTRUTURAÇÃo DO TEXTO}

A estruturação do texto é formada por três blocos distintos. O primeiro é uma revisão bibliográfica sobre o qual se apóia a dissertação; o segundo é a descrição do método proposto, baseado na revisão anterior, enquanto o terceiro bloco é um exemplo de sua aplicação.

O primeiro bloco compreende os capítulos 2, 3 e 4, onde revisamos conceitos envolvidos com a automação aplicada ao controle de sistemas produtivos e sua modelagem, e aspectos da 
engenharia de requisitos, os quais formarão as bases utilizadas para a definição apresentada da modelagem de um sistema de controle de sistemas produtivos, objetivo da dissertação.

No capítulo 2, introduzimos o conceito da automação e descrevemos o ciclo de vida da automação como produto, com base em seu histórico. Realizamos, então, uma introdução ao controle de sistemas produtivos dentro deste contexto. Com base no ciclo de vida da automação descrito, finalizamos relacionando e justificando padrões de automação existentes adotados que servirão de base para o projeto de um SCSP.

No capítulo 3, cobrimos aspectos específicos de modelagem de sistemas dirigidos por eventos (SED) relacionados a sistemas produtivos. É apresentada a técnica de modelagem "Enhanced Mark Flow Graph” (E-MFG) com comunicadores (MATSUSAKI, 2004) que adotamos como suporte para esta dissertação devido a sua adequação aos padrões ANSI/ISA S95.

No capítulo 4, revisamos abordagem relativa à engenharia de requisitos. Direcionamos o enfoque à exploração das características das linguagens de especificação, com o propósito de identificar adições à técnica de modelagem do E-MFG com comunicadores que permitam realizar o projeto de um SCSP dentro da visão integrada ao conjunto de sistemas pré-existentes em uma organização.

No segundo bloco, descrevemos o método de modelagem através dos capítulos 5, 6 e 7 . Iniciamos o capítulo 5 pelo contexto da norma ANSI/ISA S95 ('Integração de sistemas de gestão a sistemas de execução'), no qual situamos o SCSP. Através deste contexto e com base em aspectos trazidos pela engenharia de requisitos, discutimos uma sistemática que define o escopo dos requisitos de um SCSP, partindo de uma definição inicial dos limites gerais, aplicáveis a 
qualquer SCSP, finalizando com a definição das partições do SCSP e respectivas linguagens de modelagem.

No capítulo 6, detalhamos a última etapa da sistemática enumerada pelo capítulo 5 , restrita a partições do SCSP onde podemos aplicar a linguagem do E-MFG com comunicadores. Iniciamos pela definição de restrições adicionais ao emprego do caso de uso como suporte ao desenvolvimento de modelos E-MFG com comunicadores. Finalizamos com o algoritmo de conversão de casos de uso, elaborados dentro das restrições adicionais, em modelos E-MFG com comunicadores.

No capítulo 7, descrevemos a sistemática completa elaborada ao longo dos capítulos 5 e 6 .

No último bloco, constituído pelo capítulo 8, colocamos um estudo de caso, onde a aplicação da sistemática apresentada nos capítulos 5, 6 e 7 é exemplificada.

As conclusões principais que finalizam a dissertação seguem no capítulo 9. 


\section{Capítulo 2 \\ Automação do Controle de Sistemas Produtivos}

Neste capítulo, iremos abordar a automação e seu emprego no controle de sistemas produtivos. Iniciaremos pelo conceito da automação, prosseguindo com breve histórico da automação, o qual indicará a disponibilidade atual de recursos. Finalizaremos o capítulo relacionando a automação ao controle de sistemas produtivos, conceituando um SCSP, e encerrando com a descrição das tecnologias disponíveis para seu projeto sobre as quais nos basearemos.

\subsection{AUTOMAÇÃo}

Automação é a tecnologia baseada na realização de processos sem a intervenção humana, de tal forma que o homem é deslocado da sua participação direta na realização do processo para função supervisora do processo (GROOVER, 2000). A automação é definida como um processo em que máquinas realizam seqüências de operações pré-determinadas com pouco ou nenhum trabalho humano (KALPAKJIAN, 2000), sendo realizada através de uma variedade de dispositivos de diferentes naturezas envolvendo sensores, atuadores, técnicas e equipamentos que são capazes de observar e controlar um processo.

No princípio da revolução industrial, por volta dos anos 20, a mecanização da manufatura foi realizada com auxílio essencial da hidráulica, substituindo a atividade humana por dispositivos que reproduziam ações de intervenção física essencialmente repetitiva. As máquinas possuíam 
mecanismos automáticos fixos, visando produção de produto específico. Em sua etapa seguinte, em torno dos anos 50, a criação do controle numérico foi a grande inovação aplicada a máquinas ferramentas que expandiu a aplicação da automação a maior gama de produtos (KALPAKJIAN, 2000).

A partir deste ponto, a introdução da computação como inovação incorporada à automação tem sido utilizada cada vez em mais aspectos da manufatura. Os objetivos da automação passaram a ser (KALPAKJIAN, 2000):

- incrementar a integração dos elementos participantes do processo de manufatura;

- reduzir envolvimento humano com atividades repetitivas;

- melhorar fatores de competitividade nos negócios, tais como redução de custo (diminuição de perda da matéria-prima e dos custos de produção) e melhoria da qualidade através da garantia de repetibilidade;

- elevar o nível de segurança, principalmente em condições perigosas de trabalho;

- economizar espaço físico através da disposição racional dos equipamentos demandada pelo uso da automação.

Desta forma, verifica-se que projetos de automação de sistemas produtivos possuem como objetivo primordial a substituição da intervenção humana em diversas funcionalidades.

\subsection{Histórico da Automação E SEU CiClo de VidA}

Descreveremos o histórico da evolução tecnológica do ciclo de vida da automação para conhecer recursos atualmente disponíveis para construção de sistemas de automação. 
Utilizaremos um modelo de ciclo de vida de um produto (PORTER, 1985) como suporte para entendimento da evolução da tecnologia em um determinado ramo industrial. Abordaremos a automação como um produto de um ponto de vista genérico e abrangente, que inclui recursos físicos, recursos de programação e técnicas de implementação.

O modelo do ciclo de vida de um produto inclui as seguintes fases:

- inicialmente, as mudanças tecnológicas no início do ciclo de vida são focadas em inovações do produto, mantendo seu processo de manufatura flexível (denominaremos esta fase ‘inovação do produto’);

- a seguir, conforme a indústria amadurece, o desenho do produto começa a mudar mais lentamente e as técnicas de produção em massa são introduzidas, com o uso extensivo da automação. Nesta fase, o processo de inovação é deslocado da inovação do produto para a inovação do processo como forma principal de atividade tecnológica, com o objetivo de redução de custo de um produto gradualmente padronizado (denominaremos esta fase 'padronização');

- finalmente, o ritmo de todas inovações (produto e processo) diminui na última fase de maturidade, devido à diminuição dos investimentos nas várias tecnologias (denominaremos esta fase 'obsolescência').

\subsubsection{Princípio: Inovação da Automação}

Durante este tópico iremos observar a automação como um produto conforme o conceito de ciclo de vida utilizado no tópico anterior (PORTER, 1985). 
Descreveremos o histórico do surgimento dos controladores programáveis, que permite posicionar o atual estágio tecnológico disponível do ponto de vista de hardware para automação (MIYAGI, 1996).

Este histórico inicia-se com o controle de sistemas seqüenciais (classe de sistemas dirigidos por eventos discretos) no século XIX, através do surgimento de máquinas de tear automáticas (controladas mecanicamente). A seguir, algumas tecnologias básicas necessárias para o desenvolvimento da automação surgiram, passando pela invenção dos relés eletromagnéticos por Henry (por volta de 1836) e pela proposta de Boole para a álgebra que leva seu nome (1854).

Na década de 50, o conceito de monitoração surgiu interpondo operador e o dispositivo de controle, ao passo que entre o dispositivo de controle e o objeto de controle surgem os dispositivos de atuação, viabilizado pelo controle remoto.

O aparecimento da eletrônica e do transistor na década de 60 resultou na criação de controladores onde os chaveamentos não possuem contato físico (evitando os problemas envolvidos com o desgaste de relés eletromagnéticos), assim como os circuitos de controle, agora eletrônicos, tornaram-se mais compactos e mais confiáveis.

Em uma visão conceitual mais abrangente do sistema de controle de sistemas de eventos discretos (MIYAGI, 1996), o diagrama conceitual passa a ser representado diferenciando os fluxos de comando e atuação dos fluxos de detecção e monitoração (figura 2.1).

Em face à contínua aplicação da estratégia de integração aos processos de negócio (PORTER, 1985), surgiu neste princípio de década um modelo ainda mais abrangente do sistema produtivo, que extrapola os limites do controle do processo e inclui a gestão operacional da manufatura e a 
integração deste aos outros sistemas de gestão. Este modelo é definido através da norma ANSI/ISA S95, e identifica uma hierarquia funcional que se aplica sobre a gestão operacional da manufatura. Cada nível desta hierarquia provê funções especializadas e possui tempos de respostas característicos (ver figura 2.2). São cinco os níveis:

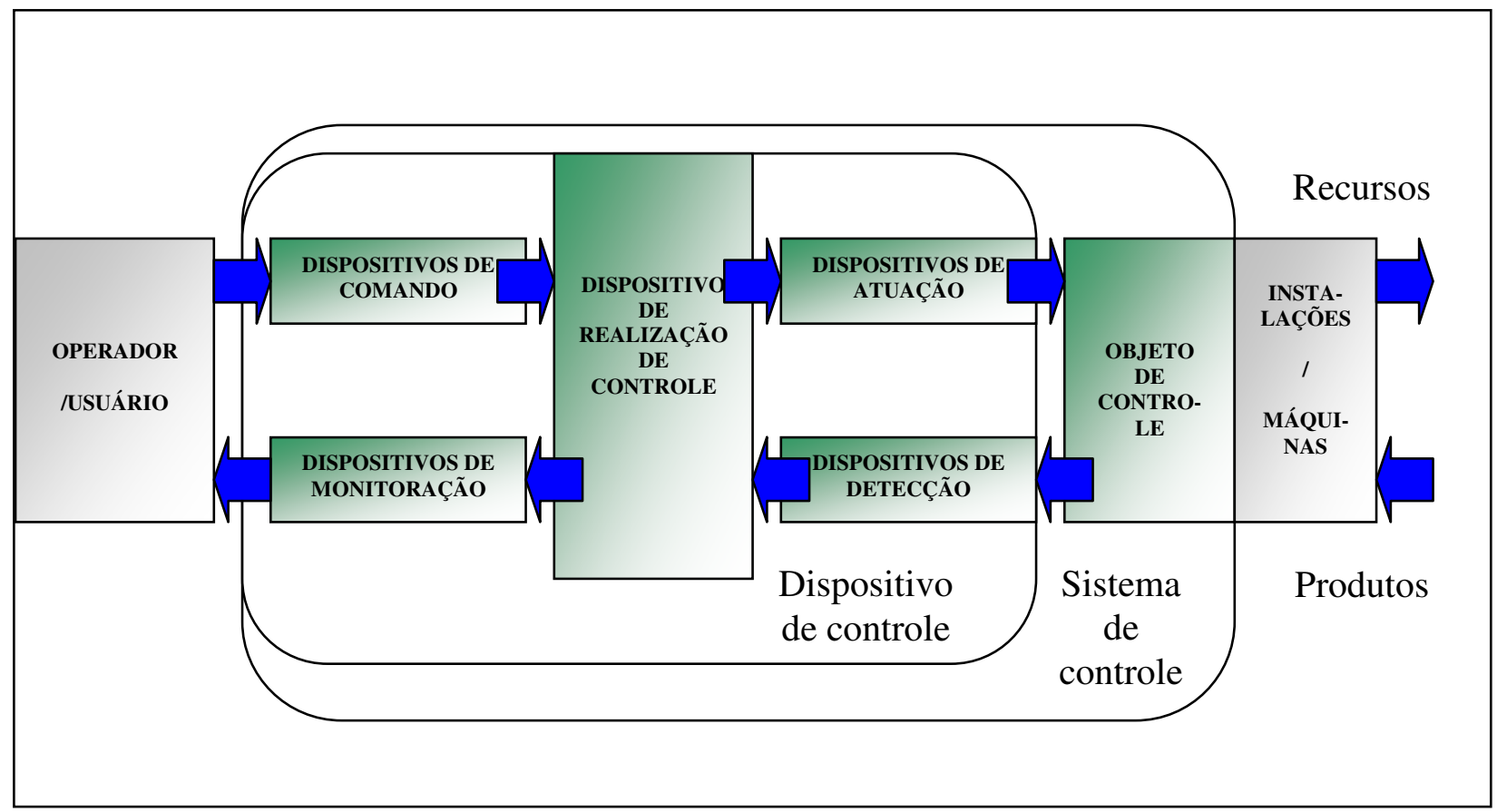

Figura 2.1. Diagrama conceitual básico do sistema de controle de sistemas a eventos discretos

- nível 0 , que define o processo físico real,

- nível 1, que define as atividades envolvidas na monitoração e manipulação dos processos físicos, operando tipicamente dentro de janelas de tempo da grandeza de segundos ou menos,

- nível 2, que define as atividades de monitoramento e controle local dos processos físicos, operando dentro de janelas de tempo da ordem de minutos, segundos ou suas 
divisões. O nível 2 tipicamente opera um equipamento dentro de um centro de trabalho, conforme a hierarquia proposta pela norma,

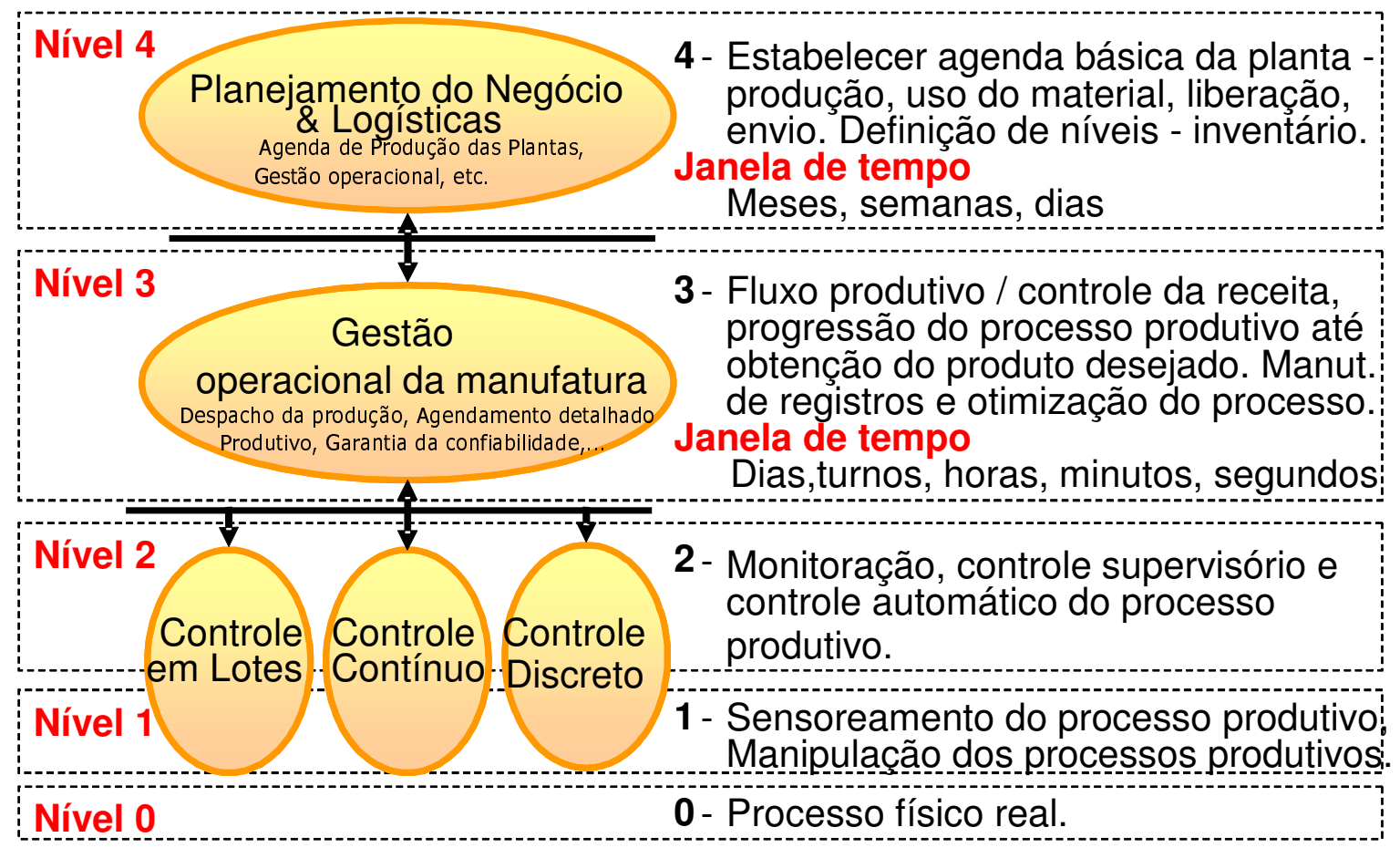

Figura 2.2. Hierarquia funcional de níveis atividades

(extraído da norma em elaboração ANSI/ISA S95, parte 3)

- nível 3, que define as atividades que realizam a progressão dos processos para gerar os produtos finais. Inclui as atividades de manutenção de registros e coordenação dos processos. O nível 3 opera tipicamente dentro de janelas de tempo de dias, turnos, horas, minutos e segundos, operando sobre áreas de centros de trabalho e

- nível 4, que define as atividades do negócio necessárias para gerar a organização da manufatura. Entre as atividades relacionadas com a manufatura estão o estabelecimento da agenda principal da planta, determinação de níveis de inventário e garantir que os materiais são liberados em tempo ao lugar certo para produção. As informações do nível 3 são críticas para as atividades do nível 4 . O nível 4 opera tipicamente em uma janela 
de tempo da grandeza de meses, semanas e dias, atuando sobre o negócio como um todo ou em localidades. No nível 4 ou superiores existem outras atividades relacionadas com o negócio, mas que estão fora do escopo da norma.

\subsubsection{Padronização da Automação}

O processo de inovação começa a ser deslocado da criação de novas soluções de automação para a sua padronização. O objetivo passa a ser a redução do custo dos produtos necessários para a implementação da automação. Esta nova fase padroniza dois aspectos envolvidos: o hardware utilizado na automação, que é aperfeiçoado e passa a ter seu processo produtivo menos dispendioso, e como consequiência as linguagens de programação.

No final da década de 60, surgem os circuitos integrados, tecnologia esta que, quando evoluída, fez surgirem os controladores programáveis (CP). No final da década de 70, a tecnologia de 16 bits e de processamento múltiplo possibilitou aos $\mathrm{CP}$ a realização de todas as funcionalidades necessárias para o controle de sistemas de SED.

A partir de então, funções de comunicação foram melhoradas para permitir a aplicação dos CP em rede, permitindo sua integração a outros elementos do ambiente produtivo. Questões tais como sua integração à gestão e aos processos de controle contínuo tiveram suas soluções viabilizadas.

Dentro deste quadro tecnológico, o controle realizado pelo $\mathrm{CP}$ passou a ser baseado na execução de programas que definem a seqüência e evolução dos processos (MIYAGI, 1996). Estendendo o conceito da programação como parte do produto final da automação, podemos empregar técnicas de software para solucionar projetos de automação. A engenharia de software permite o 
estabelecimento e uso de sólidos princípios de engenharia para que se possa obter economicamente um software que seja confiável e que funcione eficientemente em máquinas reais (PRESSMAN, 1995). Desta forma, a engenharia de software passou a ser alternativa tecnológica válida para a programação realizada numa automação.

Retornando ao aspecto do hardware, em contraposição ao grande número de opções de produtos de automação desenvolvidos neste princípio do ciclo, o grau de maturidade atingido pela indústria de $\mathrm{CP}$ (tanto em produtos como em processo) tornou necessária a criação de padrões para viabilizar a utilização harmônica de tais equipamentos entre diferentes locais, companhias e países, evitando desperdícios de tempo e dinheiro com o desenvolvimento e manutenção de tal variedade de soluções (LEWIS, 1998).

Com base nesta constatação, em 1979 o IEC (“International Electro-technical Commission”) estabeleceu um grupo para observar a questão do desenho de CP, incluindo aspectos de desenho do hardware, instalação, teste, documentação, programação e comunicação. O IEC possui comitês e grupos de trabalhos formados por representantes de órgãos padronizadores da maior parte dos países industriais do mundo, constituindo uma organização irmã da ISO ("International Organizations for Standardization”) .

O comitê técnico TC65 do IEC, o qual focaliza os padrões relacionados com medição e controle de processos industriais, estabeleceu o Grupo de trabalho 7 (designado posteriormente 65B/WG7) para desenvolver o padrão de CP. O grupo empreendeu a tarefa estabelecendo diversas equipes especialistas força-tarefa para ser capaz de abordar todas as questões envolvidas. Como resultado deste trabalho, foi gerado o padrão IEC 61131, constituído por 8 partes, que 
abordam questões que vão desde a terminologia, passam por padrões de construção de CP e de linguagem de sua programação.

Tendo em vista a necessidade cada vez maior de integração, a IEC prosseguindo nos esforços de padronização ao desenvolver a norma 61499 (blocos funcionais) como uma maneira efetiva de realizar a modelagem e criação do algoritmo de controle para sistemas de controle distribuído (LEWIS, 1998). A IEC define sistemas distribuídos de controle como sendo um sistema de processamento de recursos que efetua o controle de um processo através de uma rede de comunicação, contendo computadores, controladores programáveis, medidores e dispositivos de controle interconectados como no exemplo da figura 2.3.

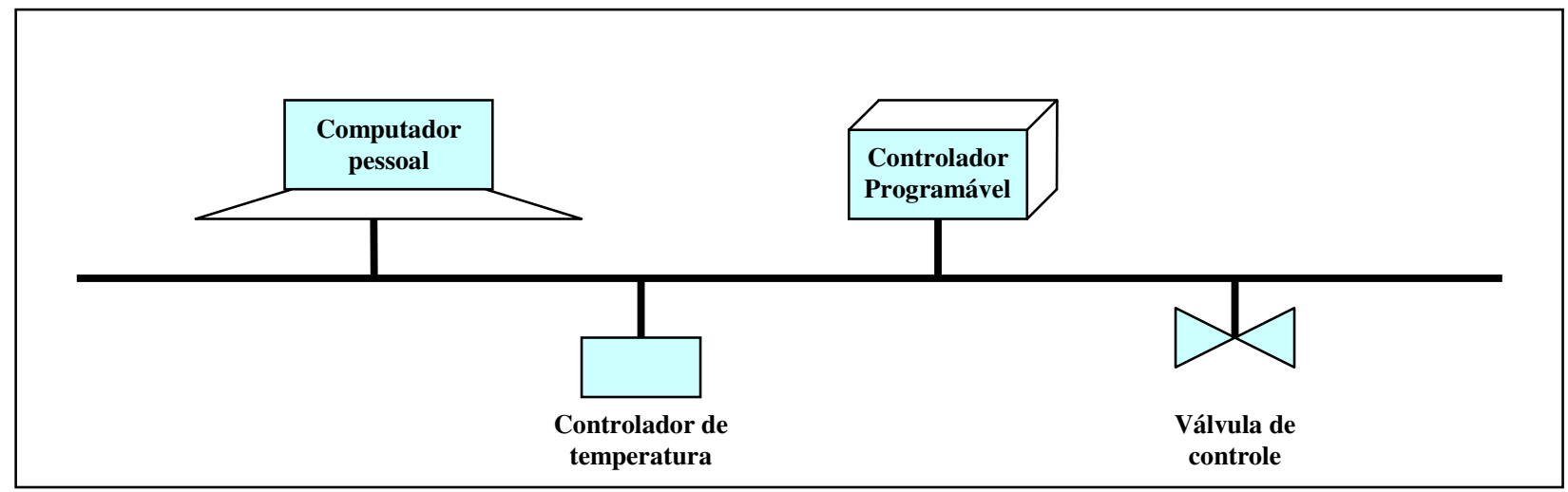

Figura 2.3. Exemplo da interconexão de equipamentos de um sistema de controle distribuído segundo a IEC

A norma IEC 61499 padroniza a modularização das funcionalidades e o protocolo de comunicação utilizado para a comunicação entre os módulos, mas não considera a topologia da rede de comunicação entre os dispositivos de controle.

Tais ações de padronização concretizaram o uso da programação como parte do produto final de um projeto de automação, e reforçam a utilização da engenharia de software como alternativa técnica para estes projetos. 
Assim, os controladores passaram a ser produzidos em grande quantidade e de forma padronizada, reduzindo o seu custo. Tal fato viabilizou a padronização de linguagens; desta forma, a automação dos processos, mesmo quando estes são específicos, passaram a independer do "hardware" (MIYAGI, 1996).

\subsubsection{Obsolescência da Automação}

Apesar do estabelecimento de diversos padrões na área de automação, não podemos deste fato deduzir que estamos atingindo a fase de obsolescência desta solução. Como evidências para este fato, encontramos grandes necessidades de padronização ainda presentes no mercado, evidenciadas pela dificuldade de integração entre os sistemas de automação e sistemas de informação existentes (vide norma ANSI/ISA S95 - "Enterprise / Control System Integration"). A existência de conjunto recente de normas publicadas e em desenvolvimento implica na inexistência de produtos que as contemplem, e que ainda serão desenvolvidos, o que evidencia a distância da fase de obsolescência.

\subsection{Tecnologia da Automação Aplicada ao Controle de Sistemas Produtivos}

Em uma formulação distinta, o controle pode ser definido como a aplicação de ação previamente planejada para que o objeto de controle considerado atinja certos objetivos (MIYAGI, 1996). Esta segunda formulação traz um conceito importante na questão do controle: o objeto de controle. Iremos utilizá-lo ao longo deste capítulo para delimitar o escopo do problema a ser resolvido pelos projetos de automação de sistemas produtivos.

\subsubsection{Sistema Automático de Controle de Sistema Produtivo (SCSP)}


Abordaremos os SCSPs dentro do contexto de evolução do ciclo de produto da automação. Iniciaremos conceituando um SCSP, conceito o qual utilizaremos para descrever ao final as soluções tecnológicas atualmente disponíveis que suportarão os métodos de projeto de um SCSP descritos.

\subsubsection{Conceito de SCSP}

Os sistemas produtivos (SP) constituem uma classe específica de sistemas onde suas partes são constituídas pelo conjunto de pessoas, equipamentos e procedimentos, organizados para a realização das operações de manufatura de uma empresa. As operações de manufatura possuem como objetivo a realização de produtos em atendimento a solicitações do mercado ao qual se destinam, que são a finalidade do sistema produtivo (GROOVER, 2000).

Os sistemas produtivos são inerentemente complexos (SANTOS FILHO, 2000), o que torna difícil impor comportamento dinâmico desejado devido aos indeterminismos em relação ao tempo e à seqüência de ocorrências de eventos de sistemas produtivos.

Por tal motivo, a definição usual de controle calcada na necessidade de um comportamento de referência desejado (CASSANDRAS, 1993) é substituída pelo conceito da aplicação de ação previamente planejada para que o objeto de controle considerado atinja certos objetivos (MIYAGI, 1996).

Com base no exposto, um SCSP é um controlador cujo objeto de controle é um SP e seu objetivo é a realização completa de todos processos produtivos necessários para a elaboração dos produtos aos quais o sistema produtivo se propõe entregar. Como toda automação, o SCSP substitui o homem no exercício das ações necessárias à realização dos objetivos do SP (GROOVER, 2000). 
Classificamos um SCSP como sistema de controle qualitativo, com base na hipótese relativa ao comportamento dos sistemas produtivos de que o fluxo de informações é estritamente qualitativo (SANTOS FILHO, 2000). Esta hipótese restringe informações quantitativas ao nível de controle local dos equipamentos.

\subsubsection{Tecnologias empregadas em um SCSP}

Fundamentados no atual estágio de padronização do ciclo de vida da automação, e na classificação do controle como qualitativo, basearemos o projeto de um SCSP no uso de CP. Como conseqüência, iremos abordar seu projeto como um projeto de programa de computador (SANTOS FILHO, 2000).

Com base nestas duas premissas (uso de CP e de programação), e no atual nível de padronização da automação, os métodos descritos empregarão como base os seguintes padrões:

- IEC 61131 - padrões para CP: requisitos de equipamento e testes, linguagens de programação, comunicações.

- IEC 61499 - padrão para blocos funcionais de programação de controle e controle distribuído de sistemas.

- ANSI/ISA S95, partes 1 a 5 - padrão para integração de sistemas de gestão com sistemas de execução.

\subsection{OBSERVAÇÕES COMPLEMENTARES}

Neste capítulo abordamos a automação, descrevendo um breve histórico do seu ciclo de vida, o qual encontramos atualmente no transcorrer da fase de padronização. Finalizamos o capítulo 
relacionando a automação ao controle de sistemas produtivos, conceituando e caracterizando um SCSP, e encerrando com a descrição das tecnologias de programação e CP disponíveis para realização de seu projeto sobre as quais nos basearemos. 


\section{Capítulo 3}

\section{APliCAÇÃo de MODElos À AutomaÇÃo de Sistemas Produtivos}

Exploraremos neste capítulo o papel da modelagem em projetos de SCSP, iniciando pela conceituação da classe dos SED aos quais pertencem os SP, conceituando modelo e seu emprego em projetos. Após a formação do contexto, encerramos o tópico descrevendo as técnicas de modelagem que empregaremos.

\subsection{Sistemas A Eventos Discretos}

Sistemas a eventos discretos (SED) são sistemas cuja evolução no tempo depende da interação entre diversos eventos discretos. Nestes sistemas, o histórico do estado evolui passo a passo, e mudanças do mesmo ocorrem somente em instantes discretos nos quais ocorrem os eventos (figura 3.1). São sistemas feitos pelo homem, os quais, ao contrário dos sistemas do mundo físico governados por equações diferenciais, são dirigidos por eventos. Tais eventos representam ações ocorridas em um intervalo finito de tempo, e que implicam em transição de estado discreto (HO, 1989).

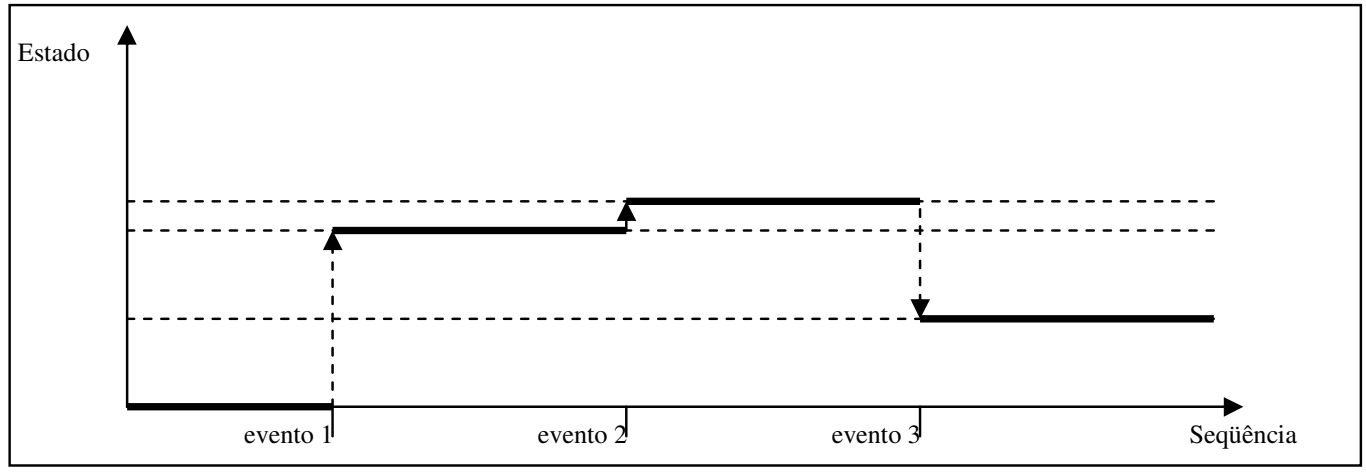

Figura 3.1. Exemplo da evolução de estado de um SED 
São exemplos reais de SED (HO, 1989):

- sistemas produtivos, onde cada elemento (por exemplo, máquinas ou transportadores) possui estados tais como 'em serviço', 'disponível' ou 'em manutenção',

○ sistemas de comunicação, onde cada elemento de rede possui estados tais como 'ocupado', 'disponível' ou 'em manutenção',

- sistemas de transporte, onde, por exemplo, podemos abordar as pistas de aterrissagem utilizando como espaço de estado os valores 'aterrissando', 'decolando', 'em reparo' e 'disponível', por exemplo.

Como conseqüência natural de sua definição, o espaço de estado $X$ (conjunto de todos os estados) de um SED é um conjunto discreto de estados. A evolução no tempo do estado de um SED é imprevisível, dependendo apenas da seqüência de eventos. Uma vez que este trabalho contempla o estudo de SP, estaremos tratando de sistemas que são da classe de SED.

\subsection{CONCEito DE Modelo}

Em uma conceituação abrangente (JACOBSON, 1987), 'modelo é uma abstração de um sistema, especificando o sistema modelado de um certo ponto de vista e a um certo nível de abstração'. Um ponto de vista, por exemplo, é aquele da especificação (realizada por analistas de automação em um projeto), enquanto outro é o ponto de vista físico de sua implementação (realização física do projeto percebida pelo usuário). Este conceito de modelo, baseado no ponto de vista de quem o utiliza, permite sua aplicação em conformidade com a diversidade de pontos de vista existentes em um projeto possibilitando a coexistência de diversos tipos de modelos em cada projeto, cada qual focado na classe de equipe envolvida com determinado 
subproduto do projeto (JACOBSON; BOOCH; RUMBAUGH, 1998), e será sobre o qual elaboraremos este trabalho.

\subsection{Uso de Modelos em Projetos}

Existe um grande esforço no sentido de desenvolver notações e semânticas para classificar e descrever diferentes sistemas. Um esforço ainda maior é dispendido para a modelagem de sistemas. Este esforço suporta as necessidades das soluções de alguns problemas reais de engenharia e, em decorrência, a construção de sistemas que realizem, no dia a dia, funções desejadas pelo homem de maneira eficiente e economicamente viável (CASSANDRAS, 1993).

A forma de organização para a solução de problemas de engenharia é o projeto. Projetos são empreendimentos cujo objetivo é a obtenção de um produto ou serviço único, elaborado de maneira progressiva (PROJECT MANAGEMENT INSTITUTE, 2000). Os projetos são compostos por processos que representam uma série de ações para atingir um resultado. São conduzidos por pessoas e se encontram em uma das duas grandes categorias (PROJECT MANAGEMENT INSTITUTE, 2000):

○ processos para a gestão do projeto, os quais descrevem, organizam e complementam o trabalho do projeto e

○ processos orientados ao produto, os quais especificam e criam o produto do projeto. São tipicamente definidos pelo ciclo de vida do projeto e variam conforme a área de aplicação.

Dentro dos processos orientados ao produto, encontramos as tarefas de especificação. Conforme a 'teoria de sistemas' (CASSANDRAS, 1993); (PRESSMAN, 1995), os modelos 
são úteis para especificar, abrangendo análise, síntese, controle, avaliação de performance e otimização de sistemas.

Portanto, também para o propósito do projeto de sistemas automáticos de controle de sistemas produtivos (SCSP), a modelagem é opção para a análise e especificação do sistema. Por outro lado, tem-se evidenciado o uso de uma diversidade de técnicas de modelagem para representação de sistemas da classe SED (CAO; HO, 1990); (CASTILLO; SMITH , 2002); afirma-se improvável o surgimento de técnicas universais que sirvam para a descrição de SED (BOEL, 2002). Dado que a matéria é relativamente nova, os diversos paradigmas e linguagens que surgem para realizar tais representações devem ser ainda muito explorados para que se possam desenvolver teorias e aplicações.

Desta forma, observamos quão importante é explicitar o escopo do método explanado, que é a especificação de um SCSP. Considerar este escopo de aplicação nos permitirá a escolha da técnica de modelagem adequada para a representação de um SCSP nos projetos pretendidos.

\subsection{Modelagem de SED APlicada aOs Sistemas Produtivos}

Tendo em vista a impossibilidade de utilizar equações diferenciais para o tratamento de SED (HO, 1989);(CASSANDRAS, 1989), outras técnicas de modelagem foram desenvolvidas para esta finalidade. Os diversos modelos desenvolvidos nestes últimos anos para a modelagem de SED apresentam características conceitualmente distintas e cada modelo é mais adequado para propósitos específicos distintos dos propósitos de outros, além de impor premissas particulares ao comportamento do modelo definido (CAO; HO, 1990).

Neste tópico, descreveremos um conjunto de técnicas de modelagem de SED particularmente adequadas ao projeto de um SCSP. Estas técnicas darão suporte aos capítulos posteriores desta dissertação. 
A seguir serão apresentadas diversas destas classes de modelos e comentadas suas características e premissas.

\subsubsection{Mark Flow Graph (MFG)}

O MFG é um modelo elaborado a partir das Redes de Petri (PETERSON, 1981); (REISIG, 1985); (MURATA, 1989). Sua definição incorpora todos os elementos da rede de Petri marcada, recebendo elementos adicionais que permitem a interação do modelo com o ambiente externo ao sistema em questão, assim como assegura que o sistema representado por ele não apresenta situações de contato (MIYAGI, 1996). O modelo MFG não define peso para os arcos, permitindo apenas uma marca por box.

O MFG é um grafo bipartido direcionado representado por:

$$
M F G=\left\{\mathbf{B}, \mathbf{T}, \mathbf{A}, \mathbf{G}_{\mathbf{I}}, \mathbf{G}_{\mathbf{E}}, \mathbf{S}, \mathbf{D}, \mathbf{M}\right\}
$$

onde:

B - conjunto de boxes.

T - conjunto de transições.

A - conjunto de arcos, subconjunto de $(\mathbf{B}$ X T $) \cup($ T X B $)$

$\mathbf{G}_{I}-$ conjunto de portas internas, subconjunto de (B X T)

$\mathbf{G}_{E}$ - conjunto de portas externas, subconjunto de (D X T)

S - conjunto de arcos de sinais de saída, subconjunto de (B X M)

onde: 
D - conjunto de fontes de sinais externos

M - conjunto de dispositivos externos

A definição de marcação $\mu$ de um MFG é uma função:

$$
\mu: \mathbf{B} \rightarrow\{0,1\}
$$

Uma representação gráfica para visualização de um modelo MFG é definida da seguinte forma (ver exemplo na figura 3.2):

$b_{i}$ - cada box é representado por um quadrado.

$t_{i}$ - cada transição é representada por um segmento de reta.

$\left(b_{i}, t_{j}\right)$ - é representado por um arco orientado ligando o box $p_{i}$ ao segmento de reta que representa a transição $t_{j}$.

$\left(t_{k}, p_{z}\right)$ - é representado por um arco orientado ligando o segmento de reta que representa a transição $t_{z}$ ao box $p_{z}$.

$g_{i}$ - porta interna representada por um círculo negro (quando habilitadora) ou em vazio (quando inibidora) postada junto a transição. Faz uso de $\operatorname{arcos}$ orientados $\left(b_{i}, t_{j}\right)$, da mesma forma já indicada acima.

$g_{e}$ - porta externa representada por um círculo negro (quando habilitadora) ou em vazio (quando inibidora) postada junto a transição. Faz uso de $\operatorname{arcos}$ orientados $\left(d_{i}, t_{j}\right)$, ligando um elemento externo $d_{i}$ ao sistema ao segmento de reta que representa uma transição $t_{j}$.

$s_{i^{-}}$saída externa representada por um arco orientado $\left(b_{j}, m_{k}\right)$ conectando o quadrado do box $b_{j}$ ao elemento externo $m_{k}$. 
$\mu_{i}$ - marcação representada por um círculo negro inscrito no box $b_{i}$.

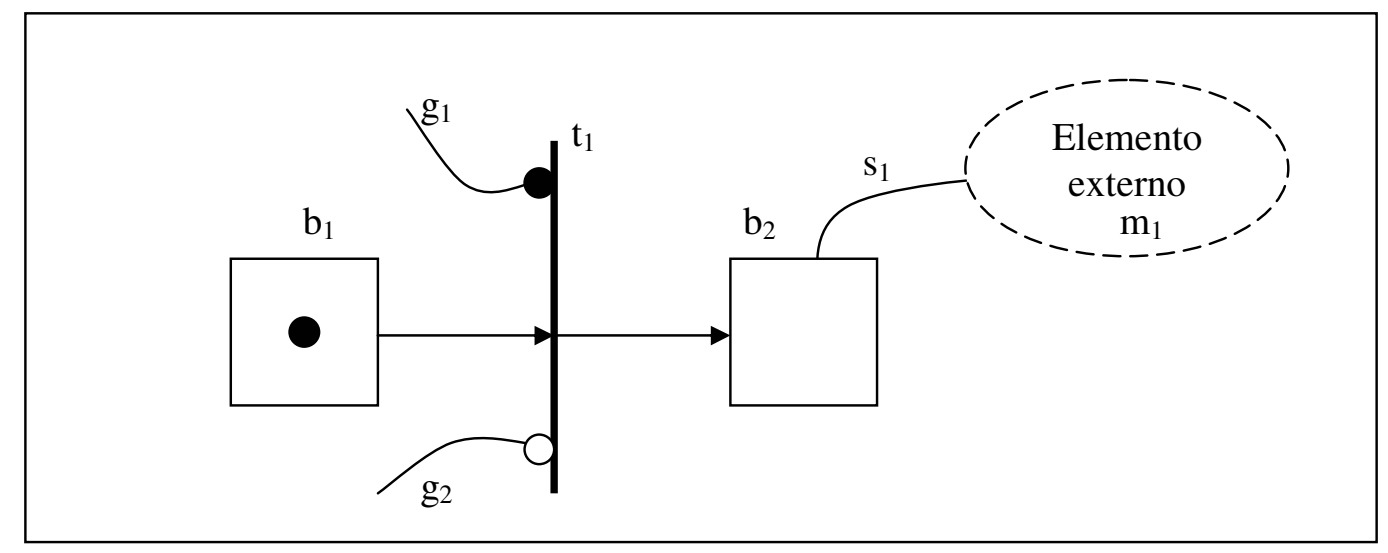

Figura 3.2. Exemplo de representação gráfica de modelo MFG

\subsubsection{Marcação e seu comportamento dinâmico}

O estado do sistema é representado em um MFG pela disposição das marcas no grafo, denominada marcação. O estado inicial do sistema é definido pela marcação inicial; para o MFG, cada box contém no máximo uma marca.

O comportamento dinâmico de um SED é alterado pela ocorrência de eventos; no MFG, a ocorrência de eventos é designada pelas regras de disparo das transições (MIYAGI, 1996) (SANTOS FILHO, 2000).

A dinâmica de disparo de uma transição é estabelecida por regras de decisão que obedecem a dois níveis hierárquicos:

- a habilitação do disparo, quando verificamos se não existe box no lado de saída com marca, box do lado de entrada sem marca, porta habilitadora (interna ou externa) no estado de desabilitação e porta inibidora (interna ou externa) no estado de habilitação. Uma transição nesta situação é denominada transição habilitada e 
- a realização do disparo, quando verificamos regras de arbitragem em situações que envolvem conflito (regras que resolvem conflitos provenientes da existência de transições em relação de concorrência) (MIYAGI, 1996). Uma transição nesta situação é denominada transição disparável e seu disparo é imediato.

Uma saída $s_{i}$ (conectada ao box $b_{z}$ ) envia sinal habilitador ao elemento externo toda a vez que a marcação esteja presente no box $b_{z}$ ao qual está conectada.

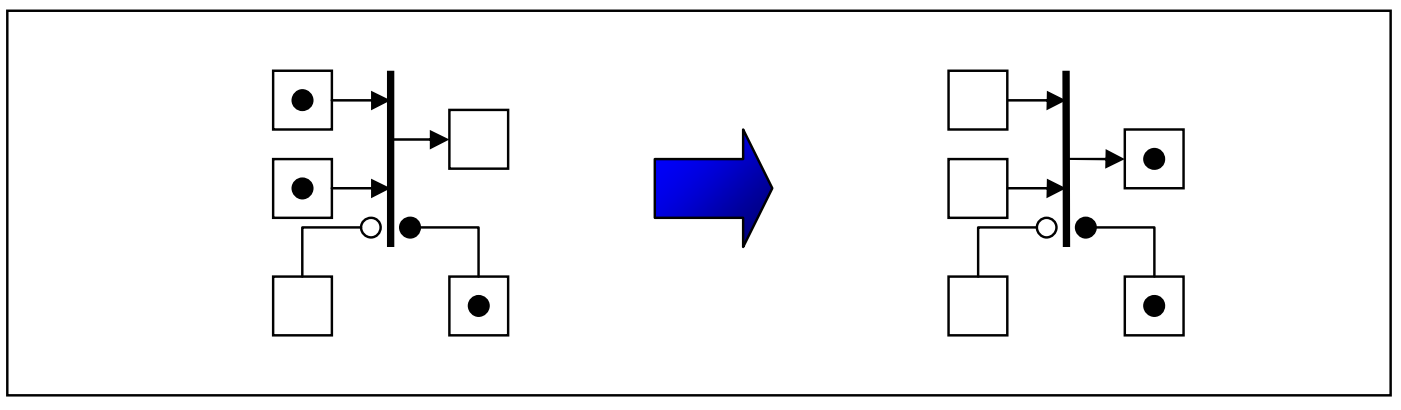

Figura 3.3. Exemplo da dinâmica de disparo de uma transição

\subsubsection{Enhanced Mark Flow Graph (E-MFG)}

A incorporação de novos elementos estruturais tais como emprego das marcas com atributos e das regras adicionais de transição (permitindo controle das alterações de fluxo, como no caso das rotas alternativas), conforme veremos adiante, resultou na modelagem E-MFG (SANTOS FILHO, 1993); (SANTOS FILHO; MIYAGI, 1995). Apresentaremos a seguir os elementos estruturais adicionais ao MFG propostos pelo E-MFG, incluindo revisão da regra de disparo das transições resultante da adição destes novos elementos.

\subsubsection{Marcas}

Cada marca possui um conjunto de atributos distintos, que lhe individualiza. Cada atributo da marca pode, por exemplo, designar uma propriedade ligada a um produto em fabricação pelo 
SP (detalhamento do processo e controle, por exemplo, ou especificações). Os atributos são definidos previamente e reunidos através de um registro (SANTOS FILHO, 1993). A manipulação dos atributos de marcação acontece em função de alterações condicionadas (box controlador) ou através de filtragens seletivas, como será detalhado posteriormente.

Diversas marcas são agrupadas, opcionalmente, em uma marca composta. Esta marca composta passa a representar um vetor das marcas originais, com cada marca preservando todos seus atributos originais. Assim, pode-se representar um agrupamento ou desempacotamento de informações de um determinado processo produtivo (figura 3.4).

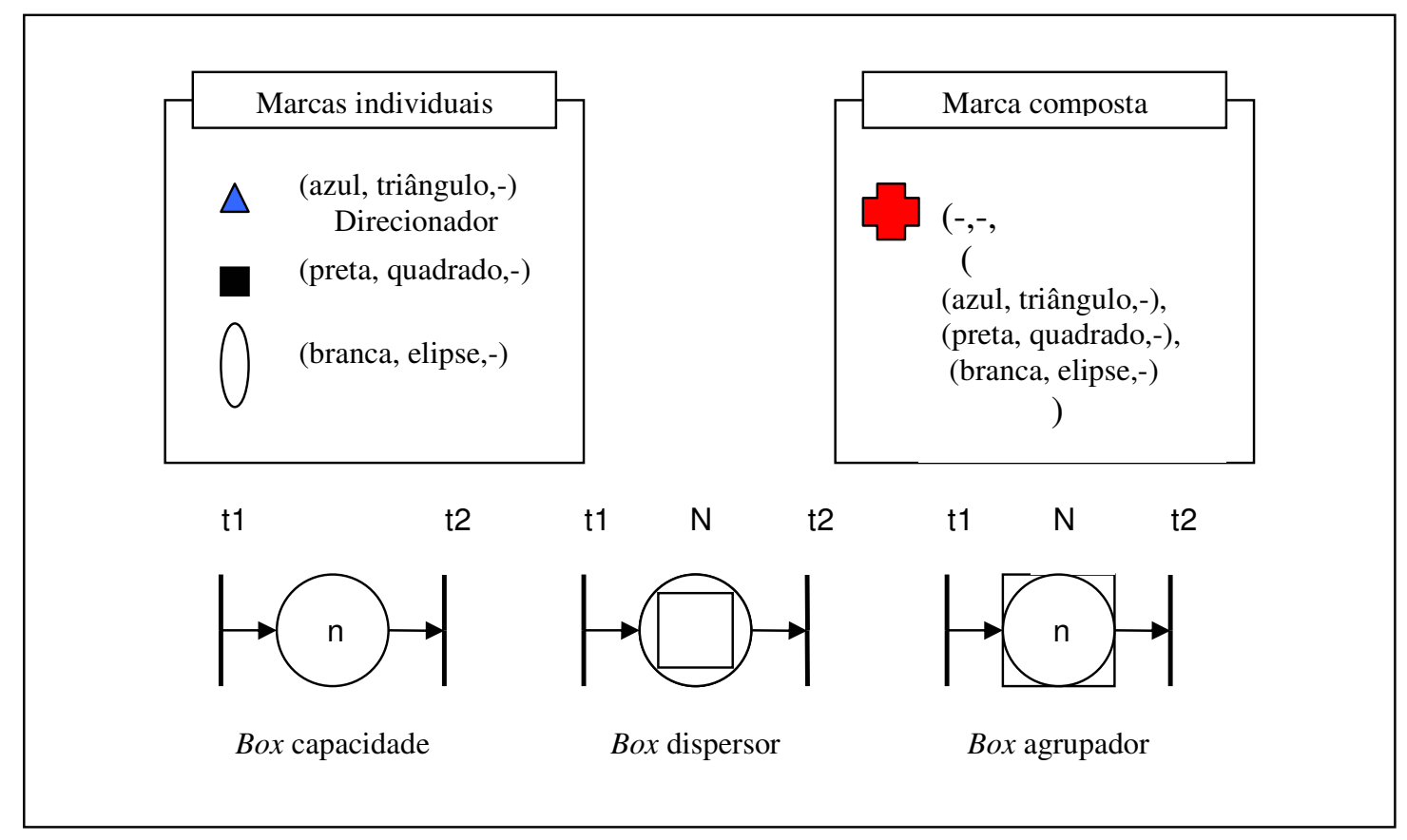

Figura 3.4. Exemplos de marcas individuais e composta, e boxes funcionais básicos

\subsubsection{Boxes}

Foram criadas especializações do box definido na modelagem MFG para o E-MFG. São cinco (figura 3.4.) especializações (SANTOS FILHO, 1993): 
- box capacidade: especifica número máximo de marcas (maior que um) e opcionalmente a regra para retirada das marcas armazenadas. Podem ser aplicadas no box as regras para filas ou para pilhas na retirada de marcas individuais,

- box agrupador: reúne todas as marcas recebidas até o próximo disparo em apenas uma marca composta, limitado a quantidade especificada. Na ocasião de um disparo, a marca composta prosseguirá como única ao longo do modelo. A marca composta possui uma estrutura que preserva o conteúdo de todas as marcas que a compõe, incluindo seus atributos,

- box dispersor: decompõe toda marca individual composta nas marcas individuais originais que a compunham,

- box controlador: associa um conjunto de regras de controle para atualizar os atributos das marcas. As regras são como regras de produção do tipo 'se...então...' e são utilizadas nas especificação de ações de controle para supervisão das informações que acompanham as marcas e

- box temporizador: é um box de capacidade unitária que retém a marca em seu interior durante um intervalo de tempo. O intervalo de tempo pode ser definido previamente ou através de um atributo da marca.

Os boxes funcionais do tipo capacidade, agrupador e dispersor controlam e limitam apenas a quantidade de peças na situação em que, respectivamente, se modelam processos de empacotamento, desempacotamento, ou ainda um "buffer" de armazenamento temporário em um sistema de manufatura. No caso de serem utilizadas marcas individuais nestes boxes, 
podemos controlar também a seqüência de entrada e saída de materiais, assim como o conteúdo das cargas.

O box funcional controlador exerce a função de controlar o estado dos atributos de uma marca, atualizando o estado local representado por uma destas marcas e conseqüentemente atualizando o estado global. Regras do tipo 'se-então' são aplicadas para a verificação e atualização dos atributos previamente especificados (SANTOS FILHO, 2000). A figura 3.5 ilustra um exemplo de box controlador alterando os atributos de uma marca.

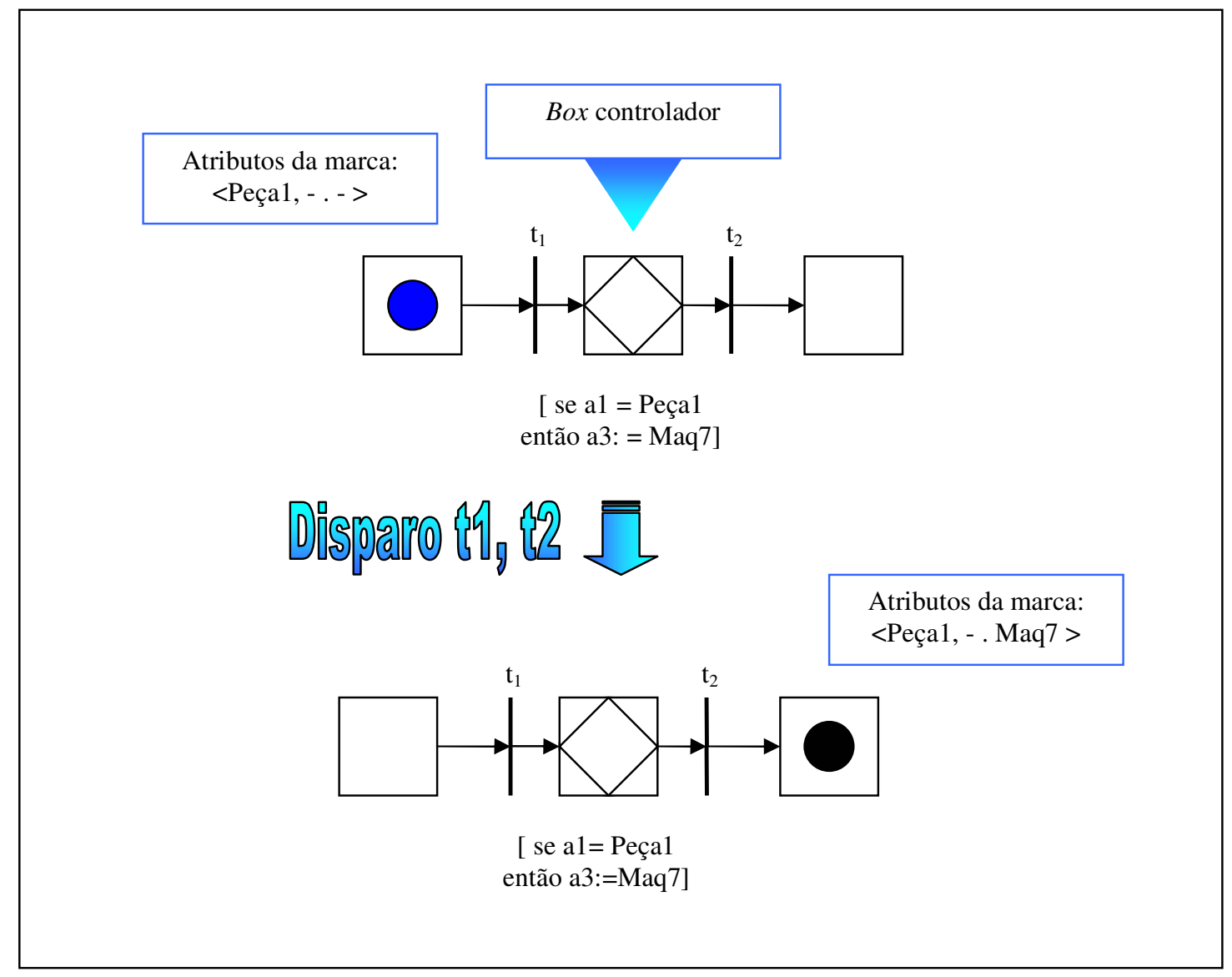

Figura 3.5. Representação de box controlador alterando o estado de uma marca individual 


\subsubsection{Regras de disparo}

Na dinâmica de disparos das transições, são estabelecidos três níveis hierárquicos de decisão para o E-MFG (SANTOS FILHO, 2000):

- primeiro nível: corresponde às regras de transição adicionais de disparo, realizadas através de inscrições nas transições (tipo ‘se-então'). Não havendo inscrições em uma transição, não há regras adicionais que limitem seu disparo. Uma transição satisfaz regras de restrições adicionais é denominada transição em prontidão.

- segundo nível: corresponde às regras de habilitação de disparo, iguais às definidas para o MFG. Toda transição em prontidão é considerada como transição habilitada quando satisfizer as condições:

○ não existem boxes na saída com marcas em número acima da sua capacidade,

○ não existem boxes no lado de entrada sem marcas ou apenas com marcas com restriçõos,

○ não existe porta habilitadora (interna ou externa) que esteja no estado de desabilitação e

○ não existe porta inibidora (interna ou externa) que esteja no estado de inibição.

- terceiro nível: corresponde às regras de realização de disparo propriamente ditas. Neste caso, isto corresponde a verificar regras de arbitragem em situações de conflito (exemplo: na situação de concorrência na saída de uma transição, quando é necessária regra de arbitragem). Uma transição habilitada que satisfizer as regras de realização de disparo denomina-se transição disparável. 
Uma transição disparável dispara imediatamente, fazendo com que as marcas fluam pelo grafo da mesma forma que no MFG. No disparo, são observadas as regras de filtragem seletiva de atributos conforme as inscrições dos arcos. A figura 3.6 ilustra um disparo de uma transição e a realização das regras de filtragem seletiva.

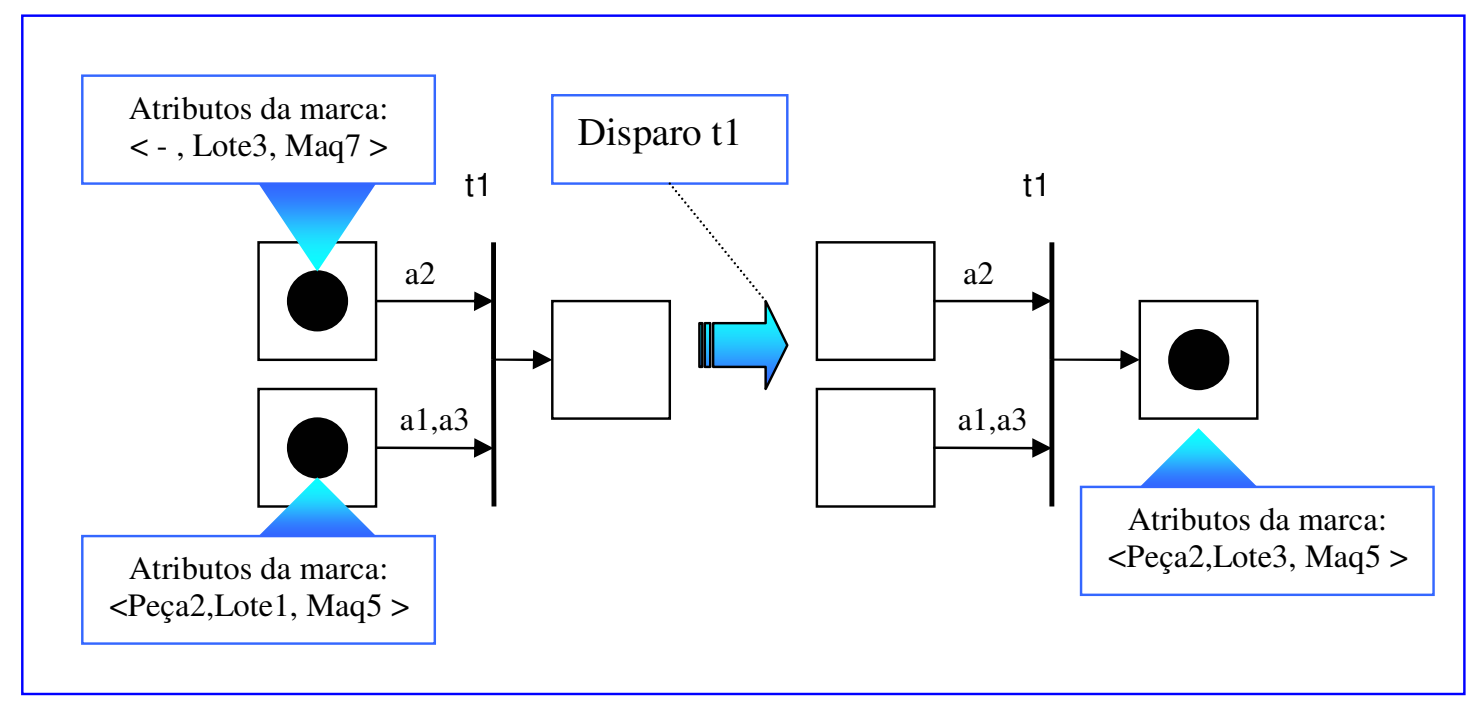

Figura 3.6. Alteração e atributos das marcas decorrentes do disparo

\subsubsection{E-MFG com Comunicadores}

Para viabilizar a colaboração entre sistemas modelados por E-MFG e que constituem o SCSP, tornou-se necessária incorporação de elementos comunicadores ao E-MFG (MATSUSAKI, 2004). Verificamos que tais elementos comunicadores também são necessários em outras situações, onde a integração dos SCSP com os sistemas de controle dos equipamentos e com os sistemas de informação gerenciais forma um novo contexto para o projeto (ANSI/ISA S95). São utilizados os seguintes elementos estruturais estendidos:

- transições: continuam indicando a ocorrência de eventos, admitindo inscrições que representam regras adicionais restritivas para a evolução do estado do sistema, e agora podem também ser conectados a interfaces de recepção, 
- box: sem alterações, continuam indicando pré e pós-condições, representando a natureza condição-evento do sistema produtivo, podendo ser conectados a interfaces de envio,

- arcos orientados: mantidos exatamente como no E-MFG (função de estabelecer a relação de precedência, ou causal, entre os eventos e as condições, recebendo opcionalmente a adição de inscrições, que permitem controlar a transmissão dos atributos das marcas),

- marcas: mantidas como no E-MFG,

São adicionados os seguintes elementos estruturais:

- interfaces de envio de mensagem: os arcos de sinal de saída do MFG são alterados, recebendo a adição de uma transição de emissão, que permite a transmissão de informações aos elementos externos. A transmissão se dá através da emissão de uma mensagem assíncrona eventual no disparo da transição, e que ocorre quando o box ao qual está ligado o arco de envio contém uma marca e

- interfaces de recepção de mensagem: substituem as portas habilitadoras e inibidoras da ocorrência de eventos. Uma interface de recepção de mensagem é constituída por um box receptor que conecta este box à transição a ser habilitada ou inibida.

Detalharemos e ilustraremos a aplicação deste elementos a seguir. 


\subsubsection{Interfaces de envio}

A interface de envio corresponde à chamada de um método de outro objeto, e formada pelos seguintes elementos (cuja representação gráfica está na figura 3.7, e exemplo de seu emprego na figura 3.8):

- transição de envio (ou transmissor): indica a ocorrência do evento de envio da mensagem. Possui inscrição que identifica a instância e seu método solicitados pelo disparo da transição de envio, separados por um ponto. É representado graficamente por dois segmentos de reta paralelos e próximos.

- arco de envio (ou arco transmissor): conecta a transição de envio ao box de origem. Seu papel é o de habilitar o disparo da transição de envio quando existe marcação presente no box de origem. É identificado por possuir em cada extremidade um conector circular barrado na direção oposta da sua conexão.

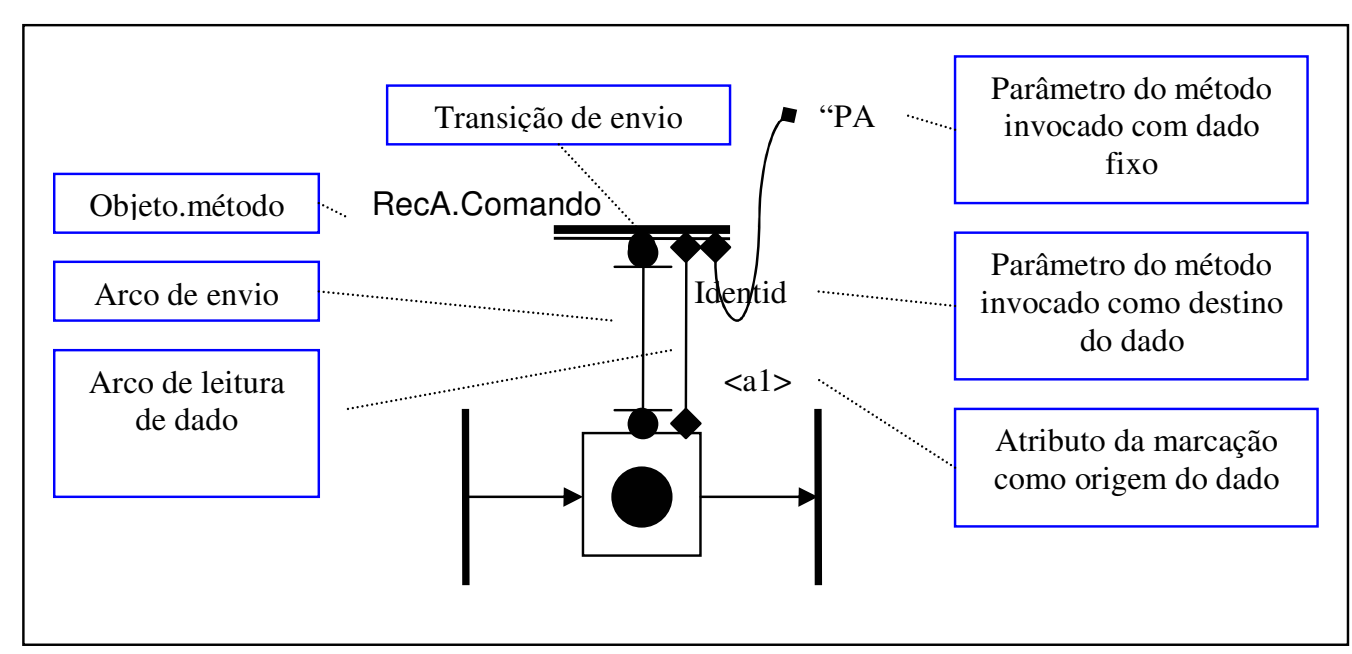

Figura 3.7. Elementos da interface de envio

- arco de dado (opcional): cada arco fornece o valor de um parâmetro do método quando este é invocado (identificado pela inscrição da transição) pelo disparo da 
transição de envio. $\mathrm{O}$ arco de dado recebe duas inscrições; uma próxima à conexão do arco com o box de origem da interface, que indica qual atributo da marca será a origem do dado, e outra próximo à sua conexão com a interface de envio, identificando o parâmetro do método invocado ao qual se destina o valor a ser enviado do atributo da marca. Importante notarmos que o arco de dados não é interpretado por semântica assemelhada ao arco, pois o arco de dado representa o mapeamento entre o parâmetro do método invocado e o atributo da marcação, enquanto que o arco estabelecem a semântica da relação causal entre eventos e condições, não ficando sujeito a restrição sintática de que um arco sempre liga box a transição ou vice-versa. É identificado por possuir em suas extremidades um conector em forma de losango.

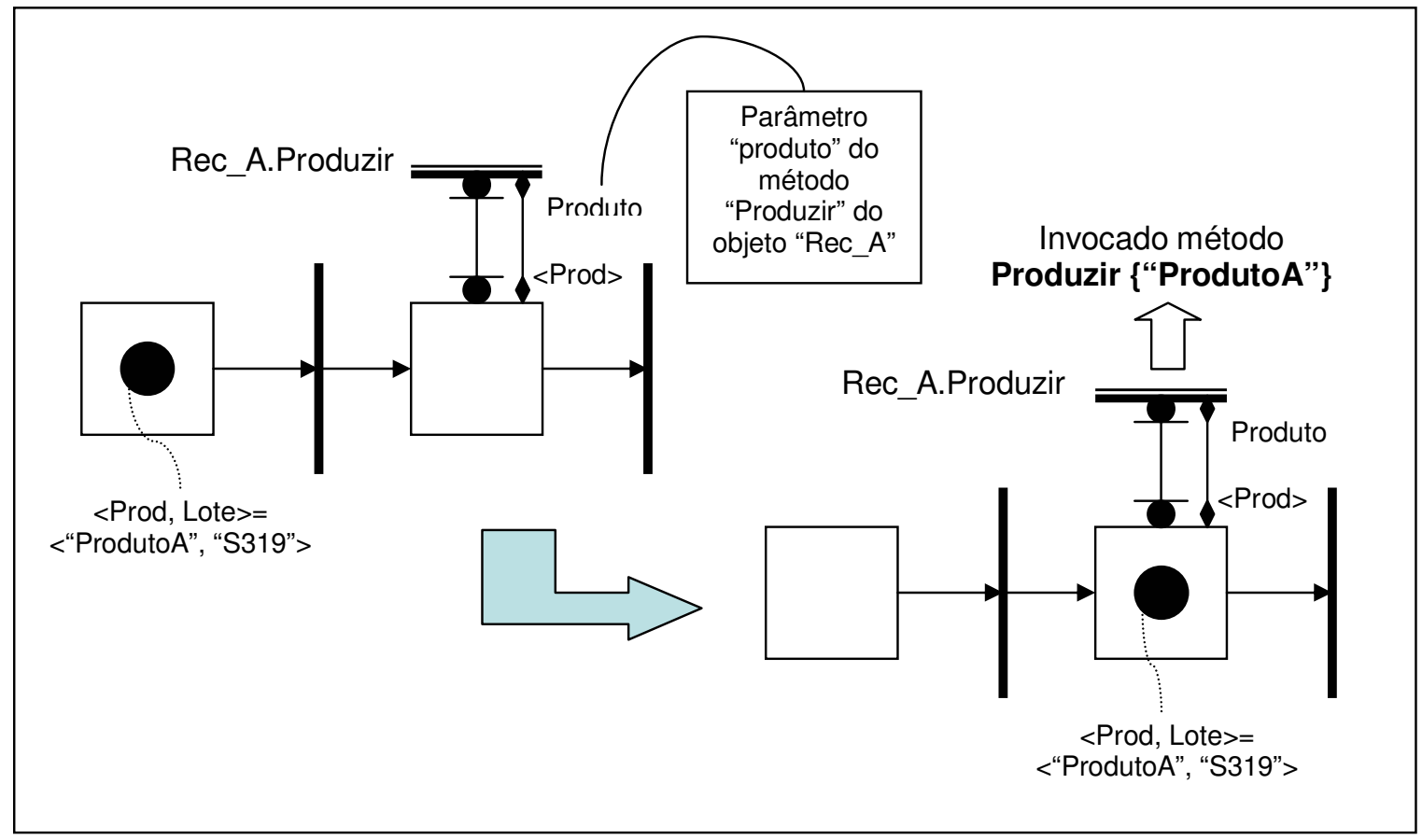

Figura 3.8. Exemplo de atuação da interface de envio 


\subsubsection{Interfaces de recepção}

A interface de recepção representa a invocação por objeto externo ao modelo de um método a ser realizado pelo E-MFG com comunicadores, e sua estrutura é composta pelos seguintes elementos (representação gráfica e exemplo de utilização na figura 3.9):

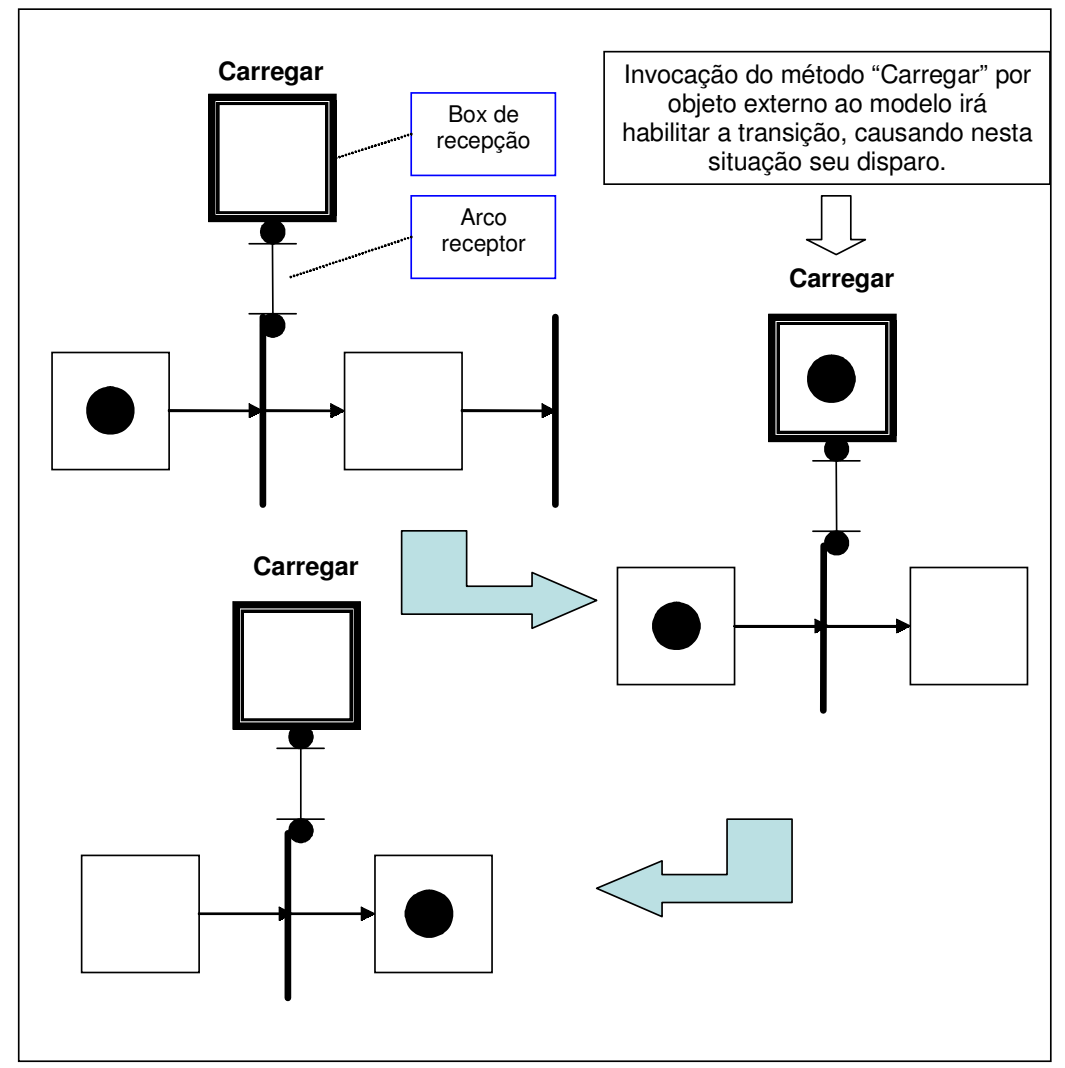

Figura 3.9. Exemplo de atuação da interface de recepção

- box de recepção (ou receptor): representa a condição do recebimento efetuado da invocação de um método. Os atributos da marca contêm os parâmetros enviados pela invocação. Possui inscrição que identifica o método colocado à disposição pelo modelo E-MFG. O box de recepção é representado com linhas duplicadas e

- $\quad$ arco de recepção (ou arco receptor): conecta o box de recepção à transição que inicia o processamento da mensagem, habilitando-a quando do recebimento de uma invocação. 
Também é identificado por possuir em cada extremidade um conector circular barrado na direção oposta da conexão. É representado graficamente por dois segmentos de reta paralelos e próximos.Um box de recepção recebe de um a vários arcos de recepção.

Um segundo tipo de interface de recepção, cujo tipo passaremos a denominar interface de recepção para habilitação condicionada a mensagem, foi definida através de sintaxe específica que aplica sinais de porta aos arcos de recepção. O sinal de porta é definido por uma regra, a qual utiliza os parâmetros do método invocado para seu cálculo. A sintaxe original definia todas as regras em um único elemento sintático, o direcionador (MATSUSAKI, 2004), o qual define o sinal de porta de cada arco, este identificado por uma inscrição variável (figura 3.10).

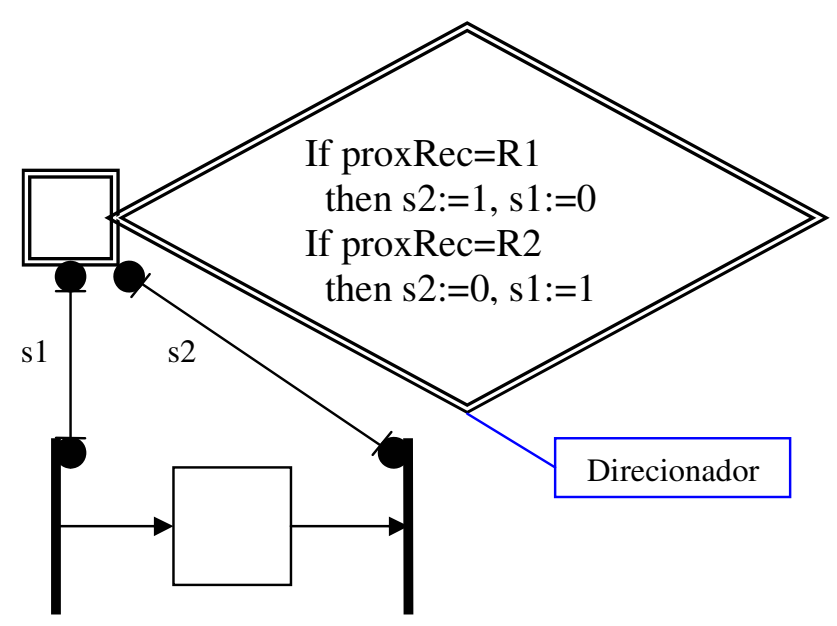

Figura 3.10. Sintaxe original da interface de recepção para habilitação condicionada a mensagem

Neste trabalho modificamos esta sintaxe original para permitir a imediata identificação do arco de recepção e de seu sinal de porta quando necessária sua manutenção. A sintaxe proposta está na figura 3.11, onde encontramos um exemplo de sua aplicação. 


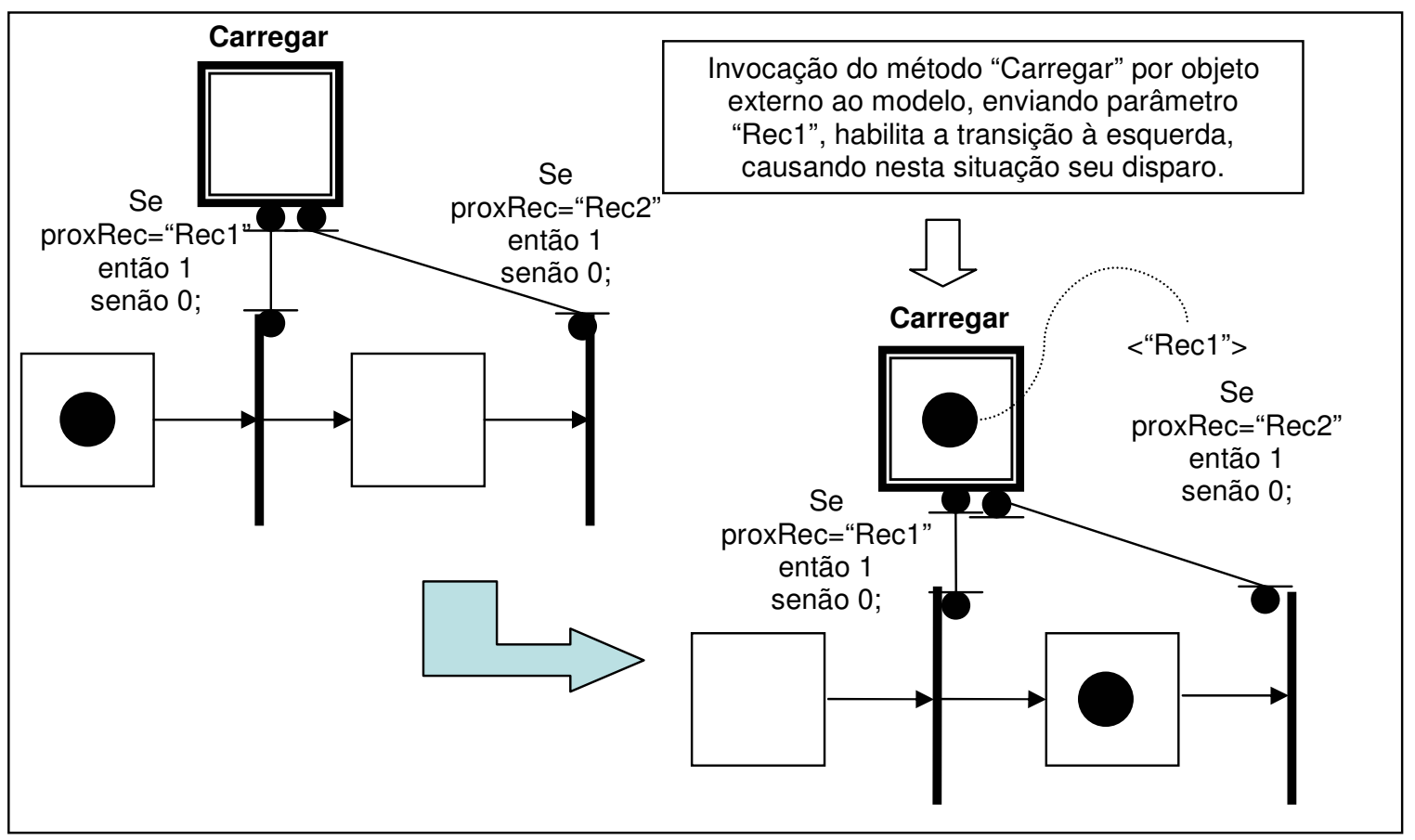

Figura 3.11. Exemplo de atuação da interface de recepção para habilitação condicionada a mensagem (sintaxe revista) 
CAPÍTULO 4

ENGENHARIA DE

REQUISITOS

Uma vez que nosso objetivo é projetar o SCSP, neste capítulo, focalizaremos nossas atenções nas fases iniciais do ciclo de vida do projeto. Tal abordagem implica em atenção específica aos tópicos que envolvam a engenharia de requisitos, e a discussão de aspectos ligados a linguagens de especificação e suas características.

Para elaborar modelos, nosso objetivo final, necessitaremos conhecer linguagens de especificação e como explorar de maneira eficaz suas características, assim como dominar a terminologia e conceituação envolvida. Estes são os tópicos discutidos neste capítulo.

\subsection{REQUISITOS E ESPECIFICAÇÕES}

Iniciaremos nossa abordagem com conceituações. Em primeiro lugar, colocamos o conceito de requisito. Um requisito expressa as necessidades, explicitadas em termos quantitativos ou qualitativos, visando definir características de uma entidade, permitindo sua realização e exame (ASSOCIAÇÃO BRASILEIRA DE NORMAS TÉCNICAS, 2000).

Para atender a projetos de um SCSP, precisamos desenvolver este conceito de requisito trazido pela qualidade para um contexto aplicável. A engenharia de requisitos revisa o conceito de requisito trazido pela qualidade para o contexto do projeto de um SCSP. Antes de colocar este conceito, necessitamos introduzir dois termos empregados pela engenharia de requisitos e utilizados na elaboração do mesmo. 
O termo ambiente representa a porção do mundo real relevante ao projeto de desenvolvimento de um programa (ZAVE; JACKSON, 1997); (JACOBSON; BOOK; RUMBAUGH, 1998), representando 'coisas' que existem ou eventos que ocorram neste ambiente onde o sistema operará.

Utilizaremos o termo sistema para o programa desenvolvido, suportado por um recurso físico computacional, e conectado com o ambiente resultante do projeto (ZAVE; JACKSON, 1997). É desenvolvido para atender a um propósito específico e descrito por um conjunto de modelos, possivelmente proveniente de diversos pontos de vista (JACOBSON; BOOK; RUMBAUGH, 1998).

Partindo destes termos, requisitos são condições ou capacidades às quais um sistema necessita atender (JACOBSON; BOOK; RUMBAUGH, 1998), pela qual o usuário expressa sua intenção (ZAVE; JACKSON, 1997).

Uma questão importante abordada pela engenharia de requisitos é a viabilidade de implementação de um determinado requisito; o conjunto de condições ou capacidades implementáveis por um sistema computacional, independentemente da plataforma que será utilizada, é o que denominamos especificação (ZAVE; JACKSON, 1997). A especificação é a referência fundamental para a implementação de um sistema, servindo de base para sua verificação (DUKE; ROSE, 2000), e como contrato e meio de comunicação entre usuário, analistas e implementadores (WING, 1990).

A especificação é essencialmente um modelo abstrato capturando uma visão (ou ponto de vista) particular de um sistema (DUKE; ROSE, 2000); (JACOBSON; BOOK; RUMBAUGH, 1998). 


\subsection{LINGUAGENS DE ESPECIFICAÇÃ̃o ${ }^{1}$}

Diversas técnicas foram desenvolvidas para elaborar especificações de um sistema a partir de seus requisitos. Muitas abordagens, usualmente empregadas no desenvolvimento de sistemas são imprecisas (PARNAS; MADEY, 1995), expressando-se até mesmo por linguagem natural. Como tal, não podem ser utilizadas como referência para validação de um sistema, pois suas afirmações são potencialmente ambíguas e incompletas.

Em outro extremo encontramos as especificações formais, expressas através de linguagens de especificação formais. As linguagens de especificação formais empregam notações e técnicas de manipulação encontradas na Matemática (WING, 1990); (DUKE; ROSE, 2000); (LIGHTFOOT, 2001). Tal característica confere às especificações formais a precisão, e a independência de linguagens naturais que as levam a universalidade de compreensão (LIGHTFOOT, 2001), além da possibilidade do emprego de provas para verificar sua correção (WING, 1990).

Uma linguagem de especificação formal utiliza uma coleção de símbolos (constantes, variáveis e conectores lógicos) e um conjunto de regras gramaticais que permitem a combinação destes símbolos em sentenças, formando o que denominamos seu domínio sintático (WING, 1990); (CASTILLO; SMITH, 2002).

De outro lado, encontramos o domínio semântico (WING, 1990), constituído pelos objetos do ambiente envolvidos com o sistema que pretendemos especificar.

Cada objeto do ambiente é relacionado ao respectivo elemento sintático da linguagem de especificação formal através do que denominamos designação, ao passo que a relação inversa,

\footnotetext{
${ }^{1}$ A expressão linguagem de especificação não está sendo utilizada como estritamente previsto em Ciências da Computação, mas sim como um modelo matemático de representação.
} 
na qual partimos do elemento sintático para o respectivo objeto do domínio semântico, é denominada interpretação (CASILLO; SMITH, 2002).

$\mathrm{Na}$ figura 4.1, podemos observar esquematicamente o relacionamento entre os domínios semânticos e o sintático. Observamos um sistema físico J, governado por causalidade (arco orientado '1') e um modelo formal $\mathbf{F}$, governado por inferência (arco orientado '3'), onde causalidade e inferência possuem significados intuitivos. O processo de formalização requer a elaboração dos seguintes mapeamentos (CASILLO; SMITH, 2002):

- um mapeamento que codifica observáveis de $\mathbf{J}$ pelos teoremas de $\mathbf{F}$, indicado pelo arco orientado '2', ao qual denominamos designação e

- outro mapeamento para decodificação das proposições de $\mathbf{F}$ de volta aos observáveis de J, indicado pelo arco orientado '4', ao qual denominamos interpretação.

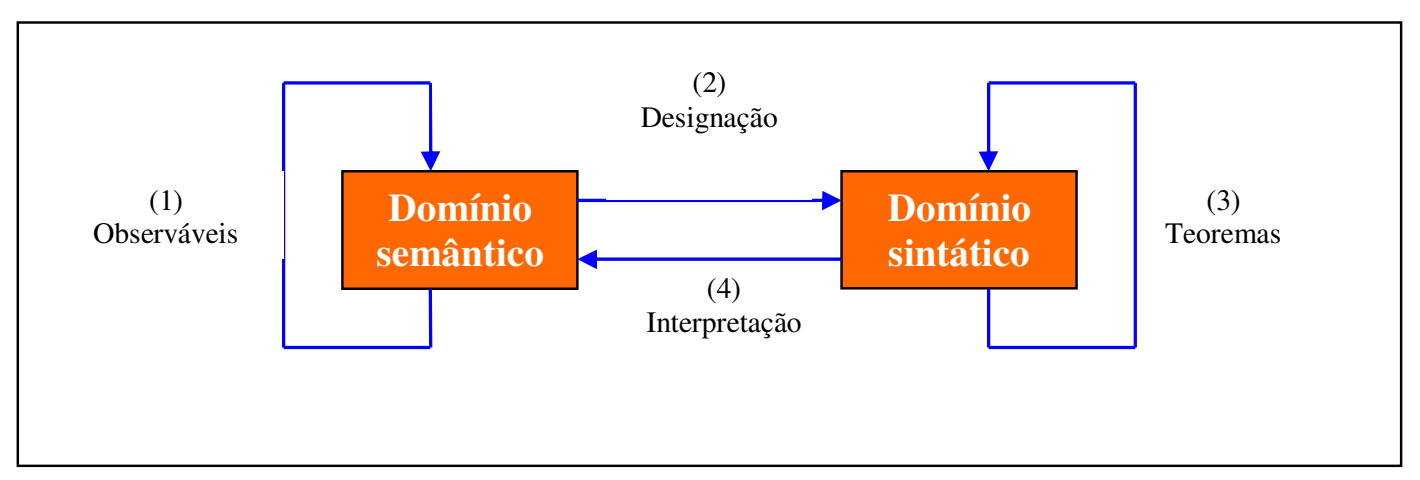

Figura 4.1. Representação do relacionamento de um modelo formal com domínio semântico

Um domínio sintático não necessita ser restrito a elementos textuais; elementos gráficos também podem ser utilizados, tais como arcos (orientados ou não), linhas e círculos, colocando à disposição semânticas tão precisas quanto as fornecidas pelas notações textuais (WING, 1990). 
Definimos linguagem de especificação formal como uma tripla $<$ Syn, Sem, Sat $>$ onde Syn e Sem são conjuntos e Sat $\subseteq$ Sem X Syn é uma relação entre os conjuntos. Syn é denominado domínio sintático da linguagem, Sem é o domínio semântico da linguagem e Sat é a relação que satisfaz a linguagem (WING, 1990).

Complementando termos utilizados, definimos que, para uma dada linguagem de especificação formal, considerando syn elemento de Syn e sat elemento de Sat, se Sat ( syn, sem ) então syn é a especificação de sem, enquanto sem é o especificando de syn (WING, 1990).

\subsubsection{Propriedades ligadas às Especificações}

Complementaremos uma visão introdutória das linguagens de especificação com algumas definições, iniciando com duas importantes propriedades de uma especificação: consistência e a não ambigüidade.

Definição 1: Dada uma linguagem de especificação <Syn, Sem, Sat>, uma especificação syn em Syn não é ambígua se, e somente se, Sat mapeia syn para exatamente um conjunto de especificandos.

Uma especificação não é ambígua se possui apenas um sentido. Esta propriedade chave da especificação formal significa que qualquer linguagem de especificação baseada em uma linguagem natural (tal qual o português) não é formal, já que é naturalmente ambígua (WING, 1990).

Definição 2: Dada uma linguagem de especificação <Syn, Sem, Sat>, uma especificação syn em Syn é consistente se, e somente se, Sat mapeia Syn para um conjunto especificando não vazio. 
Com base nesta definição, não derivamos nenhuma contradição a partir de uma especificação consistente. Na hipótese de recebermos uma questão baseada em uma especificação consistente, não podemos obter respostas múltiplas mutuamente exclusivas. Uma especificação inconsistente, a qual nega em uma ocasião o que afirma em outra, significa que não possuímos conhecimento completo (WING, 1990).

Para finalizar o conjunto de definições ligadas às especificações, segue a definição do que é uma implementação correta em relação a uma linguagem de especificação. $O$ domínio semântico empregado neste caso versa sobre sistema (WING, 1990), onde sistema é compreendido como colocado ao princípio do tópico 4.1 .

Definição 3: Dada uma linguagem de especificação <Syn, Sem, Sat>, uma implementação prog em Sem é correta com relação a uma dada especificação spec em Syn se, e apenas se, Sat (spec, prog) (WING, 1990).

\subsubsection{Linguagens de Especificação e Homomorfismos}

Freqüentemente, nós gostaríamos de especificar diferentes aspectos de um único especificando, talvez utilizando diferentes linguagens de especificação. Por exemplo, podemos especificar o comportamento de uma coleção de módulos de programas como a composição do comportamento funcional dos módulos individuais. Adicionalmente, poderíamos desejar especificar o relacionamento estrutural entre os módulos; por exemplo, qual conjunto de módulos que cada módulo invoca diretamente.

Para acomodar diferentes visões de um especificando, nós associamos cada linguagem de especificação a uma função de abstração, a qual particiona o especificando em classes de equivalência. 
Definição 4: Dado um domínio semântico, Sem, uma função de abstração semântica é um homomorfismo, $A:$ Sem $\rightarrow 2^{\text {Sem }}$, que mapeia elementos do domínio semântico em classes de equivalência.

Para uma linguagem de especificação, nós escolhemos uma função de abstração semântica para induzir uma relação abstrata de satisfação entre especificações e a classe equivalente de especificandos. Esta relação define uma visão de especificandos.

Definição 5: Dada uma linguagem de especificação, <Syn, Sem, Sat>, e uma função de abstração semântica, $A$, definida em Sem, uma relação abstrata de satisfação, ASat : Syn $\rightarrow$ $2^{\text {Sem }}$, é uma relação induzida tal que:

$$
\forall \text { spec } \in \text { Syn, prog } \in \text { Sem } .[\text { Sat(spec,prog })=\text { ASat(spec, A(prog) }]
$$

Diferentes funções de abstração semânticas tornam possível escrever múltiplas visões da mesma classe de equivalência de sistemas, ou similarmente, impor diferentes tipos de restrições a estes sistemas. Possuir diversas linguagens de especificação com diferentes funções de abstração semânticas para um único domínio semântico pode ser útil. Tal fato encoraja e suporta especificações complementares de diferentes aspectos de um sistema.

Como exemplo, na figura 4.2, encontramos um domínio semântico único Sem à direita. Uma função de abstração semântica particiona especificandos em Sem em um conjunto de classes de equivalência, três das quais são desenhadas em linhas sólidas. Outras partições de especificandos são formadas por um diferente conjunto de classes equivalentes, duas das quais são desenhadas em linhas descontínuas. Através da função de satisfação abstrata ASatl, mapeamos a especificação $A$ do domínio sintático Synl para uma classe equivalente de 
especificandos (linhas sólidas), e através de $A S a t 2$, mapeamos as especificações $B$ do domínio sintático Syn2 para diferentes classes de equivalência de especificandos (linhas descontínuas). Notemos a sobreposição entre as áreas delimitadas pelas linhas contínuas e linhas descontínuas.

Como exemplos de funções de abstração semânticas, podemos citar duas classes amplas: as abstrações que preservam o comportamento do sistema e aquelas que preservam a estrutura dos sistemas.

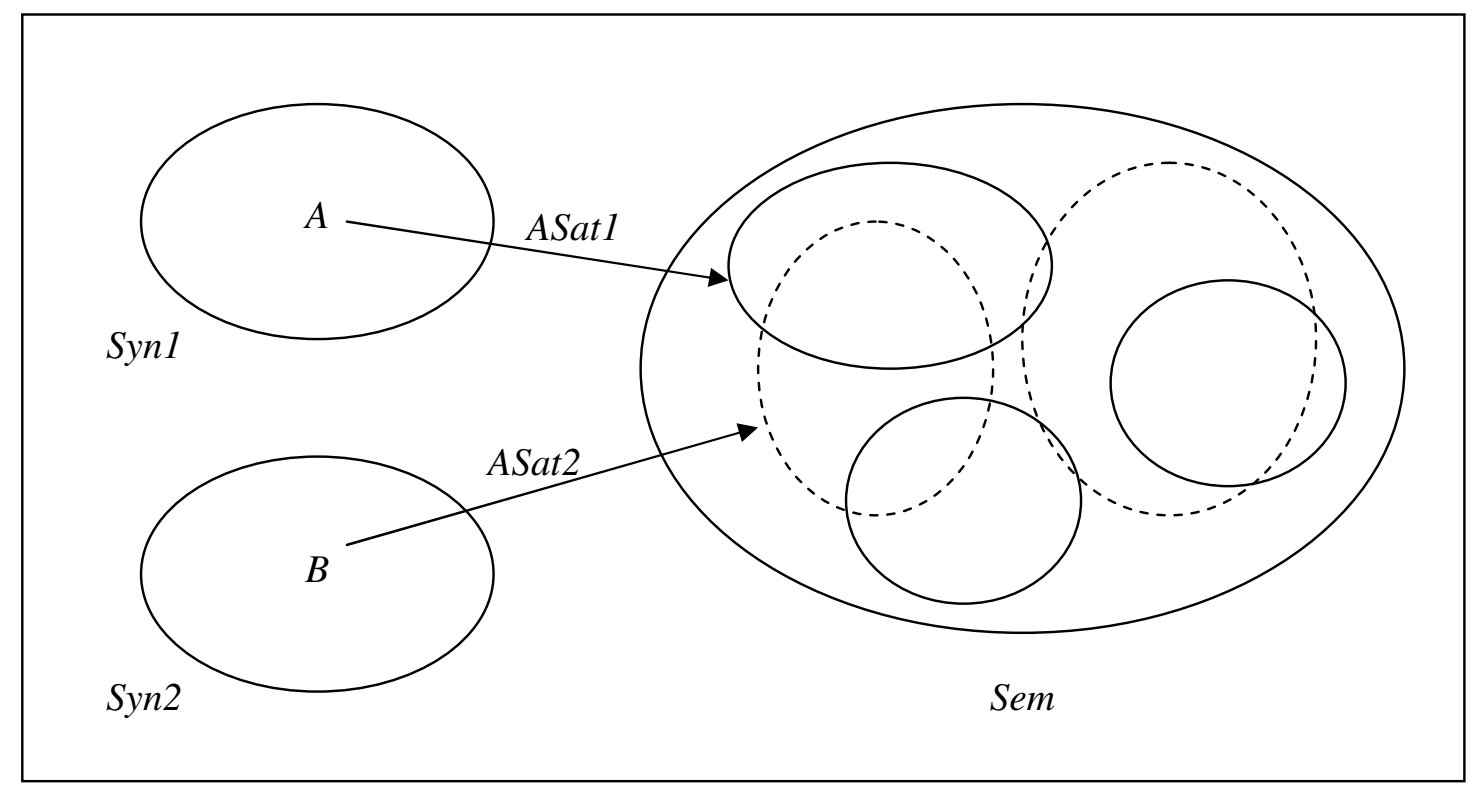

Figura 4.2. Múltiplos homomorfismos referentes a um mesmo domínio semântico

\subsection{REQUiSITOS PARA LINGUAGENS DE ESPECIFICAÇÕES}

Com base no exposto anteriormente neste capítulo, verificamos a necessidade do uso de uma linguagem de especificação para realizar a modelagem de um SCSP em um projeto, escopo desta dissertação. Algumas características mínimas por parte da linguagem de especificação são necessárias para obtenção de uma especificação consistente, não ambígua e que atenda estritamente aos requisitos (ZAVE; JACKSON, 1997). Tais características são: 
- fundamentam terminologia utilizada na realidade do ambiente para o qual o sistema de controle será construído (JACOBSON; BOOK; RUMBAUGH, 1998); (ZAVE; JACKSON, 1997),

- possibilitam a construção do sistema de controle não definida pela especificação (ZAVE; JACKSON, 1997); (PARNAS; MADEY, 1995) . A descrição restringe-se ao ambiente externo, este descrito de duas formas: como seria sem ou a despeito do sistema de controle, e como esperamos que se torne com o sistema de controle. Com conseqüência, podemos usar de estados do ambiente (levando em conta apenas o ambiente antes da implementação) para a especificação, mas não estados do sistema de controle (ZAVE; JACKSON, 1997),

- permitem a identificação de quais ações são controladas pelo ambiente (divididas, mais uma vez, entre aquelas que o ambiente compartilha com o sistema e aquelas que o ambiente não compartilha com o sistema), e as controladas pelo sistema (necessariamente compartilhadas com o ambiente) (ZAVE; JACKSON, 1997); (PARNAS; MADEY, 1995),

- permitem também refinamento dos requisitos visando especificações implementáveis, através do emprego do conhecimento do domínio como suporte. Especificações corretas, em conjunto com conhecimento do domínio apropriado, implicam na satisfação dos requisitos (ZAVE; JACKSON, 1997).

Representações formais utilizadas na definição de requisitos devem obedecer a estas quatro regras. Se uma linguagem de especificação não é suficiente neste sentido, deve ser estendida ou complementada conforme necessário (ZAVE; JACKSON, 1997). 
A distinção precisa entre requisitos e especificações depende da definição precisa da interface entre sistema e ambiente (PARNAS; MADEY, 1995), localizando a interface com precisão que permita conhecer o que são as ações compartilhadas entre o ambiente e o sistema (ZAVE; JACKSON, 1997).

A partir deste ponto, exploraremos alguns aspectos destas regras para clarificarmos seu emprego e propósito.

\subsubsection{Fundamentando Representação Formal no Ambiente}

A representação formal usa termos primitivos sem nenhum significado inerente; o significado destes termos está na realidade. A semântica de termos primitivos é estabelecida por uma explicação informal (designação). Na definição de requisitos de um projeto, a designação precisa ser clara e precisa, mantida e documentada.

O conceito da designação auxilia a diferenciar entre definição e asserção. Enquanto a definição parte de designações para estender a semântica existente a novos termos, a asserção utiliza apenas designações existentes para restringir o ambiente relacionando-as, podendo ser verdadeira ou falsa, e necessitando ser validada antes de usada.

As designações estabelecidas dentro do escopo de um projeto auxiliam também a definir os objetivos propostos para o projeto e para o sistema. Ao definir as designações envolvidas, as estratégias de satisfação de objetivos são aplicáveis apenas a estas, o que limita o estabelecimento dos objetivos.

Por último, o conceito de designação auxilia na identificação, importante aspecto da representação formal. Ao designar um termo, a descrição pode definir processos de criação e uso do termo designado, auxiliando no estabelecimento da identificação. 
Por tais aspectos, o uso da designação aplicada aos elementos sintáticos empregados na modelagem confere ao modelo a semântica fundamentada no sistema real que permite estabelecer escopo de aplicação, objetivos do sistema e o claro entendimento de suas partes (ZAVE; JACKSON, 1997).

Como exemplo, na linguagem UML, encontramos a técnica da modelagem de domínio, a qual objetiva modelar o contexto do sistema (e não sua implementação), capturando objetos e relações existentes entre os mesmos no ambiente e permitindo a usuários e analistas a utilização de terminologia comum (ROSENBERG, 1999); (JACOBSON; BOOK; RUMBAUGH, 1998). Tal tarefa produz como resultados diagramas de classes (os quais permitirão identificar os objetos existentes no ambiente), assim como um glossário, onde o domínio sintático das classes é associado ao domínio semântico, fornecendo sua interpretação.

\subsubsection{Influência da implementação nos requisitos}

Requisitos supostamente descrevem o que o sistema fará, e não como (PARNAS; MADEY, 1995); (WING, 1990). Sendo mais preciso, pressupõe-se que os requisitos descrevam apenas o que é observável pela interface entre o ambiente e o sistema. Qualquer descrição adicional a este escopo relativa ao sistema é denominada influência da implementação (ZAVE; JACKSON, 1997).

O ambiente dentro do qual o sistema é desenvolvido é uma parte do mundo real cujo comportamento é insatisfatório de alguma forma. O sistema é desenvolvido para que seja conectado a este ambiente de tal forma que este modifique seu comportamento. Desta perspectiva, todas afirmações efetuadas durante a engenharia de requisitos são afirmações relativas ao ambiente. 
Visando a distinção entre o que se aplica a um sistema e o que se aplica ao ambiente ao qual este é inserido, uma proposta é a adoção de modos verbais aplicados às ações (ZAVE; JACKSON, 1997):

- afirmações no modo indicativo descrevem o ambiente como é na ausência do sistema ou a despeito da presença deste; estas afirmações são denominadas premissas ou conhecimento do domínio e

- afirmações no modo subjuntivo descrevem o ambiente como o usuário gostaria que fosse e esperamos que seja quando o sistema desenvolvido for incorporado ao mesmo. Tais afirmações são denominadas requisitos.

Uma linguagem para definição de requisitos deve prover propriedades no modo indicativo ou no subjuntivo, fazendo clara distinção entre elas, o que permite distinguir entre o conhecimento do domínio e os requisitos.

Desta forma, se um estado é considerado como do sistema, o problema da influência da implementação força esta especificação ser mínima; no entanto, se for compreendido como estado do ambiente, ficamos livres para coletar bibliotecas de informação reutilizável sobre o ambiente mesmo que não estejamos seguros de que será necessária (ZAVE; JACKSON, 1997). É importante notarmos que freqüentemente as implementações mantêm um estado interno que copia o atual estado do ambiente.

\subsubsection{Controle de ações}

Quando discutimos requisitos, estamos sempre preocupados com as duas partes: o ambiente e o sistema. Em uma situação com dois ou mais agentes, é de fundamental importância entender questões relativas ao controle de ações (ZAVE; JACKSON, 1997). 
Duas capacidades de expressão são necessárias para uma linguagem de requisitos (ZAVE; JACKSON, 1997):

- a primeira capacidade de uma linguagem de expressão de requisitos é de prover a declaração de dois tipos de ações: ações controladas pelo ambiente ou ações controladas pelo sistema, indicando qual parte realiza ou toma a responsabilidade pelas ações deste tipo.

- uma segunda capacidade de expressão da linguagem é a habilidade de colocar restrições em ações de qualquer das categorias definidas acima, de forma a conferir ao sistema propriedades desejadas (como exemplo, "liveness").

Detalhando a primeira capacidade de expressão, cada tipo de ação pode ser adicionalmente identificada como ação compartilhada ou ação não compartilhada. Se a ação é compartilhada, então é parte do mundo real que é compartilhada pelo sistema e pelo ambiente. Se não é compartilhada, então é privativa do ambiente e não observável pelo sistema.

É óbvio que uma ação não pode ser uma ação controlada pelo sistema e ação não $\underline{\text { compartilhada, levando apenas a três combinações possíveis de tipos de ações: controladas }}$ pelo sistema e compartilhadas, controladas pelo ambiente e compartilhadas e controladas pelo ambiente e não compartilhadas.

Uma linguagem de expressão de requisitos precisa ser capaz de expressar a qual categoria cada ação pertence. A importância desta informação é evidente; o sistema implementado precisa executar apenas ações controladas pelo sistema. Por outro lado, o sistema implementado pode observar e fazer uso de seu conhecimento das ações compartilhadas, enquanto que as ações não compartilhadas estão além de seu alcance (ZAVE; JACKSON, 1997). 


\subsubsection{Conhecimento do domínio}

Um requisito é afirmado em modo subjuntivo, ou seja, propriedade conferida ao sistema a ser implementado futuramente, e não do ambiente prévio. Seja $\mathbf{R}$ o conjunto de requisitos de um projeto de SCSP (portanto, o conjunto de propriedades subjuntivas cujo atendimento satisfarão completamente o usuário).

Uma especificação é também uma propriedade subjuntiva, mas uma que é implementável. Seja $\mathbf{S}$ o conjunto de especificações do projeto de um SCSP; $\mathbf{S}$ pode ser cedida a equipe de desenvolvimento do projeto, que será capaz de implementar o SCSP sem recorrer a nenhum auxílio adicional além das informações definidas pelo próprio S (ZAVE; JACKSON, 1997).

O espaço entre requisitos e especificações é reconhecido; o processo que atravessa este espaço é referido como refinamento de requisitos (ZAVE; JACKSON, 1997).

Enquanto o refinamento de especificações é voltado para a remoção de funcionalidades de uma especificação que não são executáveis na plataforma escolhida e sua substituição por outras funcionalidades executáveis nesta plataforma, o refinamento de requisitos é voltado a identificar os aspectos de requisitos que não podem ser realizados ou garantidos por automação, e a aumentar ou substituir estes requisitos até que sejam completamente implementáveis (ZAVE; JACKSON, 1997).

O papel primário do conhecimento do domínio é permitir a ligação entre requisitos e especificações. Requisitos que não são especificações são sempre convertidos em especificações com o auxílio do conhecimento do domínio. Seja K o conhecimento de domínio relevante (conjunto de propriedades indicativas, ou seja, pertinentes ao ambiente).

Então $\mathbf{S}$ e $\mathbf{K}$, em conjunto, necessitam serem suficientes para que os requisitos sejam satisfeitos: 


\section{$\mathbf{S}, \mathbf{K} \vdash \mathbf{R}$}

É importante notar que a caracterização precisa das diferenças entre especificação e requisito depende da precisa localização da interface entre o sistema e o ambiente, ou seja, em saber aonde as ações compartilhadas estão (ZAVE; JACKSON,1997) . 


\section{CAPÍtUlo 5}

\section{ESCOPO FUNCIONAL DE UM}

SCSP

Visando definir limites gerais para o escopo funcional de qualquer SCSP, iremos discutir aspectos da norma em elaboração ANSI/ISA S95 ("Enterprise - Control System Integration”),

focando principalmente na sua terceira parte, onde as funcionalidades ligadas ao que se denominou até então sistema de execução da manufatura (MES - "Manufaturing Execution System”) estão sendo descritas de forma estruturada e sistemática. Entre os objetivos desta norma, encontramos o suporte a decisões de implementações e integração a outros sistemas de informação destes dentro das empresas, assim como o suporte ao desenvolvimento de novos produtos nesta área de aplicação. O escopo da norma inclui as funções do controle de sistemas produtivos de nosso interesse.

Após uma justificativa inicial da abordagem e da descrição de aspectos relevantes da norma, finalizamos com a definição de limites gerais do escopo funcional de um SCSP. Esta definição irá fornecer contexto para o método descrito nos capítulos seguintes.

\subsection{Norma ANSI/ISA S95 E a GeStão Operacional de Sistemas Produtivos}

Dizemos que o projeto do SCSP inicia-se a partir da especificação inicial da funcionalidade que se deseja associar ao sistema para que este possa realizar um determinado conjunto de processos, e portanto cumpra a missão de produção ao qual se destina. Dentro desta abordagem, é suficiente 
para este controle funcionalidade tal que permita sua atuação física sobre a planta de tal forma que seja preservada a realização do conjunto de processos pretendidos pelo sistema produtivo (SANTOS FILHO, 2000).

Em outra abordagem, encontramos como controle do SP a gestão e controle das operações físicas dentro da planta de forma que o plano de produção seja realizado. As informações fluem do controle para as operações no 'chão de fábrica', ou vice-versa. Estão incluídos entre as funcionalidades os controles do 'chão de fábrica', do inventário e da qualidade, entre outras (GROOVER, 2000).

No entanto, considerando o objetivo desta dissertação como a descrição de um método a ser utilizado na especificação de um SCSP que considere visão integrada ao ambiente, em conformidade com normas técnicas existentes, basearemos nossa abordagem quanto ao escopo em práticas consolidadas de mercado manifestadas recentemente pela norma ANSI/ISA S95.

Para a abordagem empregada, utilizaremos as três primeiras partes (de um total de seis partes atualmente planejadas) da norma ANSI/ISA S95 ("Enterprise - Control System Integration”), duas publicadas e uma em rascunho. Aa partes utilizadas são:

- a primeira ("Enterprise-Control System Integration Part 1: Models and Terminology”) e a a segunda partes ("Enterprise-Control System Integration Part 2: Object Model Attributes"), que definem a integração entre os sistemas de controle da produção e outros sistemas corporativos, além do modelo de objetos envolvido e 
- a terceira parte (“Activity Models of Manufacturing Operations Management”) da norma, que define modelos funcionais aplicáveis à gestão operacional da manufatura, extensível segundo a própria norma a todos os tipos de sistemas produtivos.

As partes não utilizadas são a quarta parte (definição de modelos de objeto e atributos das atividades da gestão operacional da manufatura), a quinta parte (transações entre negócio e manufatura) e a sexta parte (transações entre operações de manufatura).

Um dos objetivos da norma é reduzir riscos, custos e erros associados com a implementação de sistemas corporativos e de operação da manufatura de tal forma que possam ser facilmente integrados e tenham interoperabilidade preservada. Outro objetivo da norma ANSI/ISA S95 é a redução de esforços associados com a implementação de novas funcionalidades aos produtos relacionados.

Os modelos definidos na terceira parte da norma auxiliam no entendimento do escopo de funcionalidades que envolvem a execução e controle da produção, e podem ser utilizados no desenvolvimento de novas funcionalidades na manufatura. $\mathrm{O}$ padrão em desenvolvimento oferecido pela ANSI/ISA S95 é o mais recente padrão. Por tal motivo, pôde considerar outros padrões anteriormente desenvolvidos (tais como o padrão PERA, desenvolvido pela MESA “Manufacturing Execution Systems Association”), abrangência que tem possibilitado sua adoção como referência para projetos de integração e desenvolvimento de sistemas.

Conforme a norma, os modelos e terminologias definidos em sua terceira parte enfatizam boas práticas na operação da manufatura, que potencialmente podem ser implementadas para melhorar sistemas de manufatura já existentes, sendo aplicáveis independentemente do grau de automação. 
Entre os benefícios potenciais mencionados pela norma em sua aplicação incluem-se, entre outros:

- identificação uniforme e consistente das necessidades da produção,

- redução do custo de automação dos processos de manufatura e

- habilitação de fornecedores no desenvolvimento de ferramentas apropriadas para operações da manufatura.

Estes pontos reforçam a afirmação de que a norma ANSI/ISA S95 é adequada para direcionar as atividades de projetos de um SCSP a alcançar o objetivo de integração destes aos sistemas corporativos e a outros sistemas de execução, assim como para a especificação e implementação de um SCSP.

Ainda conforme a norma, a gestão operacional na manufatura engloba as atividades manufatureiras que coordenam pessoal, material e a energia na conversão de insumos e outras partes em produtos. Incluem atividades que podem ser realizadas por equipamentos físicos, esforço humano e sistemas de informação. Realizando tais atividades definidas pela terceira parte da norma, a manufatura satisfaz sua missão no negócio.

As atividades da gestão operacional da manufatura, objeto da terceira parte da norma e do escopo de nossa dissertação por incluírem a funcionalidade do SCSP (controle do sistema produtivo), possuem correspondência com o conjunto de atividades definidas na primeira parte desta norma (figura 5.1). Todas as atividades da gestão operacional da manufatura (englobadas pela terceira parte da norma) estão representadas pelas funções contidas dentro da área delimitada pela linha espessa pontilhada da figura 5.1. 


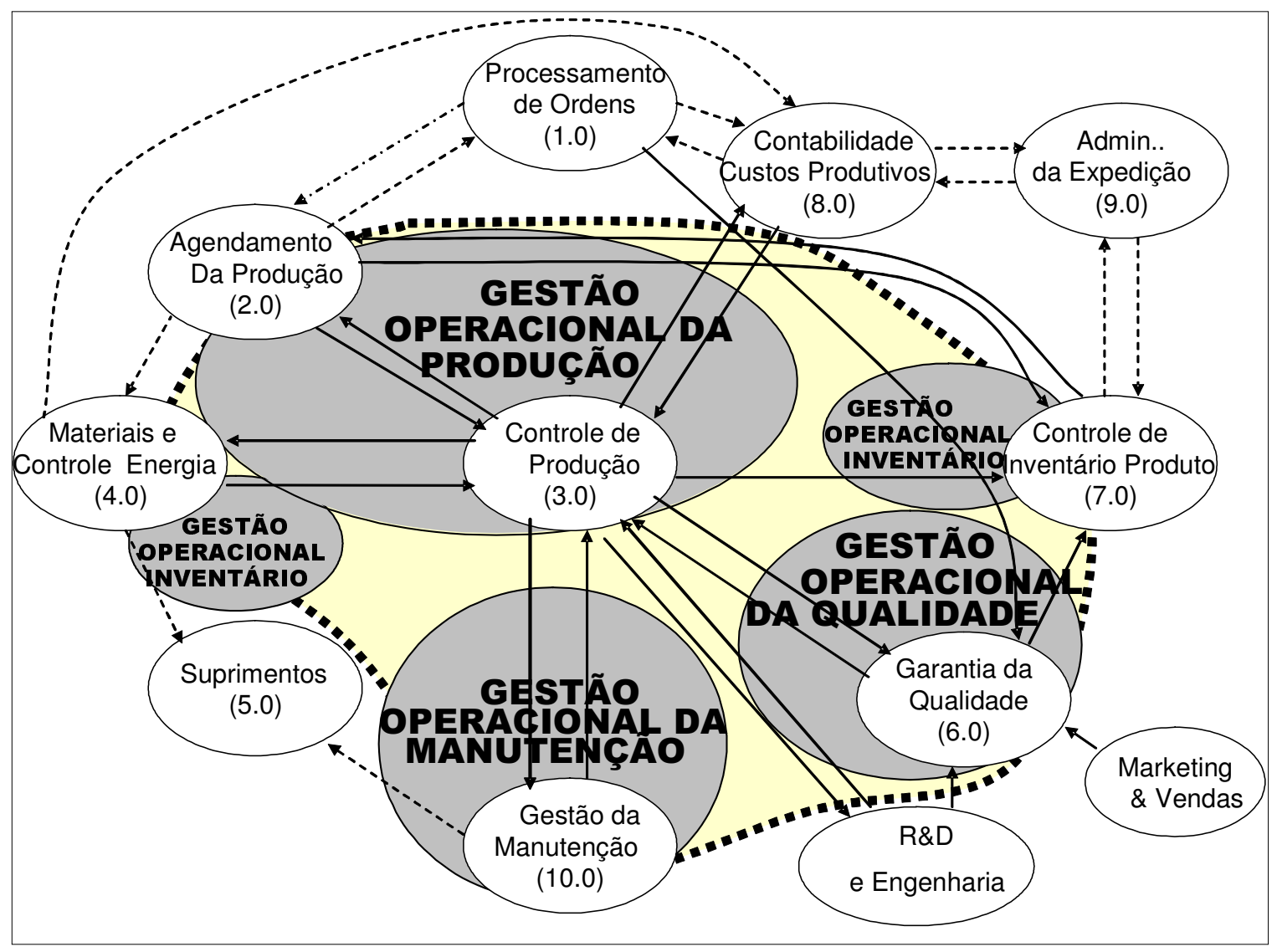

Figura 5.1. Modelo da gestão operacional da manufatura (extraído da norma em elaboração

$$
\text { ANSI/ISA S95, parte 3) }
$$

Para contextualizar as funções da gestão operacional da manufatura dentro de todas as funções existentes em uma organização, a terceira parte da norma utiliza como referência a mesma hierarquia funcional de quatro níveis definida em sua primeira parte, fundamentada nos tempos de resposta característicos (apresentada no tópico 2.2.1 e representada novamente na figura 5.2). A linha espessa pontilhada é equivalente à interface entre os níveis 3 e 4 definida na primeira parte desta norma, mencionada anteriormente no capítulo 2 (figura 5.2). Todas atividades da gestão operacional da manufatura modeladas pela terceira parte da norma operam entre as funções de logística e planejamento (nível 4 da hierarquia funcional da figura 5.2) e as funções de 
controle de processo, realizadas de forma manual ou automática (nível 1 da hierarquia funcional da figura 5.2).

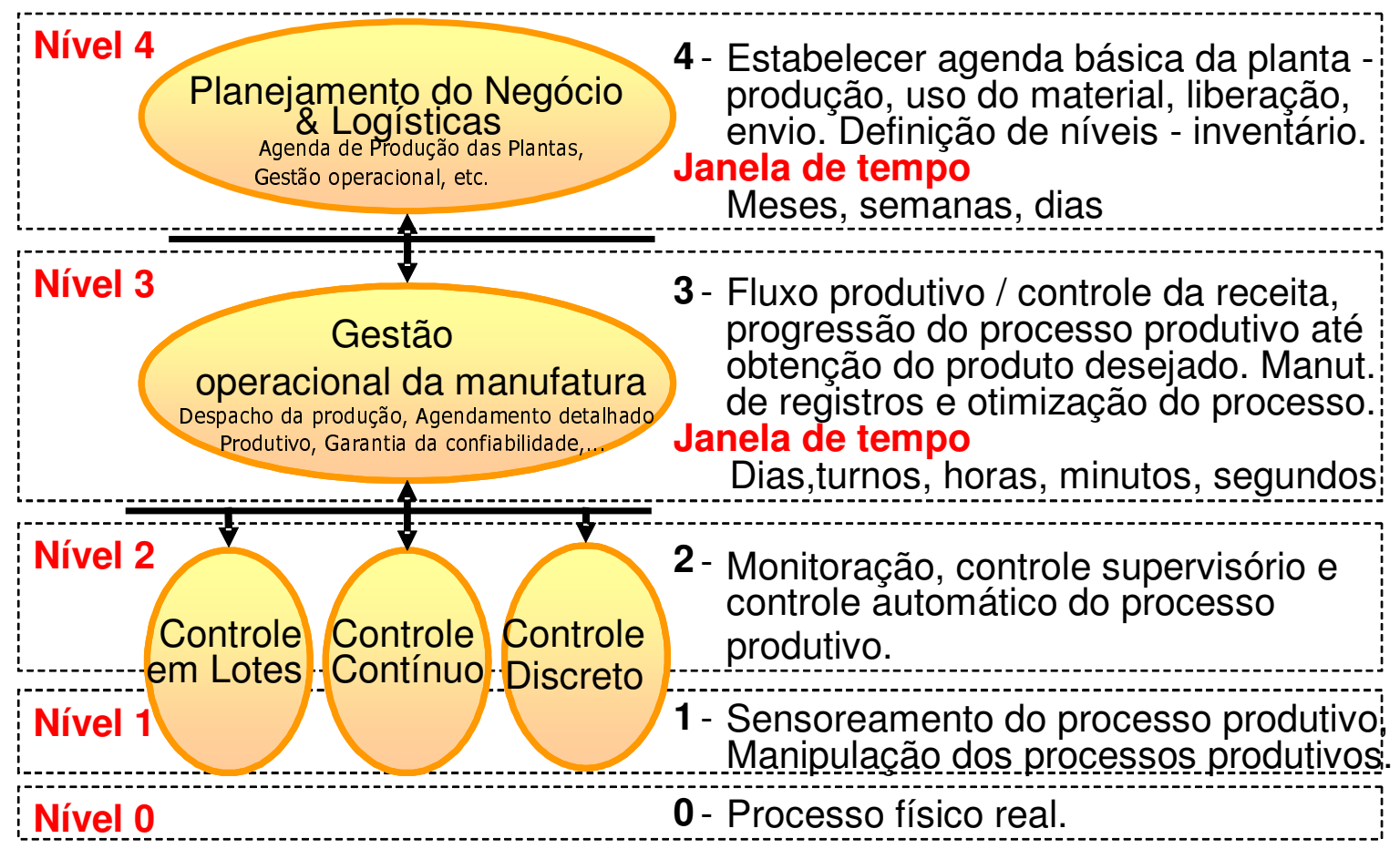

Figura 5.2. Hierarquia funcional de níveis atividades

(extraído da norma em elaboração ANSI/ISA S95, parte 3)

\subsubsection{Modelos da Gestão Operacional da Manufatura conforme ANSI/ISA S95}

A terceira parte da norma define um modelo de atividades genérico (figura 5.3) para auxiliar na definição e descrição das atividades englobadas por cada uma das quatro áreas da gestão operacional (áreas cinzentas da figura 5.1). 


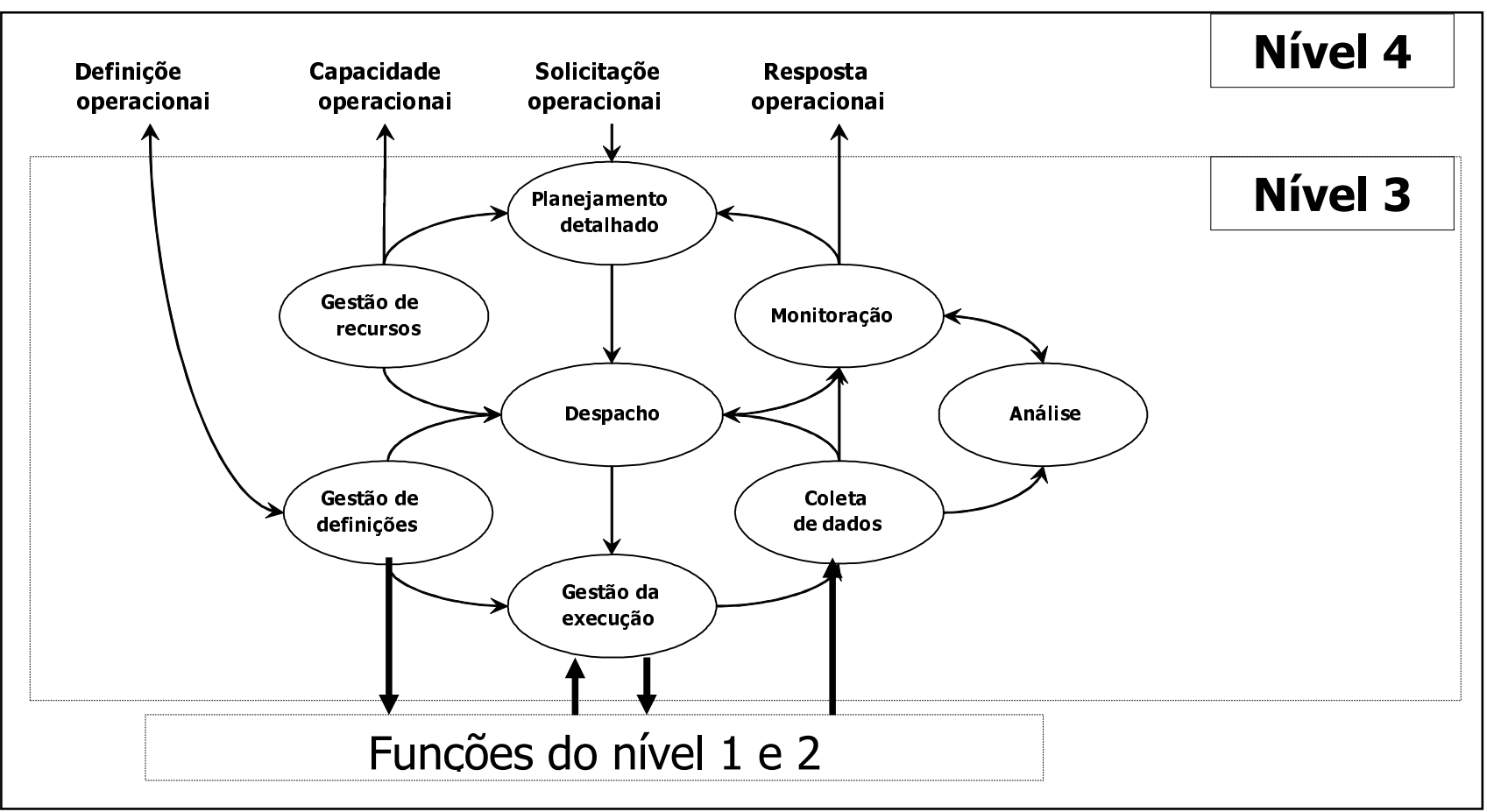

Figura 5.3. Modelo de atividades genérico da gestão operacional da manufatura

Este modelo é reproduzido na definição das atividades de cada um dos quatro modelos formais da gestão operacional (áreas cinzentas da figura 5.1):

- gestão operacional da produção, incluindo as funções de controle da produção (item 3.0 da figura 5.1) e um subconjunto do escalonamento da produção (item 2.0 da figura 5.1), fazendo parte do nível 3 (figura 5.2) da hierarquia funcional,

- gestão operacional da manutenção, incluindo as atividades de gestão da manutenção e que opera como parte do nível 3 (figura 5.2) da hierarquia funcional,

- gestão operacional da qualidade, incluindo as atividades de garantia da qualidade e que também opera como parte do nível 3 (figura 5.2) da hierarquia funcional e 
- gestão operacional dos inventários, incluindo funções da gestão do inventário e de materiais e inclui a função de controle do inventário de produção (item 5.0 da figura 5.1) e funções de controle de materiais e energia definidas como parte do nível 3 (figura 5.2) da hierarquia funcional, conforme figura 5.1.

Em todas as considerações efetuadas nesta dissertação relativas a definiçãa do escopo funcional no âmbito da ANSI/ISA S95, consideraremos que uma atividade é vizinha à outra quando obedecem aos dois quesitos:

- as duas atividades pertencem ao mesmo modelo operacional de gestão (por exemplo, as duas pertencem ao modelo operacional da produção) e

- existe um fluxo de dados que conecta diretamente as duas atividades dentro do modelo operacional a que pertencem, visualizado com auxílio da figura 5.3 (exemplo de vizinhas: despacho e gestão da execução, dentro da gestão operacional da produção).

Além das atividades definidas com o auxílio dos quatro modelos citados, outras atividades não pertencentes aos quatro modelos operacionais de gestão (produção, inventário, manutenção e qualidade) são também descritas pela terceira parte da norma, mas não foram formalmente modeladas pela mesma. Estas outras atividades podem ser geridas de forma independente dos quatro modelos formais de gestão conforme políticas da corporação ou organização, e não foram incluídas no escopo desta dissertação. 


\subsection{LIMITES GERAIS DO ESCOPO FUNCIONAL DE UM SCSP}

É um dos objetivos deste capítulo o estabelecimento de limites para o escopo máximo de um SCSP. Verificaremos seus limites em duas visões: a proporcionada pela hierarquia funcional (figura 2.4), e aquela definida pelos quatro modelos formais de gestão.

\subsubsection{Limites de Escopo conforme Visão da Hierarquia Funcional}

Verificamos que um SCSP pertence ao terceiro nível da hierarquia funcional:

- reconhecendo como uma de suas fronteiras aquela definida por seus objetos de controle (recursos de transformação e de transporte), pertencentes ao segundo nível da hierarquia funcional da norma (conforme a primeira parte da norma ANSI/ISA S95, este nível realiza monitoração, controle supervisório e controle automático do processo produtivo em tempo real) e

- identificando as funções que o SCSP se propõe a realizar dentro dos modelos de atividades oferecidos pelo nível 3. Entre as funções realizadas pelo escopo funcional da metodologia de projetos de SCSP que suporta esta dissertação, encontramos a gestão da execução dos recursos de transformação e transporte e a gestão da alocação destes recursos (SANTOS FILHO, 2000); (MATSUSAKI, 2004) e excluímos o planejamento detalhado.

Concluímos que, dentro da visão proporcionada pela hierarquia funcional, o escopo de um projeto de SCSP engloba funções contidas pelo nível 3, faz fronteira com o nível 2 e pode ou não fazer fronteira com o nível 4, dependendo do conjunto de atividades selecionado. 


\subsubsection{Limites do Escopo Funcional conforme Modelos Operacionais de Gestão}

Conforme a norma, os modelos de gestão operacional da produção, manutenção e qualidade possuem interface direta com os recursos de transformação, enquanto o modelo de gestão de transporte possui interface direta com recursos de transporte.

Como os objetos de controle do SCSP são os recursos de transporte e de transformação, verificamos que existem atividades dentro dos quatro modelos de gestão operacional que possuem os mesmos objetos de controle de um SCSP. Analisando os quatro modelos, encontramos os modelos de atividade seguintes dentro de cada modelo formal de gestão operacional:

- gestão operacional da produção: gestão da execução da produção (solicitam início de atividades produtivas do nível 2 junto a recursos de transformação),

- gestão operacional da manutenção,: gestão da execução da manutenção (solicitam início de atividades de para teste de produto no nível 2 junto a recursos de transformação),

- gestão operacional da qualidade: gestão da execução de testes da qualidade (solicitam atividades envolvidas pela manutenção no nível 2 junto a recursos de transformação) e

- gestão operacional dos inventários: gestão da execução de movimentações de inventário (solicitam início de atividades do nível 2 junto a recursos de transporte).

Comparando estas informações com o escopo funcional da metodologia de projeto de SCSP que suporta esta dissertação (SANTOS FILHO, 2000); (MATSUSAKI, 2004), verificamos que o escopo funcional do SCSP é coincidente no mínimo com dois modelos formais de gestão: 
produção e inventário. Sendo o recurso de transformação necessariamente objeto de controle de um SCSP, a adoção do modelo de gestão operacional da produção é obrigatória, ao passo que a adoção do modelo de gestão do inventário é condicionada a aplicação do SCSP ao controle de recursos de transporte. Por outro lado, analisando os três primeiros modelos formais de gestão (produção, manutenção e testes da qualidade), verificamos que os objetos de controle destes são coincidentes (recursos de transformação). A norma ANSI/ISA S95 e o escopo funcional da metodologia de projeto de SCSP que suporta esta dissertação consideram ainda que:

- conforme a norma, o modelo de gestão operacional de produção inclui a atividade de despacho, a qual realiza a gestão da alocação de recursos de transformação,

- o escopo funcional SCSP do qual partimos esta dissertação realiza gestão da alocação dos recursos de transformação (SANTOS FILHO, 2000); (MATSUSAKI, 2004) e

- a norma indica a necessidade de que a gestão da alocação de recursos de transformação realizada pelo despacho produtivo na gestão de produção seja realizada de forma coordenada com as alocações de manutenção e dos testes de qualidade.

Levando em conta as considerações acima, concluímos que, se as atividades de execução pertencentes aos modelos de gestão da manutenção e de teste da qualidade forem realizadas por um sistema, estas necessitam ser realizadas através da gestão da alocação de recursos de transformação do modelo de gestão da produção.

Assim, verificamos que além dos modelos de gestão da produção (obrigatório) e de inventário, os modelos de gestão de testes de qualidade e de manutenção podem ser incluídos no escopo. 
Assim, todos os quatro modelos formais de gestão definido na terceira parte da norma ANSI/ISA S95 são incluídos no limite geral de escopo de um SCSP.

\subsection{DEFINIÇÃO DO ESCOPO FUNCIONAL DE UM SCSP}

Dedicaremos o restante deste capítulo à descrição da primeira parte do método proposto pela dissertação. O objetivo é estabelecer como partida do projeto um método para a definição de escopo de requisitos do SCSP baseada no ambiente produtivo previamente estabelecido e na integração do SCSP a este ambiente.

Utilizaremos novamente como base a terceira parte da norma em elaboração pela ANSI/ISA S95, fundamentando o método na padronização de terminologia e práticas operacionais do negócio propostos. Tais terminologias e práticas operacionais servirão de referência na elaboração de requisitos do ambiente do $\mathrm{SP}$.

Como descrição da primeira parte do método, descrevermos os seguintes passos envolvidos na definição de requisitos:

- descrição do ambiente externo ao SCSP e sua terminologia (modelagem do domínio semântico do sistema produtivo),

- determinação da linguagem de especificação adequada à semântica da integração do SCSP ao ambiente,

- definição do escopo de atividades desenvolvidas pelo SCSP atendendo ao modelo de atividades da norma ANSI/ISA S95 em sua terceira parte e às necessidades específicas do sistema produtivo pertencente a organização empreendedora do projeto, 
- descrição das partições homomórficas definidas no domínio semântico interno ao SCSP,

- definição das linguagens de especificação adequadas a cada partição e

- especificação das partições, incluindo integração destas ao ambiente e ao SCSP, utilizando a linguagem de especificação definida previamente para a partição, com auxílio dos casos de uso, o que resultará no fluxo de informações previsto entre o SCSP e o ambiente e o fluxo de informações entre as partições.

\subsubsection{Descrição do Ambiente Externo Ao SCSP}

Conforme capítulo referente à engenharia de requisitos, para definir adequadamente os requisitos de um sistema, necessitamos definir inicialmente o ambiente em que o SCSP irá atuar. Por outro lado, sabemos que as funções realizadas neste ambiente são descritas com auxílio da norma ANSI/ISA S95.

Conforme proposto por diversos métodos definidos pela engenharia de requisitos, uma definição de requisitos adequada exige o uso de terminologia fundamentada no ambiente prévio ao desenvolvimento do SCSP (ZAVE; JACKSON, 1997), reconhecendo o ambiente e suas partes que receberão o SCSP antes de sua implementação. Descreveremos o ambiente inteiramente com base nas funcionalidades descritas pela norma ANSI/ISA S95, em sua terceira parte. Identificaremos duas situações distintas, que demandarão abordagens igualmente distintas:

- dentro do conjunto de funcionalidades do segundo e terceiro níveis da hierarquia funcional descritas pela terceira parte da norma, relacionaremos todos sistemas prévios que estiverem sendo empregados no ambiente para realizá-las, sistemas estes que potencialmente possuirão interfaces com o SCSP, e 
- ainda restritos ao conjunto de funcionalidades descritas para o terceiro nível da hierarquia funcional, onde nenhum outro sistema estiver sendo empregado no ambiente em questão para realizar as funções previstas, sistemas adicionais capazes de realizar tais funções necessitarão ser identificados para desenvolvimento posterior, caso necessário.

Na primeira situação, iremos relacionar e identificar os sistemas previamente existentes, os quais serão utilizados durante a especificação do sistema. $\mathrm{Na}$ segunda, relacionaremos as funções previstas, posteriormente nomeando-as e identificando a necessidade de desenvolvê-las.

\subsubsection{Linguagem de Especificação Aplicável à Integração do SCSP ao Ambiente}

Para definir requisitos de desenvolvimento do controle, decidimos partir da abordagem proposta pela norma ANSI/ISA S95. O domínio semântico sob o qual o desenvolvimento é iniciado passa a ser explorado pela abstração proposta pela norma. Ao descrever o ambiente através de classes de objetos e atributos (partes 2 e 4 da norma), de suas transações (partes 5 e 6) e suas funções (parte 3), a semântica deste ambiente é descrita pela abstração da orientação a objetos, permitindo a aplicação da linguagem de especificação UML ("Unified Modeling Language") (JACOBSON; BOOK; RUMBAUGH, 1998); (ROSENBERG, 1999) para a integração entre o ambiente e o controle.

Desta forma, a modelagem que integra o SCSP neste ambiente é especificada através da linguagem UML, com o auxílio da orientação a objeto, empregando classes, mensagens e métodos. Inserido neste contexto, a integração do SCSP o fará receber e enviar mensagens às classes de objetos descritas conforme o tópico anterior. 


\subsubsection{Escopo de Atividades Do Controle}

Reconhecemos no tópico anterior os limites gerais do escopo de um SCSP:

- com relação à hierarquia funcional, pertencendo ao terceiro nível e fazendo fronteira com o segundo nível e

- com relação aos quatro modelos formais de gestão, podendo apresentar atividades em todos os modelos de gestão, mas apresentando obrigatoriamente atividades dentro do modelo de gestão da produção.

Atendendo a necessidade da engenharia de requisitos em definir o escopo do SCSP a partir do ambiente existente, utilizaremos a norma ANSI/ISA S95 para detalhar e reconhecer as funções a serem desempenhadas pelo SCSP. Desta forma, estaremos aptos a definir os requisitos sem abordar aspectos resolvidos pela implementação, condição essencial para uma especificação do SCSP não restritiva (ZAVE; JACKSON, 1997). Especificamos o SCSP definindo quais as ações compartilha com o ambiente, tanto enviando como recebendo mensagens.

Baseados no limite geral de escopo de um SCSP que o restringe ao terceiro nível da hierarquia funcional, utilizaremos a terceira parte da norma ANSI/ISA S95 (a que descreve as atividades deste terceiro nível da hierarquia) para definição do escopo começando de uma visão mais abrangente, detalhada progressivamente ao longo de três etapas através das seguintes seleções sucessivas suportadas pelas relações fornecidas pela norma:

- seleção dos modelos formais de gestão da operação da norma ANSI/ISA S95 (produção, manutenção, inventário e qualidade) que serão abordados pelo escopo do controle, 
- $\quad$ seleção das atividades dentre as existentes em cada modelo formal de gestão selecionado incluídas no escopo do SCSP, utilizando o modelo respectivo de atividades definido pela norma ANSI/ISA S95 e

- seleção das tarefas que descrevem cada atividade incluída, conforme relação de tarefas relacionadas pela ANSI/ISA S95 parte 3 para cada atividade, e que farão parte do escopo do SCSP, aprofundando o detalhamento.

O uso da norma permite a exaustão da identificação de funcionalidades necessárias e o reconhecimento do ambiente por completo, viabilizando integração do SCSP e uso de visão completa do sistema produtivo.

\subsubsection{Seleção dos Modelos Formais de Gestão Operacional Aplicáveis}

O SCSP, como definido pela metodologia que suporta esta dissertação (SANTOS FILHO, 2000); (MATSUSAKI, 2004), possui como objetos de controle os recursos de transformação e transporte e como funções desempenhadas mínimas o monitoramento da condição dos recursos, a gestão da alocação dos recursos de transformação as atividades de processamento produtivas e o controle da sequiência de operações da atividade de processamento.

Conforme visto, entre os quatro modelos operacionais propostos pela norma ANSI/ISA S95, em três deles existem atividades definidas cujo objeto de controle (recursos de transformação) coincide com o definido no parágrafo anterior: produção, manutenção e teste da qualidade. Discutiremos a seleção de cada um destes três a partir desta coincidência.

A norma define a gestão operacional da produção como o conjunto de atividades de coordenação, direção e monitoração dos processos de transformação. As funções desempenhadas mínimas que 
o SCSP em que nos baseamos realiza são coincidentes com o escopo de aplicação do modelo operacional da produção quando aplicadas sobre os recursos de transformação. Assim, o modelo da gestão operacional da produção é obrigatório como opção de escopo de aplicação do controle.

Quanto aos outros dois modelos (qualidade e manutenção), conforme a terceira parte da norma ANSI/ISA S95, necessitamos considerar que a gestão de execução dos mesmos atua diretamente sobre os recursos de transformação, e de que suas ações sobre os recursos necessitam gestão coordenada com a atividade de despacho produtivo, como demanda a própria norma. Assim, em todo projeto específico em que, por critérios alheios ao escopo desta dissertação, forem inclusas semânticas destes modelos no escopo do SCSP (testes de qualidade de produto e estado de manutenção do recurso de transformação ou transporte), incluiremos os modelos respectivos da gestão operacional da qualidade e da manutenção para que possamos realizar estas atividades de forma adequada.

O quarto modelo operacional (gestão operacional do inventário) é obrigatório toda vez que o escopo do SCSP incluir o transporte, opção esta também por critérios alheios a esta dissertação. A argumentação que aplicamos para incluí-lo é a mesma utilizada na gestão operacional da produção.

Como exemplo, suponhamos que aplicaremos um SCSP que:

- controlará os recursos de transformação de um sistema produtivo, cujo transporte será realizado manualmente,

- alocará os recursos produtivos para manutenção através do SCSP, acompanhando o estado de manutenção do equipamento e 
- não realizará controle relacionado com testes da qualidade de produtos.

Para esta situação, optaremos pela seleção dos modelos operacionais de gestão da produção e manutenção (seleção representada na figura 5.4).

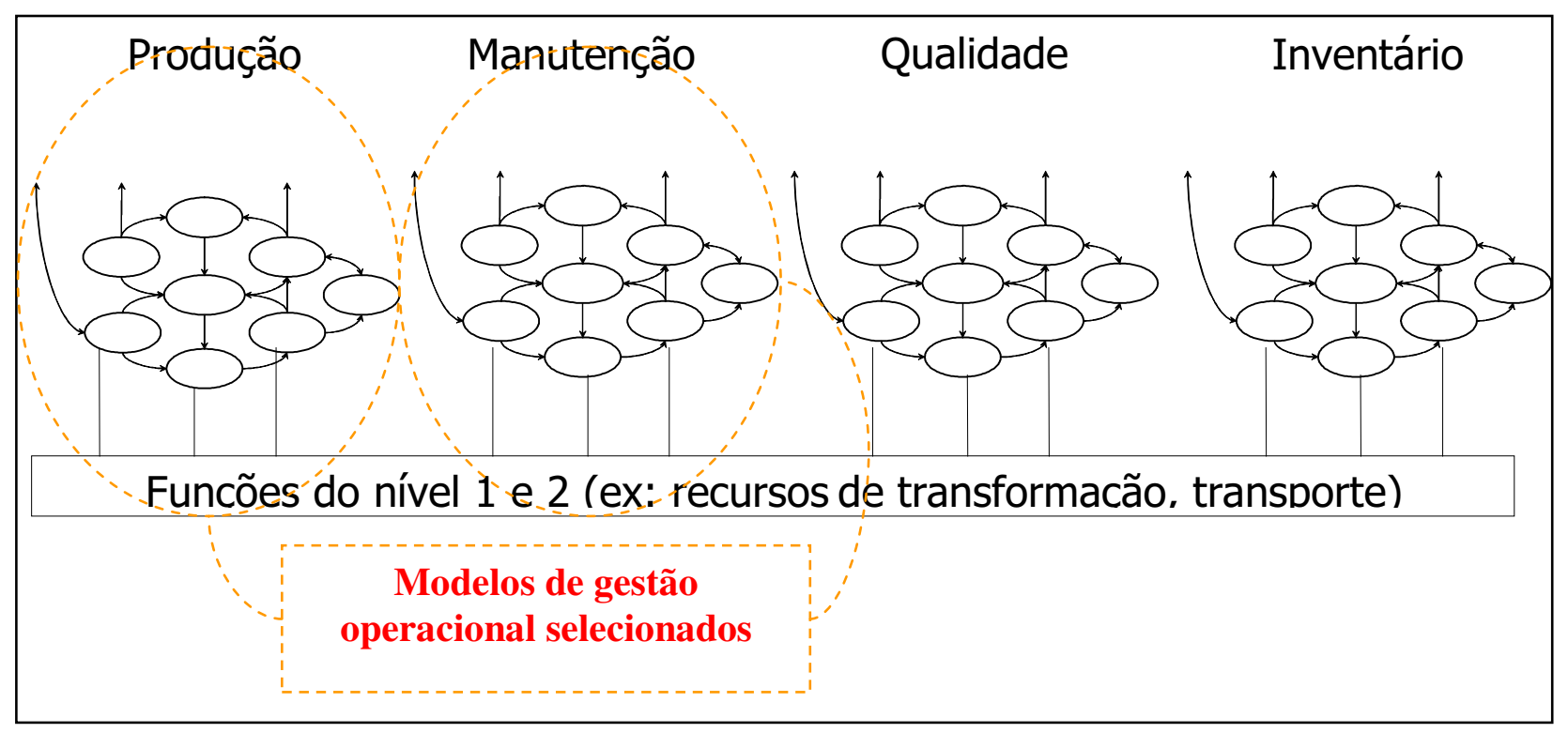

Figura 5.4. Exemplo de seleção dos modelos operacionais de gestão

\subsubsection{Seleção das Atividades dentro dos Modelos de Gestão Operacional}

O escopo do SCSP em que nos baseamos implica na inclusão obrigatória de algumas atividades existentes em cada um dos quatro modelos de gestão operacionais (conforme selecionados), segundo o escopo mínimo definido pelas referências (SANTOS FILHO, 2000); (MATSUSAKI, 2004).

Definiremos a seguir as atividades obrigatórias em cada modelo de gestão operacional. Na gestão operacional da produção, dentre as atividades que constam na terceira parte da norma ANSI/ISA S95 e com base no escopo mínimo do SCSP em que nos baseamos nesta dissertação, são obrigatórias as atividades de: 
- despacho produtivo (alocação dos recursos de transformação às atividades de processamento),

- coleta de dados produtivos (monitoramento dos recursos de transformação quanto a seu estado) e

- gestão da execução da produção (controle da seqüência de operações da atividade de processamento).

Na gestão operacional da manutenção, quando selecionada, dentre as atividades que constam na terceira parte da norma ANSI/ISA S95, são obrigatórias as atividades de:

- despacho da manutenção (escolha também motivada pela alocação dos recursos de transformação pelas atividades de manutenção),

- coleta de dados de manutenção (também pelo monitoramento do estado dos recursos de transformação) e

- gestão da execução da manutenção (coordenação com a gestão de execução da produção).

$\mathrm{Na}$ gestão operacional do teste de qualidade, quando selecionada, dentre as atividades que constam na terceira parte da norma ANSI/ISA S95, são obrigatórias as atividades de:

- despacho dos testes de qualidade (também pela alocação dos recursos de transformação as atividades de processamento),

- coleta de dados do teste de qualidade (também pelo monitoramento dos estados de recursos de transformação) e 
- gestão da execução do teste de qualidade (coordenação com a gestão de execução da produção).

No quarto modelo operacional (gestão operacional do inventário), quando selecionado, dentre as atividades que constam na terceira parte da norma ANSI/ISA S95, são obrigatórias as atividades de:

- despacho do transporte de inventário (alocação dos recursos às atividades de processamento),

- coleta de dados de transporte (monitoramento do estado dos recursos de transporte) e

- gestão da execução do transporte de inventário (controle da seqüência de operações do recurso de transporte).

Por outro lado, devemos excluir a atividade de planejamento detalhado de todos os modelos de gestão operacional, fora do escopo de um sistema de controle.

Além de considerar estas inclusões e exclusões obrigatórias, podemos incluir no escopo do SCSP outras atividades dentre as identificadas pelos quatro modelos de gestão operacional propostos pela norma ANSI/ISA S95 que atendam a critérios específicos da organização.

Esta seleção adicional de atividades dentro de cada modelo de gestão operacional fica restrita, no entanto, àquelas atividades vizinhas às obrigatórias.

Esta premissa é suportada pela suposição de que, se pudéssemos escolher um conjunto adicional de atividades que formassem uma região adicional disjunta do conjunto de atividades que inclui as atividades obrigatórias descritas para o SCSP, definiríamos uma parte do sistema sem fluxo de 
dados (integração) com a outra parte obrigatória. Assim, a definição de requisitos para esta parte adicional seria independente dos requisitos da parte que inclui o conjunto obrigatório, constituindo outro sistema. O método que descrevemos nesta dissertação não seria relevante para este escopo, o que nos leva a exclusão do escopo.

Desta forma, reforçamos a premissa de inclusão no escopo deste método apenas do conjunto de atividades que forem conectadas diretamente por fluxos de dados entre si, dentro de cada um dos quatro modelos de gestão operacional, incluindo sempre as respectivas atividades obrigatórias.

Esta segunda seleção resulta, portanto, na relação das atividades incluídas no escopo do SCSP para cada um dos modelos de gestão operacional escolhidos na primeira seleção.

Continuando o exemplo anterior, suporemos que o mesmo SCSP (seleção representada na fig. $5.5)$ :

- dentro da gestão operacional da produção, também realize a atualização dos processos produtivos pelo SCSP e

- dentro da gestão operacional da manutenção, empregue apenas as atividades obrigatórias. 


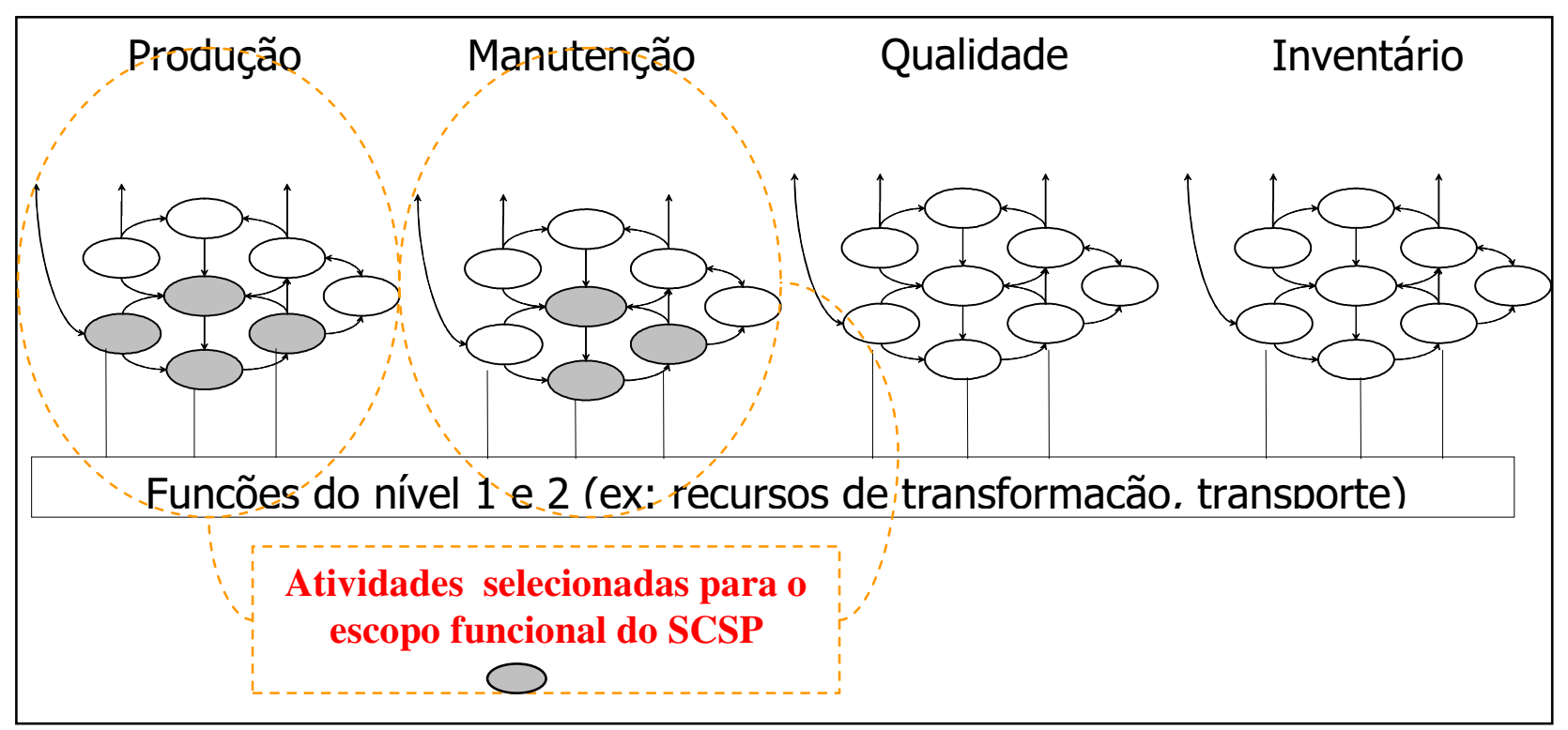

Figura 5.5. Exemplo de seleção de atividades para o escopo funcional do SCSP

No exemplo em questão, é necessário utilizar o modelo genérico de atividades da figura 5.3 para a identificação das atividades em cada modelo de gestão operacional, assim como aplicar a definição das atividades obrigatórias dentro de cada modelo operacional de gestão adotado para a seleção de atividades, sobre a qual podemos adicionar outras atividades vizinhas, com exceção do planejamento detalhado.

\subsubsection{Seleção das Tarefas dentro das Atividades}

Ainda com base na terceira parte da norma ANSI/ISA S95, a última etapa para estabelecimento do escopo inicial das funções exercidas pelo SCSP envolve a definição das tarefas a serem realizadas dentro da atividade. Esta seleção é realizada para cada atividade selecionada dos modelos de gestão operacional selecionados para o escopo. Novamente, a norma ANSI/ISA S95 nos fornece a relação de tarefas desempenhadas dentro de cada atividade, e esta relação é utilizada para a seleção das tarefas. A seleção deve obedecer à realidade do SP, assim como levar 
em consideração questões estratégicas e táticas do negócio. Os critérios de seleção, no entanto, estão fora do escopo deste procedimento e é considerado premissa o conhecimento prévio de quais são e como utilizá-los; esta etapa de seleção de tarefas é opcional, sendo realizada apenas quando é necessária precisão adicional nas funções realizadas por decisão do analista que efetua a definição dos requisitos.

\subsubsection{Identificação de Homomorfismos no Domínio Semântico do Controle}

No SCSP encontramos distintas partições de seu domínio semântico, diferenciadas pela abstração associada (SANTOS FILHO, 2000); (MATSUSAKI, 2004). Utilizando o conceito empregado pela engenharia de requisitos, denominamos cada partição por homomorfismo, ou função de abstração (WING, J. 1990). O conjunto de homomorfismos distintos englobado pelo SCSP varia conforme as características de cada sistema produtivo e da extensão de automação que pretemos implementar. Diversas partições homomórficas já foram identificadas, entre as quais estão:

- controle de processo local (SANTOS FILHO, 2000); (NAKAMOTO, 2002); MATSUSAKI, 2004),

- controle de recursos de transformação (SANTOS FILHO, 2000); (NAKAMOTO, 2002); (MATSUSAKI, 2004),

- controle de designação de recursos de transporte (MATSUSAKI, 2004),

- controle do fluxo entre unidades produtivas (MATSUSAKI, 2004) e

- controle de transporte local. 
É importante observarmos que as partições mencionadas não esgotam a relação. A evolução tecnológica e a agregação de novas funcionalidades ao escopo do SCSP podem trazer contribuições novas ao domínio semântico e contribuir com novas partições homomórficas (MATSUSAKI, 2004).

A seguir, cada uma das abstrações semânticas já identificadas que definem estas partições do SCSP serão descritas.

\subsubsection{Controle de Processo Local}

Sua atividade é a execução da dinâmica da seqüência fixa das operações que definem a atividade de processamento local (SANTOS FILHO, 2000); (NAKAMOTO, 2002); MATSUSAKI, (2004). É obrigatório, constituindo o contato entre o sistema de controle e o recurso de transformação.

Pode trocar informações com:

- recursos de transformação locais, delegando e liberando a evolução das atividades de processamento e monitorando o estado do recurso (SANTOS FILHO, 2000); (NAKAMOTO, 2002); ( MATSUSAKI, 2004),

- controle de recursos de transformação, enviando solicitações de alocação e recebendo respostas de alocações visando a continuação do processo global do produto (SANTOS FILHO, 2000); (NAKAMOTO, 2002); (MATSUSAKI, 2004) e

- controles de designação de transporte (MATSUSAKI, 2004) visando envio do produto ao recurso alocado para a próxima atividade de processamento (ou despacho), enviando solicitações de designação e recebendo suas respostas. 


\subsubsection{Controle de Recursos de Transformação}

Sua função é a alocação exclusiva dos recursos de transformação a cada atividade de processamento de cada produto (SANTOS FILHO, 2000); (NAKAMOTO, 2002); MATSUSAKI, (2004). A sequiência de atividades para cada produto é definida pelo seu processo global previamente planejado, em conformidade com instruções de engenharia de processos e da qualidade (HALEVI; WEILL, 1995).

Neste homomorfismo, a abstração reconhece todas as alocações de recursos necessários para os processos de cada produto, assim como a sequiência em que as alocações são empregadas e eventuais compartilhamentos de recursos entre processos de distintos produtos.

Sua semântica permite a aplicação de regras de controle complementares às regras de alocação impostas pelos processos globais. Por exemplo, podem ser aplicadas regras que visem garantir propriedades de continuidade ("liveness") (SANTOS FILHO, 2000), (NAKAMOTO, 2002); (MATSUSAKI, 2004), permitindo que o sistema produtivo não atinja "deadlock", ou regras externas, tais como a imposição de uma escala fina de produção que restrinja a alocação dos recursos de transformação.

Esta partição do SCSP contribui toda vez que os processos de manufatura demandam alocação de um recurso de transformação. Pode trocar informações com:

- controle de processo local, conforme descrito anteriormente e

- controle de fluxo entre unidades produtivas, toda vez que este for empregado (descrito adiante). 


\subsubsection{Controle de Designação de Recursos de Transporte}

Sua atividade é a alocação exclusiva de um recurso de transporte disponível em resposta à solicitação de transporte gerada por um controle de processo local, solicitação esta que define origem e destino do transporte a ser realizado (SANTOS FILHO, 2000); (MATUSAKI, 2004).

O compartilhamento do uso de recursos de transporte é identificado pelo eventual excesso da quantidade de solicitações endereçadas a um número menor de recursos de transporte disponíveis, sobreposição esta que é dinâmica, dependendo das solicitações de transporte em atendimento simultâneo pelo controle de designação de recursos de transporte.

Pode trocar informações com:

- controlador de processo local, conforme descrito anteriormente e

- controlador de transporte local, ao designá-lo para atendimento à solicitação efetuada, e monitorar seu estado.

\subsubsection{Controle do Fluxo entre Unidades Produtivas}

Unidade produtiva (UP) é um conjunto de recursos de transformação para o qual existe um controle de recurso de transformação específico (MATSUSAKI, 2004). É utilizado toda vez que torna-se necessário um controle para designação de recursos de transporte empregados para realizar a movimentação entre múltiplas unidades, demandando alocação exclusiva do espaço físico de uma unidade produtiva a um recurso de transporte.

Pode trocar informações com: 
- controle de recurso de transformação, recebendo solicitações de alocação das unidades produtivas em função da progressão dos processos produtivos, assim como respondendo as mesmas.

\subsubsection{Controle de Transporte Local}

Sua atividade é a execução da dinâmica da seqüência fixa de operações pelo recurso de transporte para o transporte de produto entre recursos de transformação por solicitação do controle de processo local daquele recurso que finalizou atividade de processamento (MATSUSAKI, 2004).

Pode trocar informações com:

- recurso de transporte, delegando e liberando a evolução das atividades de transporte e monitorando o estado do recurso e

- controle de designação de recursos de transporte.

\subsubsection{Linguagens de Especificação Adequadas às Partições}

Para elaborar a especificação de cada partição, necessitamos estabelecer uma relação entre cada partição homomórfica e uma linguagem de especificação adequada à expressão da abstração da partição (WING, 1990).

Com base na modelagem de SCSP que adotamos para esta dissertação, adotamos as seguintes linguagens de especificação para as partições mencionadas anteriormente:

- para a classe de controle de processo local : E-MFG com comunicadores (MATSUSAKI, 2004), 
- para a classe do controle de recursos de transformação (SANTOS FILHO, 2000); (NAKAMOTO, 2002); (MATSUSAKI, 2004): E-MFG com comunicadores construído a partir da aplicação do GAR de processos do sistema produtivo,

- para a classe do controle de designação de recursos de transporte (MATSUSAKI, 2004): algoritmos do problema de designação (PUCCINI, 1972), modelados com auxílio da linguagem UML, cujo detalhamento não foi considerado nesta dissertação,

- para a classe de controle de transporte local : E-MFG com comunicadores, estendendo o uso desta linguagem de forma análoga ao emprego encontrado para a classe de controle de processo local e

- para a classe do controle de fluxo entre UP: também o E-MFG com comunicadores.

Tendo em vista a necessidade de abstração em nível superior da integração entre cada partição do SCSP e entre estes e o ambiente, e que esta comunicação é estabelecida tendo por base o paradigma da orientação a objeto (MATSUSAKI, 2004), cada linguagem de especificação utilizada necessitará, obrigatoriamente, possuir elementos sintáticos específicos que designem tal comunicação.

\subsubsection{Especificação das Partições do SCSP e Integração destas ao Sistema e ao Ambiente}

Após a adoção de uma linguagem de especificação para cada partição, realizaremos a especificação de cada partição através da mesma. Para realizar a especificação, partiremos do uso da linguagem UML através do emprego do caso de uso, o qual permitirá definir de forma adequada expressar a integração da partição ao ambiente através da descrição do uso que se faz da partição em questão. 
Conforme vimos anteriormente, empregamos como linguagem de especificação aplicável à integração do SCSP ao ambiente uma linguagem suportada pela orientação a objetos, em nosso caso, a linguagem de especificação UML. Da mesma forma que aplicada para a integração do SCSP ao ambiente, estenderemos esta linguagem para uso interno a este, entre suas partições (MATSUSAKI, 2004). Tal abordagem está em conformidade com a norma ANSI/ISA S95, que se utiliza para a comunicação entre sistemas pertencentes ao terceiro nível funcional hierárquico (terceira parte da norma) e outros sistemas de qualquer nível hierárquico da mesma abordagem.

É importante notarmos que a utilização de mensagens de comunicação entre as partições do SCSP e entre este e o ambiente encontra suporte na norma IEC 61499 (LEWIS 1998), onde o contexto do controle passa a ser resolvido através de módulos de controle distribuídos. A IEC 61499 padroniza os blocos funcionais, viabilizando o emprego de interfaces entre as diversas partições do controle. Para a viabilização da metodologia proposta, é essencial que a modelagem realizada esteja em conformidade com os recursos providos pelos padrões de linguagem de programação de controle da IEC 61499.

Iniciamos a especificação do SCSP através do modelo de caso de uso (JACOBSON; BOOK; RUMBAUGH, 1998); (ROSENBERG, 1999), ferramenta da UML que permite a representação gráfica dos casos de uso de um sistema e sua relação com os atores. Do ponto de vista de cada partição do SCSP, todas as classes externas (pertencentes ao ambiente ou a outras partições do SCSP) são atores. Ao elaborar um modelo de caso de uso para cada partição do SCSP, iremos identificar e modelar todos os casos de uso relacionados com a partição. Este modelo auxiliará na visualização da integração de cada partição do SCSP com o ambiente e outras partições do SCSP. 


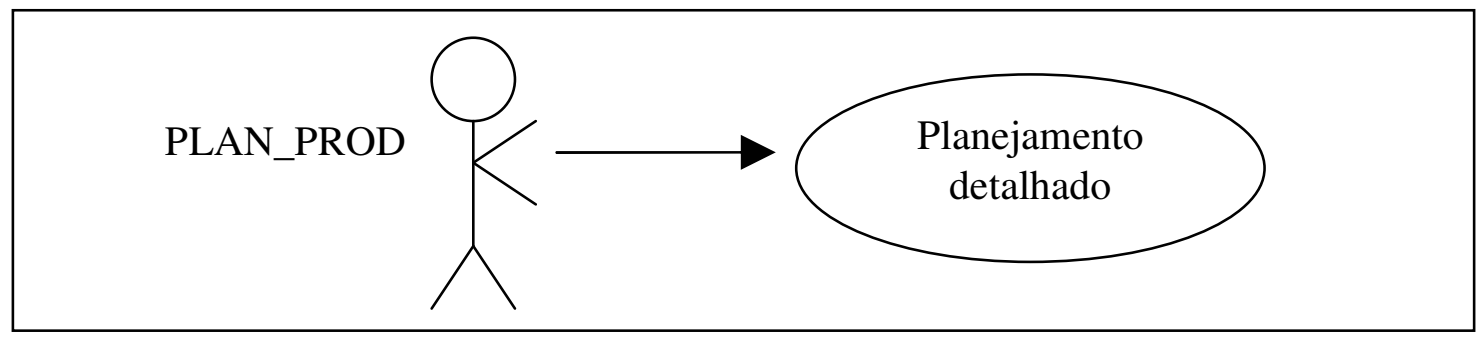

Figura 5.6. Exemplo de modelo de caso de uso

Encontramos um exemplo de modelo de caso de uso na figura 5.6, onde representamos o uso da partição controle de recursos de transformação na sua utilização por um sistema de planejamento produtivo (PLAN_PROD) informando a escala produtiva (planejamento detalhado).

Após discutirmos aspectos de especificação da integração de cada partição, passaremos a discutir questões das especificações destas partições como um todo. Para cada partição, todos os casos de $\underline{\text { uso }}$ identificados pelo modelo de caso de uso devem ser elaborados. O conjunto de todos casos de uso elaborado para uma partição constitui a definição dos requisitos para esta partição.

Para cada partição, o passo seguinte é a conversão do caso de uso em modelos que empreguem a respectiva linguagem de especificação. Dependendo da linguagem de especificação, o emprego do caso de uso deverá ser restringido quanto à sua sintaxe para permitir a conversão correta e não ambígua.

Esta conversão é necessária face à necessidade de expressar abstrações adicionais não contempladas pelo caso de uso e que são adicionadas ao modelo após a conversão.

Importante observar que cada caso de uso empregado deverá atender a:

- requisitos definidos pelo conjunto de atividades e tarefas que constituem o escopo do SCSP, e estabelecidos durante a terceira etapa deste método e 
- requisitos definidos pela sexta etapa deste método em que a partição está envolvida, pela troca de informações compartilhadas entre os níveis 3 e 4 da ANSI/ISA S95 externo a partição do SCSP e a própria partição do SCSP, e pela troca de informações compartilhadas entre a partição do SCSP e o nível 2 da ANSI/ISA S95 (controles de processos físicos).

A especificação da partição referente ao controle de designação de recurso de transporte não será desenvolvida nesta dissertação. Podemos encontrar técnicas para tal especificação, compatíveis com o método apresentado, em outros trabalhos (MATSUSAKI, 2004). 


\section{Capítulo 6}

\section{ESPECIFICAÇÃO DAS}

PARTiÇões do SCSP

Dedicaremos este capítulo à definição da segunda parte da sistemática proposta por esta dissertação. O objetivo é a especificação das partições do SCSP que empregam o E-MFG com comunicadores como linguagem de especificação. Utilizaremos a técnica do caso de uso disponível na UML, restringindo-a para atender à demandas da qualidade definidas pela engenharia de requisitos às linguagens de especificação e adequando-a ao propósito posterior de sua conversão sistemática em modelos E-MFG com comunicadores.

Iniciamos definindo e justificando o produto final esperado deste processo (E-MFG com comunicadores). Prosseguimos na exposição dos motivos que nos levaram a adotar o caso de uso como preliminar ao desenvolvimento da modelagem E-MFG com comunicadores. Detalhamos, então, um conjunto de restrições adicionais impostas a um caso de uso que permitem sua adoção na especificação inicial de requisitos.

A seguir, convertemos o caso de uso restrito em um modelo E-MFG com comunicadores. Primeiro, complementamos as alternativas da interface de recepção do E-MFG com comunicadores no papel de um método, adicionando novos elementos sintáticos. A partir deste ponto, descrevemos a sistemática de conversão do caso de uso no modelo E-MFG com comunicadores.

Encerramos tratando da situação particular da fusão de lugares, aplicável a casos de uso convertidos para uma modelagem de mesma classe. 
Capítulo 6 - Especificação das Partições do SCSP Modeladas por E-MFG com Comunicadores 101

\subsection{E-MFG COM COMUNICADORES E CASOS DE USO DA UML}

O MFG é uma técnica de modelagem adequada para representação de SP, que podem ser vistos como SED, e que permite sua conversão sistemática em linguagem de programação para controladores programáveis (SANTOS FILHO; MIYAGI, 1997) que atendam aos padrões da norma ISO/IEC 61131 e ISO/IEC 61499 (CAVALHEIRO, 2004). Desta forma, dentro do nosso objetivo de criar uma sistemática de modelagem do SCSP a partir dos requisitos, estabeleceremos como produto final desta sistemática a modelagem de SCSPs em E-MFG com comunicadores.

A opção acima é encontrada em diversas propostas anteriores sobre as quais baseia-se esta dissertação (SANTOS FILHO, 2000); (NAKAMOTO, 2002); (MATSUSAKI,2004), e sua escolha beneficia-se em diversos quesitos de qualidade, tais como a portabilidade (adoção dos padrões IEC 61131 e IEC 61499 aos quais fornecedores de controladores programáveis aderem) e a manutenibilidade (suportada pela rastreabilidade proporcionada pela conversão sistemática entre o modelo MFG e a linguagem de programação).

O uso da orientação a objeto proporcionado pela adoção de extensões presentes no E-MFG com comunicadores permite ainda adicionar outras características importantes:

- a reusabilidade proporcionada pelos blocos funcionais (ISO/IEC 61499) e

- interoperabilidade, também pela adoção da orientação a objetos.

Por outro lado, partindo do paradigma da orientação a objeto, a descrição da seqüência de ações realizada na utilização de um sistema pode ser representada pela técnica do caso de uso dentro da modelagem UML (JACOBSON; BOOCH; RUMBAUGH, 1998); (ROSENBERG; SCOTT, 1999). Esta seqüência de eventos representa em um SP o que é denominado por trajetória de eventos (RAMADGE; WONHAM, 1989). 
Capítulo 6 - Especificação das Partições do SCSP Modeladas por E-MFG com Comunicadores 102

Desta forma, podemos descrever a seqüência de ações (trajetória de eventos) em um SP utilizando a técnica de caso de uso da UML. Um caso de uso é redigido da perspectiva do usuário no presente, e em voz ativa (ROSENBERG; SCOTT, 1999) e utilizando linguagem natural (JACOBSON; BOOK; RUMBAUGH, 1998). Tal característica dos casos de uso permite seu emprego como um acordo entre o usuário e o analista (JACOBSON; BOOCH; RUMBAUGH, 1998), tornando a especificação mais facilmente compreensível do ponto de vista do primeiro.

O caso de uso define os estados (condições) e as possíveis transições (eventos) entre estes estados (JACOBSON; BOOCH; RUMBAUGH, 1998). A parte principal de um caso de uso é denominada fluxo de eventos, onde definimos a seqüência de eventos. O fluxo de eventos é dividido em duas partes: a fluxo de eventos básico, onde descrevemos a seqüência de eventos mais provável, e fluxo de eventos alternativo. Em um caso de uso, cada fluxo alternativo constitui uma seqüência de ações menos freqüente que ocorre em detrimento da ocorrência da seqüência de ações a qual substitui (JACOBSON; BOOCH; RUMBAUGH, 1998); (ROSENBERG; SCOTT, 1999).

Com base nestas equivalências de representação, observamos que os casos de uso podem realizar potencialmente a mesma designação de um SP que o MFG representa, permitindo-nos conversão sistemática do caso de uso em modelo MFG.

O princípio desta conversão é a associação de cada evento de um caso de uso a uma transição de um MFG, a qual dá origem a uma nova condição (sua pós-condição). Dois eventos sucessivos em um caso de uso identificam duas transições no MFG, onde a primeira é conectada por um arco de saída a uma condição (que é sua pós-condição), a mesma condição (neste caso, pré-condição) a qual é conectada à segunda transição por um arco de entrada. Mostramos um exemplo hipotético desta conversão na figura 6.1, onde duas unidades 
Capítulo 6 - Especificação das Partições do SCSP Modeladas por E-MFG com Comunicadores 103

produtoras são conectadas por um magazine, o qual serve de passagem para o envio de produtos elaborados pela primeira unidade produtora para a segunda. Encontramos no exemplo um trecho do fluxo de eventos do caso de uso, assim como a parte do modelo MFG originada de sua conversão.

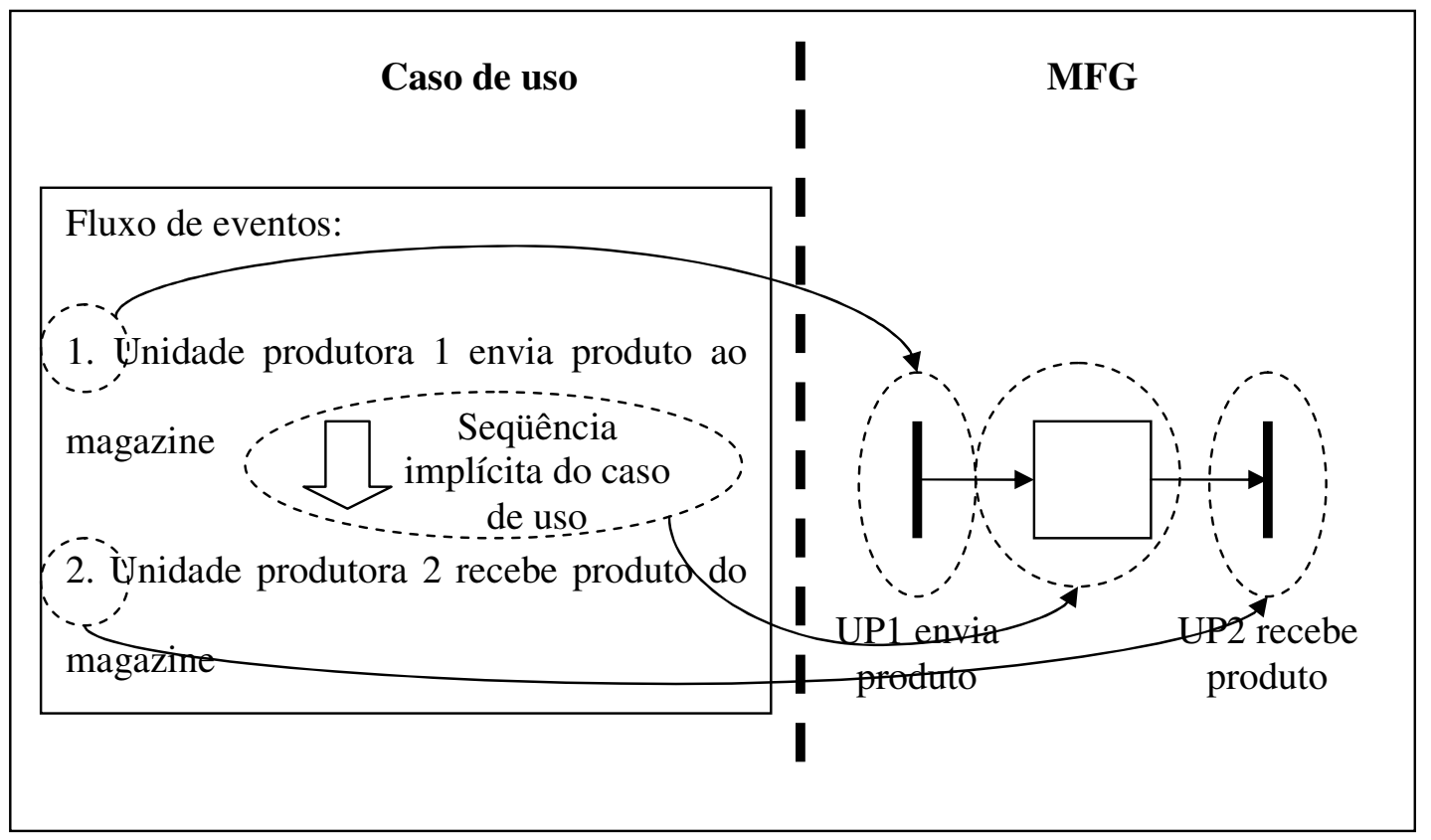

Figura 6.1. Exemplo da conversão do fluxo de eventos de um caso de uso em modelo MFG

O exemplo da figura 6.1, apesar de verdadeiro, traz consigo questões que precisam ser resolvidas através de restrições adicionais na aplicação do caso de uso quando nosso interesse é especificar um SCSP. Tais restrições são necessárias quando levamos em conta o uso da linguagem natural na elaboração de casos de uso, que traz ambigüidades potenciais a seu conteúdo. A elaboração de restrições adicionais ao caso de uso que permitam seu emprego adequado na modelagem é o assunto que exploraremos no restante do capítulo.

Iremos adotar daqui por diante o paradigma da orientação a objetos no estabelecimento de diversas restrições adicionais a serem empregadas nos casos de uso, o que implica no uso de 
Capítulo 6 - Especificação das Partições do SCSP Modeladas por E-MFG com Comunicadores 104

sua terminologia. Tal ação nos facilitará relacionar as implicações das restrições gerais com as restrições específicas geradas pela orientação a objeto impostas ao caso de uso.

\subsection{Restrições ao Caso de Uso para Conversão em e-MFg com}

\section{COMUNICADORES}

A engenharia de requisitos solicita algumas características mínimas por parte da linguagem de especificação para obtenção de uma especificação consistente, não ambígua e que atenda restritamente aos requisitos, conforme visto no capítulo 4.

Em nosso caso, além de aplicar as restrições demandadas pela engenharia de requisitos para atender as características descritas no capítulo 4, elaboraremos outro conjunto de restrições, acrescido a este primeiro, empregando adicionalmente o paradigma da orientação a objeto.

Antes de discutir o segundo grupo de restrições, iremos contextualizar a abordagem empregada dentro da orientação a objeto. Para elaborar o segundo grupo de restrições, necessitaremos tipificar os métodos utilizados pelas classes de objetos em duas naturezas distintas: os comandos (métodos que implicam em alterações de estados dos objetos) e as consultas $^{1}$ (métodos que não alteram estados dos objetos, e que retornam informações sobre o conjunto) (MITCHELL; MCKIM, 2001) (CORMEN, 2002). Após esta contextualização, podemos relacionar algumas características adicionais necessárias para a linguagem de especificação (MITCHELL; MCKIM, 2001), visando não ambigüidade, correção e atendimento restrito a requisitos aplicados à modelagem do objeto em questão. Estas características serão utilizadas para restringir o caso de uso. As características são obtidas através de elementos sintáticos que:

\footnotetext{
${ }^{1}$ Existem métodos que são consultas e comandos ao mesmo tempo.
} 
Capítulo 6 - Especificação das Partições do SCSP Modeladas por E-MFG com Comunicadores 105

- definam métodos de tal forma que diferenciemos os comandos puros (métodos que implicam em alterações de estados, e que não respondem a informações sobre os objetos) das consultas (métodos que não alteram estados, e respondem a solicitação de informações sobre o objeto),

- permitam-nos separar as consultas básicas das derivadas. As derivadas são aquelas que podem ser obtidas através de respostas fornecidas pelas básicas. Devemos especificar pós-condições para as consultas derivadas que definam as respostas esperadas em termos das básicas,

- para cada comando, permitam especificar como pós-condição qual o valor de resposta esperado para cada consulta básica em função da alteração de condição prevista (o que permite definir o conjunto completo de alterações da condição esperada) e

- para cada comando e consulta, que permitam especificar quais pré-condições são adequadas para assegurar a execução do método.

Restrições aplicadas ao caso de uso baseadas neste segundo conjunto de características proporcionam aos programas desenvolvidos com base na modelagem obtida outra característica de qualidade pretendida, que é a robustez (BONFATTI; MONARI; SAMPIERI, 1999). Esta é alcançada pela adição das pré-condições e pós-condições, trazendo integridade e persistência ao programa. A integridade é obtida pela obtenção de respostas corretas do sistema, mesmo quando sujeito a circunstâncias não esperadas; a persistência é obtida pela continuidade do programa em situações não previstas, pois o sistema responde a estas situações preservando seu controle.

Neste tópico, iremos elaborar dois conjuntos de restrições a serem aplicados aos casos de uso: 
Capítulo 6 - Especificação das Partições do SCSP Modeladas por E-MFG com Comunicadores 106

- restrições gerais de uma linguagem de especificação aplicadas aos casos de uso na modelagem de SCSP, baseadas nas características gerais de linguagem de especificação definidas pela engenharia de requisitos no capítulo 4, e

- restrições particulares de uma linguagem de especificação aplicadas aos casos de uso na modelagem de SCSP, geradas em função da aplicação da abordagem explanada aos tipos de métodos (consultas e comandos), própria da orientação a objeto.

\subsubsection{Restrições Gerais a Casos de Uso para Especificação de SCSP}

Nosso objetivo é a modelagem de um SCSP. Desta forma, para nos concentrarmos nas questões relevantes apenas para este contexto, definiremos como premissa o desenvolvimento de uma solução que parta do domínio semântico do problema que abordamos (controle do sistema produtivo), o que invalida seu emprego direto a outros domínios semânticos.

Desenvolveremos neste tópico, partindo desta premissa inicial, restrições adicionais à técnica de caso de uso geradas por aspectos gerais da engenharia de requisitos com o objetivo de concedê-la atributos de qualidade, tais como não ambigüidade e correção.

Ao elaborar as restrições, nosso propósito é obter solução similar à proposta identificada no tópico 6.2 e exemplificada na figura 6.1, onde o caso de uso irá descrever uma seqüência de ações atômicas (eventos), ordenando esta seqüência de ações, e passível de conversão em EMFG com comunicadores.

A partir deste ponto, procuraremos atender em cada tópico a cada restrição levantada no capítulo de engenharia de requisitos, aplicáveis a qualquer fluxo de eventos de um caso de uso, finalizando com um tópico enfocado a restrições aplicadas aos fluxos de eventos alternativos de um caso de uso.

\subsubsection{Terminologia fundamentada na realidade do ambiente}


A adoção dos nomes que identificam as classes em casos de uso da UML é apenas uma recomendação, e auxiliada através da modelagem de domínio. Na sistemática que desenvolvemos iremos além, restringindo definitivamente a identificação das classes a seus nomes dentro dos casos de uso.

Para atingir este objetivo, os nomes das classes a serem utilizados são provenientes das duas fontes externas fronteiriças da classe especificada do SCSP: aquelas previamente disponíveis dentre os outros sistemas do ambiente, definidas com auxílio do modelo de atividades de cada gestão operacional dentro da abordagem ANSI/ISA S95, e aquelas que necessitarão ser modeladas e programadas (partes do SCSP).

Torna-se necessário definir um glossário com auxílio da tabela de classes do ambiente. Para desenvolvê-lo, técnicas de desenvolvimento da modelagem de domínio existentes na UML poderão ser utilizadas (ROSENBERG; SCOTT, 1999); (JACOBSON; BOOCH; RUMBAUGH, 1998). A tabela resultante relaciona:

- nome da classe fronteiriça externa (identificada em outro sistema externo do ambiente), que se não existir previamente, recebe nomeação,

- sistema externo ao qual a classe pertence, que se não existir previamente, recebe nomeação,

- nível hieráquico funcional (conforme ANSI/ISA S95, níveis entre 2 e 4),

- $\quad$ se nível 3:

○ modelo de gestão operacional ao qual pertence (produção, manutenção, qualidade ou inventário, conforme nível 3 da ANSI/ISA S95), 
Capítulo 6 - Especificação das Partições do SCSP Modeladas por E-MFG com Comunicadores 108

- modelo de atividade ao qual pertence (conforme parte 3 da ANSI/ISA S95) dentre os existentes no modelo de gestão operacional definido,

○ tarefas realizadas dentro do modelo de atividade ao qual pertence (também conforme parte 3 da ANSI/ISA S95) e

○ operação que realiza, eventualmente detalhando tarefas definidas acima.

- $\quad$ se nível 4, modelo de função que desempenha conforme parte 1 da ANSI/ISA S95 (figura 5.1).

Por outro lado, definimos no capítulo 5 as partições (as quais constituirão classes dentro do paradigma da orientação a objeto) do SCSP, demandando diferentes técnicas de especificação. A partir deste fato, necessitamos descrever cada classe das partições do SCSP como um sistema em particular (PARNAS; MADEY, 1995), tratando como externas à classe:

- todas as classes externas ao SCSP (ambiente prévio), assim como

- todas outras classes que fazem parte, cada qual, das diversas partições do próprio SCSP.

Desta forma, necessitamos definir um glossário adicional de classes, relativas às classes do SCSP definidas conforme capítulo anterior. Esta é a tabela de classes do SCSP e conterá as informações: nome da classe para a partição e partição homomórfica a que atende.

A partir da definição destas duas tabelas, todos as classes utilizadas pelos casos de uso pertencerão à relação de nomes das classes identificadas por estas tabelas.

Como exemplo simplificado, suponhamos um SCSP cujo escopo funcional seja apenas o modelo de gestão operacional da produção. Dentro deste modelo, o SCSP desempenha as 
atividades de gestão da execução, despacho produtivo e coleta de dados. Suponhamos, também, que será integrado ao SCSP um sistema de planejamento detalhado. O escopo funcional do SCSP exemplificado está na figura 6.2.

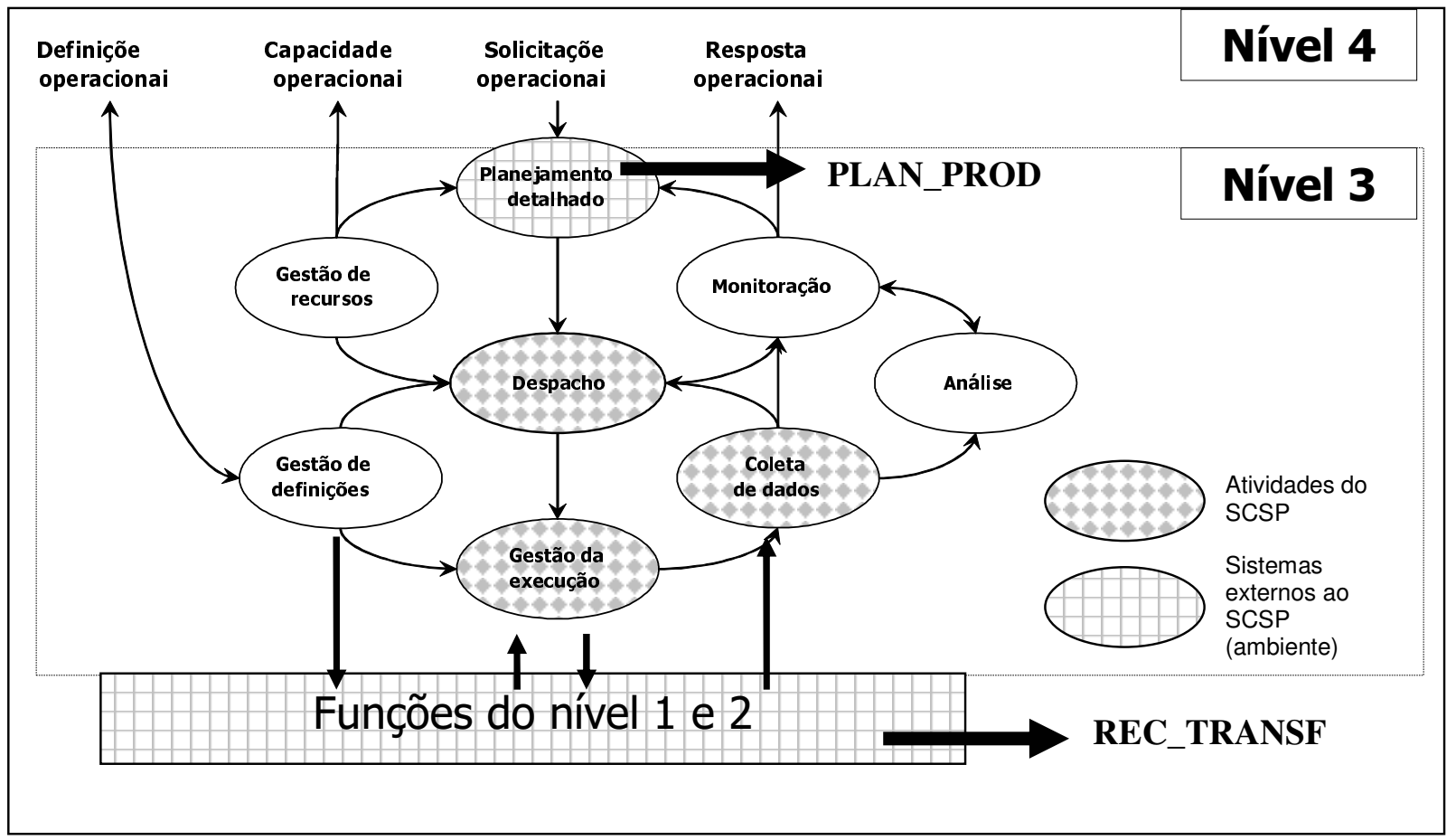

Figura 6.2. Exemplo de escopo funcional de SCSP

A tabela de classes do ambiente identificará as classes de sistemas externos pelas fronteiras representadas em cada modelo de gestão operacional. No exemplo, fazem parte do ambiente a relação de classes identificadas na tabela 6.1 .

Tabela 6.1. Tabela de classes do ambiente

\begin{tabular}{|l|c|c|c|c|}
\hline Nome da classe & Sistema & $\begin{array}{c}\text { Nível } \\
\text { ANSI/ISA }\end{array}$ & $\begin{array}{c}\text { Modelo de gestão operacional (nível } \\
\text { 3) / Modelo de função (nível 4) }\end{array}$ & $\begin{array}{c}\text { Atividade } \\
\text { (nível 3) }\end{array}$ \\
\hline REC_TRANSF & - & 2 & & \\
\hline PLAN_PROD & SISPLAN & 3 & $\begin{array}{c}\text { Gestão operacional da } \\
\text { produção }\end{array}$ & $\begin{array}{c}\text { Escalonamento } \\
\text { detalhado da produção }\end{array}$ \\
\hline
\end{tabular}


Para atender o escopo funcional das atividades definidas para o exemplo, selecionamos os apenas dois domínios semânticos:

- controle de processo local e

- controle de recursos de transformação.

Desta forma, o SCSP será formado apenas por duas partições de classes: uma para o controle de recurso de transformação, e outra com a classe de controles de processo local.

Tabela 6.2. Tabela de partições do SCSP

\begin{tabular}{|l|l|}
\hline \multicolumn{1}{|c|}{ Nome da classe } & \multicolumn{1}{c|}{ Partição homomórfica } \\
\hline CNT_PROC.RECX & Controle de Processo Local do Recurso X \\
\hline CNT_REC_TRANSF & Controle de Recursos de Transformação \\
\hline
\end{tabular}

\subsubsection{Controle de ações pelo ambiente ou pelo SCSP}

O ambiente irá realizar as ações através dos métodos colocados à disposição pelas classes pertencentes à tabela de classes do ambiente, enquanto que o SCSP irá realizá-lo através dos métodos colocados à disposição pelas classes da tabela de classes do SCSP.

Para cada ação, necessitamos definir qual parte do ambiente e qual parte do SCSP participam da ação, bem como seus papéis. Os papéis são diferenciados entre aquele que solicita a ação (em linguagem natural, o sujeito da ação) e aquele que recebe a solicitação da ação (em linguagem natural, objeto indireto da oração). Passamos a identificar estes papéis pela prática que adotamos de colocá-lo ao lado esquerdo, iniciando a oração com um sujeito, ao passo que a outra classe (sofre a ação) é colocada à direita na oração. As duas classes serão diferenciadas do restante das palavras pelo uso do negrito em seus nomes. 
Capítulo 6 - Especificação das Partições do SCSP Modeladas por E-MFG com Comunicadores 111

Precisamos inicialmente distinguir quais classes desempenham papel de ambiente do ponto de vista da especificação de uma classe particular do SCSP, correspondente a uma determinada partição. Ao definir a especificação de uma classe do SCSP, tanto o ambiente prévio ao SCSP como todas outras classes do SCSP são considerados externos à classe especificada. Portanto, ao especificar uma classe do SCSP, podemos empregar outras classes do SCSP nos papéis complementares das ações em que participa uma classe do SCSP em especificação.

Utilizando o caso simplificado deste capítulo para exemplificar, quando estivermos modelando a partição do controle de recursos de transformação (CNT_REC_TRANSF), serão considerados como parte do ambiente:

- as classes do ambiente que fazem fronteira com o SCSP, que são REC_TRANSF e PLAN_PROD e

- $\quad$ todas outras classes do SCSP que não a classe modelada, que é CNT_PROC.RECX.

Toda ação descrita ao longo do caso de uso equivale a um evento, o qual estabelece implicitamente uma respectiva condição (pós-condição do evento). No entanto, conforme o papel da classe modelada na ação (solicita ou recebe a solicitação da ação), o evento mencionado pode ou não constituir um método desta classe; onde a classe do SCSP solicita a ação, o método definido pela ação é pertinente à outra classe, e a condição alterada não é relativa ao da classe solicitante. Portanto, não constitui um evento relativo à modelagem da classe em questão, e sim ao ambiente.

Dentro do caso simplificado, suponhamos que estamos modelando a classe CNT_REC_TRANSF. Para a modelagem desta classe, a seguinte ação é exemplo da situação do parágrafo anterior:

- CNT_REC_TRANSF LiberaProducao $a$ CNT_PROC.RECX. 
Capítulo 6 - Especificação das Partições do SCSP Modeladas por E-MFG com Comunicadores 112

Neste exemplo, a classe CNT_REC_TRANSF solicita o método LiberaProducao para a classe CNT_PROC.RECX. Desta forma, o método é pertencente a uma classe do ambiente (do ponto de vista de CNT_REC_TRANSF), e sua condição não é alterada (o evento é pertinente à classe do ambiente cujo método foi invocado).

Por outro lado, quando o papel da classe modelada do SCSP é de receber a solicitação da ação, o evento constitui um método da própria classe, alterando sua condição. Nesta segunda situação, a pós-condição é, também implicitamente, uma pré-condição para o evento seguinte no qual a classe recebe solicitação de uma ação.

Dentro do mesmo caso simplificado, continuaremos a modelagem da classe CNT_REC_TRANSF. Nesta segunda situação, a seguinte ação é exemplo:

- CNT_PROC.RECX SolicitaAlocaçao $a$ CNT_REC_TRANSF.

Neste exemplo, a classe CNT_PROC.RECX solicita o método SolicitaAlocaçao para a classe CNT_REC_TRANSF. Desta forma, o método é pertencente à classe modelada, e então sua condição é alterada e o evento em questão lhe é pertinente, em atendimento ao método invocado.

A tabela 6.3 relaciona as posições das classes dentro das ações de um caso de uso em função do controle da ação realizado pelo ambiente ou pelo SCSP (capítulo 5), através de suas classes.

Nas ações onde a classe do SCSP modelada invoca um método de outra classe, não existe alteração da condição dentro da respectiva partição do SCSP. O que existe é a solicitação de método de uma classe externa. Analisando os elementos disponíveis no E-MFG com comunicadores, identificamos nesta situação a interface de envio, onde a condição não é alterada e é utilizada uma mensagem solicitando método externo. 
Capítulo 6 - Especificação das Partições do SCSP Modeladas por E-MFG com Comunicadores 113

Utilizando o caso simplificado do capítulo, na especificação da classe CNT_REC_TRANSF, a ação 'CNT_REC_TRANSF LiberaProducao $a$ CNT_PROC.RECX' é convertida em interface de envio.

Tabela 6.3. Posição das classes dentro das ações do caso de uso

\begin{tabular}{|c|c|c|}
\hline Papel na ação & $\begin{array}{c}\text { Posição na ação de classe } \\
\text { do ambiente (tabela de } \\
\text { classes do ambiente) }\end{array}$ & $\begin{array}{c}\text { Posição na ação da classe } \\
\text { do SCSP (tabela de } \\
\text { classes do SCSP) }\end{array}$ \\
\hline $\begin{array}{c}\text { Ambiente controla ação não } \\
\text { compartilhada com SCSP }\end{array}$ & Esquerda, Direita $(* *)$ & - \\
\hline $\begin{array}{c}\text { Ambiente controla ação } \\
\text { compartilhada com SCSP }\end{array}$ & Esquerda & Direita \\
\hline $\begin{array}{c}\text { Classe do SCSP controla ação } \\
\text { compartilhada com ambiente }\end{array}$ & Direita & Esquerda \\
\hline $\begin{array}{c}\text { Classe do SCSP controla ação } \\
\text { compartilhada com outra classe } \\
\text { do SCSP }\end{array}$ & - & Esquerda, Direita $\left(^{*}\right)$ \\
\hline
\end{tabular}

(**) duas classes distintas do ambiente

(*) duas classes distintas do SCSP

Por outro lado, nas ações onde a classe do SCSP modelada é invocada através de um método por outra classe, existe alteração da condição da partição respectiva do SCSP, e o evento é pertencente à classe em questão. Analisando os elementos disponíveis no E-MFG com comunicadores, identificamos nesta situação a interface de recepção, onde a condição é alterada.

Ainda utilizando o caso simplificado do capítulo, na especificação da classe CNT_REC_TRANSF, a ação 'CNT_PROC.RECX SolicitaAlocaçao $a$ CNT_REC_TRANSF' é convertida em interface de envio. 
A conversão da ação em elementos sintáticos do E-MFG é diferenciada em função da identificação de um dos dois tipos de eventos (ações) através da posição da classe modelada do SCSP na ação:

- quando à direita da ação, o evento é pertinente ao seu contexto e origina um par formado pela transição e respectiva pós-condição e

- quando à esquerda da ação, o evento é externo ao seu contexto e origina uma interface de envio, a qual é conectada a condição presente.

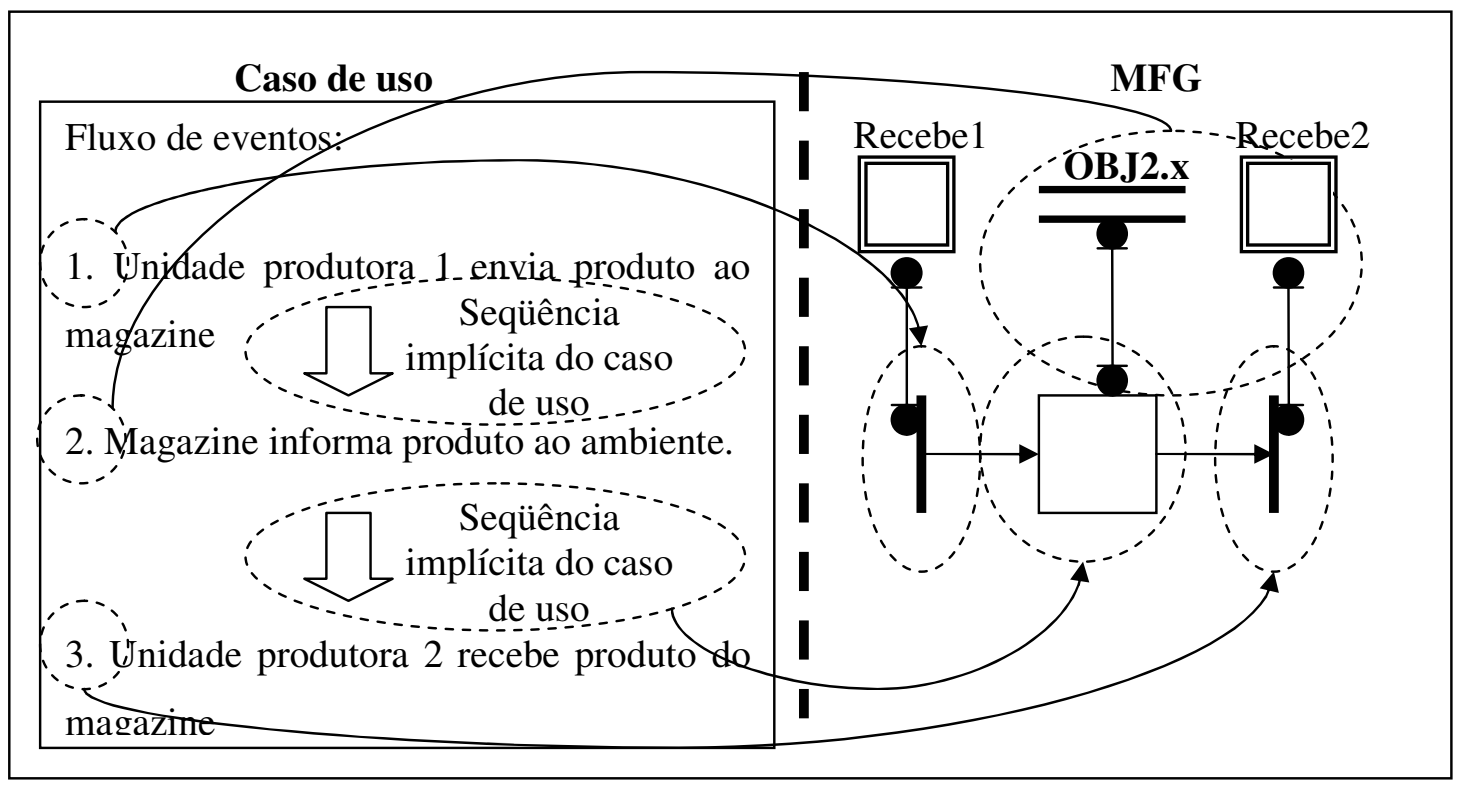

Figura 6.3. Exemplo da conversão do fluxo de eventos de caso de uso em modelo E-MFG com comunicadores

Na figura 6.3, encontramos em exemplo com três ações que permite identificar as duas situações acima, convertendo as ações do caso de uso nos respectivos elementos sintáticos do E-MFG com comunicadores, onde uma classe relativa a uma partição de um SCSP considerado neste exemplo é a classe modelada (controlador do magazine). 
Capítulo 6 - Especificação das Partições do SCSP Modeladas por E-MFG com Comunicadores 115

\subsubsection{Especificações das partições do SCSP restritas a ponto de vista externo}

Ações onde uma classe do SCSP invoca método dela mesma (portanto, participa nas duas posições), ou que não possuam apenas uma posição (aparece apenas uma classe, à esquerda ou à direita da ação) não existem na tabela 6.3. Estas ações devem ser excluídas do caso de uso para que não sejam incluídas especificações restritivas, relacionadas exclusivamente com a implementação do SCSP, ou incompletas.

Por exemplo, a ação:

- 'CNT_REC_TRANSF LiberaUsoRecurso a CNT_REC_TRANSF' é uma ação excluída, por tratar-se de ação que define ação interna à classe modelada, não compartilhada pelo ambiente e, portanto, não conhecida por este. Desta forma, é restritiva do ponto de vista de especificação, excluída de conversão.

\subsubsection{Utilização de estados do ambiente para especificação}

Verificaremos neste tópico a restrição ao emprego de descrição de estados definida pela futura implementação. Conforme a proposta inicial de conversão de um caso de uso para MFG, a ocorrência de uma ação (evento) ao longo do fluxo de eventos do caso de uso condiciona implicitamente uma pós-condição aplicável ao sistema produtivo. Assim, o uso de estados do ambiente na especificação é realizado implicitamente pela interpretação que fazemos da seqüência de seu fluxo de eventos. Ou seja, a própria linguagem de especificação (caso de uso) utilizada implica na existência das pós-condições.

Assim, concluímos que os casos de uso empregados pela sistemática desenvolvida implicam na existência de pós-condições e pré-condições pertinentes ao ambiente pré-existente, e não pertinentes à futura implementação. Não demandam, portanto, imposição de restrição adicional à sistemática para impedir o uso de estados definidos por implementação futura. 
Capítulo 6 - Especificação das Partições do SCSP Modeladas por E-MFG com Comunicadores 116

\subsubsection{Papel do conhecimento do domínio no refinamento de especificações}

Necessitaremos restringir os casos de uso evitando situações em que os requisitos não sejam implementáveis, posto que todo requisito de uma especificação que não é implementável não é conversível. Poderemos restringir o caso de uso se detectarmos sistematicamente requisitos não implementáveis. Apresentaremos três razões gerais para a existência de situações onde o requisito não é implementável, resolvidas através apenas do conhecimento do domínio (ZAVE; JACKSON, 1997). No entanto, devido ao fato de que este conhecimento é estabelecido essencialmente no domínio abstrato do problema, e não está presente previamente na especificação expressa dentro do domínio sintático da linguagem de especificação, sua solução sistemática não é realizável dentro do domínio sintático, pois os elementos necessários não estão expressos nos requisitos existentes. Para exemplificar tal fato, discutiremos as três razões.

A primeira razão é ligada a requisitos definidos por ações não compartilhadas com o SCSP. Nesta situação, a informação relativa a tais requisitos necessitaria do compartilhamento para tornar-se disponível ao SCSP, de tal forma que este não pode utilizá-la caso solicitado.

Como exemplo, suponhamos a identificação de um lote recebido por um recurso de transformação sendo utilizada como critério de seleção para alocação deste recurso, apesar de nunca informada ao SCSP.

A solução para esta situação ocorre com o auxílio do conhecimento do domínio. Substituímos

o requisito original, não implementável, por outros requisitos implementáveis (portanto especificações) que empregam conhecimento do domínio (ambiente). Para o exemplo indicado, suponhamos que o conhecimento do domínio indicasse que, se por um lado, a identificação do lote não é compartilhada, por outro a identificação do produto poderia ser. Neste caso, basta substituir o requisito original que demanda o uso da identificação do lote, 
Capítulo 6 - Especificação das Partições do SCSP Modeladas por E-MFG com Comunicadores 117

não implementável, por outro que utiliza conhecimento do domínio (ambiente). No entanto, constatamos que a solução (substituir requisito não compartilhado por outro compartilhado) não está originalmente expresso nos requisitos, e não pode ser identificado através dos mesmos.

A segunda razão decorre de situações onde requisitos são definidos em termos de um fato futuro, portanto desconhecido pelo SCSP. Exemplo: um requisito define que o SCSP deve impedir que o sistema produtivo entre em "deadlock". Para atender a este requisito, a cada evento, o sistema deveria analisar o estado futuro do sistema produtivo após a respectiva transição verificando este critério, antes de habilitá-la.

A solução para esta situação é satisfazer o requisito que referencia o futuro relacionando-o ao passado, utilizando o conhecimento do domínio. Para o exemplo em questão, a estratégia "flow-in suppression" aplicada ao E-MFG com comunicadores que modela o controlador de recursos de transformação (SANTOS FILHO, 2000); (NAKAMOTO, 2002) permite associar previamente regras de produção adicionais às transições que impedem seus disparos em situações que conduzam ao estado de "deadlock". Constatamos que a solução (relacionar o requisito que referencia o futuro ao passado) não está originalmente expresso nos requisitos, pois apenas o conhecimento do domínio reconhece uma situação de "deadlock", constatável apenas após a ocorrência do disparo da transição.

A terceira razão ocorre quando um requisito é implementável apenas se adicionarmos uma restrição ao próprio ambiente. Nesta situação, a solução é externa a especificação. Portanto, não conduzirá a nenhuma restrição adicional ao SCSP em especificação.

Estes exemplos apenas ilustram a situação, não alterando a afirmação inicial deste tópico de que nenhuma restrição adicional deve ser imposta ao caso de uso de nossa sistemática baseados no refinamento de especificações. 
Capítulo 6 - Especificação das Partições do SCSP Modeladas por E-MFG com Comunicadores 118

\subsubsection{Restrições aos Fluxos de Eventos Alternativos}

Um fluxo de eventos alternativo define uma sequiência específica de ações do fluxo básico de eventos ao qual substitui. Cada fluxo de eventos alternativo define uma continuidade da trajetória de eventos através de uma nova seqüência toda vez que um evento distinto daquele que define o progresso através do fluxo básico ocorre (JACOBSON; BOOCH; RUMBAUGH, 1998); (ROSENBERG; SCOTT, 1999), tais como ações de outros atores, erros ou exceções. Tanto a seqüência do fluxo de eventos alternativo, como a seqüência do fluxo de eventos básico substituída, iniciam com eventos (ou seja, na ação, a classe modelada é invocada, e estará do lado direito da ação).

\subsubsection{Restrições Particulares a Casos de Uso para Especificação de SCSP}

Dentro do paradigma da orientação a objeto, o princípio de encapsulamento dos dados coloca como único recurso para o relacionamento entre classes o uso dos métodos que cada classe coloca à disposição de outras classes (JACOBSON; BOOCH; RUMBAUGH, 1998); (DUKE; ROSE, 2000); (DATE, 2000).

Esta é uma restrição importante que adicionamos à definição de cada ação (evento) do caso de uso. Além dos papéis da classe que invoca posicionada à esquerda e da classe invocada à direita identificados em cada ação do caso de uso (classes distintas), para completar uma visão em conformidade com o paradigma da orientação a objeto, necessitamos identificar o método invocado (pertencente à classe que recebe a invocação) e a definição de uma mensagem com parâmetros enviada durante a invocação do método.

Com o objetivo de facilitar futura geração de código para o sistema, empregamos uma restrição adicional a cada uma das quatro partes (classe que invoca, método, classe invocada e mensagem), fazendo com que cada parte seja nomeado por um identificador, que será formado por uma composição de palavras unidas pelo símbolo ‘_.'. Adicionalmente, caso seja 
Capítulo 6 - Especificação das Partições do SCSP Modeladas por E-MFG com Comunicadores 119 necessário representar uma instância genérica específica dentre múltiplas, adiciona-se ao final do identificador um ponto seguido de um pós-fixo genérico que indicará que estamos empregando uma instância específica da classe.

Para facilitar a identificação dos papéis na ação (classe que invoca e classe solicitada) e das outras duas partes (método e mensagem), elaboramos uma ordenação da disposição dos identificadores utilizados nas orações do caso de uso distribuídos em partes conforme:

- primeira parte: identificador da classe que invoca,

- segunda parte: método da classe invocada,

- terceira parte: identificador da classe invocada e

- quarta parte: relação de parâmetros da mensagem trocada.

Utilizando o caso simplificado com exemplo, na ação 'CNT_REC_TRANSF LiberaProducao $a$ CNT_PROC.RECX com $<$ Prod, Lote> ' temos:

- primeira parte, classe que invoca: CNT_REC_TRANSF

- segunda parte, método da classe CNT_PROC.RECX invocada: LiberaProducao

- terceira parte, identificador da classe invocada: CNT_PROC.RECX e

- quarta parte, relação de parâmetros da mensagem trocada: <Prod, Lote>.

As palavras em itálico a e com foram empregadas apenas como palavras de ligação entre as partes, facilitando sua interpretação, não sendo obrigatórios. 
Capítulo 6 - Especificação das Partições do SCSP Modeladas por E-MFG com Comunicadores 120

\subsubsection{Recursos para diferenciação entre comandos e consultas}

A definição dos métodos (ações) deve ser efetuada de tal forma que sejam diferenciados comandos puros de consultas.

Antes de definirmos novas restrições adicionais para casos de uso aplicados a nossos propósitos, devemos explorar quais elementos sintáticos do E-MFG com comunicadores estão disponíveis para a comunicação para explorarmos sua utilização dentro do contexto de métodos tipificados como questões.

Existem dois elementos sintáticos para comunicação dentre os disponíveis pela modelagem EMFG com comunicadores: interfaces de envio e interfaces de recepção.

Ao analisarmos a interface de recepção, verificamos que, ao receber mensagem, pode alterar a condição da partição do SCSP, habilitando transições as quais se associa. Apresenta, portanto, característica que não corresponde ao padrão esperado de uma consulta, e por tal motivo a classificaremos como um método tipificado como comando.

Por outro lado, do ponto de vista da orientação a objeto, a interface de envio é uma invocação de um método pertinente à classe externa, portanto, fora do nosso escopo quanto às restrições adicionais ao caso de uso aplicadas a seus próprios métodos.

Assim, verificamos que os dois elementos sintáticos colocados à disposição pela modelagem E-MFG com comunicadores não são métodos tipificados como consultas, constituindo a interface de recepção um comando, enquanto a interface de envio é uma invocação de método externo ao modelo, inexistindo elementos sintáticos que permitam a uma classe externa realizar um método tipificado como consulta. 
Capítulo 6 - Especificação das Partições do SCSP Modeladas por E-MFG com Comunicadores 121

Tendo em vista que as ações do caso de uso serão convertidas em elementos sintáticos do EMFG com comunicadores disponíveis, e como o E-MFG com comunicadores não necessita adicionar restrição para distinguir consultas básicas de derivadas, também não aplicaremos restrição por este motivo ao caso de uso.

\subsubsection{Recursos para distinção entre consultas básicas e derivadas}

Como vimos no tópico anterior, não existem métodos tipificados como consultas na modelagem E-MFG com comunicadores. Por dedução equivalente ao tópico anterior, não existe restrição adicional a aplicar na distinção entre questões básicas e derivadas.

\subsubsection{Recurso para definição de pré e pós-condições para cada evento}

Cada evento é representado por uma transição no E-MFG. Exceto pelo evento inicial, ocorre sempre em um contexto em que uma pré-condição o precede, assim como sua ocorrência origina uma pós-condição. Sua representação origina elementos sintáticos que são designações destas pré e pós-condições. Desta forma, para cada evento (exceto iniciais e finais) pertinente à modelagem (ou seja, uma ação do caso de uso em que uma classe do SCSP seja invocada), a representação sintática que a efetua torna desnecessário qualquer tratamento adicional.

Quanto a eventos iniciais, não existe pré-condição, o que origina também uma transição sem pré-condição no E-MFG, denominada transição fonte (MIYAGI, 1996). Quanto à póscondição do evento inicial, esta é similar a pós-condições de eventos intermediários.

Para eventos finalizadores, não existe pós-condição, o que origina também uma transição sem pós-condição no E-MFG, denominada transição sorvedouro (MIYAGI, 1996). Quanto à précondição do evento finalizador, esta é similar a pré-condições de eventos intermediários. 
Capítulo 6 - Especificação das Partições do SCSP Modeladas por E-MFG com Comunicadores 122

\subsection{Conversão do Caso de Uso restrito EM E-MFG COM}

\section{COMUNiCADORES}

Neste tópico convertemos o caso de uso restrito em um modelo E-MFG com comunicadores. Antes da conversão propriamente dita, adicionaremos alternativas à interface de recepção do E-MFG com comunicadores através de novos elementos sintáticos.

Iniciando a descrição da conversão, seguimos estabelecendo o princípio no qual se baseia a conversão do caso de uso em E-MFG com comunicadores. A partir deste ponto, descrevemos a sistemática de conversão do caso de uso no modelo E-MFG com comunicadores, construindo paralelamente partes do algoritmo de conversão.

Para encerrar, trataremos situação particular que requer passo adicional após a conversão, a qual se aplica a técnica de fusão de lugares (SANTOS FILHO, 2000) a um conjunto gerado de modelos individuais que atendem a condições específicas.

\subsubsection{Elementos Sintáticos Complementares para E-MFG com Comunicadores}

Dentro do paradigma da orientação a objeto, todo método colocado à disposição por uma classe envolve opcionalmente a definição de um conjunto de parâmetros enviados pela classe que a invoca. Os parâmetros enviados em conjunto com a invocação nos permitem ampliar as alternativas de sintaxes oferecidas pela interface de recepção existente no E-MFG com comunicadores. Até esta dissertação, a sintaxe definida para a interface de recepção é capaz de realizar dois tipos de métodos, até então não nomeados, os quais passaremos a denominar interfaces de recepção para habilitação de transição incondicional (figura 3.9) e interfaces de recepção para habilitação condicionada à mensagem (figura 3.11).

A abordagem de ampliação das alternativas de sintaxe nos permite adicionar dois novos tipos (figura 6.4 'a' e 'b') aos dois tipos de interface de recepção definidos para o E-MFG com 
comunicadores, obtidos pela exploração dos seguintes elementos sintáticos combinados a uma transição do E-MFG com comunicadores:

- regras adicionais de disparo inscritas nas transições e

- box controlador, alterando os atributos das marcas.

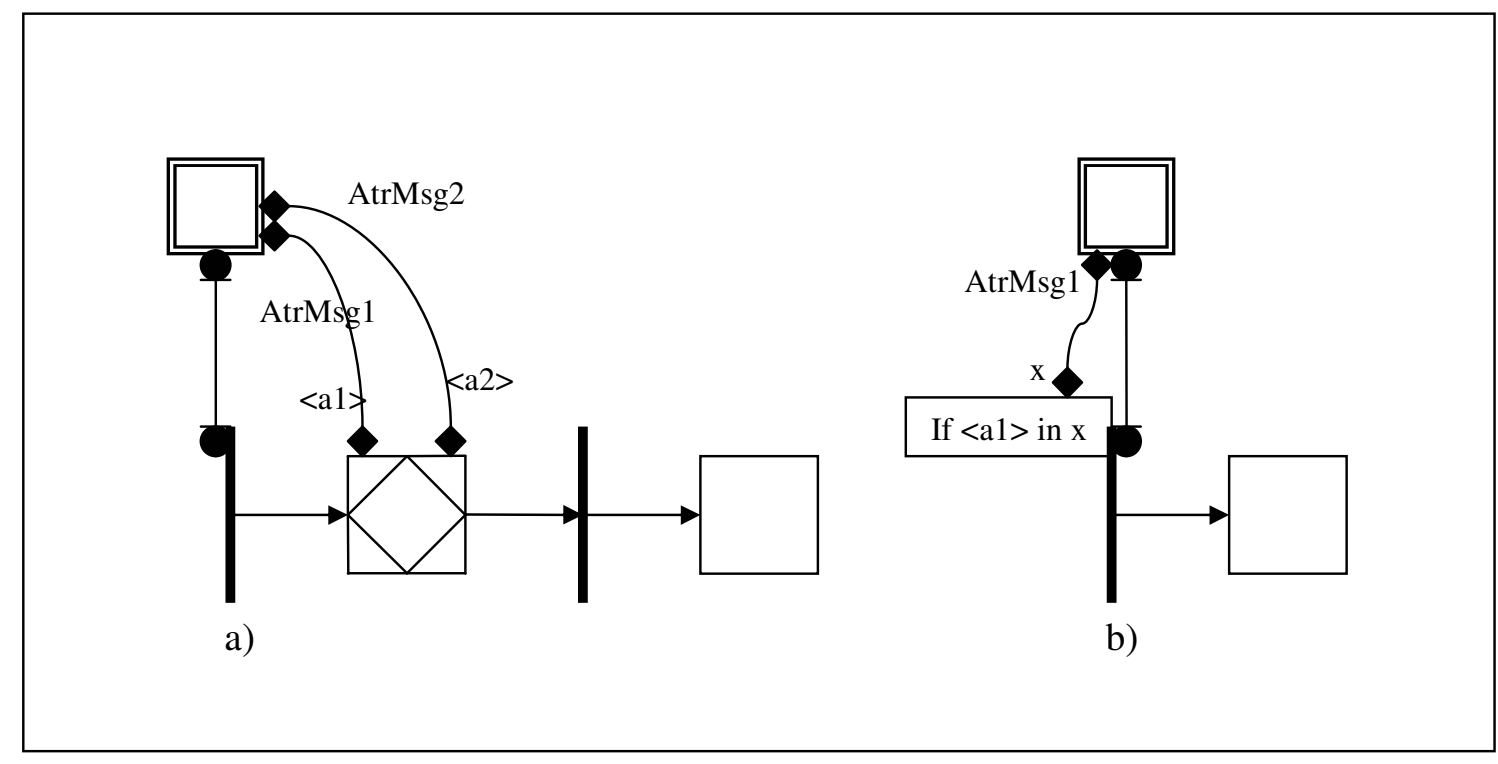

Figura 6.4. Dois novos tipos de interface de recepção

Colocamos a seguir as definições dos dois novos tipos de interfaces de recepção.

\subsubsection{Interface de Recepção para Habilitação Associada à Informação}

O primeiro tipo adicional de interface de recepção proposto é a interface de recepção para habilitação associada à informação. Sua atuação é ilustrada na figura 6.5, onde encontramos à esquerda situação anterior ao disparo e à direita situação posterior. A mensagem recebida possui parâmetros, os quais são relacionados aos atributos aos quais se destinam através de arcos de leitura de dados, a qual define qual alteração é imposta pelo box controlador. Nem todos os parâmetros da mensagem recebidos necessariamente serão destinados aos atributos das marcas; apenas os conectados o são. O disparo da transição realiza a passagem da 
marcação para a nova condição, definida pelo box controlador. A alteração de atributos da marca é realizada em todos atributos que possuírem arcos de leitura mapeando parâmetros da mensagem para estes atributos. A figura 6.5 exemplifica a interface definida.

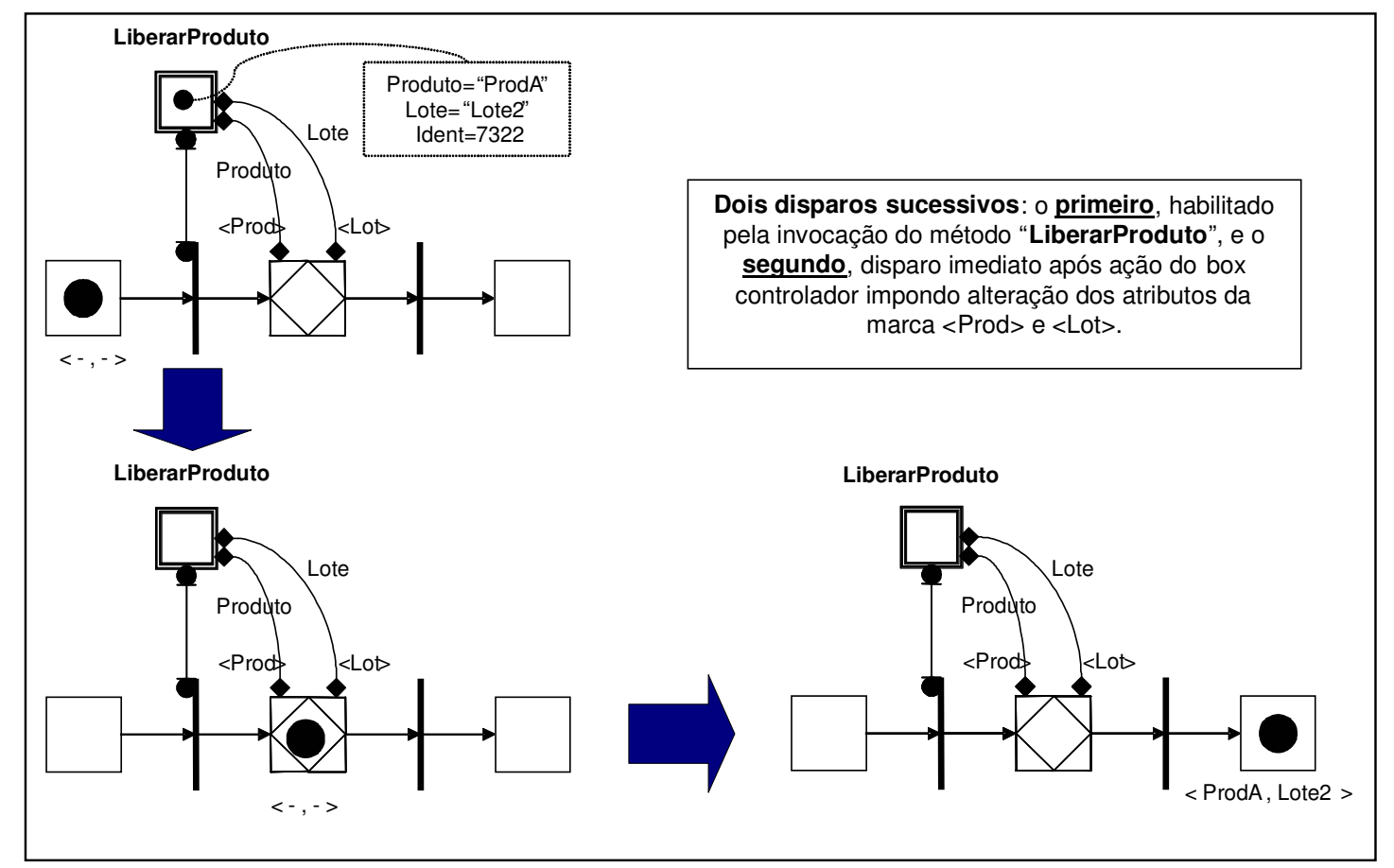

Figura 6.5. Interface de recepção de habilitação associada à informação

\subsubsection{Interface de Recepção para Parametrização das Regras Adicionais da Transição}

O segundo tipo de interface de recepção proposto é a interface de recepção para parametrização de regra adicional de uma transição. Seu funcionamento é ilustrado na figura 6.6, onde encontramos à esquerda da figura situação anterior à recepção da mensagem e à direita a situação posterior. A mensagem recebida possui parâmetros, alguns dos quais passam a fazer parte da regra adicional de transição pelo mapeamento definido através dos arcos de leitura de dados, o qual identifica o parâmetro da mensagem (na figura 6.6, 'Lote') utilizado como parte da regra. 


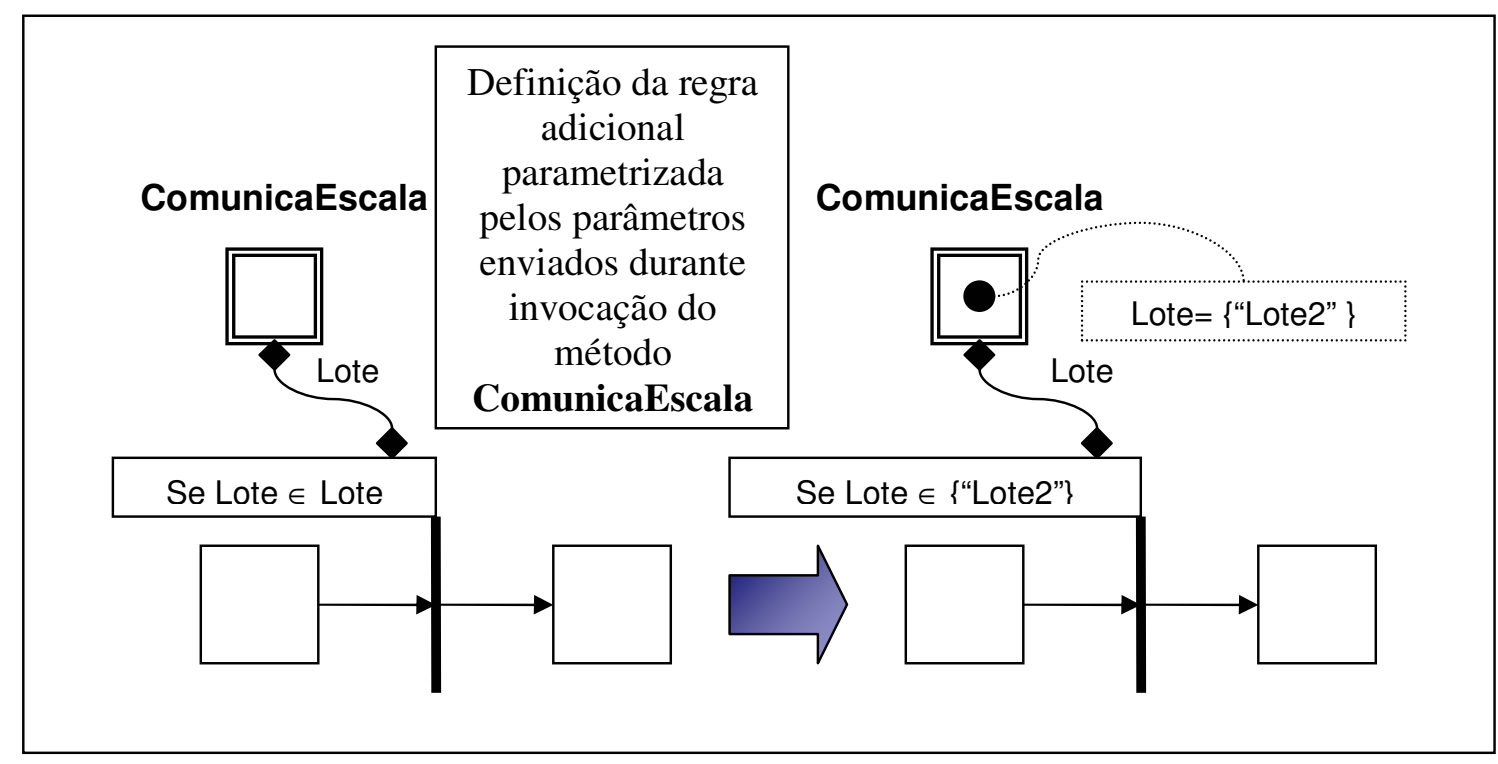

Figura 6.6. Interface de recepção para parametrização de regra adicional

Após a habilitação de uma transição, esta é colocada em prontidão apenas se a regra de transição inscrita (definida pelo processo de substituição de variáveis originais da regra pelos parâmetros da mensagem, conforme exemplo da figura 6.6) for atendida em função dos atributos da marca, como indica a figura 6.7 (nesta figura, a regra de transição parametrizada utiliza o atributo 'Lote' da marca). Uma observação importante: enquanto o método da interface de recepção para parametrização de regra adicional não é invocado, variáveis da respectiva regra de transição são consideradas nulas. 


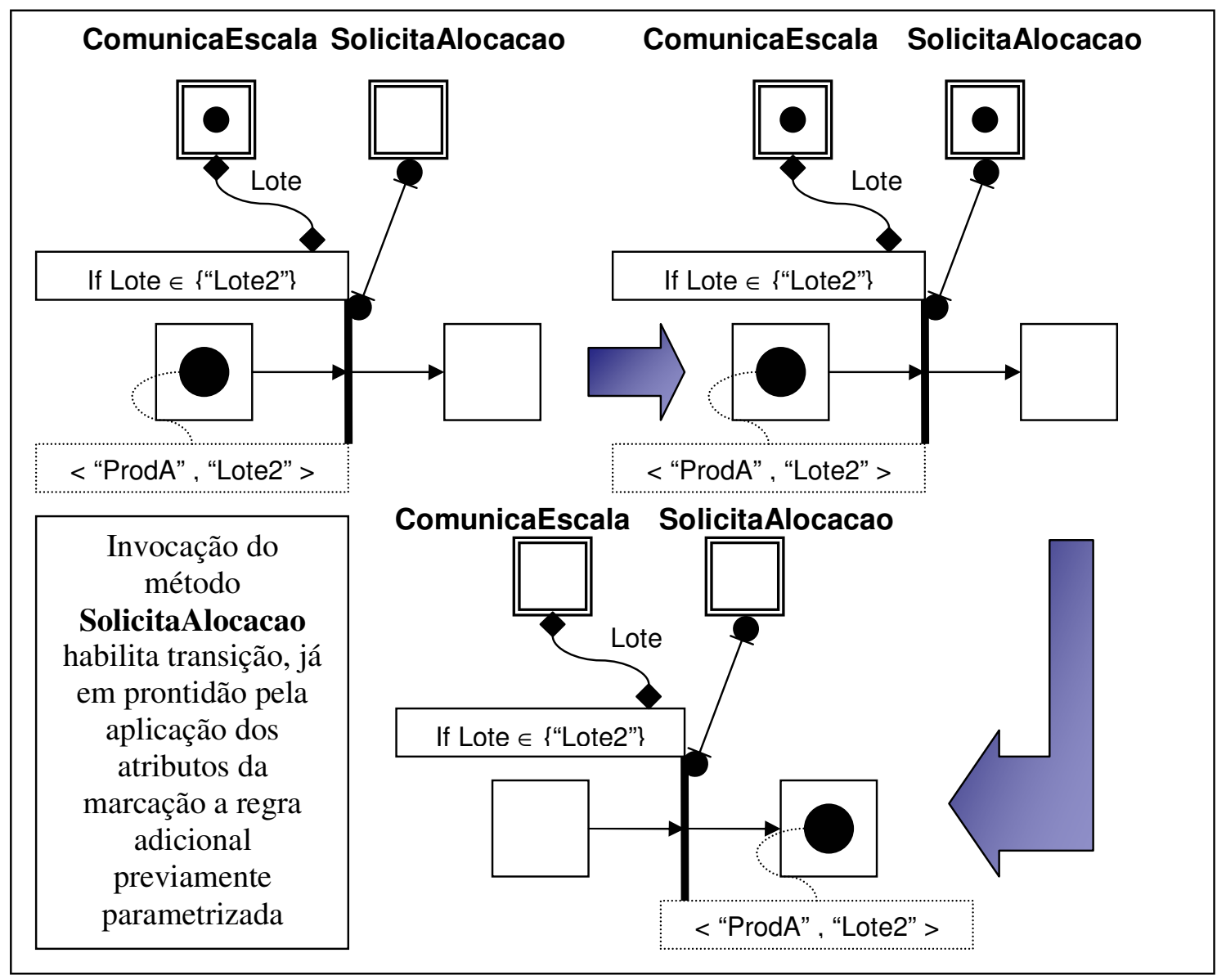

Figura 6.7. Disparo da transição condicionada à regra adicional parametrizada por interface de recepção para parametrização de regra adicional

\subsubsection{Sistemática da conversão do Caso de uso para um E-MFG com comunicadores}

A sequiência das ações de um caso de uso configura o estabelecimento de pré-condições para cada ação. A condição para que uma ação possa ser realizada é de que a prévia já o tenha sido.

Por outro lado, a pós-condição de uma ação é de permitir a realização da próxima ação. Assim, a pré-condição de uma ação do caso de uso é a pós-condição da anterior. Esta situação é designada por elementos sintáticos adequados do E-MFG com comunicadores em que eventos e as respectivas condições são suas principais interpretações. 
Capítulo 6 - Especificação das Partições do SCSP Modeladas por E-MFG com Comunicadores 127

O princípio da conversão do caso de uso para o E-MFG é o estabelecimento de uma relação unívoca entre a ação do caso de uso e um elemento sintático adequado do E-MFG. Descreveremos a sistemática de conversão através da seqüência de passos:

- escolha da classe a ser modelada (escopo) dentre os casos de uso do modelo,

- para cada caso de uso, conversão do fluxo de eventos básico pela análise da seqüência de ações deste fluxo,

- conversão fluxo de eventos alternativos, integrando-o ao fluxo de eventos básicos e

- definição dos atributos de marcas do modelo E-MFG com comunicadores convertido.

Ao longo deste tópico desenvolveremos o algoritmo de conversão completo do caso de uso em E-MFG com comunicadores, empregando abordagem top-down e refinamento sucessivo. Para permitir a conexão entre os diversos trechos do algoritmo, identificamos os trechos com um nome e colocamos em parênteses, ao lado, o número da figura onde é detalhado.

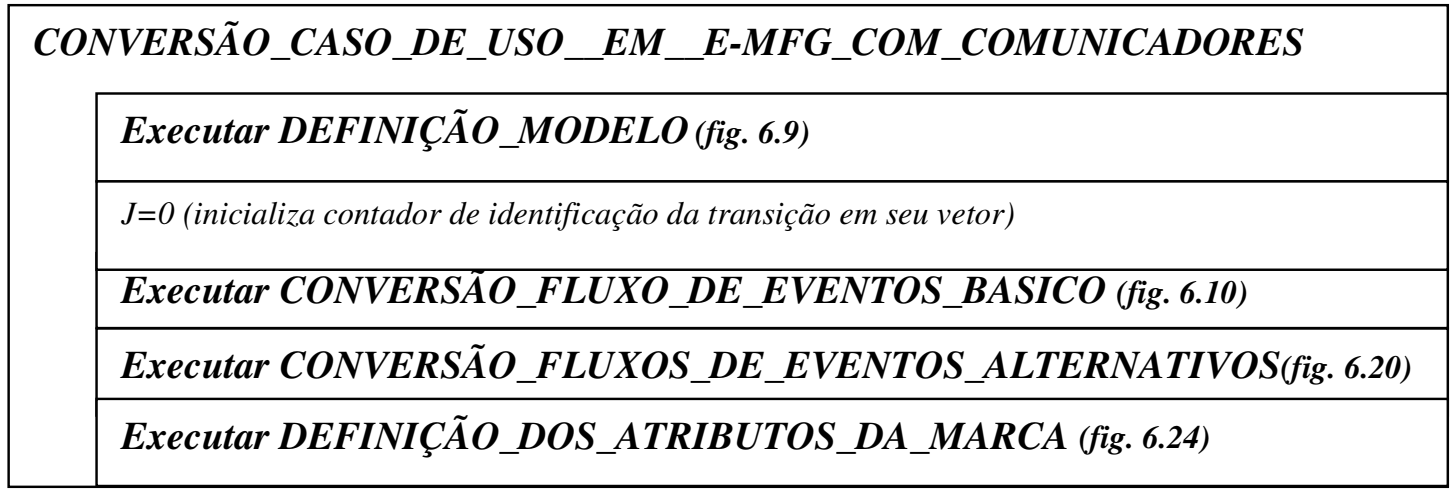

Figura 6.8. Algoritmo completo de conversão do caso de uso em E-MFG com comunicadores

\subsubsection{Definição da Classe Modelada (Escopo da Modelagem)}

O primeiro passo da conversão do caso de uso para modelo E-MFG é a definição da classe do SCSP a ser modelada, cujo nome consta na tabela de classes do SCSP. 
Capítulo 6 - Especificação das Partições do SCSP Modeladas por E-MFG com Comunicadores 128

Uma vez definido o escopo da modelagem, excluiremos as ações do caso de uso que representam apenas conhecimentos do domínio. Estas ações são identificadas como aquelas que não se referem à classe modelada (nestas não encontramos a classe modelada na primeira e na segunda parte da ação, referindo-se a ação apenas ao ambiente ou outras classes do SCSP). Excluímos também as ações onde a classe modelada está presente nas duas posições da ação, ou não existe a terceira parte da ação, situações em que a ação representa requisito elaborado com base na implementação, conforme visto. Este algoritmo de definição do escopo e exclusão de ações não relevantes para a modelagem está na figura 6.9.

\section{DEFINIÇÃO_MODELO}

Atribuir à Classe_Modelada a Classe do SCSP a modelar

Excluir toda Ação do Fluxo_Básico do Caso_de_uso e de todos Fluxos_Alternativo onde

Parte1 da Ação \# Classe_Modelada e Parte3 \# Classe_Modelada ou

Parte1 da Ação = Classe_Modelada e Parte3 = Classe_Modelada ou

Parte1 da Ação = Classe_Modelada e Parte3 = null

Figura 6.9. Algoritmo de definição do escopo de modelagem

Vejamos a aplicação da exclusão de ações de um trecho de um caso de uso:

1. CNT_REC_TRANSF LiberaUsoRecurso $a$ CNT_REC_TRANSF

2. CNT_PROC.RECX SolicitaAlocacao $a$ CNT_REC_TRANSF

3. CNT_REC_TRANSF LiberaAlocacao $a$ CNT_PROC.RECX

\section{CNT_PROC.RECX Alimenta $a$ CNT_PROC.RECX}

Suponhamos que a classe modelada é o controlador de recurso de transformação. Teremos, portanto, aplicando o algoritmo, a 'Classe_Modelada' como: CNT_REC_TRANSF.

Ações excluídas: 
Capítulo 6 - Especificação das Partições do SCSP Modeladas por E-MFG com Comunicadores 129

- Ação 1 (motivo: Parte1 da ação = Classe_Modelada e Parte3 da ação = ClasseModelada)

- Ação 4 (motivo: Parte1 da ação \# Classe_Modelada e Parte3 da ação \# ClasseModelada)

A conversão será posteriormente realizada apenas sobre as ações restantes (inicialmente, eram as ações '2' e '3'):

\section{CNT_PROC.RECX SolicitaAlocacao $a$ CNT_REC_TRANSF}

\section{CNT_REC_TRANSF LiberaAlocacao $a$ CNT_PROC.RECX}

\subsubsection{Conversão das Ações do Fluxo de Eventos Básico}

A sistemática proposta converte o fluxo de eventos básico analisando a sequiência das ações e, em paralelo, sintetizando o E-MFG com comunicadores empregando cada elemento sintático identificado na análise. Consideraremos apenas as ações do caso de uso não excluídas após a definição da classe modelada (conforme 6.3.2.1). Algoritmo de conversão da sequiência de ações de um fluxo de eventos básico está na figura 6.10 .

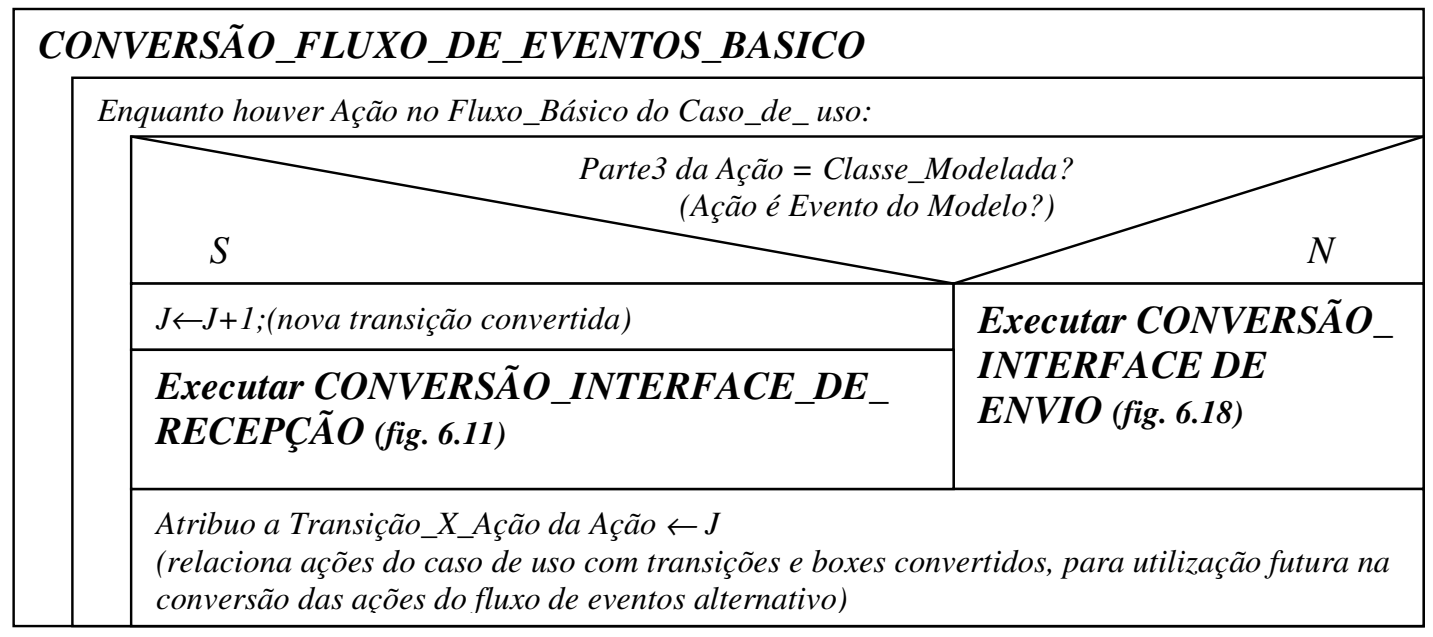

Figura 6.10. Algoritmo de conversão para seqüência de ações do fluxo de eventos básico 
Capítulo 6 - Especificação das Partições do SCSP Modeladas por E-MFG com Comunicadores 130

Para exemplificar este trecho do algoritmo, iremos aplicá-lo as duas ações restantes do caso de uso em utilização. Conforme o algoritmo, iremos examinar seqüencialmente cada ação do fluxo de eventos básico.

Para a primeira ação 'CNT_PROC.RECX SolicitaAlocacao a CNT_REC_TRANSF', teremos:

Questão: Parte3 da Ação '1' = CNT_REC_TRANSF (Classe_Modelada)?

$\underline{\text { Resposta: }}$ Sim $\rightarrow$ A ação será convertida em interface de recepção, seguindo detalhamento do algoritmo específico posterior (CONVERSÃO_INTERFACE_DE_RECEPCẼ̃O). Um contador ' $\mathrm{J}$ ' é utilizado para registrar qual ação do caso de uso foi convertida em qual transição, permitindo posteriormente conexão com a conversão de fluxos de eventos alternativos, como veremos.

Para a segunda ação 'CNT_REC_TRANSF LiberaAlocaçao $a$ CNT_PROC.RECX', teremos:

Questão: Parte3 da Ação '1' = CNT_REC_TRANSF (Classe_Modelada)?

$\underline{\text { Resposta: }}$ Não $\rightarrow$ A ação será convertida em interface de envio, seguindo detalhamento do algoritmo específico posterior (CONVERSÃO_ INTERFACE DE ENVIO).

Seguindo na definição do algoritmo, com base no paradigma da orientação a objeto, uma ação implicará sempre na alteração do estado do objeto que recebe a solicitação, já que na modelagem E-MFG com comunicadores só existem métodos de comando. Em um E-MFG com comunicadores, tal semântica é designada por uma transição para representar a ação como evento, a qual é habilitada através da interface de recepção. A interface de recepção 
Capítulo 6 - Especificação das Partições do SCSP Modeladas por E-MFG com Comunicadores 131

define o método invocado externamente identificando-o em conformidade da segunda parte da ação (predicado).

Discutiremos a conversão das ações de um caso de uso para a modelagem EMFG com comunicadores para duas situações: na primeira, a classe modelada é invocada; na segunda, a classe modelada invoca outra.

Para a primeira situação, a conversão desta ação resulta em transição e uma respectiva interface de recepção. Tais ações possuem em sua terceira parte (classe invocada) a classe modelada. Para realizar a conversão, necessitamos detalhar a conversão da interface de recepção e conectá-la ao modelo. Na figura 6.11 encontra-se este algoritmo de conversão.

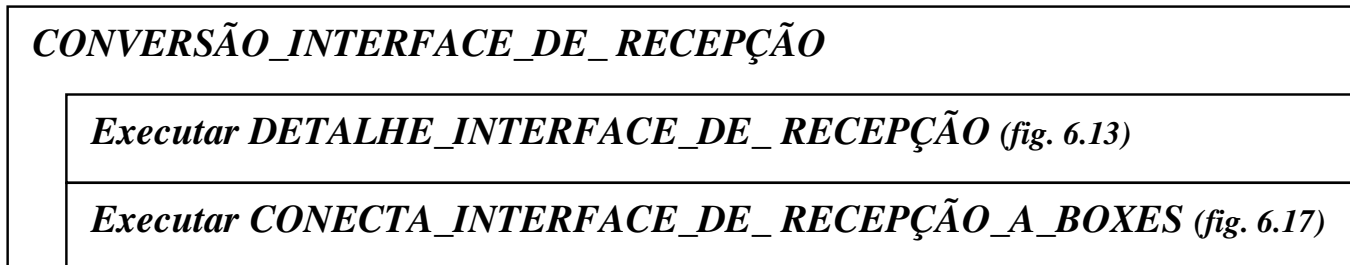

Figura 6.11. Algoritmo de conversão de interface de recepção

Detalhamos a conversão da ação identificando nesta todos tipos de interface representados e que tomarão parte da transição resultante. Para tal, identificamos a ocorrência na ação do caso de uso das partes que podem ser convertidas em elementos sintáticos correspondentes a cada um dos quatro tipos de interface de recepção. Concentraremos-nos apenas na quarta (mensagem), quinta (condição), sexta (direcionamento) e sétima (box de controle modificado) partes da ação, pois as primeiras três não estão envolvidas nesta definição.

Todo outro tipo de interface de recepção inclui em sua sintaxe todos elementos sintáticos da interface de recepção de habilitação incondicional, o que implica que toda conversão em interface de recepção inclui todos elementos sintáticos de uma interface de recepção de 
habilitação incondicional (figura 6.12, à esquerda, acima). Desta forma, quando identificada como interface de recepção, qualquer ação será convertida, no mínimo, no conjunto comum de elementos sintáticos da interface de recepção de habilitação incondicional,(transição, método, box e arco de envio).

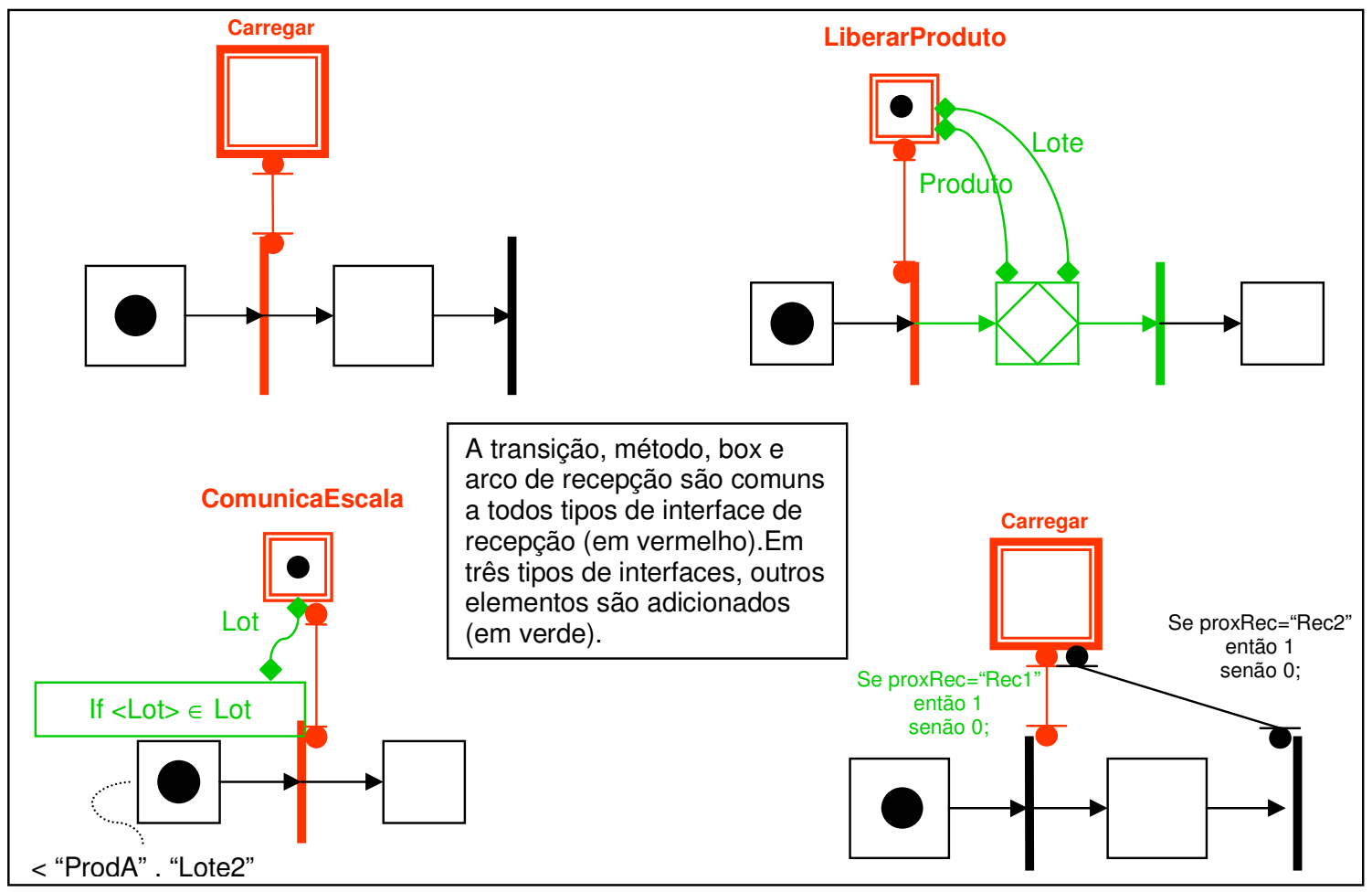

Figura 6.12. Elementos sintáticos comuns a todos tipos de interface de recepção

Complementando a conversão em interface de recepção, necessitamos reconhecer a ocorrência na ação de cada um dos outros três tipos de interface. Utilizamos como regras para o reconhecimento:

- das interfaces de recepção para habilitação associada à informação: a localização, na quarta parte da ação, da presença de informações de atribuição dos parâmetros de mensagem aos atributos de marcação, reconhecidas pelo emprego dos caracteres ' $<$ ' e '>' antecedendo e sucedendo o parâmetro da mensagem, 
Capítulo 6 - Especificação das Partições do SCSP Modeladas por E-MFG com Comunicadores 133

- das interfaces de recepção para parametrização de regra adicional: presença da quinta parte da ação (condição da ação), localizada pela palavra 'se' antecedente. A quinta parte define regra de restrição adicional que emprega atributos da marca (obrigatórios) e parâmetros da mensagem (opcionais, e reconhecidos por serem representados entre os caracteres '<" e '> ) ou constantes em sua definição e

- das interfaces de habilitação condicionada a mensagem: presença da sexta parte da ação (direcionamento da habilitação), localizada pela palavra 'para' antecedente. A sexta parte define regra que modifica o peso do arco de recepção conforme os parâmetros da mensagem (reconhecidos por serem apresentados entre os caracteres '<' e '>'), nunca empregando atributos da marca.

Em adição à conversão em interface de recepção de envio, falta-nos apenas considerar os eventos da classe modelada em que, condicionada a sua ocorrência, é imposta regra de produção fixa sobre os valores dos atributos da marca. No E-MFG com comunicadores, a sintaxe equivalente é a do box controlador.

A presença da sétima parte permite obter as informações para a conversão em box controlador. Para identificar a sétima parte, localizamos a expressão precedente 'de forma que'. A sétima parte representa, integralmente, a regra de produção fixa. A regra de produção é representada por uma condição expressa através de expressão lógica, a qual sempre utilizará ou constantes (representadas por cadeias de caracteres entre aspas duplas, ou constantes numéricas) e atributos de marcas, nunca empregando parâmetros da mensagem (estes últimos identificados entre os caracteres ' $<$ ' e '>').

Como exemplo, convertemos a ação seguinte em interface de recepção (estaremos realizando a modelagem da classe CNT_REC_TRANSF). 
Capítulo 6 - Especificação das Partições do SCSP Modeladas por E-MFG com Comunicadores 134

Ação: 'CNT_PROC SolicitaAlocacao $a$ CNT_REC_TRANSF com Lote, Prod, <Oper>,

PlanEST3 se Prod= "ELE_B" e Oper= "B2", para Lote $\in$ PlanEST_3, de forma que

Destino="EST_3" 。

Nesta ação, identificamos as seguintes partes:

- parte 1: CNT_PROC (em negrito, classe que invoca, externa e não representada no modelo),

- parte 2: SolicitaAlocacao (método),

- parte 3: CNT_REC_TRANSF (em negrito, classe modelada),

- parte 4: Lote, Prod, <Oper>, PlanEST3 (parâmetros enviados com a invocação, reconhecidos pela palavra precedente 'com'),

- parte 5: Prod= "ELE_B" e Oper= "B2” (regra adicional da transição, reconhecidos pela palavra precedente ' $s e$ '),

- parte 6: Lote $\in<$ PlanEST_3> (regra adicional da transição parametrizada, reconhecidos pela palavra precedente 'para') e

- parte 7: Destino= "EST_3" (regra de produção do box controlador, reconhecido pela palavra precedente 'de forma que').

Para a construção completa da interface de recepção de envio empregamos sempre os elementos sintáticos de uma interface de recepção de habilitação incondicional adicionada a todos outros elementos sintáticos convertidos dentre os três tipos de interface de recepção reconhecidos. O algoritmo referente à conversão em interface de recepção está na figura 6.13. 
Capítulo 6 - Especificação das Partições do SCSP Modeladas por E-MFG com Comunicadores 135

\begin{tabular}{|c|c|}
\hline \multicolumn{2}{|l|}{ DETALHE_INTERFACE_RECEPÇÃO } \\
\hline \multicolumn{2}{|l|}{$\begin{array}{l}\text { Adicionar Transição }[J] \text { com: } \\
\text { Nome_Metodo da Interface_Recepção } \leftarrow \text { Parte } 2 \text { da Ação }\end{array}$} \\
\hline Existe Parte4 da Aç & ? \\
\hline $\begin{array}{l}\text { Parâmetros da Interface_Recepção } \leftarrow \text { Parâmetros da } \\
\text { Parte4 da Ação entre }<<e^{\prime}>{ }^{\prime} \\
\text { Tipo_Interface_Associada_Informaçao } \leftarrow \text { Sim }\end{array}$ & - \\
\hline Existe Parte5 da Açc & $?$ \\
\hline $\begin{array}{l}\text { Regra_Adicional da Interface_recepção } \leftarrow \text { Parte } 5 \text { da } \\
\text { Ação } \\
\text { Tipo_Interface_recepçao_regraadic } \leftarrow \text { Sim }\end{array}$ & - \\
\hline Existe Parte6 da A & $\tilde{a} o$ \\
\hline $\begin{array}{l}\text { Regra_Peso_ArcoHab da Interface_recepção } \leftarrow \\
\text { Parte6 da Ação } \\
\text { Tipo_Interface_recepção_Habil_direcionada } \leftarrow \text { Sim }\end{array}$ & - \\
\hline
\end{tabular}

Figura 6.13. Algoritmo de conversão para detalhamento da interface de recepção

Aplicando este algoritmo à ação mencionada no exemplo precedente, realizamos a conversão conforme a figura 6.14. Nesta figura, o modelo resultante da conversão é representado em linhas e símbolos pretos. Todo o restante, em coloração vermelha, são notações auxiliares à figura para explanação da conversão. Identificamos na figura duas etapas. $\mathrm{Na}$ primeira, convertemos a ação nos elementos sintáticos comuns a todas interfaces de recepção (na figura 6.14, à esquerda). Na segunda etapa, localizamos a quarta, quinta e sexta partes da ação, e convertemos estas nos elementos sintáticos adequados a cada tipo de interface de recepção identificado sobre os mesmos elementos convertidos na primeira etapa (na figura 6.14, à direita). 


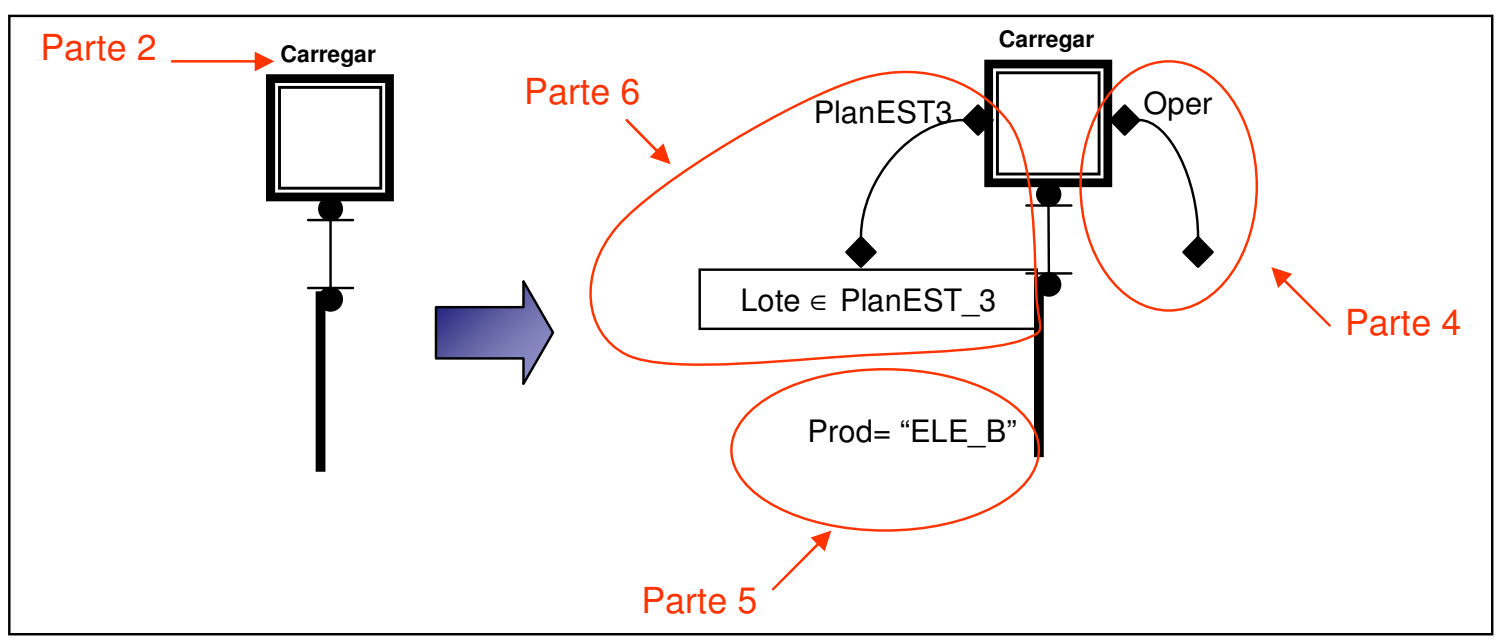

Figura 6.14. Conversão da ação exemplificada em interface de recepção

A conversão de uma ação em uma interface de recepção é complementada pela definição das sintaxes que expressam sua seqüência à ação prévia, assim como sua precedência à ação seguinte do caso de uso. Consideraremos que toda transição do E-MFG é a designação de um evento, o qual é sucedido por uma pós-condição (exceto o finalizador, que não a possui) e precedido por uma pré-condição (exceto a transição inicial, que não a possui).

Para realizar a sintaxe da pré-condição, inserimos um arco box-transição originado no box anterior convertido e direcionado a transição. Para a pós-condição, inserimos um arco transição-box originado na transição convertida e direcionado a um novo box, também adicionado, que designará a pós-condição. A figura 6.15 exemplifica esta conversão. Na figura, os elementos sintáticos adicionados mencionados neste parágrafo são representados em símbolos e linhas pretas. Em linhas e símbolos vermelhos, os elementos sintáticos anteriormente já convertidos. Em verde estão as anotações auxiliares. 


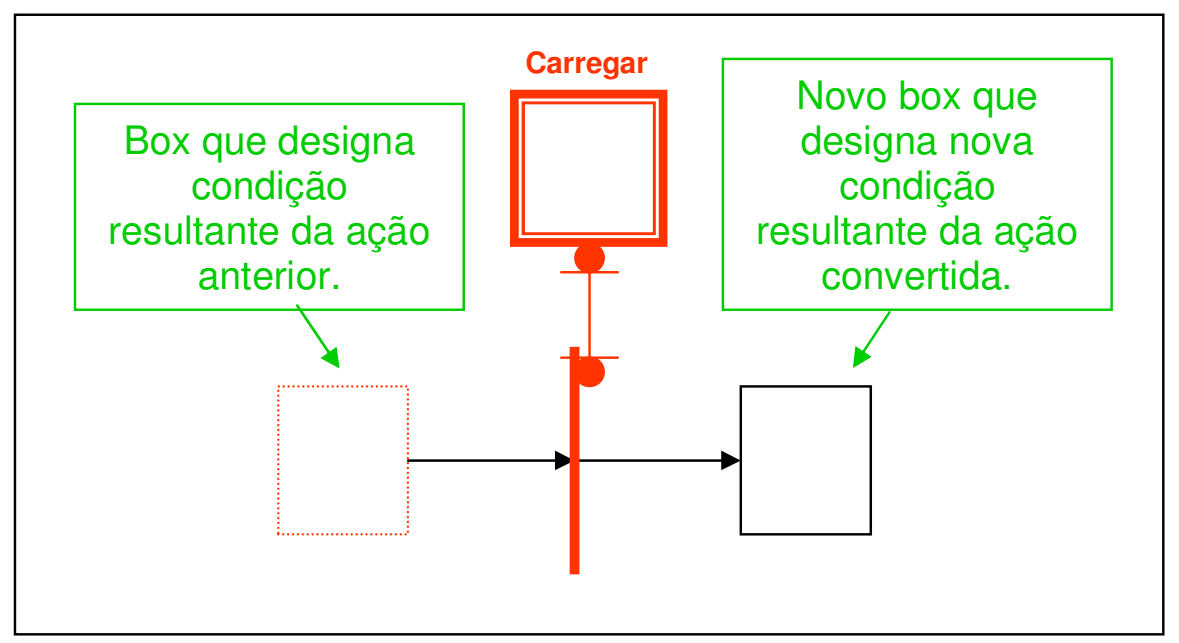

Figura 6.15. Conexão de uma interface de recepção à pré e à pós-condição

Além da conexão da transição da interface de recepção, necessitamos complementar a conversão da ação em interface de envio com as informações relativas as quarta e sétima partes, que identificam elementos sintáticos relativos a um box controlador. A quarta parta define um mapeamento dos parâmetros de mensagem para atributos da marcação, enquanto a sétima parte define a regra de produção aplicada ao box. O algoritmo que conecta a interface de envio ao modelo convertido até então está na figura 6.17, enquanto seu esquema está na figura 6.16 .

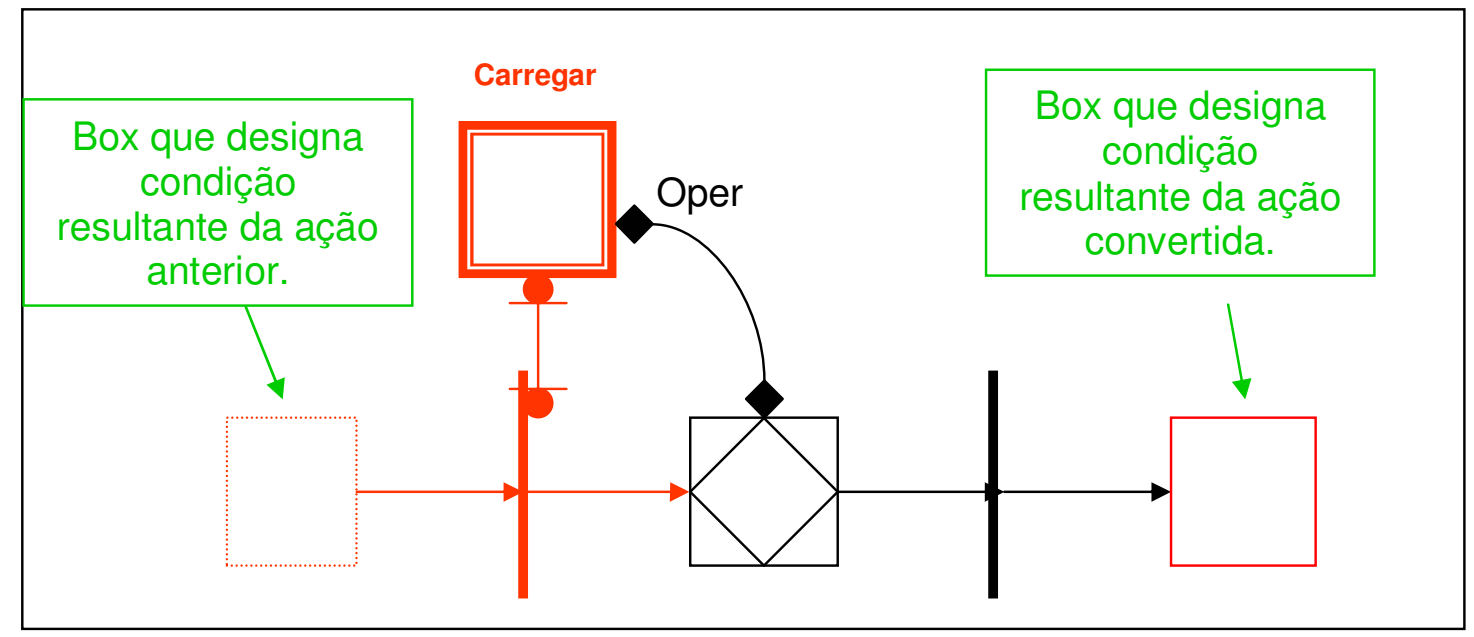

Figura 6.16. Complementação da conexão da interface de recepção com box controlador 
Capítulo 6 - Especificação das Partições do SCSP Modeladas por E-MFG com Comunicadores 138

Na figura 6.16, colocamos em vermelho a modelagem antes da complementação da conversão com a definição do box controlador. Em verde, as anotações auxiliares. Em preto, elementos sintáticos adicionados. Desta forma, se a quarta parte da ação de uma interface de recepção contiver parâmetros a serem atribuídos a marcação (indicados entre os caracteres '< e '> na quarta parte), ou se localizarmos a sétima parte (regra de produção), necessitamos adicionar um box controlador a interface, o que implica na inserção entre a transição referente a interface de recepção e a pós-condição de todos os elementos sintáticos do box controlador:

- box controlador,

- arco box-transição, conectando box controlador à transição,

- transição do box controlador e

- $\operatorname{arco}$ transição-box, conectando transição do box controlador à pós-condição.

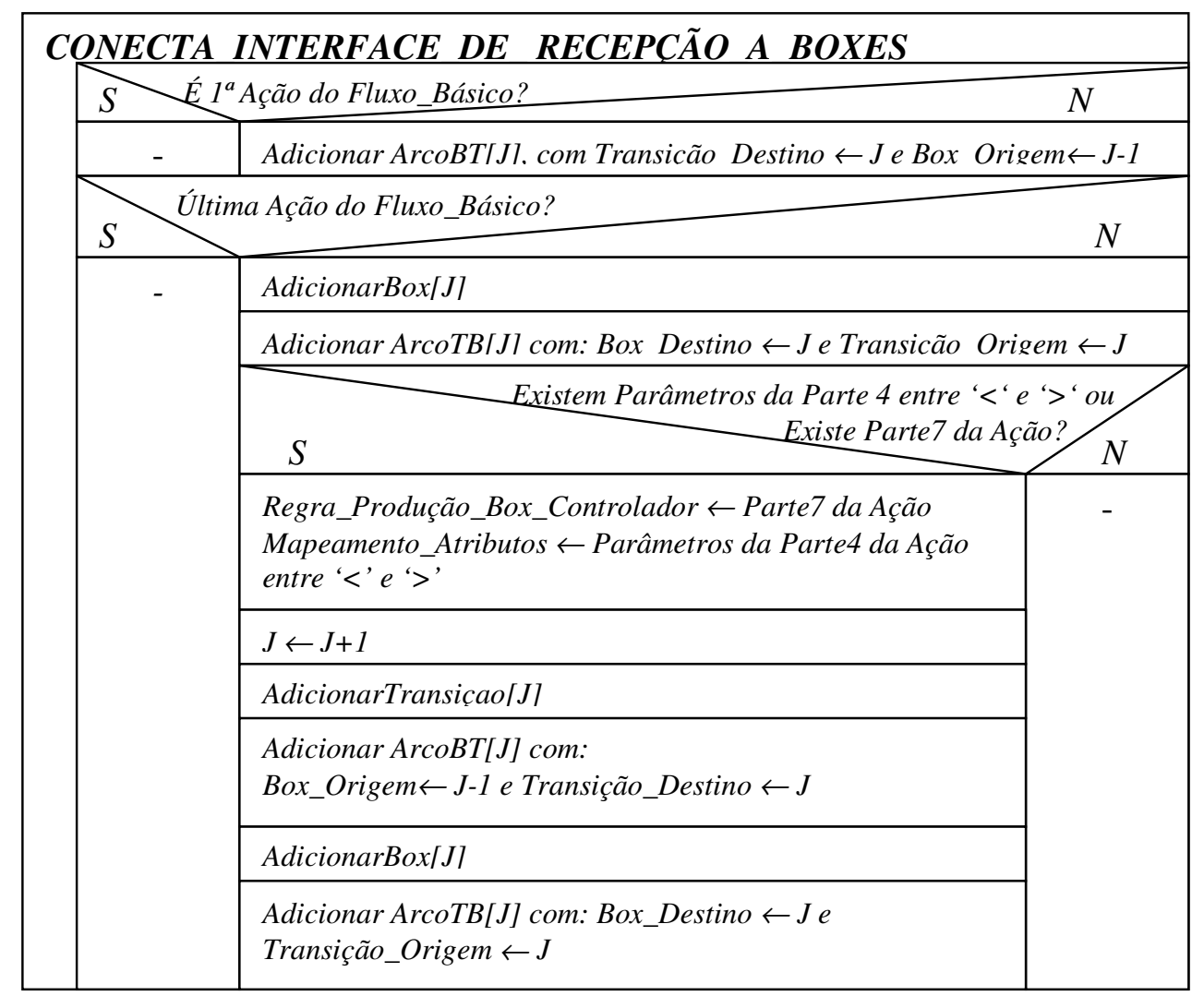

Figura 6.17. Algoritmo de conversão para conexão da interface de recepção a boxes 
Capítulo 6 - Especificação das Partições do SCSP Modeladas por E-MFG com Comunicadores 139

Para a segunda situação de conversão, a classe modelada solicita a outra classe, estando posicionada na primeira parte da ação (sujeito). Também baseado no paradigma da orientação a objeto, esta ação implica na alteração da condição da outra classe, e não da modelada. A solicitação é realizada pela chamada de método da outra classe. Em um E-MFG com comunicadores, tal semântica é designada por interface de envio que realiza chamada do método da outra classe. O método solicitado pela classe modelada é identificado pela classe que recebe a solicitação (terceira parte da ação) e pelo método (segunda parte da ação). Não há alteração da condição da classe modelada, e assim utiliza-se mesma pós-condição da ação anterior (box convertido). Algoritmo de conversão na figura 6.18 .

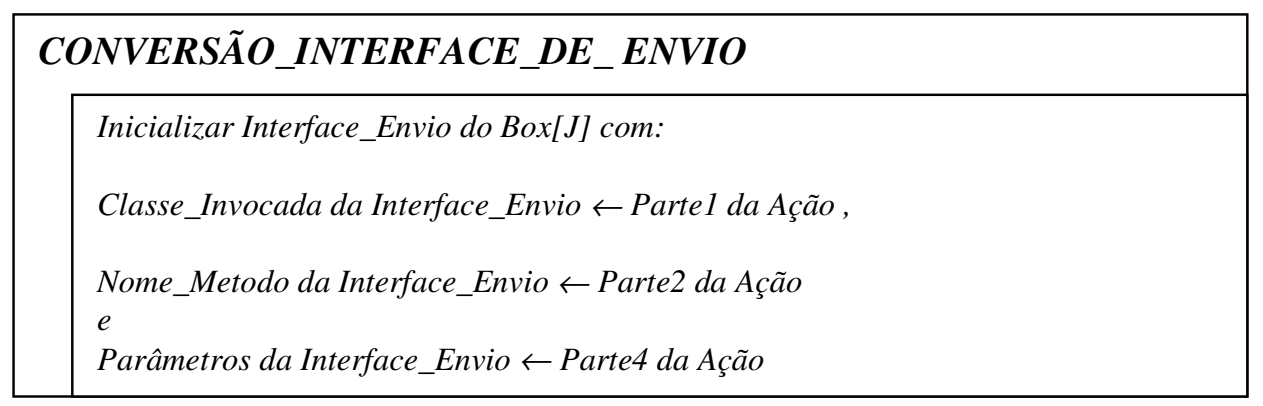

Figura 6.18. Algoritmo de conversão para interface de envio

Exemplifiquemos a conversão. Supondo a ação 'CNT_REC_TRANSF Requisita $a$ CNT_REQUISICAO Lote' (para a modelagem do classe CNT_REC_TRANSF), teremos uma conversão em interface de envio (classe modelada na primeira parte, invocando outra). Seguem a identificação das partes e o modelo convertido (figura 6.19):

- parte 1: CNT_REC_TRANSF (em negrito, classe modelada invocando),

- parte 2: Requisita (método),

- parte 3: CNT_REQUISICAO (em negrito, classe externa invocada) e 
- parte 4: Lote (parâmetros enviados com a invocação).

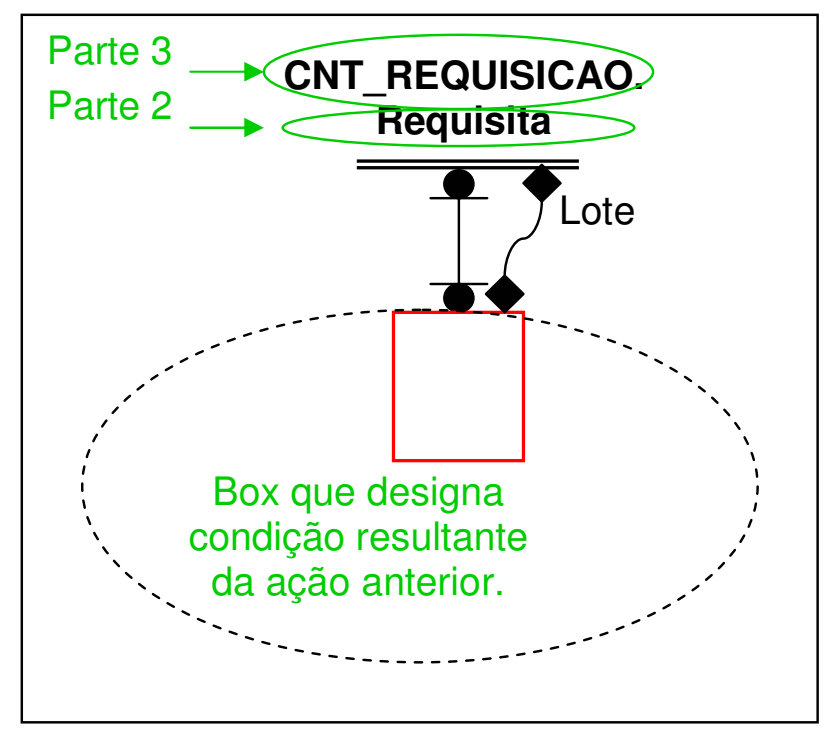

Figura 6.19. Exemplo de conversão para interface de envio

\subsubsection{Conversão das Ações do Fluxo de Eventos Alternativo}

Cada fluxo de eventos alternativo define o intervalo substituído de ações do fluxo básico. O processo de conversão do caso de uso aplicado ao fluxo de eventos alternativo é a mesmo utilizado para o fluxo de eventos básico, e é aplicada a todos fluxos de eventos alternativos.

É necessário, no entanto, procedimento adicional específico para converter sua relação com o fluxo de eventos principal. A conversão da interface de recepção para fluxo de eventos alternativos é alterada, pois a primeira e última ações são eventos relacionados com o fluxo de eventos principal. Desta forma, o algoritmo de conversão das ações do fluxo de eventos alternativo é modificado para o fluxo de eventos alternativos. O algoritmo está na figura 6.20, e é o mesmo do algoritmo da figura 6.10, exceto para a execução do algoritmo 'CONVERSÃO_INTERFACE_DE_RECEPÇÃO_FLUXO_ALTERNATIVO', que substitui 'CONVERSÃO_INTERFACE_DE_RECEPÇÃO'. 


\begin{tabular}{|c|c|}
\hline \multicolumn{2}{|c|}{ CONVERSÃO_FLUXOS_DE_EVENTOS_ALTERNATIVOS } \\
\hline \multicolumn{2}{|l|}{ Enquanto houver Fluxo_Alternativo para o Caso_de_uso: } \\
\hline \multicolumn{2}{|l|}{ Enquanto houver Ação no Fluxo_Alternativo do Caso_de_uso: } \\
\hline \multicolumn{2}{|c|}{$\begin{array}{r}\text { Parte3 da Ação = Instancia_Modelada? } \\
\text { (Ação é Evento do Modelo?) }\end{array}$} \\
\hline$J \leftarrow J+1 ;($ nova transição convertida $)$ & Executar \\
\hline $\begin{array}{l}\text { Executar CONVERSÃO_INTERFACE_DE_ } \\
\text { RECEPÇÃO_FLUXO_ALTERNATIVO (fig. 6.21) }\end{array}$ & $\begin{array}{l}\text { CONVERSAO } \\
\text { INTERFACE DE } \\
\text { ENVIO (fig. 6.18) }\end{array}$ \\
\hline
\end{tabular}

Figura 6.20. Algoritmo de conversão aplicado aos fluxos de eventos alternativos

Detalharemos então a modificação da conversão para interface de recepção. Como mencionamos, a alteração da conversão é necessária para converter a sua relação com o fluxo de eventos básico. Analisando o algoritmo empregado para conversão em interface de recepção na figura 6.11, verificamos que a alteração a ser efetuada incide sobre a parte final do algoritmo, onde os eventos dos casos de usos são ligados a suas pré e pós-condições. O algoritmo alterado é ilustrado na figura 6.21, onde o último passo dos dois passos do algoritmo original é alterado: substituímos a execução de 'CONECTA_INTERFACE_DE RECEPÇÃ O_A_BOXES' pela execução de 'CONECTA_INTERFACE_DE_ RECEPÇÃO_A_BOXES_FLUXO_ALT'.

CONVERSÃO_INTERFACE_DE_RECEPÇ̃̃O_FLUXO_ALTERNATIVO

Executar DETALHE_INTERFACE_DE_RECEPCẼO (fig. 6.13)

Executar CONECTA_INTERFACE_DE_RECEPCÃOA_A_BOXES_FLUXO_ALT (fig. 6.23)

Figura 6.21. Algoritmo de conversão de interface de recepção para fluxos de eventos alternativos 
Capítulo 6 - Especificação das Partições do SCSP Modeladas por E-MFG com Comunicadores 142

Analisaremos agora a alteração neste algoritmo. Um fluxo de eventos alternativo, da mesma forma que um fluxo de eventos básico, é iniciado e finalizado sempre por eventos, assim como a sequiência do fluxo de eventos básico substituído.

Para definir a conversão aplicada ao início e ao fim dos fluxos de eventos alternativos, iremos abordar duas situações: a relação entre a ação que inicia o fluxo de eventos alternativo e a ação que inicia o trecho substituído do fluxo de eventos principal, e uma segunda situação similar relacionada com a finalização do fluxo de eventos alternativo.

Para converter a relação entre as ações iniciais, consideramos que tanto o evento inicial do fluxo de eventos alternativos, como o evento substituído do fluxo de eventos básico são posteriores a uma mesma ação do fluxo de eventos básico. A pós-condição desta ação precedente comum é a mesma pré-condição para os dois eventos iniciais, tanto para o evento do trecho substituído do fluxo básico como para o evento do fluxo alternativo.

Tal fato é designado no E-MFG com comunicadores através de um box comum (interpretado como pré-condição dos dois eventos) do qual partem dois arcos, um conectado à transição referente à primeira ação do intervalo substituído do fluxo de eventos básico, e outro conectado à transição referente à primeira ação do fluxo de eventos alternativo. Desta forma, a sistemática de conversão utiliza o box posterior à transição anterior comum como a précondição. A figura 6.22 ilustra esta conversão.

Na conversão da a relação entre as ações finais do fluxo de eventos alternativo e do trecho substituído do fluxo básico de eventos, a ação comum de reinício no fluxo de eventos básico é um evento da classe modelada. A pré-condição deste evento é compartilhada como póscondição tanto pelo evento final do fluxo de eventos alternativo como pelo evento final da seqüência de ações substituída do fluxo de eventos básico. 


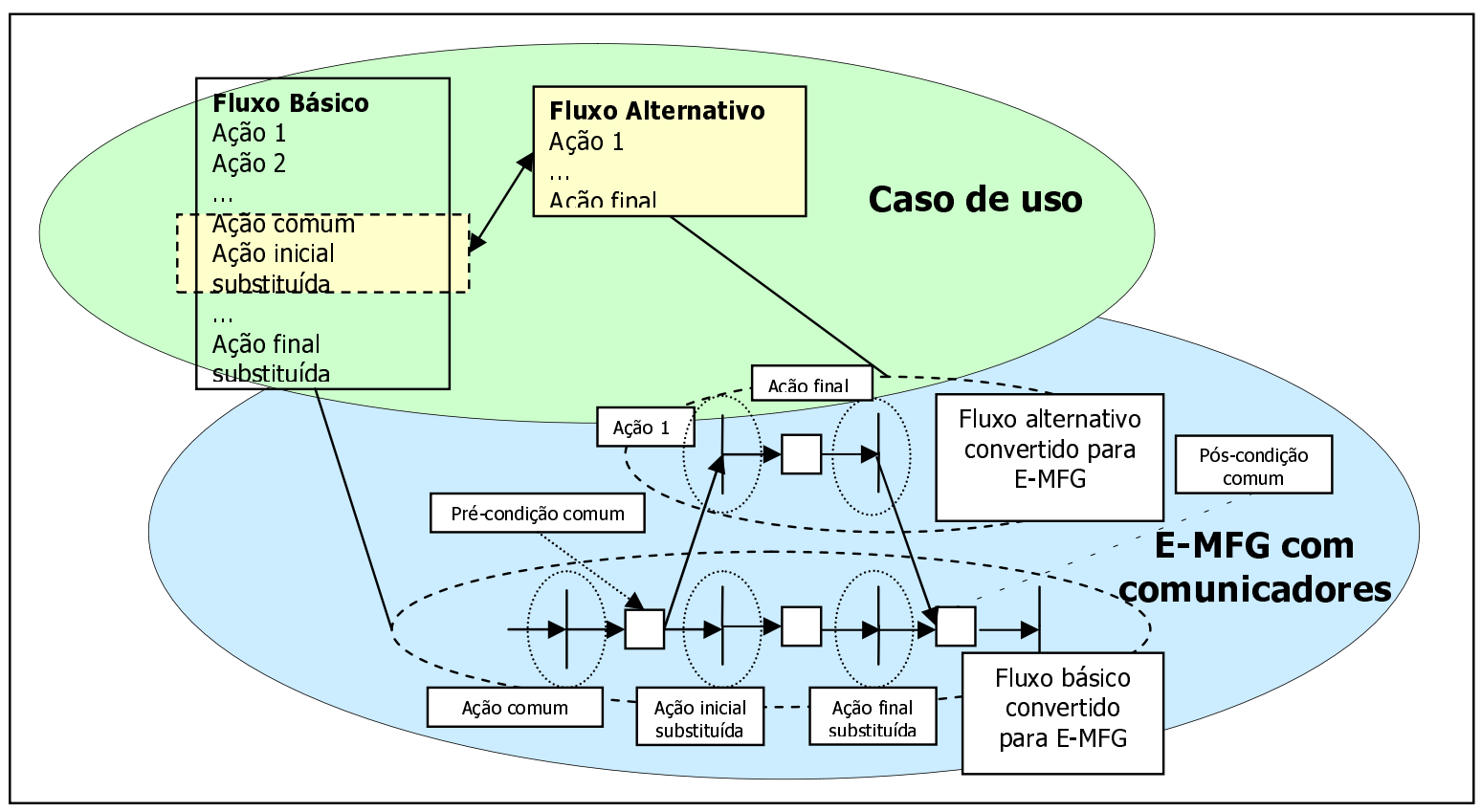

Figura 6.22. Representação do algoritmo de conversão aplicado ao início de fluxo de eventos alternativos

Para representar adequadamente este fato no E-MFG resultante da conversão, localizamos o box interpretado como pré-condição única da transição comum. É deste box que se origina um arco destinado à transição onde o fluxo de eventos básico é reassumido (e portanto o box é anterior a transição comum). Esta pré-condição da transição comum é assumida como póscondição dos dois fluxos (fluxo de eventos alternativo e pela sequiência de ações do fluxo de eventos básico substituída).

A figura 6.23 ilustra o algoritmo resultante. O algoritmo é a reprodução do algoritmo utilizado na conversão para conexão da interface de recepção a boxes (figura 6.17), alterado nos passos em resposta às perguntas:

- 'É a primeira ação do fluxo de eventos alternativo?' e

- 'É a última ação do fluxo de eventos alternativo?'. 
Capítulo 6 - Especificação das Partições do SCSP Modeladas por E-MFG com Comunicadores 144

No algoritmo original, nenhum passo era tomado para respostas positivas a estas questões, pois no fluxo de eventos básico não existem pré-condições para o evento inicial e póscondição para o evento final. $\mathrm{O}$ algoritmo alterado resolve estas questões com passos adicionais necessários para que o evento inicial do fluxo alternativo tenha a adequada précondição no fluxo de eventos básico, da mesma forma que passos adicionais são realizados para que o evento final do fluxo alternativo tenha a adequada pós-condição no fluxo de eventos básico ou que este seja finalizador.

Quando a ação final do fluxo de eventos alternativo é finalizadora não ocorre seu retorno ao fluxo de eventos básico. Partindo da premissa de que a ação final do fluxo também é um evento, sua transição designada no E-MFG com comunicadores modelado é finalizadora. Esta situação também é ilustrada no algoritmo da figura 6.21, com a inserção de um último passo questionando se a ação do fluxo de eventos é finalizadora, com sua resposta positiva não sendo desdobrada em nenhum passo adicional.

Após a conversão completa das ações do fluxo de eventos básico e dos fluxos de eventos alternativos, o último passo é a definição dos atributos de marcas da modelagem E-MFG proposta. O registro dos atributos das marcas é obtido pela relação não repetitiva formada pela reunião de todas informações de atribuição recebidas pelas interfaces de recepção convertidas (o algoritmo é descrito pela figura 6.24).

\subsection{FuSÃO DE LUGARES NO E-MFG COM COMUNICADORES}

Necessitamos um passo adicional na geração do E-MFG com comunicadores para todas as situações em que as mesmas condições estejam definidas para uma partição do SCSP. O conjunto de casos de uso que definem o sequenciamento completo do processo de produção para cada lote de produto para o controle de recursos de transformação é um exemplo da aplicação da fusão de lugares no E-MFG com comunicadores. 
Capítulo 6 - Especificação das Partições do SCSP Modeladas por E-MFG com Comunicadores 145

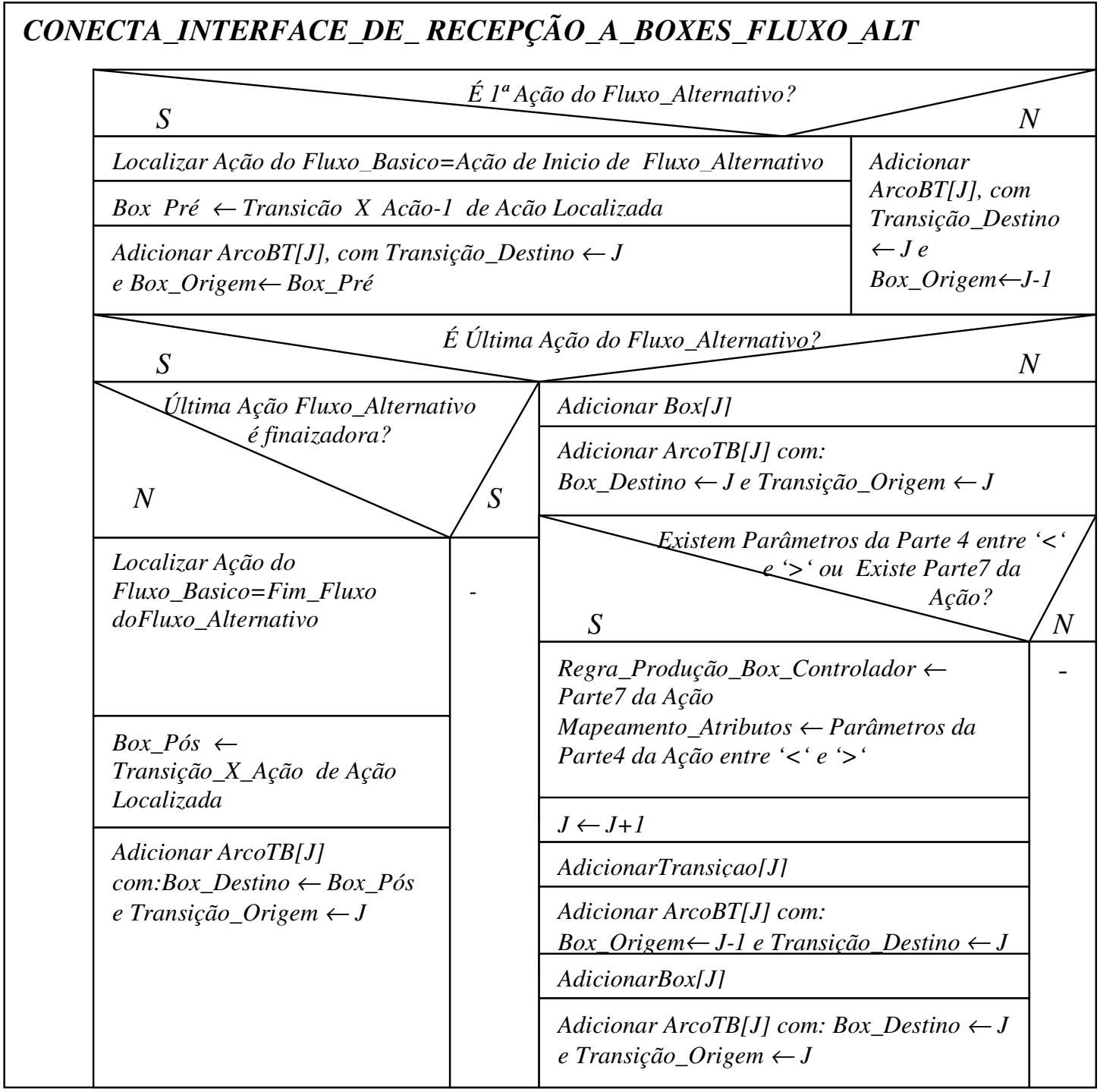

Figura 6.23. Conversão para conexão da interface de recepção a boxes em fluxos alternativos

\section{DEFINICÃO DOS ATRIBUTOS DA MARCA}

Enquanto houver Transição no Modelo:

Enquanto houver Parâmetros na Interface_Recepção da Transição:

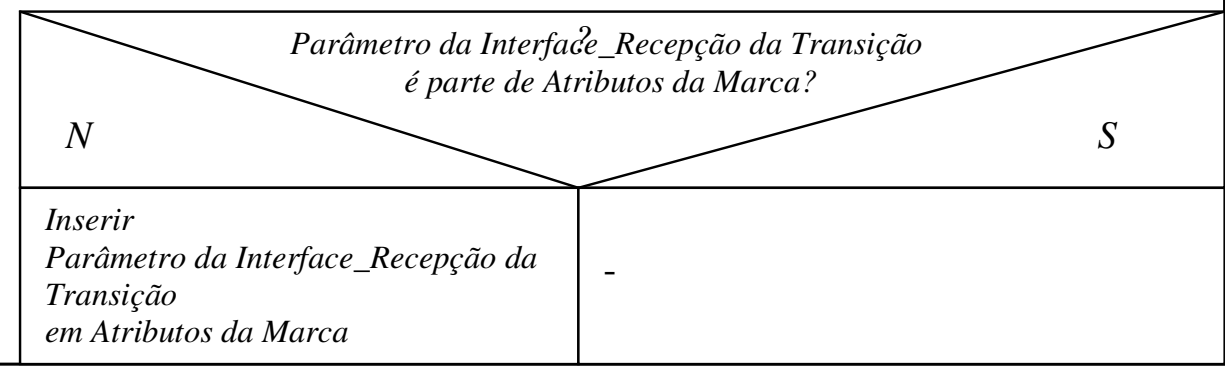

Figura 6.24. Algoritmo de definição dos atributos de marca 
Para o conjunto de todos E-MFG gerados, um para cada lote de produto, que descrevem a seqüência de ações do controle de recursos para realizar o processo produtivo, temos que:

- a classe do SCSP modelada é a mesma,

- a lista de atributos das marcas dos modelos é a mesma e

- os casos de uso distintos possuem algumas condições com semânticas idênticas (por exemplo, mesmo recurso produtivo alocado, com exclusividade).

Tal situação permite a aplicação da técnica de fusão de lugares (SANTOS FILHO, 2000), ou a equivalente conjunção das especificações (LIGHTFOOT, 2001); (DUKE; ROSE, 2000), obtendo apenas um modelo E-MFG com comunicadores em substituição aos diversos conjuntos de E-MFG com comunicadores individuais gerados a partir de cada caso de uso relativo a um lote de produto específico.

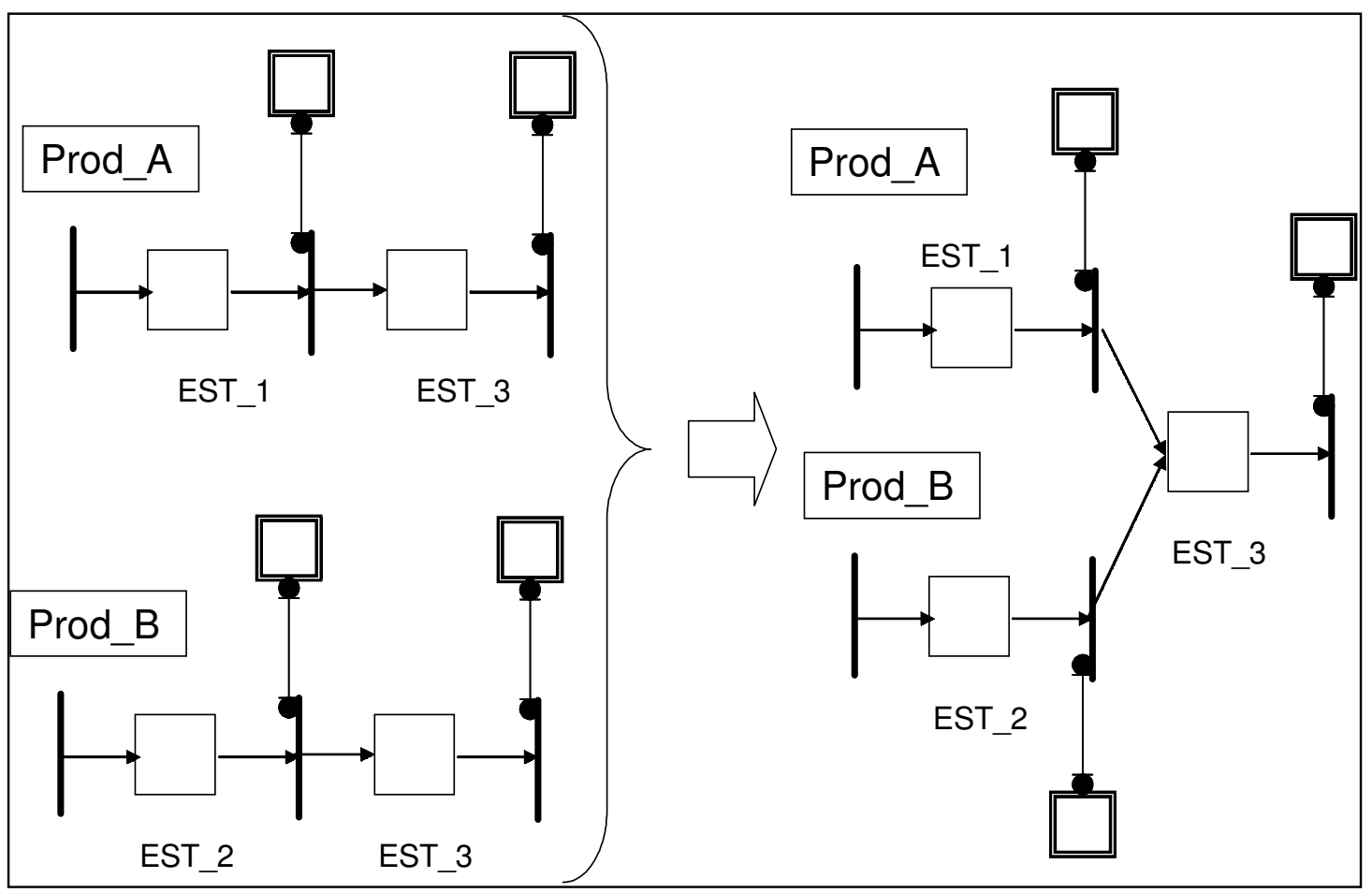

Figura 6.25. Exemplo de aplicação da técnica da fusão de lugares 
Obedecendo a estas restrições, a aplicação da fusão de lugares a todas as condições pertencentes a distintos modelos da classe do SCSP que possuírem semântica idêntica resulta na síntese de todos em uma única condição.

Como exemplo da aplicação da técnica de fusão de lugares, suponhamos um sistema produtivo com dois produtos, realizados através de duas sequiências de processos envolvendo apenas dois recursos de transformação cada, o último comum às duas seqüências de processo (figura 6.25). Através dos respectivos casos de uso, obtemos dois modelos E-MFG com comunicadores para o controle de recursos de transformação de cada produto (figura 6.25, à esquerda). Ao analisar as condições de cada modelo, verificamos que as condições das últimas operações nas duas seqüências de processos são as mesmas, pois:

- a classe do SCSP modelada é a mesma (controle de recursos de transformação),

- lista de atributos das marcas dos modelos é a mesma e

- as duas condições finais obtidas com base nos dois casos de uso possuem semânticas idênticas (memo recurso 'EST_3' de transformação alocado).

Nestas condições, podemos fundir as duas condições em apenas uma, conforme ilustrado pela figura 6.25 à direita. 


\section{Capítulo 7}

SISTEMÁTICA DE

\section{MODELAGEM DE SCSP}

Este capítulo define a sistemática de modelagem de um SCSP. Em sua primeira parte, iniciaremos pela definição do escopo da aplicação, que se encerra ao definir as partições semânticas do modelo de SCSP e respectivas linguagens de especificação. Na segunda parte, definiremos a sistemática de modelagem para as partições que podem ser expressas através da utilização do E-MFG com comunicadores, para a qual empregaremos uma abordagem algorítmica.

\subsection{DEFINIÇÃO DO ESCOPO DO SCSP}

A definição do escopo do SCSP é realizada através dos passos descritos a seguir.

\subsubsection{Passo 1}

Tarefa: descrição do ambiente externo ao SCSP e sua terminologia (modelagem do domínio semântico do sistema produtivo).

Saídas: tabela de classes do ambiente (relação de sistemas previamente existentes que realizam funcionalidades do segundo e terceiro níveis da hierarquia funcional ANSI/ISA S95 parte 3 .

Conteúdo da tabela de classes do ambiente:

- nome do sistema externo (se não existir previamente, recebe nomeação), 
- nível hieráquico funcional conforme ANSI/ISA S95 parte 3 (entre 2 a 4),

- informações de funcionalidades realizadas:

Para nível 3:

○ modelo de gestão operacional ao qual pertence,

- modelo de atividade ao qual pertence,

- tarefas realizadas dentro do modelo de atividade ao qual pertence,

- operação que realiza, eventualmente detalhando tarefas definidas acima (todas informações em conformidade com ANSI/ISA S95, parte 3)

Para nível 4

- modelo de função que desempenha conforme parte 1 da ANSI/ISA S95 (figura 5.1).

\subsubsection{Passo 2}

Tarefa: determinação da linguagem de especificação adequada à semântica da integração do SCSP ao ambiente,

Saídas: definição da linguagem UML (“Unified Modeling Language”).

\subsubsection{Passo 3}

Tarefa: definição do escopo de atividades do SCSP aderente às necessidades especificadas do SP, 
Saída: relação das funcionalidades do SCSP aderente ao modelo ANSI/ISA S95 parte 3, formada por:

- relação obrigatória de modelos operacionais de gestão adotados, onde:

○ é obrigatório: produção. Se o SCSP atuar sobre recursos de transporte, também é obrigatório inventário. São opcionais: manutenção e testes de qualidade,

- relação obrigatória de atividades dentro dos modelos operacionais de gestão adotados, onde:

○ são obrigatórios no modelo operacional de gestão da produção: despacho produtivo, coleta de dados produtivos e gestão da execução da produção. Todas outras atividades do modelo ANSI/ISA S95 para este modelo operacional de gestão da produção são opcionais,

- são obrigatórios, se modelo operacional de gestão do inventário adotado: despacho do transporte de inventário, coleta de dados de transporte e gestão da execução do transporte de inventário. Todas outras atividades do modelo ANSI/ISA S95 para este modelo operacional de gestão do inventário são opcionais,

- são obrigatórios, se modelo operacional de gestão da manutenção adotado: despacho da manutenção, coleta de dados da manutenção e gestão da execução da manutenção. Todas outras atividades do modelo ANSI/ISA S95 para este

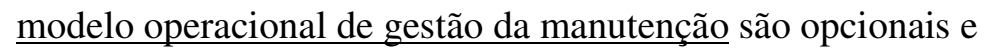

○ são obrigatórios, se modelo operacional de gestão de testes da qualidade adotado, são obrigatórios: despacho de testes da qualidade, coleta de dados de 
testes da qualidade e gestão da execução da qualidade. Todas outras atividades do modelo ANSI/ISA S95 para este modelo operacional de gestão dos testes da qualidade são opcionais.

- Relação opcional de tarefas dentro dos atividades dos modelos operacionais de gestão adotados, conforme texto da ANSI/ISA S95 parte 3, utilizada para auxiliar no detalhamento do escopo do SCSP.

\subsubsection{Passo 4}

Tarefa: descrição das partições homomórficas do SCSP definidas no domínio semântico interno deste.

Saída: tabela de partições do SCSP, identificadas e descritas em sua funcionalidade. A relação parte da seguinte lista inicial, levando em conta considerações relativas à obrigatoriedade:

- controle de processo local (obrigatório),

- controle de recursos de transformação (incluída se SCSP realizar a alocação de recursos de transformação),

- controle de designação de recursos de transporte (incluída se SCSP controla recursos de transporte e realiza a alocação de recursos de transporte),

- controle de transporte local (obrigatório se SCSP controla recursos de transporte) e

- controle do fluxo entre unidades produtivas (incluída em função da organização do sistema produtivo por unidades com transporte auxiliar, envolvendo compartilhamento de vias). 
Outras partições homomórficas do SCSP podem ser incluídas, conforme a abstração necessária para a modelagem demandar outras linguagens de especificação diversas das utilizadas nas partições do SCSPs da relação inicial deste passo.

\subsubsection{Passo 5}

Tarefa: definição das linguagens de especificação adequadas a cada partição do SCSP

Saída: linguagens de especificação para cada partição do SCSP. Para a relação inicial de partições do SCSP do quarto passo, temos:

- para a classe de controle de processo local : E-MFG com comunicadores,

- para a classe do controle de recursos de transformação: E-MFG com comunicadores construído com auxílio da técnica de fusão de lugares,

- para a classe do controle de designação de recursos de transporte: UML, aplicada a algoritmos do problema de designação,

- para a classe de controle de transporte local : E-MFG com comunicadores e

- para a classe do controle de fluxo entre UP: E-MFG com comunicadores, também construído com auxílio da técnica de fusão de lugares.

\subsubsection{Passo 6}

Tarefa: especificação de cada partição do SCSP, incluindo integração destas ao ambiente e ao SCSP, utilizando a linguagem de especificação definida previamente.

Saídas:

- modelos de caso de uso (UML) representando os casos de uso de cada partição. 
- $\quad$ modelos de cada partição expresso pelas linguagens de especificação.

\subsection{EspecificaÇão das Partições Expressas Por E-MFG COM}

\section{COMUNICADORES}

A especificação das partições do SCSP expressa por E-MFG com comunicadores é efetuada em dois passos, que se seguem.

\subsubsection{Primeiro Passo da Especificação: Casos de Uso Restritos}

Tarefa: elaboração dos casos de uso restritos aplicáveis à partição do SCSP modelada.

Entrada: Tabela de classes do ambiente, Tabela de partições do SCSP.

Saída: Casos de uso aplicáveis à partição do SCSP modelado.

\subsubsection{Estrutura do Caso de Uso Restrito}

Cada ação do caso de uso corresponde a um evento do SP, e é definida através de uma oração completa. A ação é constituída por sete partes, dispostas na ação na ordem indicada abaixo:

- parte 1 (obrigatória): classe que efetua solicitação,

- parte 2 (obrigatória): solicitação da classe da parte 1,

- parte 3 (obrigatória): classe solicitada,

- parte 4 (opcional): lista de parâmetros da mensagem da solicitação,

- parte 5 (opcional): precedida pela palavra 'se', expressa condição para a ação realizar em função do lote produtivo. 
- parte 6 (opcional): precedida pela palavra 'para', expressa condição para realização da ação em função dos parâmetros da mensagem.

- parte 7 (opcional): precedida pela expressão 'de forma que', expressa imposição de informações relativas ao lote produtivo.

\subsubsection{Restrições às Partes do Caso de Uso}

São as seguintes as restrições aplicadas às partes do caso de uso:

- em cada ação, sempre a parte 1 e a parte 3 são necessariamente distintas, e pertencem obrigatoriamente a uma das duas tabelas (tabela de partições do SCSP e tabela de classes do ambiente). Quando se referem a uma instância particular entre múltiplas, recebem um ponto ao final e um pós-fixo genérico para definir que se trata de uma instância,

- a parte 2 é constituída apenas por um identificador, formado opcionalmente por um conjunto de palavras ligadas entre si pelo símbolo ‘_,

- lista de parâmetros da parte 4 é definida pela seqüência dos parâmetros, separados por vírgulas. Adicionalmente, todo parâmetro utilizado na informação de atributos a marca é delimitado pelos caracteres ' $<$ ' e '>',

- a condição expressa após a palavra 'se' na parte 5 emprega lógica discreta, utilizando obrigatoriamente atributos da marca, opcionalmente parâmetros da mensagem (reconhecidos por serem representados entre os caracteres ' $<$ ' e ' $>$ ') ou constantes em sua definição, 
- a condição para realização da ação da parte 6 após a palavra 'para' também emprega lógica discreta, em função dos parâmetros da mensagem (reconhecidos por serem apresentados entre os caracteres ' $<$ ' e ' $>$ '), nunca empregando atributos da marca e

- as imposições de informações relativas ao lote produtivo da parte 7 após a expressão 'de forma que' são definidas atribuições de informações aos lotes produtivos, através de constantes numéricas ou cadeias de caracteres, impostos aos atributos das marcas.

\subsubsection{Segundo Passo da Especificação: Conversão para E-MFG com Comunicadores}

Tarefa: conversão dos casos de uso restritos aplicáveis à partição do SCSP modelada em modelos E-MFG com comunicadores da partição do SCSP.

Entrada: Casos de uso aplicáveis à partição do SCSP modelado.

Saída: Modelos E-MFG com comunicadores da partição do SCSP.

Técnica: Primeiro passo é o algoritmo de conversão definido nas figuras 7.1, 7.2, 7.3 e 7.4. Definimos as estruturas de dados empregadas pelo algoritmo nas figuras 7.5 para o caso de uso elaborada em linguagem de programação C, e de 7.6 a 7.10 para o E-MFG com comunicadores, elaborada em PNML ("Petri-Net Modeling Language”) (WEBER; KINDLER, 2002). 


\begin{tabular}{|c|c|c|}
\hline \multicolumn{3}{|c|}{ CONVERSÃO_CASO_DE_USO_EM_E-MFG_COM_COMUNICADORES } \\
\hline \multicolumn{3}{|c|}{ Atribuir a Instancia_Modelada a Instancia do SCSP a modelar } \\
\hline & \multicolumn{2}{|c|}{$\begin{array}{l}\text { Excluir toda Ação do Fluxo_Básico do Caso_de_uso e de todos } \\
\text { Fluxos_Alternativo onde } \\
\text { Parte1 da Ação \# Instancia_Modelada e Parte3 \# Instancia_Modelada ou } \\
\text { Partel da Ação = Instancia_Modelada e Parte3 = Instancia_Modelada ou } \\
\text { Parte1 da Ação = Instancia_Modelada e Parte3 = null }\end{array}$} \\
\hline & \multicolumn{2}{|c|}{$J=0$ (inicializa contador de identificação da transição em seu vetor $)$} \\
\hline & \multicolumn{2}{|c|}{ Executar CONVERSÃO_FLUXO_DE_EVENTOS_BASICO } \\
\hline & \multicolumn{2}{|c|}{ ExecutarCONVERSÃO_FLUXOS_DE_EVENTOS_ALTERNATIVOS } \\
\hline & \multicolumn{2}{|l|}{ Enquanto houver Transição no Modelo: } \\
\hline \multicolumn{3}{|c|}{ Enquanto houver Parâmetros na Interface_Recepção da Transição: } \\
\hline & $N=$ Parâmetro da Interf & $\begin{array}{l}\text { _Recepção da Transição } \\
\text { butos da Marca? }\end{array}$ \\
\hline & $\begin{array}{l}\text { Inserir } \\
\text { Parâmetro da Interface_Recepção da } \\
\text { Transição } \\
\text { em Atributos da Marca }\end{array}$ & \\
\hline
\end{tabular}

Figura 7.1. Algoritmo de conversão do caso de uso restrito em E-MFG com comunicadores 


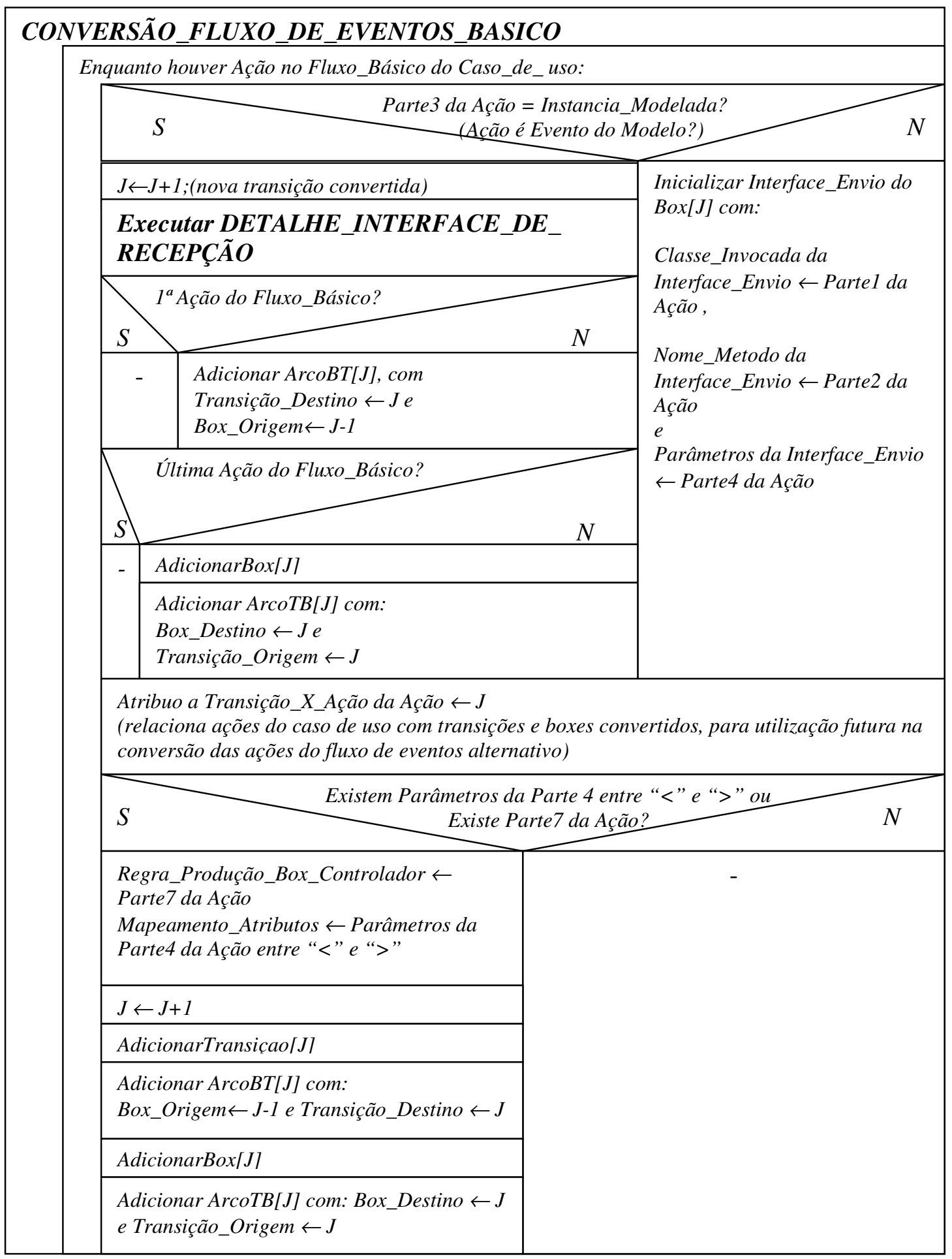

Figura 7.2. Algoritmo de conversão do caso de uso restrito em E-MFG com comunicadores (continuação: conversão do fluxo básico de eventos) 


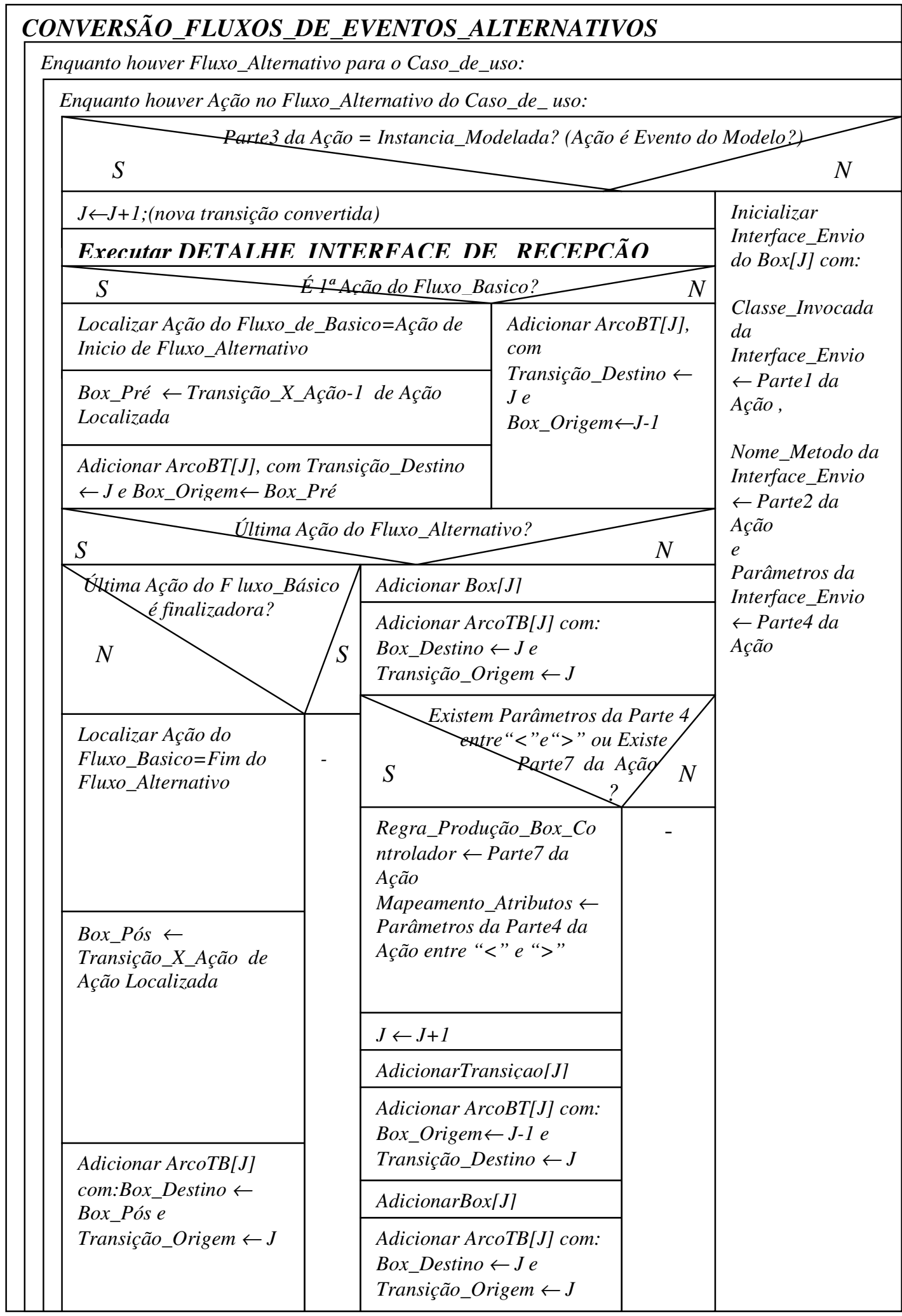

Figura 7.3. Algoritmo de conversão do caso de uso restrito em E-MFG com comunicadores (continuação: conversão dos fluxos de eventos alternativos) 


\begin{tabular}{|c|c|}
\hline \multicolumn{2}{|l|}{ DETALHE_INTERFACE_RECEPÇÃO } \\
\hline \multicolumn{2}{|l|}{$\begin{array}{l}\text { Adicionar Transição }[\mathrm{J}] \text { com: } \\
\text { Nome_Metodo da Interface_Recepção } \leftarrow \text { Parte } 2 \text { da Ação }\end{array}$} \\
\hline$S \quad$ Existe Parte4 da Açc & $?$ \\
\hline $\begin{array}{l}\text { Parâmetros da Interface_Recepção } \leftarrow \text { Parâmetros da } \\
\text { Parte4 da Ação entre '<'e '>> } \\
\text { Tipo_Interface_Associada_Informação } \leftarrow \text { Sim }\end{array}$ & - \\
\hline Existe Parte5 da Açc̀ & $?$ \\
\hline $\begin{array}{l}\text { Regra_Adicional da Interface_recepção } \leftarrow \text { Parte } 5 \text { da } \\
\text { Ação } \\
\text { Tipo_Interface_recepção_regraadic } \leftarrow \text { Sim }\end{array}$ & - \\
\hline Existe Parte6 da As & $o ?$ \\
\hline $\begin{array}{l}\text { Regra_Peso_ArcoHab da Interface_recepção } \leftarrow \\
\text { Parteб da Ação } \\
\text { Tipo_Interface_recepção_Habil_direcionada } \leftarrow \text { Sim }\end{array}$ & - \\
\hline
\end{tabular}

Figura 7.4. Algoritmo de conversão do caso de uso restrito em E-MFG com comunicadores (continuação: detalhe da conversão para interface de recepção) 


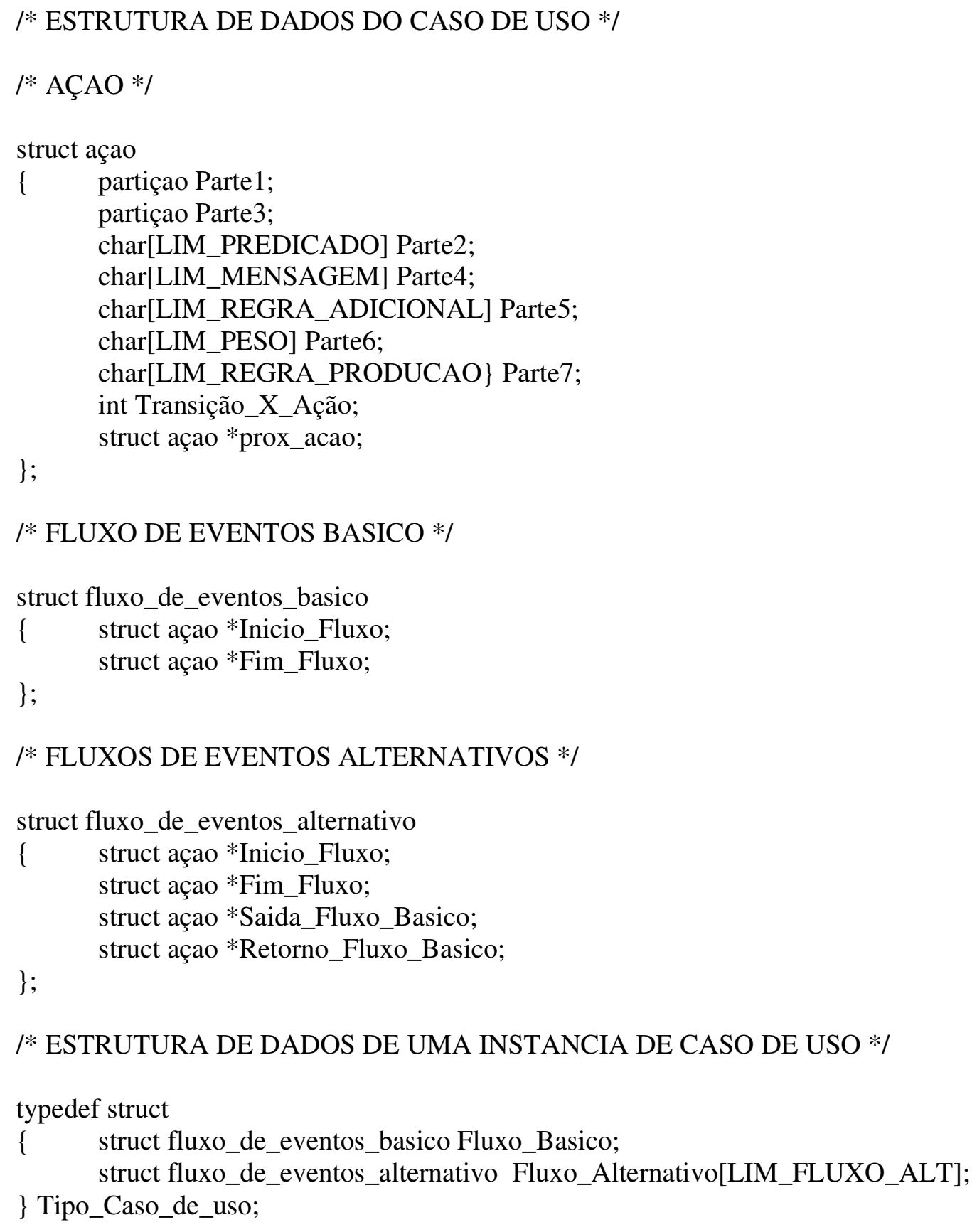

Figura 7.5. Estrutura de dados do caso de uso restrito 


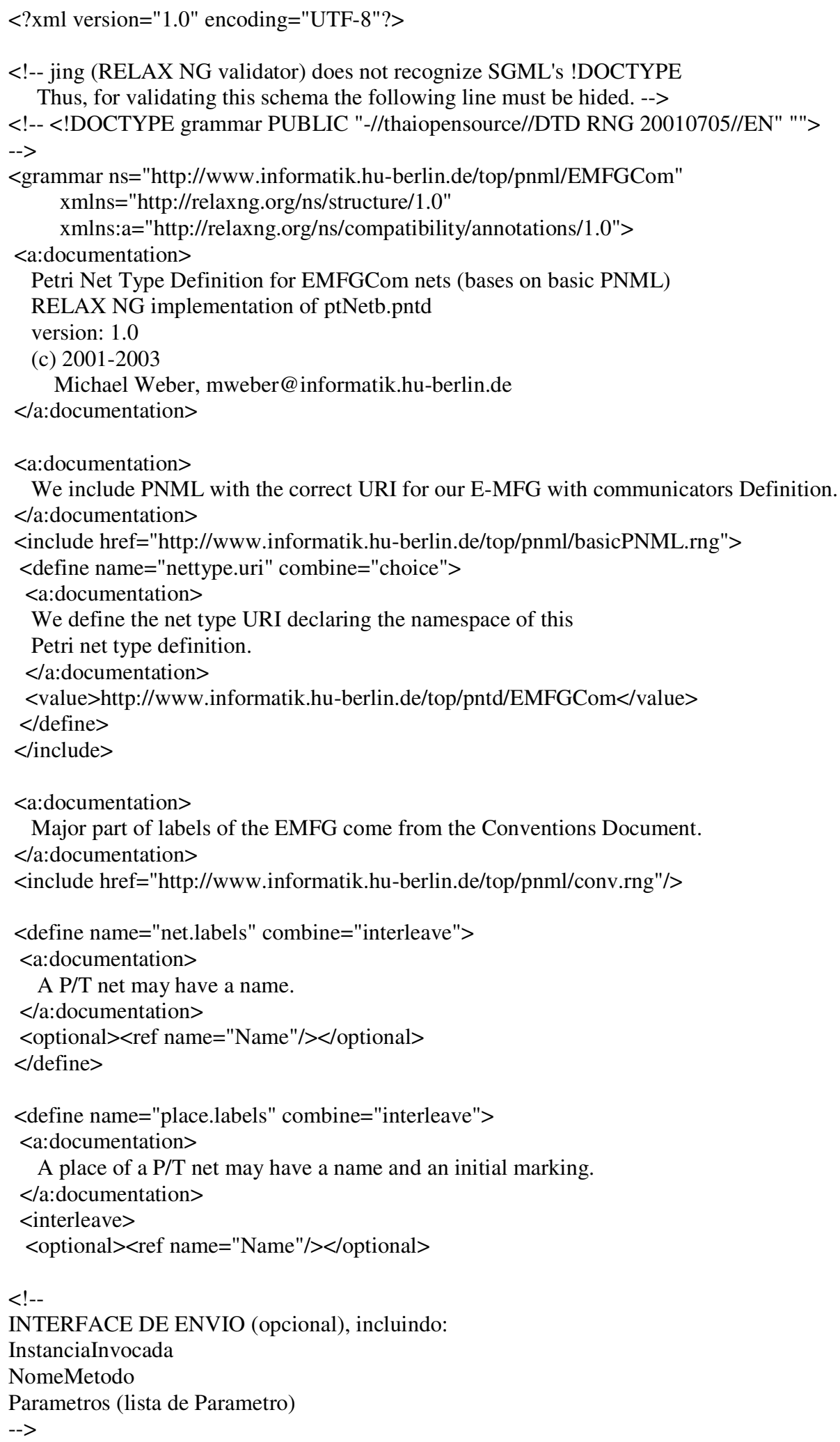

Figura 7.6. Estrutura de Dados do modelo convertido E-MFG com comunicadores (continua) 


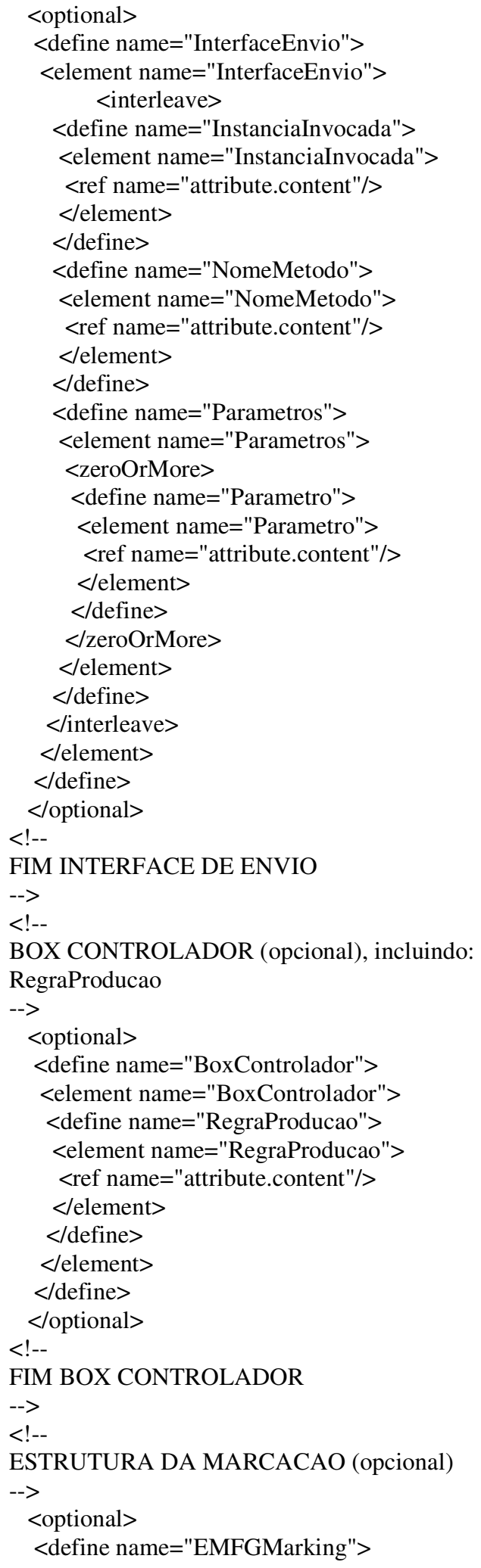

Figura 7.7. Estrutura de Dados do modelo convertido E-MFG com comunicadores (contin.) 


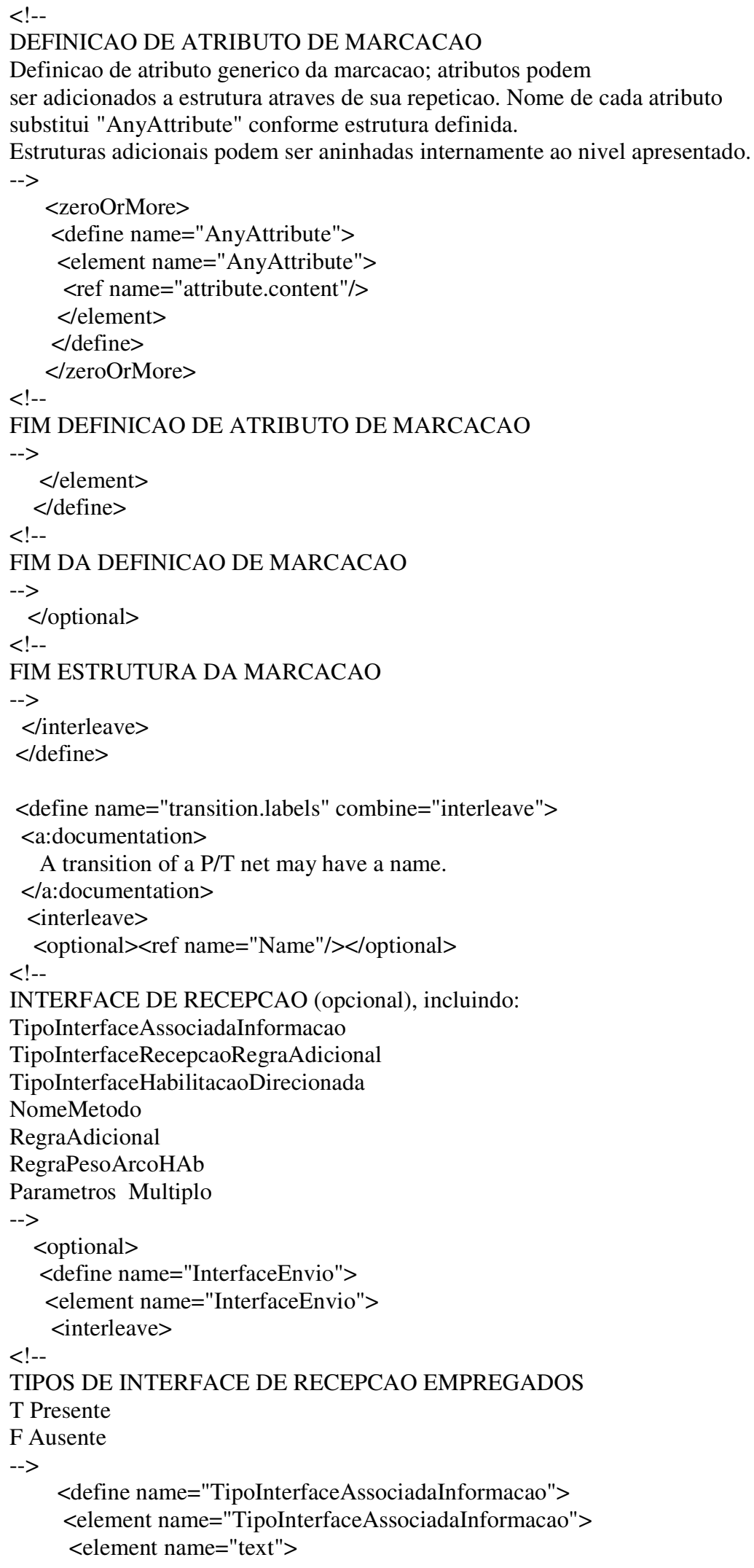

Figura 7.8. Estrutura de Dados do modelo convertido E-MFG com comunicadores (contin.) 


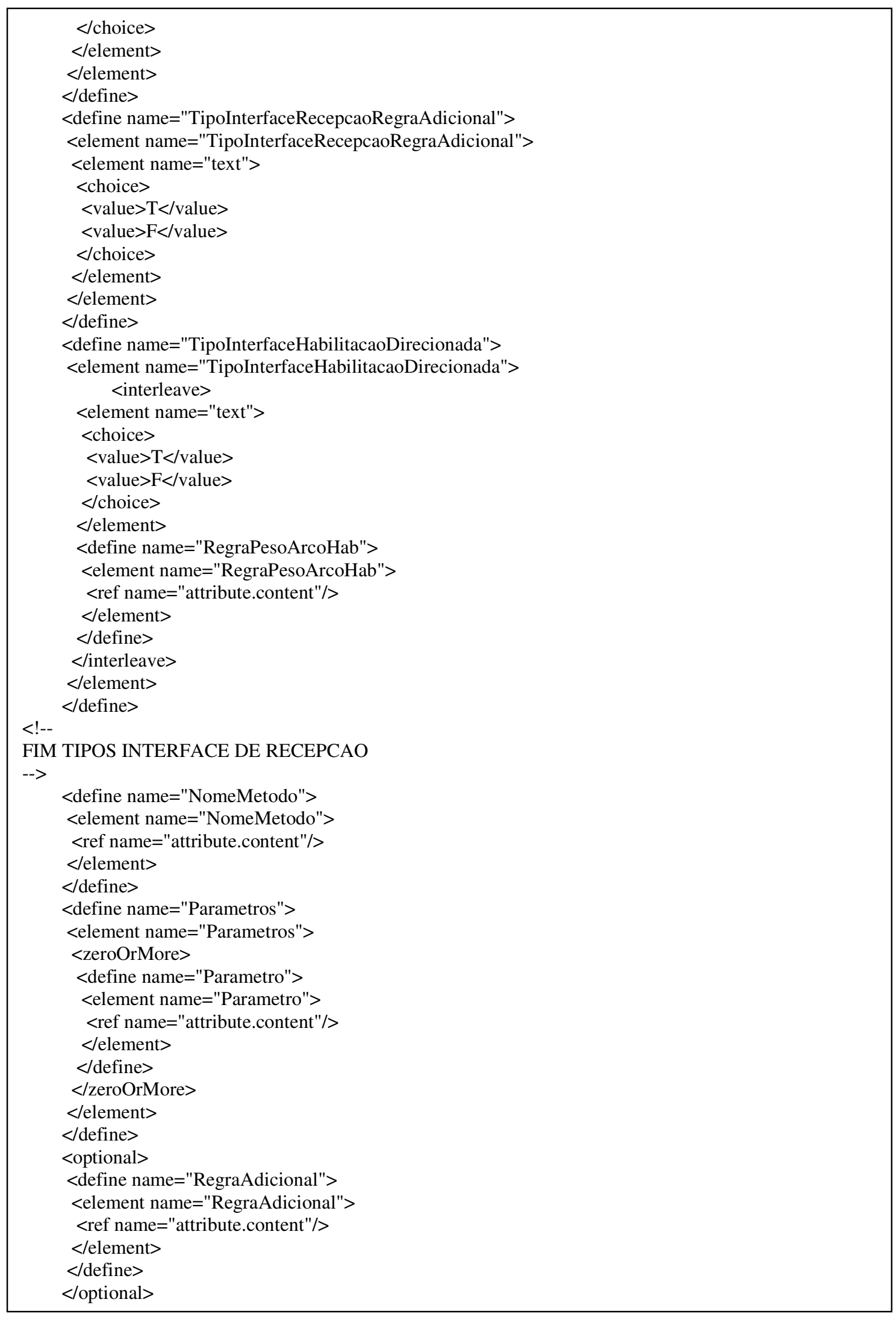

Figura 7.9. Estrutura de Dados do modelo convertido E-MFG com comunicadores (contin.) 


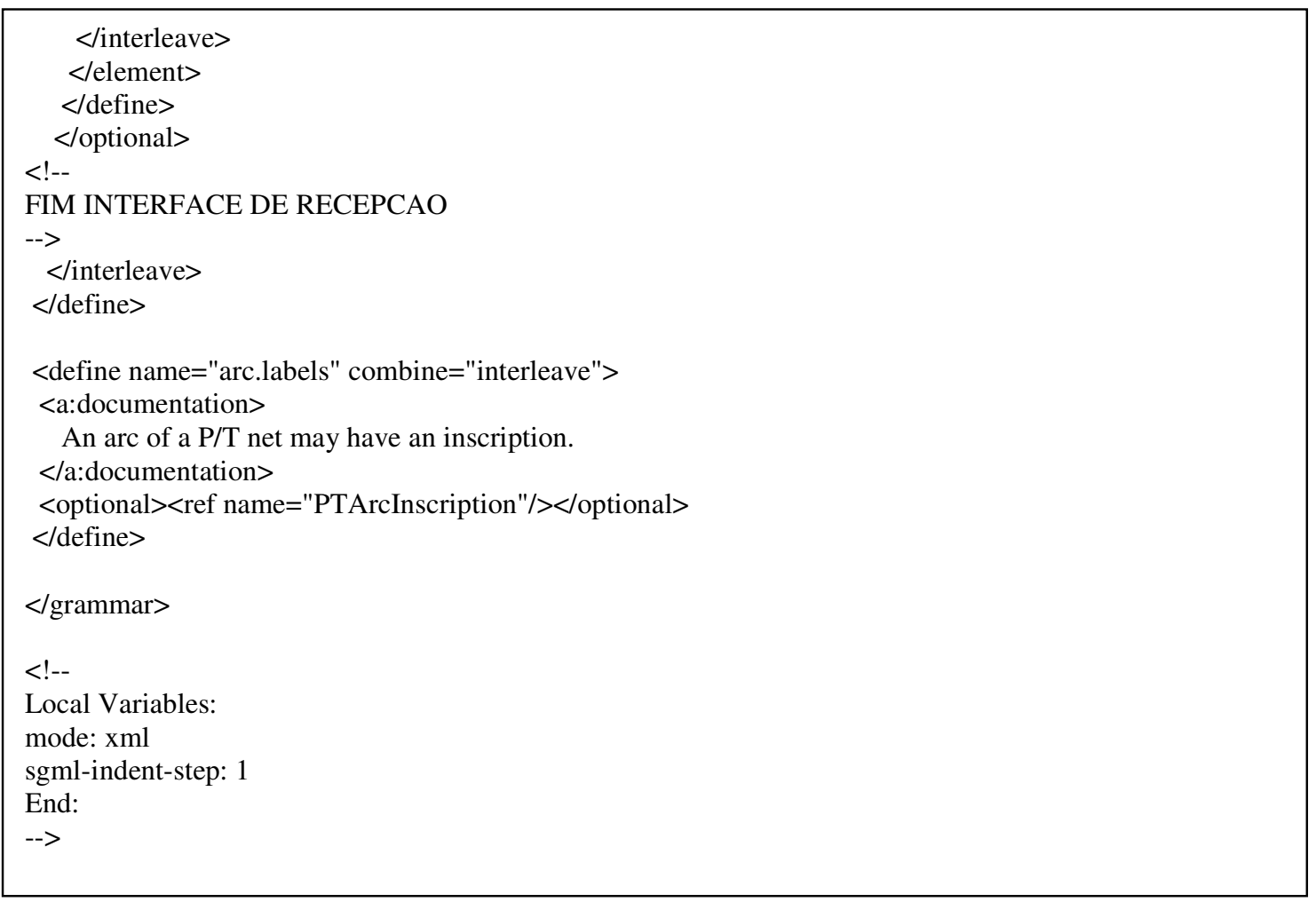

Figura 7.10. Estrutura de Dados do modelo convertido E-MFG com comunicadores (contin.)

\section{Segundo passo da conversão}

A aplicação da fusão de lugares pode ser utilizada quanto existe mais de um modelo de classe de SCSP gerado. Outras restrições para realização da fusão são:

- modelos referentes à mesma classe do SCSP,

- lista de atributos das marcas dos modelos é a mesma e

- casos de uso distintos possuem algumas condições com semânticas idênticas (por exemplo, memo recurso produtivo alocado, com exclusividade).

Obedecendo a estas restrições, a aplicação da fusão de lugares a todas as condições pertencentes a distintos modelos da classe de SCSP que possuírem semântica idêntica resulta na síntese de todos em uma única condição. 


\section{Capítulo 8 ESTUdo de CAso}

Neste capítulo, aplicaremos o método descrito ao longo do capítulo 7 a um estudo de caso para modelar um sistema de controle de sistema produtivo. São produtos finais do estudo de caso vários E-MFG com comunicadores, obtidos a partir dos casos de uso restritos desenvolvidos.

\subsection{DESCRIÇão do CASO}

\subsubsection{Recursos Produtivos}

O SP tratado é um sistema flexível de manufatura, produzindo simultaneamente uma diversidade de produtos. A produção de cada produto segue uma sequiência de operações específica. O SP é constituído por diversos recursos de transformação (estações de trabalho) e o fluxo de materiais é realizado por um sistema de transporte que emprega veículos de transporte. Estes veículos podem ser autônomos ou dirigidos por motoristas. O modelo baseia-se no apresentado em (SANTOS FILHO, 2000), e seu esquema está representado na figura 8.1.

O SP é composto pelos seguintes elementos (Figura 8.1):

- quatro estações de trabalho para processamento: EST_1,EST_2,EST_3 e EST_4,

- uma estação de entrada de materiais EST_IN que armazena a matéria prima que abastece as estações de trabalho, 


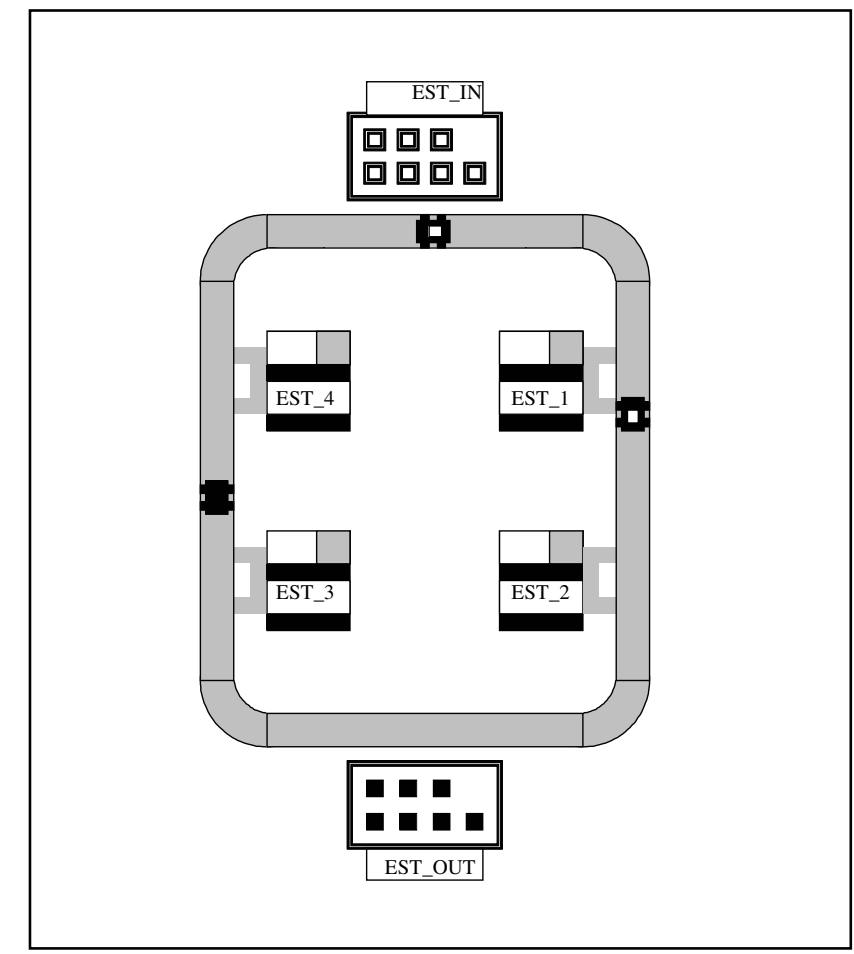

Figura 8.1. Esquema do SP com seus elementos

- uma estação de saída que armazena estoques de produtos acabados: EST_OUT,

- três veículos transportadores, VT1, VT2 e VT3,

- cada estação de trabalho possui dispositivo manipulador dedicado, que realiza as operações de carga e descarga dos itens a serem processados, assim como uma máquinaferramenta que processa um item por vez e

- para a realização do fluxo de materiais entre as estações, os veículos de transporte movimentam-se sobre circuito de via única, transportando um produto cada vez. Existem vários pontos de ramificação e confluência neste circuito, correspondentes aos desvios para entrada e saída dos veículos de transporte nas várias estações e estacionamento. À medida que os produtos são processados, os veículos de transporte são requisitados pela estação que finalizou o processamento. 


\subsubsection{Produtos}

Neste sistema são processados três tipos de itens: ELE_A, ELE_B e ELE_C. Cada um destes produtos possui um determinado processo produtivo associado que, por sua vez, representa uma seqüência determinada de etapas que utiliza os recursos de acordo com as seguintes descrições:

Produto ELE_A:

$\mathrm{r}_{\mathrm{A}}^{*}=\left\{\mathrm{B} \_\mathrm{INA}, \mathrm{EST} \_1, \mathrm{EST} \_2, \mathrm{EST} \_3, \mathrm{EST} \_4, \mathrm{~B} \_\mathrm{OUTA}\right\}$

$\mathrm{E}_{\mathrm{A}}=\{$ INIT_A, A1, A2, A3, A4, FIM_A $\}$

Produto ELE_B:

$\mathrm{r}_{\mathrm{B}}^{*}=\left\{\mathrm{B} \_\mathrm{INB}, \mathrm{EST} \_2, \mathrm{EST} \_1, \mathrm{EST} \_3, \mathrm{~B} \_\mathrm{OUTB}\right\}$

$\mathrm{E}_{\mathrm{B}}=\{$ INIT_B, B1, B2, B3, FIM_B $\}$

Produto ELE_C:

$\mathrm{r}^{*} \mathrm{C}=\left\{\mathrm{B} \_\mathrm{INC}, \mathrm{EST} \_3, \mathrm{EST} \_2, \mathrm{EST} \_1, \mathrm{EST} \_4, \mathrm{~B} \_\mathrm{OUTC}\right\}$

$\mathrm{E}_{\mathrm{C}}=\{$ INIT_C, C1, C2, C3, C4, FIM_C $\}$

Onde:

- $\mathrm{E}_{\mathrm{A}}, \mathrm{E}_{\mathrm{B}}, \mathrm{E}_{\mathrm{C}}$ são as seqüências de etapas do processo produtivo de cada produto e

- $\quad \mathrm{r}_{\mathrm{A}}^{*}, \mathrm{r}_{\mathrm{B}}^{*}, \mathrm{r}_{\mathrm{C}}^{*}$ são as seqüências de utilização dos recursos em cada processo produtivo. 


\subsubsection{Gestão}

O SCSP será implementado em um ambiente cuja gestão opera dentro das seguintes premissas:

- não é necessário que testes de qualidade interfiram na movimentação da produção, devido ao nível de qualidade atingido por intermédio do controle de processo local dos recursos de transformação,

- a gestão da manutenção não é controlada pelo SCSP, e sim por controles externos não integrados. É assumido que, durante a parada de um recurso de transformação ou transporte por manutenção, o atraso da entrega é justificado pelo controle externo,

- a gestão da introdução de novos produtos no SP é realizada em períodos noturnos, com baixa freqüência e

- a escala de produção dos recursos é realizada por sistema de informação prévio, e o SCSP deverá ser integrado ao mesmo, permitindo que a escala possa restringir a movimentação dos produtos como planejado.

\subsubsection{Objetivos do Projeto}

São objetivos:

- integrar a escala de produção dos recursos ao SCSP para que a escala possa restringir a movimentação dos produtos automaticamente, em função do planejamento,

- automatizar a gestão do controle do SP, permitindo processamento e movimentação de produtos de forma automática. 


\subsection{DEFINIÇÃO DO ESCOPO DO SCSP}

\subsubsection{Passo 1: Descrição do Ambiente Externo}

É definida pela relação de sistemas prévios e sistemas auxiliares adicionais a serem desenvolvidos que farão interface com sistema de controle. Com base nas premissas, é necessário integrar apenas o sistema de escalonamento existente. Além deste sistema, os controladores de recursos de transformação locais e de transporte farão interface com os recursos respectivos.

Tabela 8.1. Tabela de classes do ambiente

\begin{tabular}{|l|c|c|c|c|}
\hline Nome da classe & Sistema & $\begin{array}{c}\text { Nível } \\
\text { ANSI/ISA }\end{array}$ & $\begin{array}{c}\text { Modelo de gestão operacional (nível } \\
\text { 3) / Modelo de função (nível 4) }\end{array}$ & $\begin{array}{c}\text { Atividade } \\
\text { (nível 3) }\end{array}$ \\
\hline REC_TRANSF & 2 & & \\
\hline REC_TRANSP & & 2 & & $\begin{array}{c}\text { Escalonamento } \\
\text { detalhado da produção }\end{array}$ \\
\hline PLAN_PROD & & 3 & $\begin{array}{c}\text { Gestão operacional da } \\
\text { produção }\end{array}$ & \\
\hline
\end{tabular}

\subsubsection{Passo 2: Definição da Linguagem de Especificação para Integração do SCSP ao}

\section{Ambiente}

Conforme discutido, utilizaremos sempre a UML ("Unified Modeling Language”).

\subsubsection{Passo 3: Escopo de Atividades do SCSP}

Geramos três níveis de relações, que definem os requisitos funcionais do sistema de controle do sistema produtivo. Seguem os três níveis.

- Relação dos modelos formais de gestão operacional utilizados para o SCSP: 
○ gestão operacional da produção e

○ gestão operacional do inventário.

Conforme as premissas, não empregaremos os modelos de gestão da manutenção e dos testes de qualidade.

- Relação de atividades dos modelo de gestão operacional utilizados para o SCSP:

○ gestão operacional da produção (ilustrada na figura 8.2):

- despacho produtivo (em azul na figura 8.2),

- coleta de dados produtivos (em azul na figura 8.2) e

- gestão da execução da produção. (em azul na figura 8.2).

As premissas do projeto definiram como atividade não automatizada a gestão da definição do produto. Com base nos objetivos do projeto (que não inclui a automação ou integração destas atividades), e como não existe automação prévia das três atividades, são consideradas fora do escopo as atividades:

- gestão de recursos produtivos (contorno pontilhado na figura 8.2),

- monitoração da produção (contorno pontilhado na figura 8.2) e

- $\quad$ análise da performance da produção (contorno pontilhado na figura 8.2). 


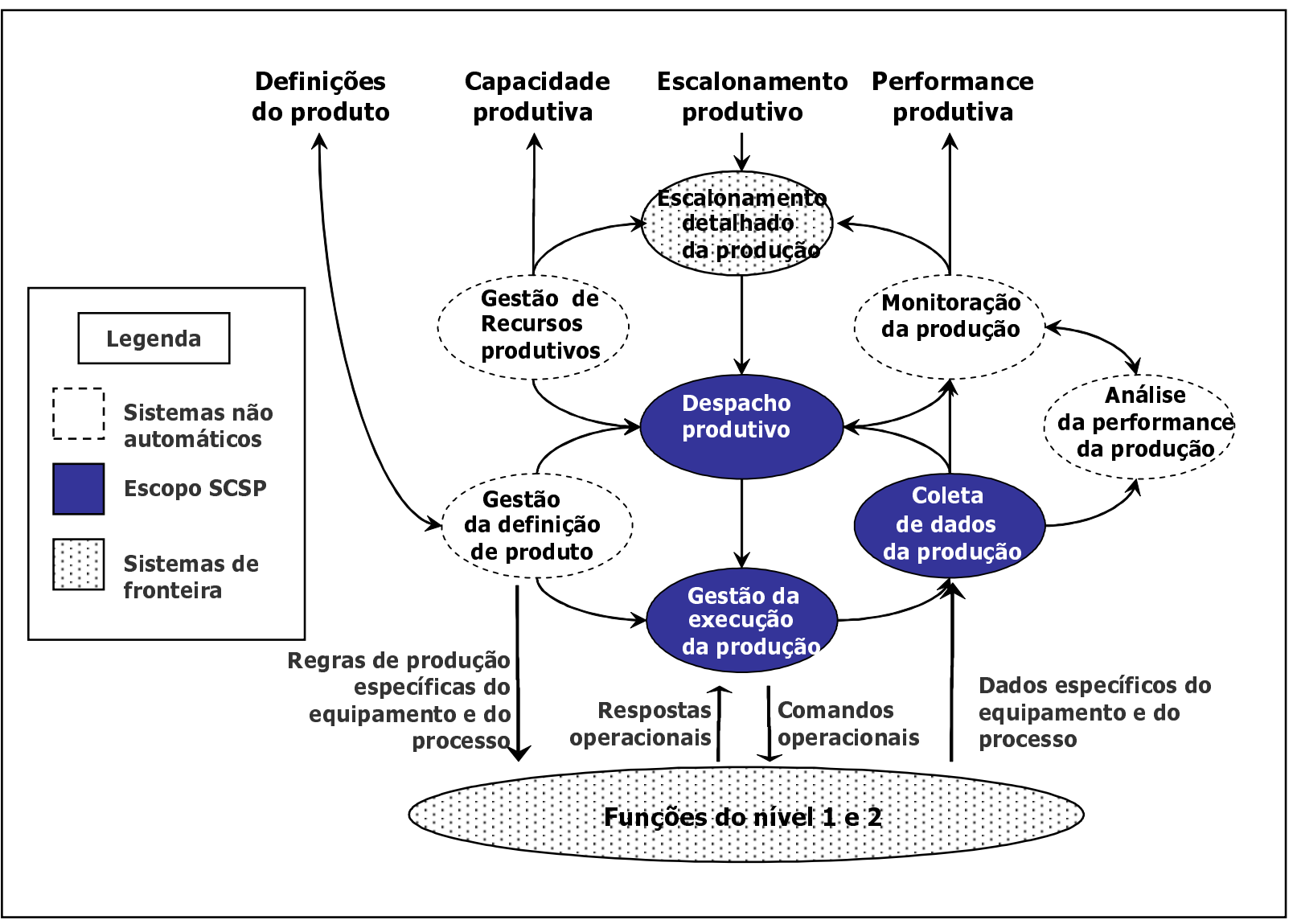

Figura 8.2. Escopo de atividades do Modelo operacional de gestão da produção do SCSP

Os sistemas prévios REC_TRANSF e PLAN_PROD são representados no modelo (na figura 8.2, o primeiro pela área em fundo pontilhado preto nomeado 'Funções do nível 1 e 2', e o último pela área ‘Escalonamento detalhado da produção’ também em fundo quadriculado cinza).

○ gestão operacional do inventário (ilustrada na figura 8.3):

- despacho do transporte de inventário (em azul na figura 8.3),

- coleta de dados de movimentação do inventário (em azul na figura 8.3) e

- gestão da execução do transporte (em azul na figura 8.3). 


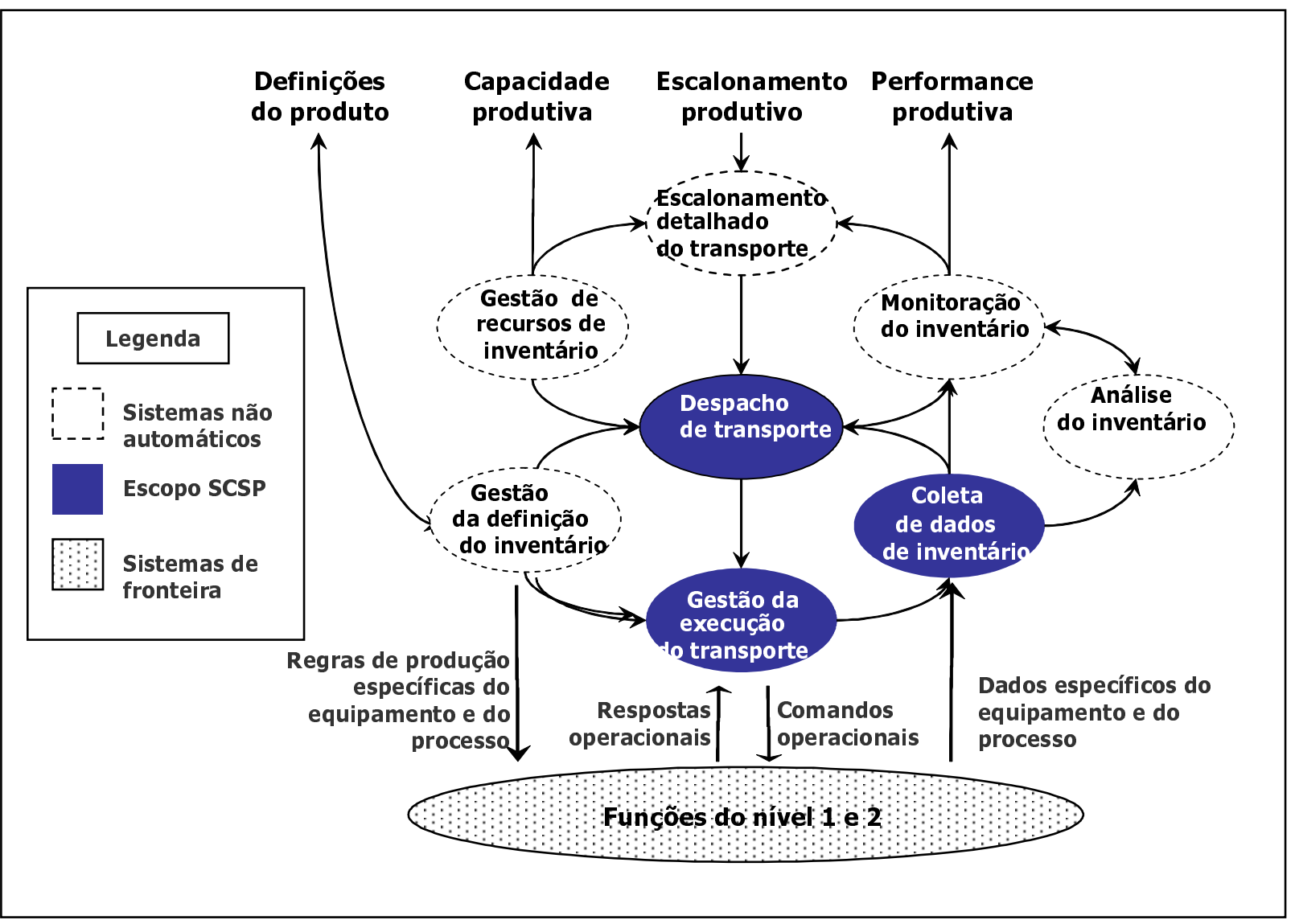

Figura 8.3. Escopo de atividades do Modelo operacional de gestão do inventário do SCSP

O sistema prévio REC_TRANSP é representado no modelo (na figura 8.3 pela área em fundo pontilhado preto nomeado 'Funções do nível 1 e 2').

Com base nos objetivos do projeto (que não inclui a automação ou integração destas atividades), e como não existe automação prévia destas cinco atividades, são consideradas fora do escopo as atividades:

- gestão de recursos de inventário (contorno pontilhado na figura 8.3),

- monitoração do inventário (contorno pontilhado na figura 8.3), 
- análise do inventário (contorno pontilhado na figura 8.3),

- gestão da definição do inventário (contorno pontilhado na figura 8.3) e

- escalonamento detalhado do transporte (contorno pontilhado na figura 8.3).

- Seleção de tarefas em cada atividade dos modelos de gestão operacional.

Esta seleção não será necessária devido ao refinamento adicional desnecessário. Apenas para exemplificar seu uso, iremos relacionar tarefas da atividade despacho produtivo, dentro do modelo de gestão da produção da ANSI/ISA S95, que precisam o requisito de sua atuação coordenada com a gestão de inventário, e portanto, o despacho de transporte:

○ emitindo ordens de produção como identificado pela escala.

○ alocando recursos a produção, onde estes não forem identificados como parte do plano detalhado de escalonamento.

- liberando recursos locais para iniciar ordens de trabalho.

○ gerindo condições não antecipadas pela escala de produção. Pode envolver julgamentos na gestão do fluxo de trabalho e material em processo. Esta informação pode necessitar de comunicação com gestão da manutenação, qualidade e inventário, assim como gestão de recursos produtivos.

Esta etapa do passo 3 possui o propósito de refinar os requisitos de funcionalidades realizadas, quando o nível de atividades não permitir esta identificação. 


\subsubsection{Passo 4: Definição de Partições Homomórficas do SCSP:}

A relação de partições homomórficas do SCSP começa de uma lista candidata inicial, que sofre remoções conforme requisitos definidos para o sistema de controle. É obrigatória a manutenção na relação da partições homomórfica para o controle de processo local. As partições relacionadas atendem à relação de atividades definidas pelo escopo do SCSP no passo 3. Relação inicial:

- controles de processo locais,

- controles de recursos de transformação,

- controles de designação de recursos de transporte,

- controles de fluxo entre unidades produtivas e

- controles de transporte local.

Tabela 8.2. Tabela de partições do SCSP (relação de classes das partições homomórficas do sistema de controle)

\begin{tabular}{|l|l|}
\hline \multicolumn{1}{|c|}{ Nome da classe } & \multicolumn{1}{c|}{ Partição } \\
\hline CNT_PROC.RECX & Controle de Processo Local do Recurso X \\
\hline CNT_REC_TRANSF & Controle de Recursos de Transformação \\
\hline CNT_REC_TRANSP & Controle de Designação de Recursos de Transporte \\
\hline CNT_TRANSP.Y & Controle de Transporte Local do Transportador Y \\
\hline
\end{tabular}


Em função do SP modelado, removemos o controle de fluxo entre unidades produtivas. Iremos adicionar ainda duas especializações adicionais ao controle de processo local: controle de despacho e o controle de requisição.

Não iremos adicionar outras partições pois as selecionadas acima são suficientes para realizar o escopo do SCSP proposto.

\subsubsection{Passo 5: Definição da linguagem de especificação para cada partição homomórfica}

O primeiro passo é desenvolver os modelos de casos de uso para cada partição do SCSP identificado no passo anterior. Seguem nas figuras 8.4 a 8.6 três modelos de caso de uso utilizados para modelagem das três partições expressadas através de E-MFG com comunicadores.

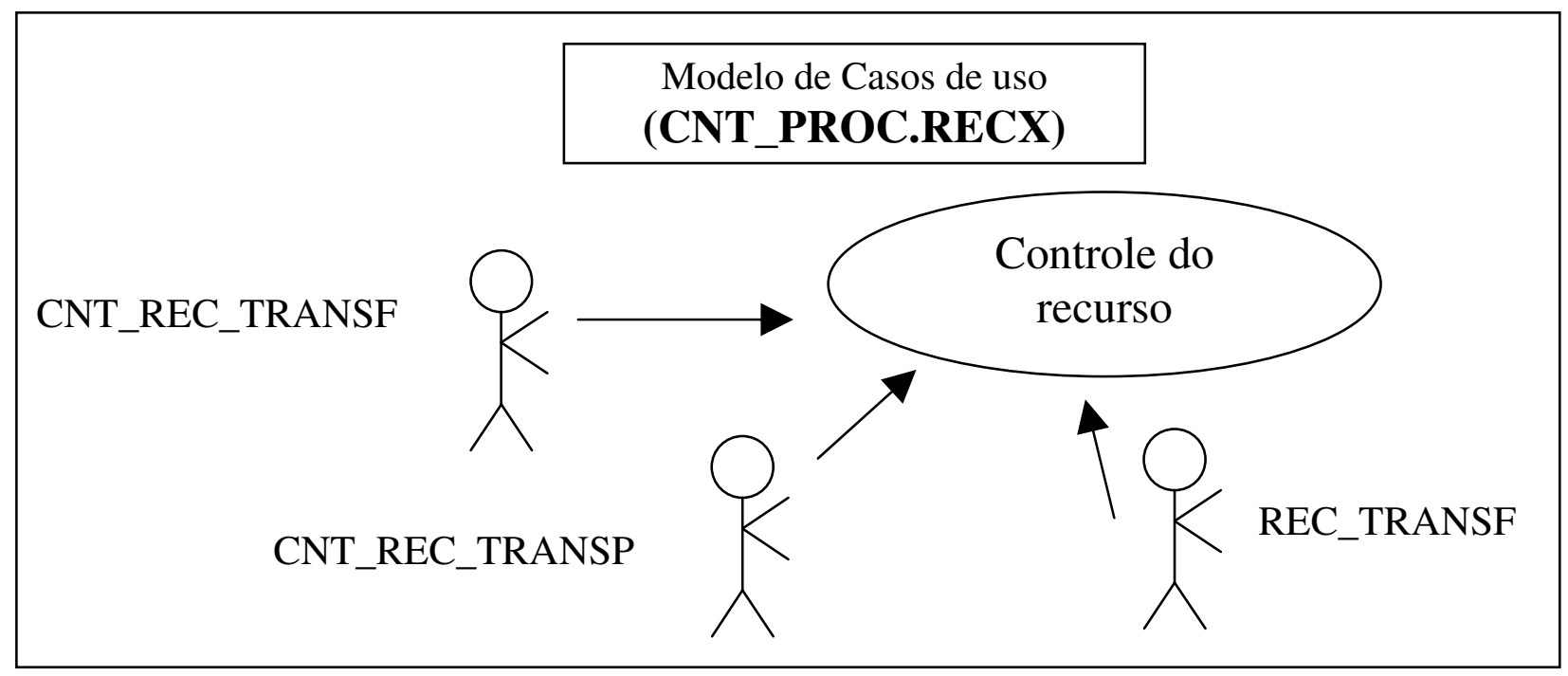

Figura 8.4. Modelo de Casos de Uso da partição 'Controle de Processo Local' 


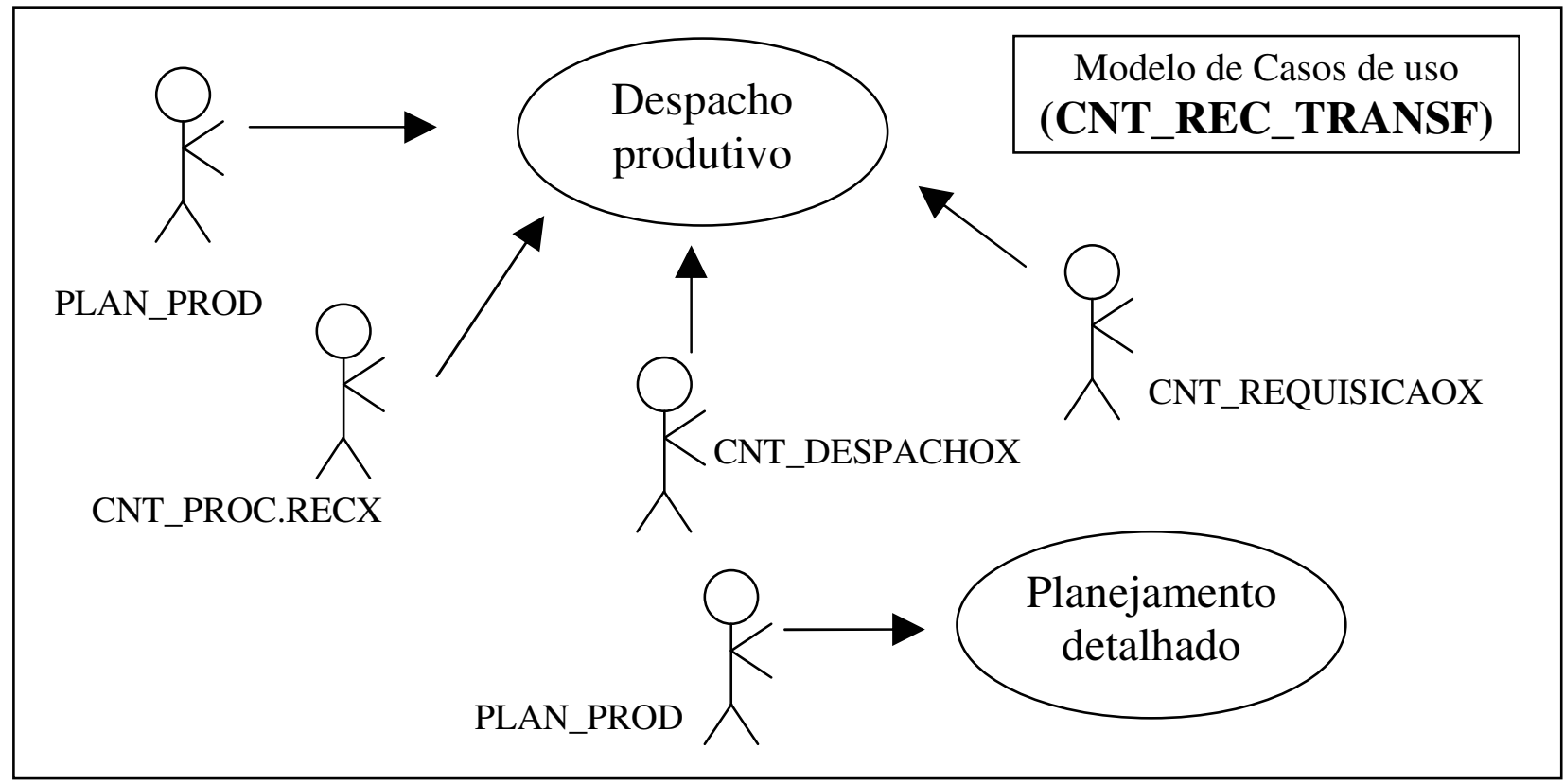

Figura 8.5. Modelo de Casos de Uso da partição 'Controle de Recursos de Transformação'

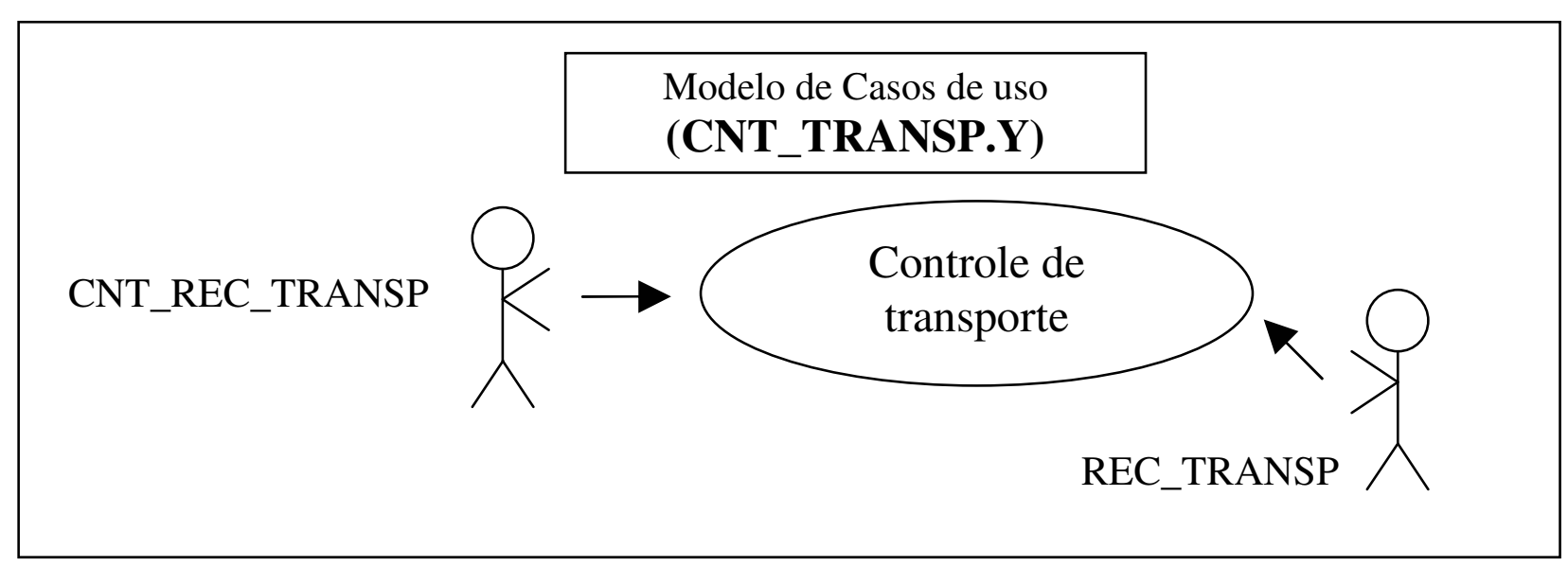

Figura 8.6. Modelo de Caso de Uso da partição 'Controle de Transporte'

Linguagens de especificação adequada a cada partição (homomorfismo): para cada partição (homomorfismo) identificada no passo anterior, uma linguagem de especificação é adotada. Para aquelas existentes na lista inicial, já existem linguagens de especificação adotadas: 
- E-MFG com comunicadores é aplicado para modelar controles de processos locais, controles de recursos de transformação e controles de transporte locais, enquanto

- UML opcionalmente pode ser utilizada para modelar controles de designação de recursos de transporte (fora do escopo deste trabalho).

O conjunto de casos de uso identificado em cada modelo de caso de uso elaborado para cada partição será utilizado para sua modelagem.

\subsection{ESPECIFICAÇÃO DAS PARTIÇÕES DO SCSP}

Iremos neste tópico especificar as partições do SCSP (incluindo integração destas ao ambiente). Utilizaremos a ferramenta caso de uso da UML, restrita especificamente para esta aplicação.

\subsubsection{Controle de processo local do recurso $X$ (CNT_PROC.RECX)}

\subsubsection{Classes das partições do SCSP envolvidas}

Tabela 8.3. Classes das partições do SCSP envolvidas

\begin{tabular}{|l|l|}
\hline \multicolumn{1}{|c|}{ Nome da classe } & \multicolumn{1}{c|}{ Descrição da partição } \\
\hline CNT_PROC.RECX & Controle de Processo Local do Recurso X \\
\hline CNT_REC_TRANSF & Controle de Recursos de Transformação \\
\hline CNT_REC_TRANSP & Controle de Designação dos Recursos de Transporte \\
\hline
\end{tabular}

\subsubsection{Caso de Uso 'Controle do Recurso'}

Seguem fluxo de eventos básico para o caso de uso 'Controle de recurso' e sua conversão em EMFG com comunicadores. 
Tabela 8.4. Fluxo básico de eventos para o caso de uso 'Controle do recurso'

\begin{tabular}{|c|c|c|c|c|c|c|c|c|}
\hline & Parte 1 & Parte 2 & & Parte 3 & & Parte 4 & & $\begin{array}{c}\text { Partes 5,6 } \\
\text { e } 7\end{array}$ \\
\hline 1 & CNT_REC_TRANSF & InformaLote & para & CNT_PROC.RECX & com & $\begin{array}{l}<\text { Lote> } \\
<\text { Prod }> \\
\text { <Oper> }\end{array}$ & & \\
\hline 2 & REC_TRANSF & AvisaChegadaLote & $a$ & CNT_PROC.RECX & & & & \\
\hline 3 & CNT_PROC.RECX & OrdenaCarga & $a$ & REC_TRANSF & & & & \\
\hline 4 & REC_TRANSF & AvisaFimCarga & $a$ & CNT_PROC.RECX & & & & \\
\hline 5 & CNT_PROC.RECX & OrdenaProduzir & $a$ & REC_TRANSF & com & Prod, Oper & & \\
\hline 6 & REC_TRANSF & AvisaFimProdução & $a$ & CNT_PROC.RECX & & & & \\
\hline 7 & CNT_PROC.RECX & SolicitaAlocacao & $a$ & CNT_REC_TRANSF & $\mathrm{com}$ & $\begin{array}{c}\text { Lote, } \\
\text { Prod,Oper }\end{array}$ & & \\
\hline 8 & CNT_REC_TRANSF & InformaAlocacao & $a$ & CNT_PROC.RECX & com & $<$ Dest $>$ & $\begin{array}{c}\text { de forma } \\
\text { que }\end{array}$ & $\begin{array}{l}<\text { Orig }>= \\
\text { "EST_X" }\end{array}$ \\
\hline 9 & CNT_PROC.RECX & SolicitaAlocTransp & $a$ & CNT_REC_TRANSP & com & Orig, Dest & & \\
\hline 10 & CNT_REC_TRANSP & AvisaAlocTransp & $a$ & CNT_PROC.RECX & & & & \\
\hline 11 & CNT_PROC.RECX & InformaDescarga & $a$ & REC_TRANSF & & & & \\
\hline 12 & REC_TRANSF & AvisaFimDescarga & $a$ & CNT_PROC.RECX & & & & \\
\hline 13 & CNT_PROC.RECX & OrdenaPrepTransp & $a$ & REC_TRANSF & & & & \\
\hline 14 & REC_TRANSF & AvisaFimPrepTransp & $a$ & CNT_PROC.RECX & & & & \\
\hline
\end{tabular}




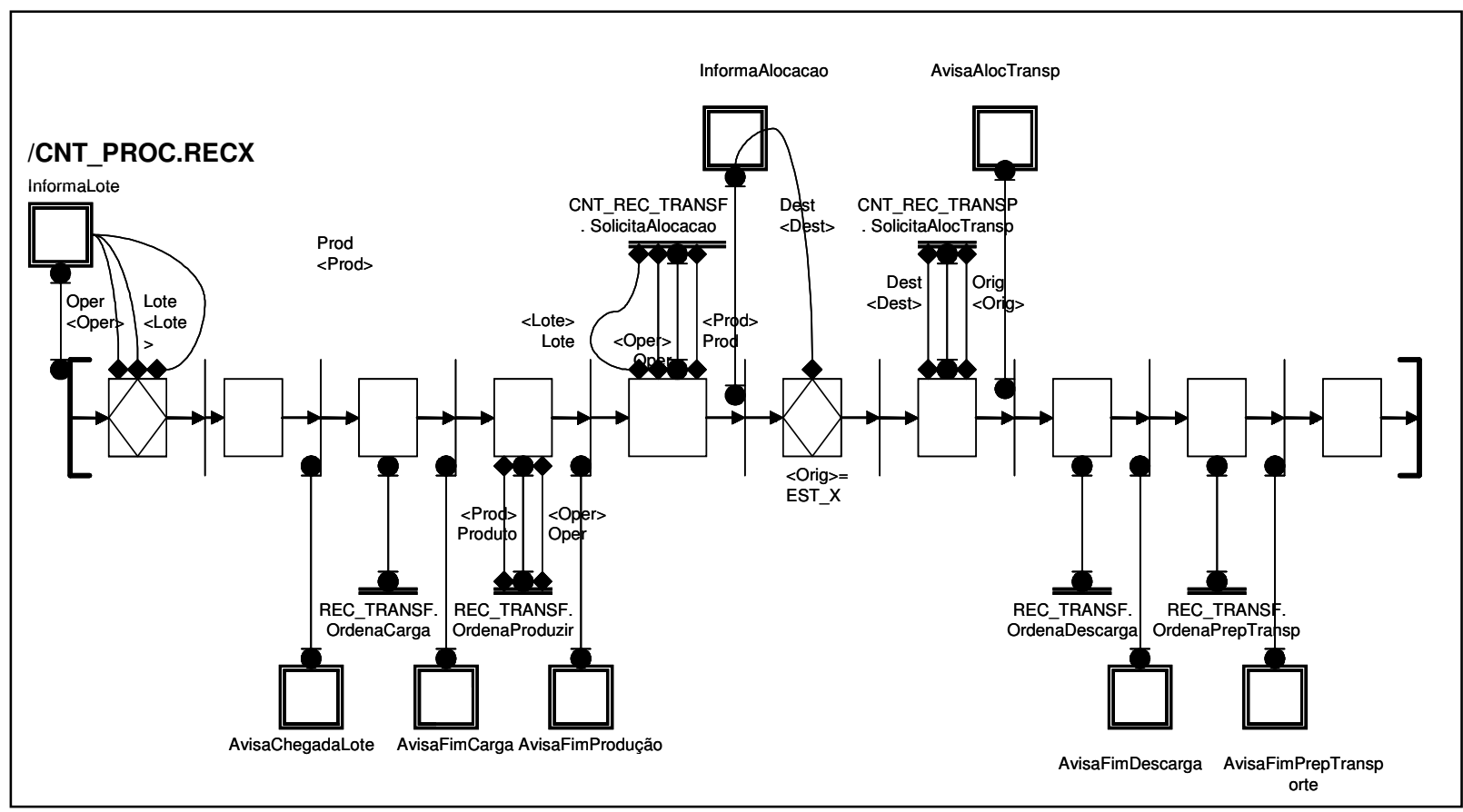

Figura 8.7. E-MFG com comunicadores relativo ao caso de uso de 'Controle do recurso'

\subsubsection{Controle de Recursos de Transformação (CNT_REC_TRANSF)}

\subsubsection{Classes das Partições do SCSP envolvidas}

Tabela 8.5. Classes das partições do SCSP envolvidas

\begin{tabular}{|l|l|}
\hline \multicolumn{1}{|c|}{ Nome da classe } & \multicolumn{1}{c|}{ Descrição da Partição } \\
\hline CNT_PROC.RECX & Controle de Processo Local \\
\hline CNT_REC_TRANSF & Controle de Recursos de Transformação \\
\hline CNT_DESPACHOX & Controle de Processo Local do Despacho X \\
\hline CNT_REQUISICAOX & Controle de Processo Local da Requisição X \\
\hline
\end{tabular}

\subsubsection{Caso de Uso 'Controle de Processamento do Produto ELE_B'}


Seguem fluxo de eventos básico para o caso de uso 'Controle de processamento do produto ELE_B' e sua conversão em E-MFG com comunicadores.

Tabela 8.6. Fluxo básico de eventos para o caso de uso 'Controle de processamento do produto ELE_B'

\begin{tabular}{|c|c|c|c|c|c|c|c|c|}
\hline & Parte 1 & Parte 2 & & Parte 3 & & Parte 4 & & Partes 5, 6 e 7 \\
\hline 1 & PLAN_PROD & Requisita & $a$ & CNT_REC_TRANSF & & $<$ Lote $>,<$ Prod $>$ & se & Prod= "ELE_B" \\
\hline 2 & CNT_REC_TRANSF & Requisita & $a$ & CNT_REQUISICAOB & & Lote & & \\
\hline \multirow[t]{3}{*}{3} & CNT_REQUISICAOB & SolicitaAlocacao & $a$ & CNT_REC_TRANSF & $\mathrm{com}$ & Lote, Prod, Oper & se & $\begin{array}{c}\text { Prod= "ELE_B" e } \\
\text { Oper= "INIT_B" }\end{array}$ \\
\hline & & & & & & & para & Lote $\in$ PlanEST_2 \\
\hline & & & & & & & $\begin{array}{c}\text { de } \\
\text { forma } \\
\text { que }\end{array}$ & $\begin{array}{c}\text { Destino= "EST_2", } \\
\text { Oper= "B1" }\end{array}$ \\
\hline 4 & CNT_REC_TRANSF & InformaDestino & $a$ & CNT_REQUISICAOB & & Dest & & \\
\hline 5 & CNT_REC_TRANSF & SolicitaProdução & para & $\begin{array}{l}\text { CNT_PROC.EST2 } \\
\text { TN_P }\end{array}$ & & Lote, Prod, Oper & & \\
\hline \multirow[t]{3}{*}{6} & CNT_PROC.EST2 & SolicitaAlocacao & $a$ & CNT_REC_TRANSF & com & Lote, Prod, Oper & se & $\begin{array}{c}\text { Prod= "ELE_B" e } \\
\text { Oper= "B1" }\end{array}$ \\
\hline & & & & & & & para & Lote $\in$ PlanEST 1 \\
\hline & & & & & & & $\begin{array}{c}\text { de } \\
\text { forma } \\
\text { que }\end{array}$ & $\begin{array}{c}\text { Destino= }=\text { "EST_1", } \\
\text { Oper= "B2"” }\end{array}$ \\
\hline 7 & CNT_REC_TRANSF & InformaDestino & $a$ & CNT_PROC.EST2 & & Dest & & \\
\hline 8 & CNT_REC_TRANSF & SolicitaProdução & para & CNT_PROC.EST1 & & Lote, Prod, Oper & & \\
\hline \multirow[t]{3}{*}{9} & CNT_PROC.EST1 & SolicitaAlocacao & $a$ & CNT_REC_TRANSF & com & Lote, Prod, Oper & se & $\begin{array}{c}\text { Prod= "ELE_B" e } \\
\text { Oper= "B2" }\end{array}$ \\
\hline & & & & & & & para & Lote $\in$ PlanEST 3 \\
\hline & & & & & & & $\begin{array}{c}d e \\
\text { forma } \\
\text { que }\end{array}$ & $\begin{array}{c}\text { Destino= }=\text { "EST_3", } \\
\text { Oper= "B3" }\end{array}$ \\
\hline 10 & CNT_REC_TRANSF & InformaDestino & $a$ & CNT_PROC.EST1 & & Dest & & \\
\hline 11 & CNT_REC_TRANSF & SolicitaProdução & para & CNT_PROC.EST3 & & Lote, Prod, Oper & & \\
\hline \multirow[t]{2}{*}{12} & CNT_PROC.EST3 & SolicitaAlocacao & $a$ & CNT_REC_TRANSF & com & Lote, Prod, Oper & se & $\begin{array}{c}\text { Prod= "ELE_B" e } \\
\text { Oper= "B3" }\end{array}$ \\
\hline & & & & & & & $\begin{array}{c}\text { para } \\
\text { de } \\
\text { forma } \\
\text { que }\end{array}$ & $\begin{array}{c}\text { Lote } \in \text { PlanDESPB } \\
\text { Destino= } \\
\text { "EST_OUT", Oper= } \\
\text { "FIM_B" }\end{array}$ \\
\hline 13 & CNT_REC_TRANSF & InformaDestino & $a$ & CNT_PROC.EST3 & com & Dest & & \\
\hline 14 & CNT_REC_TRANSF & SolicitaProdução & para & CNT_DESPACHOB & & Lote & & \\
\hline 15 & CNT_DESPACHOB & InformaFim & $a$ & CNT_REC_TRANSF & & Lote, Prod & se & Prod= "ELE_B" \\
\hline
\end{tabular}

Importante notar a omissão da regra adicional a todos eventos para Prod= "ELE_B", apenas para simplificação de apresentação. A regra aparece na fusão de lugares apresentada posteriormente. 


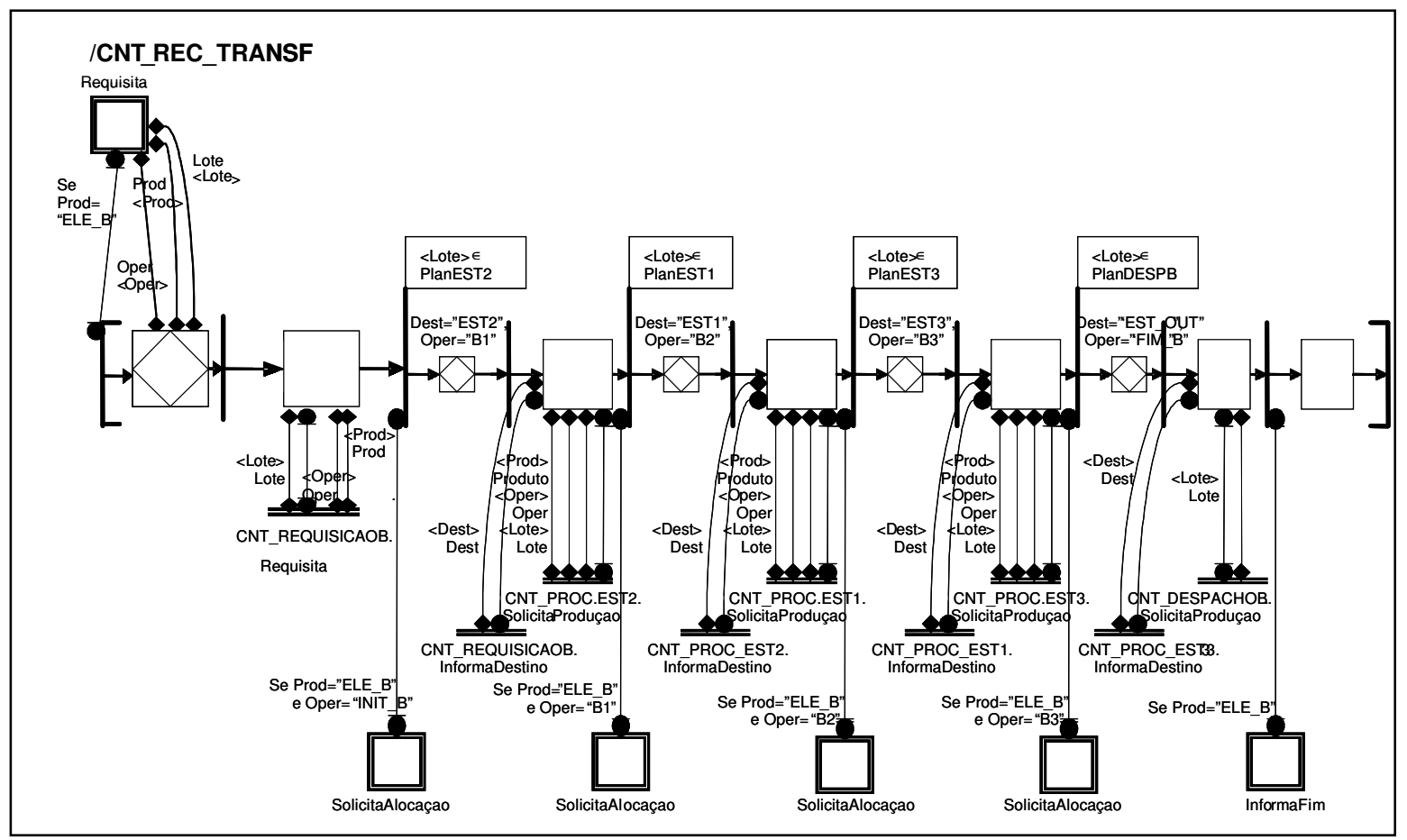

Figura 8.8. E-MFG com comunicadores resultante da conversão do caso de uso 'Controle de processamento do produto ELE_B'

\subsubsection{Caso de Uso 'Controle de escala do recurso EST_2'}

Seguem fluxo de eventos básico para o caso de uso 'Controle de escala do recurso EST_2' e sua conversão em E-MFG com comunicadores.

Tabela 8.7. Fluxo básico de eventos para o caso de uso 'Controle da escala produtiva do recurso EST_4'

\begin{tabular}{|c|c|c|c|c|c|c|c|c|}
\hline & Parte 1 & Parte 2 & & Parte 3 & & Parte 4 & & Partes 5, 6 e 7 \\
\hline 1 & PLAN_PROD & PermiteProduçao & $a$ & CNT_REC_TRANSF & $\mathrm{com}$ & PlanEST_4 & se & $<$ Lote $>\in$ PlanEST_4 \\
\hline & & & & & & & $\begin{array}{l}\text { de forma } \\
\text { que }\end{array}$ & $<$ Dest $>=$ "EST_4" \\
\hline 2 & $\begin{array}{l}\text { CNT_REC_TRAN } \\
\text { SF }\end{array}$ & SolicitaPlano & $d e$ & PLAN_PROD & $\begin{array}{c}\text { par } \\
a\end{array}$ & Dest & & \\
\hline
\end{tabular}




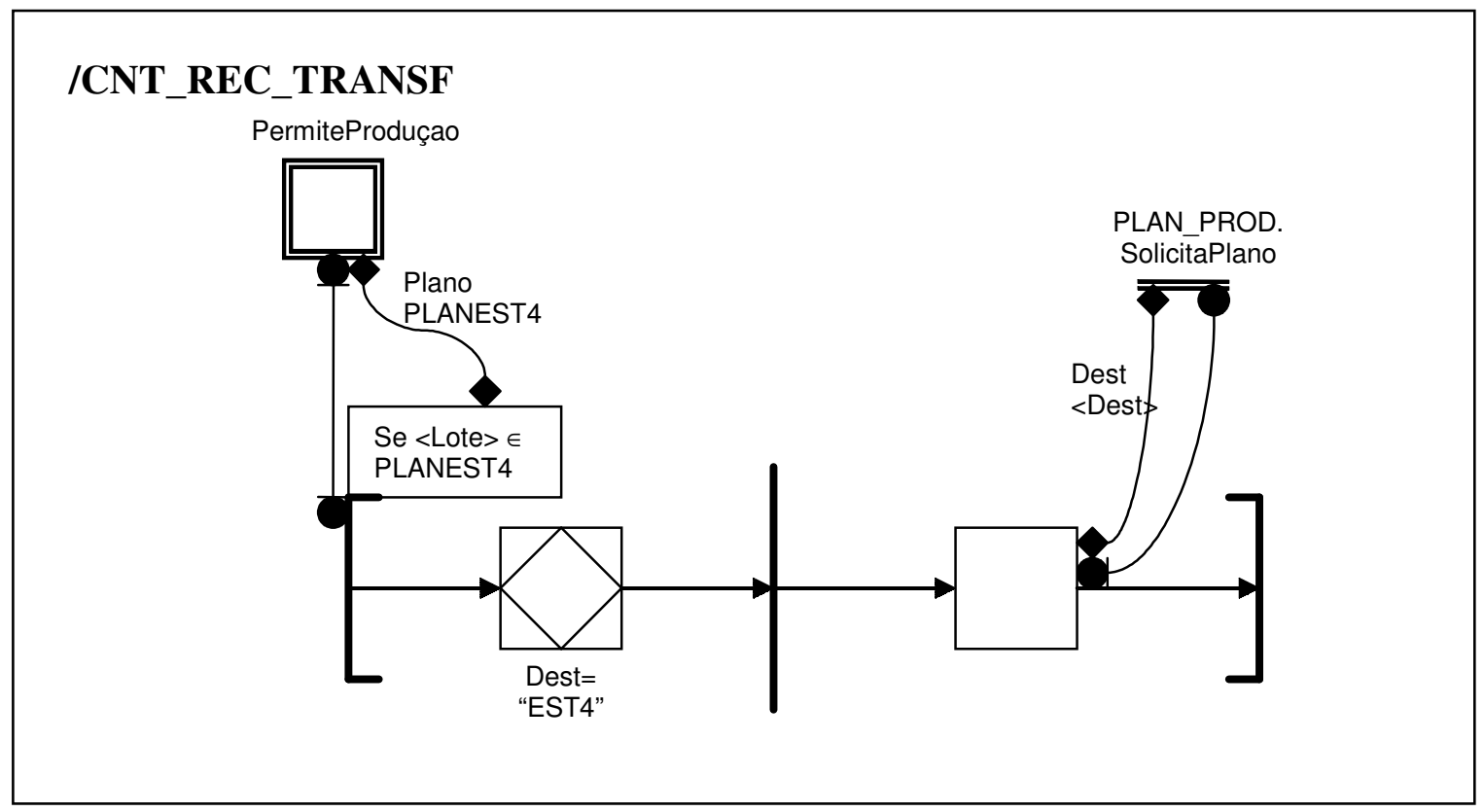

Figura 8.9. E-MFG com comunicadores resultante da conversão do caso de uso 'Controle da escala produtiva do recurso EST_4'

\subsubsection{Fusão de Lugares dos E-MFG com Comunicadores}

Os E-MFG obtidos nos tópicos 8.3.2.2 e 8.3.2.3 oferecem duas oportunidades distintas para fusão de lugares:

- fusão de lugares interpretados como alocação de recurso comum com base nos E-MFG com comunicadores obtidos a partir de todos casos de uso 'Controle de processamento do produto 'ELE_X' (aplicado aos produtos 'ELE_A', 'ELE_B' e 'ELE_C'). Nesta fusão, a regra adicional Prod $=$ 'ELE_X' encontra-se aplicada em cada evento, conforme o processo de produto que o E-MFG original representava (a figura 8.9 ilustra o resultado da fusão de lugares referentes à alocação do recurso 'EST_4' entre os E-MFG com comunicadores gerados pelos casos de uso referentes aos produtos 'ELE_A' e 'ELE_C') e 


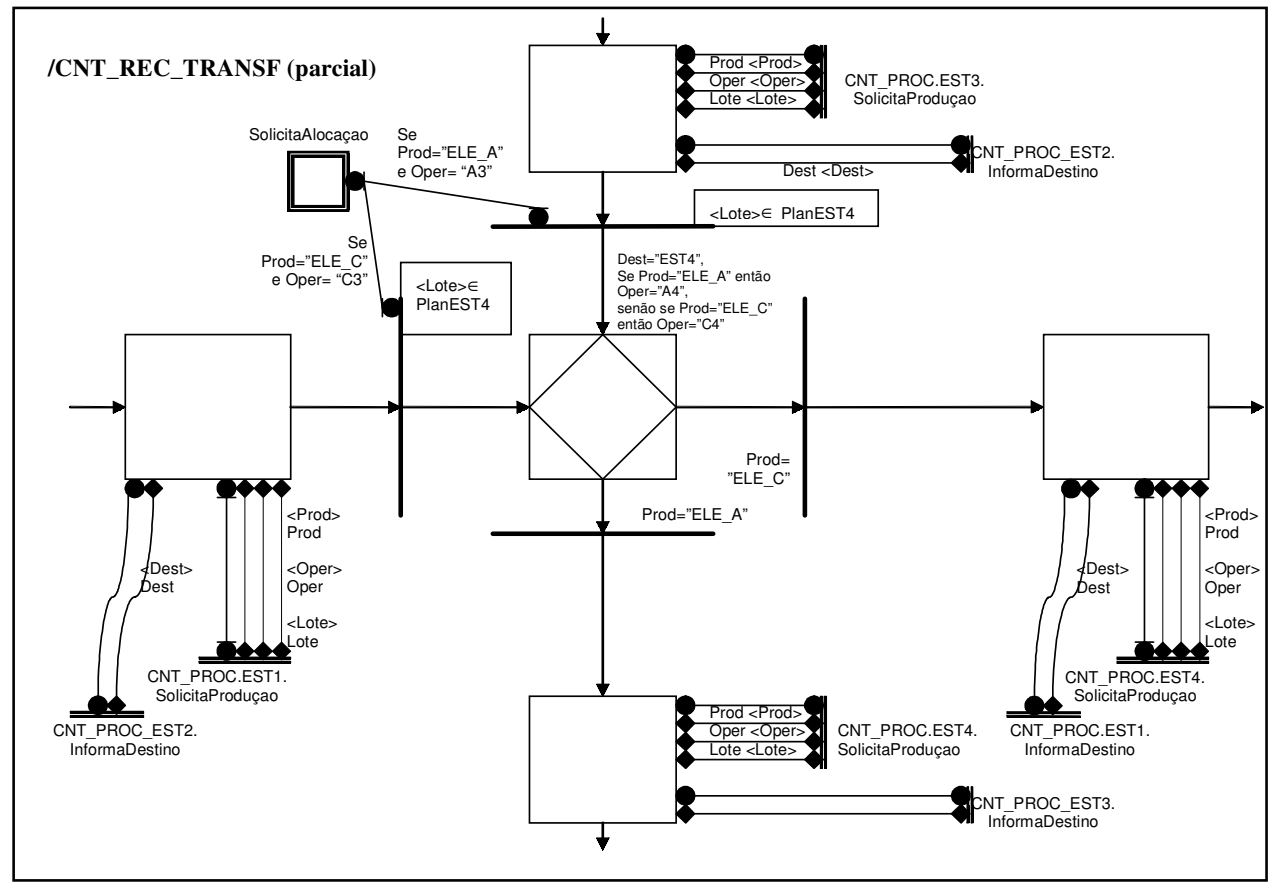

Figura 8.10. Exemplo de fusão de lugares para o E-MFG com comunicadores resultante da conversão do caso de uso 'Controle de recursos de transformação' aplicado sobre recurso EST_4

- fusão do lugar resultante da fusão precedente, interpretado como alocação de um recurso específico no E-MFG com comunicadores, com lugar referente à alocação do mesmo recurso no E-MFG com comunicadores obtido a partir do caso de uso 'Controle de escala de recurso' (na figura 8.10, ilustramos a fusão do E-MFG com comunicadores parcial anterior com o convertido com base no caso de uso escala de produção do recurso 'EST_4’). 


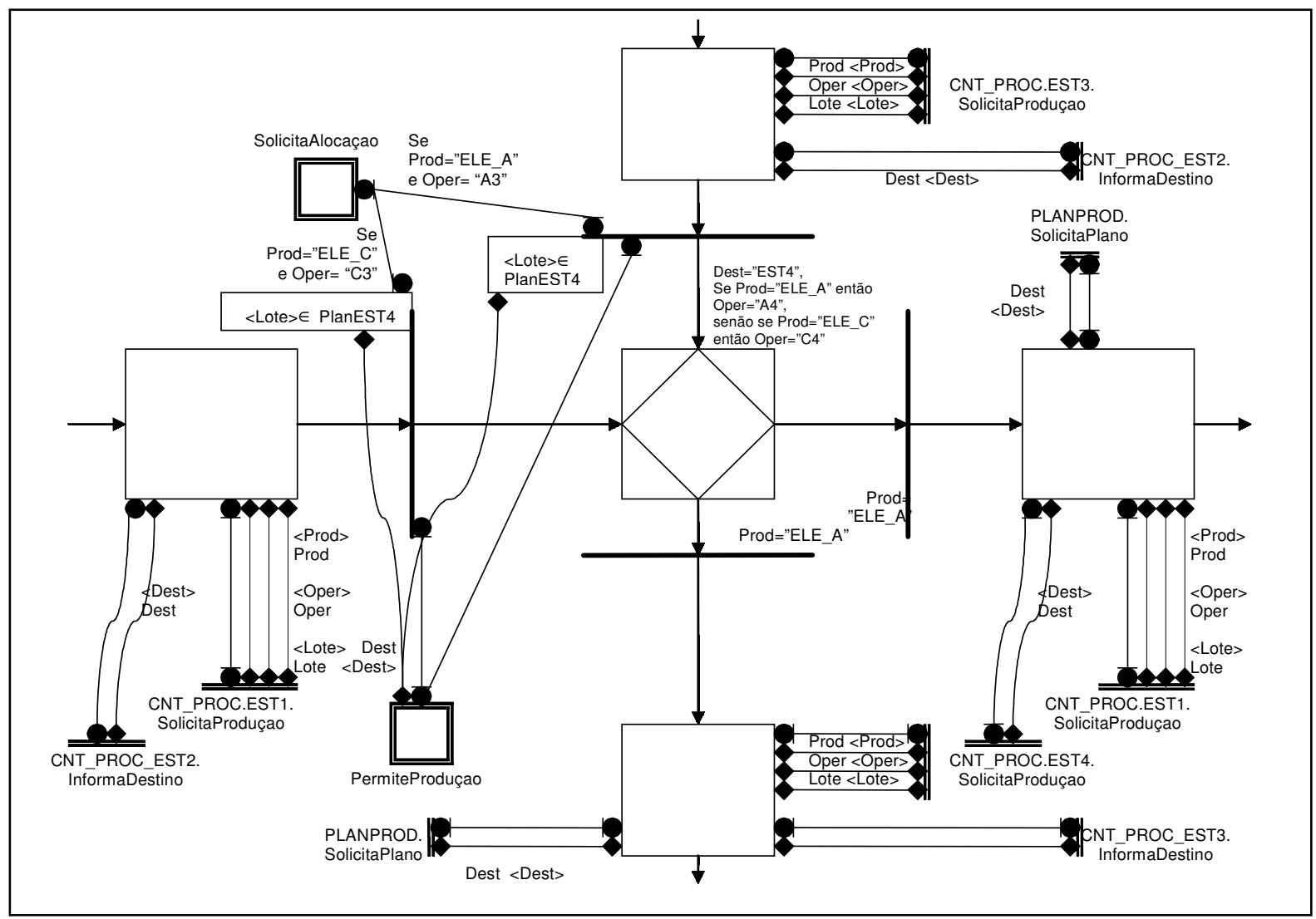

Figura 8.11. Exemplo de fusão de lugares para o E-MFG com comunicadores resultante da conversão do caso de uso 'Controle de recursos de transformação' aplicado sobre recurso EST_4

\subsubsection{Controle de Recursos de Transporte (CNT_REC_TRANSP)}

\subsubsection{Classes das Partições do SCSP envolvidas}

Tabela 8.8. Classes das partições do SCSP envolvidas

\begin{tabular}{|l|l|}
\hline \multicolumn{1}{|c|}{ Nome da classe } & \multicolumn{1}{c|}{ Descrição da Partição } \\
\hline CNT_REC_TRANSP & Controle de Designação de Recursos de Transporte \\
\hline REC_TRANSP & Recursos de Transporte \\
\hline CNT_TRANSP.Y & Controle de Transporte Local do Transportador Y \\
\hline
\end{tabular}




\subsubsection{Caso de Uso 'Controle de Transporte de Produção’}

Seguem o fluxo de eventos básico para o caso de uso 'Controle de transporte de produção’, na tabela 8.9, e sua conversão em E-MFG com comunicadores, conforme figura 8.12.

Tabela 8.9. Fluxo de eventos básico do caso de uso 'Controle de transporte de produção'

\begin{tabular}{|c|c|c|c|c|c|c|c|}
\hline & Parte 1 & Parte 2 & & Parte 3 & & Parte 4 & Partes 5, 6 e 7 \\
\hline 1 & CNT_REC_TRANSP & SolicitaTransporte & $a$ & CNT_TRANSP.Y & com & $\begin{array}{l}<\text { Orig }> \\
<\text { Dest }>\end{array}$ & \\
\hline 2 & CNT_TRANSP.Y & OrdenaTransporte & $a$ & REC_TRANSP & & $\begin{array}{l}<\text { Orig }>\text {, } \\
\text { <Dest }>\end{array}$ & \\
\hline 3 & REC_TRANSP & InformaFimTransporte & $a$ & CNT_TRANSP.Y & & & \\
\hline 4 & CNT_TRANSP.Y & InformaTransporteOK & $a$ & CNT_REC_TRANSP & & & \\
\hline 5 & CNT_REC_TRANSP & LiberaTransporte & para & CNT_TRANSP.Y & & & \\
\hline
\end{tabular}




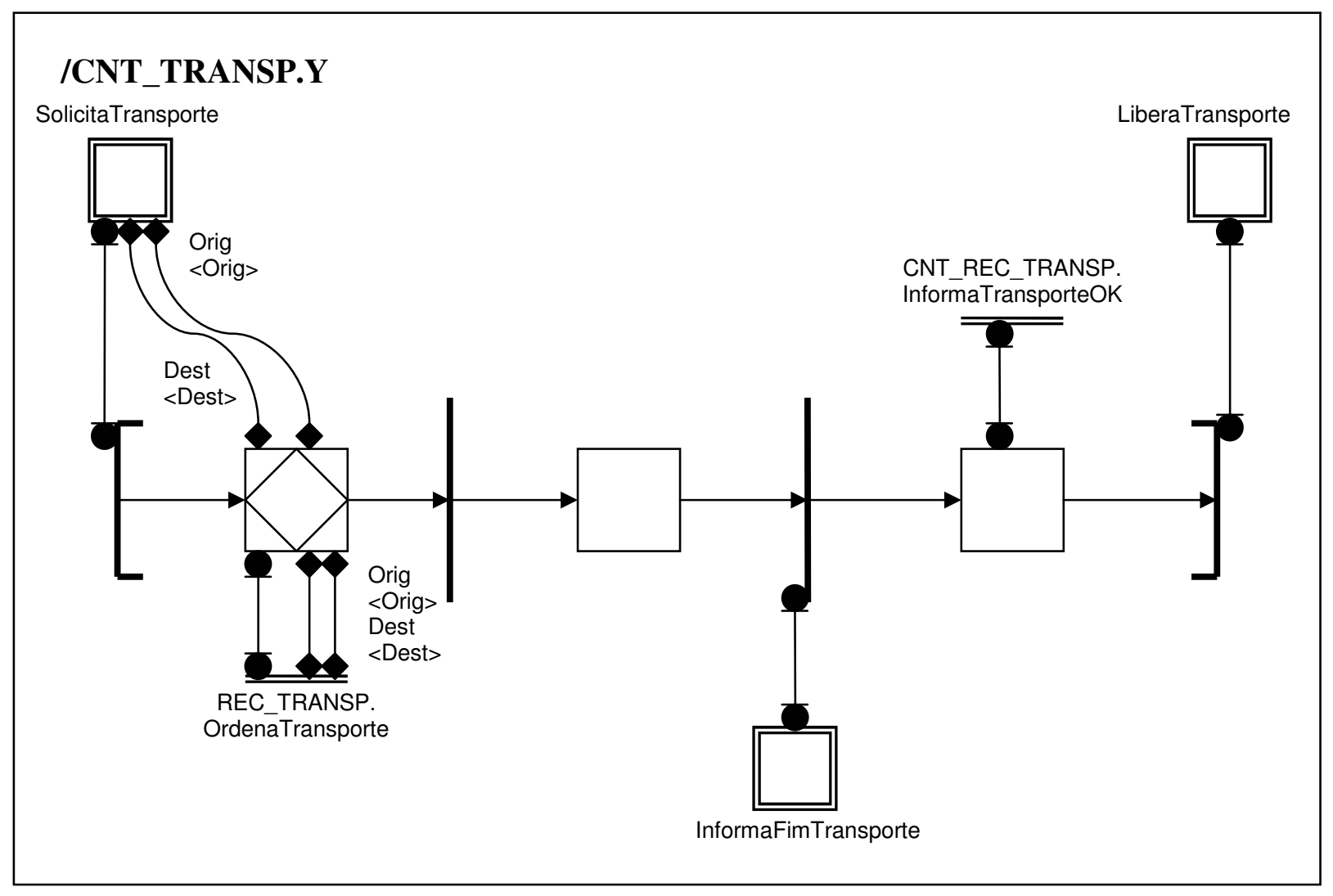

Figura 8.12. E-MFG com comunicadores resultante da conversão do caso de uso 'Controle de transporte de produção’

Neste ponto se encerram as especificações das partições através de E-MFG com comunicadores deste estudo de caso. 


\section{Capítulo 9 \\ CONCLusões Finais}

Esta dissertação contribui para o desenvolvimento de sistemática que auxilie na definição do escopo, requisitos e na geração da modelagem do SCSP, atuando de forma estruturada e padronizada em conformidade com normas técnicas que tratam da regulamentação desse assunto e integrada ao contexto da gestão.

Para atingir este objetivo, atuamos em três metas:

- estabelecer procedimento para definição do escopo de requisitos funcionais do SCSP, a partir de uma visão integrada ao ambiente existente,

- abordagem sistemática que auxilie na identificação dos diferentes domínios semânticos apresentados pelos SCSP e

- auxiliem na especificação das partes do sistema referentes aos domínios semânticos identificados, permitindo a inclusão sistemática dos requisitos estabelecidos na modelagem do SCSP dos respectivos domínios semânticos.

Em relação à primeira meta, obtivemos como resultados a elaboração de procedimento para definição do escopo funcional do SCSP integrado a gestão, baseado em padrão recente ANSI/ISA S95, permitindo o uso do conhecimento de melhores práticas na gestão operacional da manufatura e de visão abrangente da sua integração à gestão do negócio, 
Em relação à segunda meta (auxílio à identificação dos diferentes domínios semânticos), obtivemos como resultados a criação de sistemática que estrutura a definição das partições de um SCSP e de suas respectivas linguagens de especificação.

Em relação à terceira meta (especificação das partes dos sistemas abrangidos por estes domínios semânticos, permitindo a inclusão sistemática dos respectivos requisitos), obtivemos como resultados:

- a elaboração de restrições sistemáticas aplicadas aos casos de uso da UML, viabilizando seu uso na definição de requisitos das partições do SCSP expressadas através da linguagem E-MFG com comunicadores e, com isso, permitindo que a especificação seja realizada em formato próximo ao textual, permitindo recurso adicional de verificação,

- a elaboração de algoritmo de conversão sistemática do caso de uso restrito em $\underline{\text { E-MFG }}$ com comunicadores, passo preliminar à programação do SCSP por controladores programáveis, atualmente aderentes aos padrões IEC 61.131-3 (linguagens de programação para controladores programáveis) e IEC 61.499 (controle distribuído de sistemas) e

- a adição de novos elementos sintáticos ao E-MFG com comunicadores, gerando duas novas interfaces de recepção que trazem recursos adicionais de atuação do ambiente sobre o E-MFG com comunicadores (e, conseqüentemente, para a atuação do ambiente sobre o SCSP), permitindo expressão de semânticas adicionais pela especificação.

Considerando as contribuições efetivas deste trabalho, observa-se um conjunto de aspectos que podem ser explorados futuramente: 
- investigação de fonte adicional de "deadlock", e respectiva solução, como conseqüência da implementação de restrição adicional definida pelo escalonamento produtivo e

- definição de domínios semânticos e de adequada linguagem de especificação, assim como pesquisa de viabilidade tecnológica dentro dos padrões disponíveis de linguagem de programação de controladores programáveis, para as seguintes atividades produtivas:

○ gestão da definição do produto (ANSI/ISA S95) dentro do modelo operacional de gestão da produção, atendendo ao requisito de flexibilidade para definição de novos processos produtivos no SCSP,

○ estratégias para evitar "deadlock" necessárias para atender a gestão de definição do produto realizada da forma flexível indicada no tópico anterior e

○ monitoração da produção (ANSI/ISA S95) dentro do modelo operacional de gestão da produção, tendo em vista, conforme dissertação, que o modelo E-MFG não permite consulta aos estados do SP. 


\section{REFERÊNCIAS BIBLIOGRÁFICAS ${ }^{1}$}

ASSOCIAÇÃO BRASILEIRA DE NORMAS TÉCNICAS. Sistemas de Gestão da Qualidade: Requisitos. Rio de Janeiro: ABNT, 2000.

BOEL, $\mathrm{R}$ et al. Unity in Diversity, Diversity in Unity: Retrospective and Prospective Views on Control of Discrete Event Systems: Report on WODES2000, Discrete Event Dynamic Systems: Theory and Applications, Kluwer Academic Publishers, v. 12, p. 253-264, 2002.

BONFATTI, F.; MONARI, P. D.; SAMPIERI, U. IEC 1131-3 programming methodology: Software Engineering Methods for Industrial Automated Systems. Fontaine: CJ International, 1999.

CAO, X. R.; HO, Y. C. Models of Discrete Event Dynamic Systems. IEEE Control Systems Magazine, v. 10, n. ${ }^{\circ}$ 4, p. 69-76, junho 1990.

CASSANDRAS, C. G. Sample Path Properties of Timed Discrete Event Systems. Proceedings IEEE, IEEE, v. 77, n. ${ }^{\circ}$ 1, p. 59-71, janeiro1989.

CASSANDRAS, C. G. Discrete Event Systems: Modeling and Performance Analysis. Aksen Associates Incorporated Publishers, 1993.

CASTILLO, I.; SMITH, J. S. Formal Modeling Methodologies for Control of Manufacturing Cells: Survey and Comparison. Journal of Manufacturing Systems, v. 21, n. ${ }^{\circ}$ 1, p. 40-57, 2002.

CAVAlheiro, A. C. M. Projeto de Sistemas de Controle Modulares e Distribuídos. Dissertação de Mestrado, Escola Politécnica da Universidade de São Paulo, São Paulo, 2004.

CORMEN, T. H. et al. Algoritmos: Teoria e Prática. Tradução Vandenberg Dantas de Souza. $4^{\mathrm{a}}$ Reimpressão, Rio de Janeiro: Editora Campus, 2002.

DATE, C. J. Introdução a Sistemas de Bancos de Dados. Tradução Vandenberg Dantas de Souza. Rio de Janeiro: Editora Campus, 2000.

DEMING, W. E. Qualidade: a Revolução da Administração. Tradução de Clave Comunicações e Recursos Humanos. Rio de Janeiro: Editora Marques Saraiva SA, 1990.

\footnotetext{
${ }^{1}$ De acordo com:

ASSOCIAÇÃO BRASILEIRA DE NORMAS TÉCNICAS. NBR 6023: informação e documentação: referências: elaboração. Rio de Janeiro, 2002.
} 
DRUCKER, P. F. O advir da nova organização. In: MACGOWAN, W. G. Revolução em tempo real: gerenciando a Tecnologia da Informação. 2. ${ }^{\text {a }}$ ed. Rio de janeiro: Editora Campus, 1997. p. 3-15.

DUKE, R.; ROSE, G. Formal object-oriented specification using object-Z. Houndmills: Macmillan Press Limited, 2000.

GROOVER, M. P. Automation, production systems, and computer-integrated manufacturing, Second Edition. Prentice-Hall, 2000.

HALEVI, G.; WEILL, R. D. Principles of process planning: a Logical Approach. $1^{\text {a }}$ Edição. Londres: Chapman \& Hall, 1995.

HO, Y. C. Dynamics of Discrete Event Systems. Proceedings of IEEE, IEEE, v.77, nº1, p.3-6, janeiro 1989.

INSTRUMENTATION, SYSTEMS, AND AUTOMATION SOCIETY. Enterprise-Control System Integration: Part 1: models and terminology. 95.00.01, Draft 14. Available from ISA, 2000 .

INSTRUMENTATION, SYSTEMS, AND AUTOMATION SOCIETY. Enterprise-Control System Integration: Part 3: Models of Manufacturing Operations. 95.00.03, Draft 19. Available from ISA, 2003.

JACOBSON, I. Object-Oriented Development in an Industrial Environment. Proceedings of OOPSLA' 87, Special issue of SIGPLAN Notices, v. 22, n. ${ }^{\circ}$ 12, p. 183-191, dezembro 1987.

JACOBSON, I.; BOOCH, G.; RUMBAUGH, J. The Unified Software Development Process. Addison-Wesley Longmann, Inc., 1998.

KALPAKJAN, S. Manufacturing Engineering and Technology. $4^{\mathrm{a}}$ Edição. Prentice-Hall, 2000.

LACERDA, A. C. et al. Tecnologia: Estratégia para a Competitividade. São Paulo: Nobel, 2001.

LEWIS, R.W. Programming Industrial Control Systems using IEC 1131-3. Londres: Institution of Electrical Engineers, 1998.

LIGHTFOOT, D.Formal Specifications using Z. Houndmills: Palgrave, 2001.

MATSUSAKI, C. T .M. Modelagem de Sistemas de Controle Distribuídos e Colaborativos de Sistemas Produtivos. 2004. 154 f. Tese de Doutorado, Escola Politécnica da Universidade de São Paulo, São Paulo, 2004.

MITCHELL, R.; MCKIM, J. Design by Contract, by Example. Indianapolis: Addison-Wesley, 2001. 
MUENCH, S. Building Oracle XML Applications. O’Reilly \& Associates, 2000.

MURATA, T. Petri Nets: Properties, Analysis and Applications. Proceedings of the IEEE, IEEE, vol. 77, n. ${ }^{\circ}$ 4, p.541-580, 1989.

MIYAGI, P. E. Controle Programável: Fundamentos do Controle de Sistemas a Eventos Discretos. Editora Edgard Blücher Ltda,1996.

NAKAmOto, F. Y. Sistematização do Projeto do Controle de Sistemas Produtivos. 2002. 128 f. Dissertação de Mestrado, Escola Politécnica da Universidade de São Paulo, 2002.

NOORI, H. Managing the Dynamics of New Technology: Issues in Manufacturing Management. Prentice Hall Business Publishing, 1997.

PARNAS, D. L.; MADEY, J. Functional Documents for Computer Systems. Science of Computer Programming, Amsterdam, v. 25, issue 1, p. 41-61, outubro 1995.

PETERSON, J. L. Petri Net Theory and the Modeling of Systems. Prentice-Hall, Englewood, Cliffs. N.J, 1981.

PORTER, M. Competitive Advantage: Creating and Sustaining Superior Performance. The Free Press, 1985.

PRESSMAN, R. S. Engenharia de Software. Tradução José Carlos Barbosa dos Santos. São Paulo: Makron Books, 1995.

PROJECT MANAGEMENT INSTITUTE. A Guide to the Project Management Body of Knowledge (PMBOK® guide).PMI, 2000.

PUCCINI, A. L. Introdução à Programação Linear. Rio de Janeiro: Livros Técnicos e Científicos, 1972.

RAMADGE, P. J. G.; WONHAM, W. M. The Control of Discrete Event Systems. Proceedings IEEE, IEEE,vol. 77, n.o 1, pg. 81-98, Janeiro 1989.

REISIG, W. Petri Nets: an Introduction. Berlin Heidelberg, Springer-Verlag, 1985.

ROSENBERG, D.; SCOTT, K. Use Case Driven Object Modeling with UML: a Practical Approach. Addison Wesley, 1999.

SANTOS FILHO, D. J. Proposta do Mark Flow Graph Estendido para a Modelagem e Controle de Sistemas Integrados de Manufatura. São Paulo, 1993. Dissertação de Mestrado, Escola Politécnica da Universidade de São Paulo, 1993.

SANTOS FILHO, D. J.; MIYAGI, P.E. Enhanced Mark Flow Graph to Control Flexible Manufacturing Systems. Journal of The Brazilian Society of Mechanical Sciences, ABCM, Rio de Janeiro, RJ, v.17, n.2, p.232-248, 1995. 
SANTOS FILHO, D. J.; MIYAGI, P.E. Proposta de uma Ferramenta Automática de Programação de CPs a partir de Modelos MFG. In: CONGRESSO BRASILEIRO DE ENGENHARIA MECÂNICA, XIV, 1997, Bauru. Anais. CD-ROM. ABCM, 12/1997.

SANTOS FILHO, D. J. Aspectos do projeto de sistemas produtivos. 2000. 116 f. Tese de Livre docência, Escola Politécnica da Universidade de São Paulo, 2000.

TAGUCHI, G.; ELSAYED, E. A.; HSIANG, T. C. Quality Engineering in Production Systems. McGraw Hill, Inc.1989.

WEBER, M.; KINDLER, E. The Petri Net Markup Language. Abril 2002. Disponível em $<$ http://www.informatik.hu-berlin.de/top/pnml/download/about/PNML_LNCS.pdf $>$. Acesso em: 06 Agosto 2005.

WING, J. M. A Specifier's Introduction to Formal Methods. IEEE Computer, v. 23, p. 8-24, setembro 1990.

ZAVE, P.; JACKSON, M. Four Dark Corners of Requirements Engineering. ACM Transactions on Software Engineering and Methodology, v. 6, n. ${ }^{\circ}$, p. 1-30, janeiro 1997. 